$$
\text { UNIVERSIDADE DE SÃO PAULO }
$$

ESCOLA DE ENGENHARIA DE SÃO CARLOS

PROGRAMA DE PÓS-GRADUAÇÃO EM ENGENHARIA HIDRÁULICA E SANEAMENTO

DANILO ABREU DOS SANTOS

ESTUDO DA PRODUÇÃO DE BIOHIDROGÊNIO EM AnSBBR COM RECIRCULAÇÃO DA FASE LÍQUIDA TRATANDO ÁGUA RESIDUÁRIA SINTÉTICA - EFEITO DA CARGA ORGÂNICA

VERSÃO CORRIGIDA

SÃo CARLOS, SP

2012 



\title{
ESTUDO DA PRODUÇÃO DE BIOHIDROGÊNIO EM AnSBBR COM RECIRCULAÇÃO DA FASE LÍQUIDA TRATANDO ÁGUA RESIDUÁRIA SINTÉTICA - EFEITO DA CARGA ORGÂNICA
}

\author{
Dissertação apresentada à Escola de \\ Engenharia de São Carlos da \\ Universidade de São Paulo como parte \\ dos requisitos necessários à obtenção do \\ título de Mestre em Ciências.
}

Área de concentração: Engenharia Hidráulica e Saneamento

Orientador: Prof. Dr. José Alberto Domingues Rodrigues

VERSÃO CORRIGIDA

SÃo CARlOS, SP

2012 
Ficha catalográfica preparada pela Seção de Tratamento da Informação do Serviço de Biblioteca - EESC/USP

Santos, Danilo Abreu dos

S237e Estudo da produção de biohidrogênio em AnSBBR com recirculação da fase líquida tratando água residuária sintética : efeito da carga orgânica / Danilo Abreu Santos ; orientador José Alberto Domingues Rodrigues. São Carlos, 2012.

Dissertação (Mestrado - Programa de Pós-Graduação e Área de Concentração em Hidráulica e Saneamento)-- Escola de Engenharia de São Carlos da Universidade de São Paulo, 2012. 


\section{FOLHA DE IULGAMENTO}

Candidato, Engenheiro DANILO ABREU DOS SANTOS

Titulo da dissertação "Estudo da produçâo de biohidrogênio em AnSBBR com recirculaçoăo da fase liquida tratando àgua residuairia sintética - efoito da carga orgânica",

Data da defesa: 23/03/2012

Comissio Inlgadon:

Prot. svoociado Jooc Albccto Dominguea Nodrigueo 10 rientader (Escola de Engenharia de MauavEEM)

Proft-Dre Suzana Maria Ratusznei

(Escola de Engenharia de Matwa/EEM)

Prof. Dr. Rogers Ribeiro

(Faculdade de Zootecnia e Engenharia dos Alimentos/USP)
Resultado:

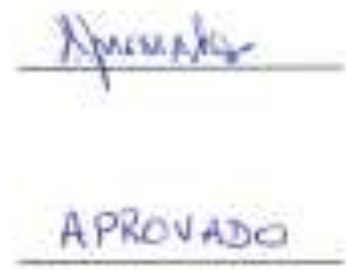

ArRoYAOO

Coondenador do Programa de Pós-Graduaçó̀ em Engenhatia Hidráulica e

Sancimento:

Prof. Tstular Edson Cezar Wendland

Fresidente da Comissàio de Pós-Graduaçióx

Prof: Associado Paulo Cesar Lima Segantine 



\section{DEDICATORIA}

Aos meus pais, Dorival e Edina, alicerces da minha vida.

Aos meus irmãos Denis e Diego.

Aos meus avós Valdemar, Ilda e Edenes. 


Não faças do amanhã o sinônimo de nunca, Nem do ontem te seja o mesmo que nunca mais.

Teus passos ficaram. Olhes pra trás... mas vá em frente Pois há muitos que precisam Que chegues para poderem seguir-te. 



\section{Agradecimentos}

Em primeiro lugar à minha família, por ter me dado condições de continuar sempre em frente, com todo o apoio e carinho. E por representarem simplesmente tudo em minha vida.

Ao meu orientador Prof. Dr. José Alberto Domingues Rodrigues. Por ter sido um grande companheiro, amigo e essencial para que o trabalho acontecesse. Um exemplo de honestidade e comprometimento.

A Profa. Dra. Suzana Maria Ratusznei. Nas horas mais impossíveis ela sempre estendeu a mão. Levarei sempre comigo.

Ao meu amigo, parceiro Mehdi. Um amigo pra todas as horas, que tornou as coisas muito mais fáceis nessa jornada pela megalópole. Uma amizade para toda uma vida.

À minha namorada Bianca. Por ter sido meu ponto forte em tudo. Nas horas mais difíceis ela sempre esteve ao meu lado. Simplesmente essencial.

Ao pessoal do SHS: Guilherme, Vitor, Rodrigo, Priscila, Ivie, Lenin, Eduardo e tantos outros, com alguns não convivi muito tempo, porém o tempo convivido foi um grande prazer.

A Carol Zampol pelo apoio nas análises microbiológicas.

Ao Departamento de Hidráulica e Saneamento da Escola de Engenharia de São Carlos da Universidade de São Paulo e a Escola de Engenharia Mauá do Instituto Mauá de Tecnologia que disponibilizaram o espaço e o apoio necessário à realização deste projeto..

À FAPESP, pela bolsa de mestrado concedida (processo $n^{\circ}$ 03.874-3) e pelo auxílio financeiro no Projeto Temático "Produção de Bioenergia no Tratamento de Águas Residuárias e Adequação Ambiental dos Efluentes e Resíduos Gerados” (processo $\mathrm{n}^{\circ}$ 09/15.984-0).

Àqueles que deram condições para a realização desse trabalho, que sem dúvida é fruto da cooperação de todos. 



\section{RESUMO}

SANTOS,D.A. Estudo da produção de biohidrogênio em AnSBBR com recirculação da fase líquida tratando água residuária sintética - efeito da carga orgânica. Dissertação (Mestrado) - Escola de Engenharia de São Carlos - Departamento de Hidráulica e Saneamento, Universidade de São Paulo, 2012.

Um reator anaeróbio com biomassa imobilizada operado em bateladas sequenciais com recirculação da fase liquida $(\mathrm{AnSBBR})$ foi aplicado à produção de biohidrogênio. Foram tratados 1.9 L de meio por ciclo, analisando a influência da variação da carga orgânica volumétrica (COAV) através da variação da concentração do afluente sintético a base de

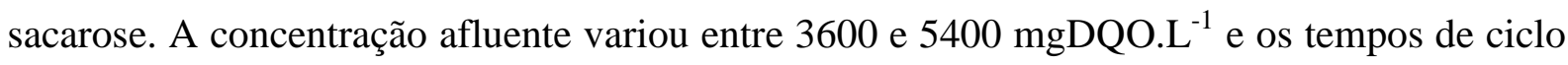
de 4, 3 e 2 horas obtendo, dessa maneira, as cargas orgânicas volumétricas de 9, 12, 13,5, 18 e 27 gDQO.L ${ }^{-1}$. O sistema foi inoculado com lodo proveniente de um UASB aplicado ao tratamento de águas residuárias de abatedouro de aves. Foram utilizados diferentes indicadores de rendimento para averiguar a estabilidade e o efeito da carga orgânica aplicada ao sistema sobre a produção de biohidrogênio. Os indicadores utilizados tiveram como base a quantidade de mols de $\mathrm{H}_{2}$ produzidos por dia em relação à massa de sólidos voláteis no interior do reator e às cargas orgânicas aplica e removida, tanto em termos de matéria orgânica (DQO) quanto de carboidratos (sacarose) aplicados. Os resultados mostraram estabilidade do sistema na produção de biohidrogênio e consumo de substrato. Em todas condições experimentais, em termos de cargas orgânicas aplicada e removida obteve-se comportamento análogo com uma redução deste indicador em função do aumento da carga orgânica. O melhor rendimento obtido foi de 4,16 mol- $\mathrm{H}_{2} \cdot \mathrm{kg}_{-} \mathrm{SAC}^{-1} \cdot \mathrm{d}^{-1}$ para a carga orgânica de 9 gDQO.L $\mathrm{L}^{-1} \cdot \mathrm{d}^{-1}$ (concentração afluente de $3600 \mathrm{mgDQO} \cdot \mathrm{L}^{-1}$ e tempo de ciclo de $4 \mathrm{~h}$ ), sendo a composição de $\mathrm{H}_{2}$ no biogás de $36 \%$ (64\% de $\mathrm{CO}_{2}$ e $0 \%$ de $\mathrm{CH}_{4}$ ). Os compostos metabólitos presentes de modo mais significativo foram o etanol, ácido acético e ácido butírico. A morfologia da microbiologia no interior do reator não apresentou variações significativas entre as diferentes condições experimentais, sendo composta por bacilos, endósporos e filamentos.

Palavras-chave: AnSBBR; biohidrogênio; carga orgânica; concentração afluente; tempo de ciclo. 



\begin{abstract}
Santos, D.A. Study of hydrogen production in AnSBBR with recirculation the liquid phase.treating sucrose based wastewater - organic load effect. (Master Degree) - School of Engineering of São Carlos, Departament of hydraulics and Sanitation, Uuniversity of São Paulo, São Carlos, 2012.

A reactor with immobilized biomass anaerobic sequencing batch operated with recirculation of the liquid phase (AnSBBR) was applied to the production of biohydrogen. The influence of the applied volumetric organic load was studied by varying the concentration of influent 3600 e $5400 \mathrm{mgDQO} . \mathrm{L}^{-1}$ and cycle times of 4, 3 and 2 hours getting this way, the volumetric organic loads of 9, 12, 13.5, 18 and 27 gDQO.L ${ }^{-1}$. The system was inoculated with sludge from a UASB applied to the treatment of wastewater from poultry slaughterhouse. Different performance indicators were used to ascertain the stability and the effect of the organic load applied to the system on the production of biohydrogen. The indicators used were based on the number of moles of $\mathrm{H}_{2}$ produced per day on the mass of volatile solids inside the reactor and the organic loads applied and removed, both in terms of organic matter (COD) and carbohydrate (sucrose) applied. The results showed system stability in the production of bio-hydrogen and substrate consumption. In all experimental conditions in terms of organic loads applied and removed analogous behavior was obtained a reduction of the indicator as a function of the increase in organic load. The best yield was $4.16 \mathrm{~mol}-\mathrm{H} 2 . \mathrm{kg}$ $\mathrm{SAC}^{-1} \cdot \mathrm{d}^{-1}$ for the organic load of $9 \mathrm{gDQO} . \mathrm{L}^{-1} \cdot \mathrm{d}^{-1}$ (influent concentration of $3600 \mathrm{mgDQO}$.L-1 and time cycle of $4 \mathrm{~h}$ ), and the composition of $\mathrm{H} 2$ in the biogas 36\% (64\% 0\% CO2 and $\mathrm{CH} 4)$. The compounds metabolites present more significantly were ethanol, acetic acid and butyric acid. The morphology of microbiology within the reactor showed no significant variations between different experimental conditions, consisting of bacilli, and filaments endospores.
\end{abstract}

Keywords: AnSBBR; biohydrogen; organic loading; influent concentration; cycle length. 


\section{LISTA DE SÍMBOLOS E ABREVIAÇÕES}

\begin{tabular}{|c|c|c|}
\hline Símbolo & Denominação & Unidade \\
\hline $\mathrm{C}_{\mathrm{ST}}$ & Concentração de matéria orgânica (amostras não filtradas) & {$\left[\mathrm{mgDQO} \cdot \mathrm{L}^{-1}\right]$} \\
\hline $\mathrm{C}_{\text {STA }}$ & Concentração de matéria orgânica afluente (amostras não filtradas) & {$\left[\mathrm{mgDQO} \cdot \mathrm{L}^{-1}\right]$} \\
\hline $\mathrm{C}_{\mathrm{STE}}$ & Concentração de matéria orgânica efluente (amostras não filtradas) & {$\left[\mathrm{mgDQO} \cdot \mathrm{L}^{-1}\right]$} \\
\hline $\mathrm{C}_{\mathrm{SF}}$ & Concentração de matéria orgânica (amostras filtradas) & {$\left[\mathrm{mgDQO} \cdot \mathrm{L}^{-1}\right]$} \\
\hline $\mathrm{C}_{\mathrm{SFE}}$ & Concentração de matéria orgânica efluente (amostras filtradas) & {$\left[\mathrm{mgDQO} \cdot \mathrm{L}^{-1}\right]$} \\
\hline$\varepsilon_{\mathrm{ST}}$ & Eficiência de remoção de matéria orgânica (amostras não filtradas) & {$[\%]$} \\
\hline$\varepsilon_{\mathrm{SF}}$ & Eficiência de remoção de matéria orgânica (amostras filtradas) & {$[\%]$} \\
\hline $\mathrm{C}_{\mathrm{C}}$ & Concentração de carboidratos & {$\left[\mathrm{mgSAC} \cdot \mathrm{L}^{-1}\right]$} \\
\hline $\mathrm{C}_{\mathrm{CT}}$ & Concentração de carboidratos (amostras não filtradas) & {$\left[\mathrm{mgSAC} \cdot \mathrm{L}^{-1}\right]$} \\
\hline $\mathrm{C}_{\mathrm{CTA}}$ & Concentração de carboidratos afluente (amostras não filtradas) & {$\left[\mathrm{mgSAC} \cdot \mathrm{L}^{-1}\right]$} \\
\hline $\mathrm{C}_{\mathrm{CTE}}$ & Concentração de carboidratos efluente (amostras não filtradas) & {$\left[\mathrm{mgSAC} \cdot \mathrm{L}^{-1}\right]$} \\
\hline $\mathrm{C}_{\mathrm{CF}}$ & Concentração de carboidratos (amostras não filtradas) & {$\left[\mathrm{mgSAC} \cdot \mathrm{L}^{-1}\right]$} \\
\hline $\mathrm{C}_{\mathrm{CFE}}$ & Concentração de carboidratos efluente (amostras filtradas) & {$\left[\mathrm{mgSAC} . \mathrm{L}^{-1}\right]$} \\
\hline$\varepsilon_{\mathrm{CT}}$ & Eficiência de remoção de carboidratos (amostras filtradas) & {$[\%]$} \\
\hline$\varepsilon_{\mathrm{CF}}$ & Eficiência de remoção de carboidratos (amostras filtradas) & {$[\%]$} \\
\hline AVT & Ácidos voláteis totais & {$\left[\mathrm{mgHAc} . \mathrm{L}^{-1}\right]$} \\
\hline AT & Alcalinidade total & {$\left[\mathrm{mgCaCO}_{3} \cdot \mathrm{L}^{-1}\right]$} \\
\hline AI & Alcalinidade intermediária & {$\left[\mathrm{mgCaCO}_{3} \cdot \mathrm{L}^{-1}\right]$} \\
\hline AP & Alcalinidade parcial & {$\left[\mathrm{mgCaCO}_{3} \cdot \mathrm{L}^{-1}\right]$} \\
\hline $\mathrm{AB}$ & Alcalinidade a bicarbonato & {$\left[\mathrm{mgCaCO}_{3} \cdot \mathrm{L}^{-1}\right]$} \\
\hline $\mathrm{pH}$ & Potencial hidrogeniônico & \\
\hline ST & Concentração de sólidos totais & {$\left[\mathrm{mg} . \mathrm{L}^{-1}\right]$} \\
\hline SVT & Concentração de sólidos voláteis totais & {$\left[\mathrm{mg} \cdot \mathrm{L}^{-1}\right]$} \\
\hline SST & Concentração de sólidos suspensos totais & {$\left[\mathrm{mg} \cdot \mathrm{L}^{-1}\right]$} \\
\hline SSV & Concentração de sólidos suspensos voláteis & {$\left[\mathrm{mg} \cdot \mathrm{L}^{-1}\right]$} \\
\hline Ac & Acetona & {$\left[\mathrm{mg} \cdot \mathrm{L}^{-1}\right]$} \\
\hline $\mathrm{MeOH}$ & Metanol & {$\left[\mathrm{mg} . \mathrm{L}^{-1}\right]$} \\
\hline $\mathrm{EtOH}$ & Etanol & {$\left[\mathrm{mg} . \mathrm{L}^{-1}\right]$} \\
\hline $\mathrm{BuOH}$ & n-Butanol & {$\left[\mathrm{mg} . \mathrm{L}^{-1}\right]$} \\
\hline
\end{tabular}




\begin{tabular}{|c|c|c|}
\hline HAc & Ácido Acético & {$\left[\mathrm{mg} \cdot \mathrm{L}^{-1}\right]$} \\
\hline $\mathrm{HPr}$ & Ácido Propiônico & {$\left[\mathrm{mg} \cdot \mathrm{L}^{-1}\right]$} \\
\hline $\mathrm{HIBu}$ & Ácido Isobutírico & {$\left[\mathrm{mg} \cdot \mathrm{L}^{-1}\right]$} \\
\hline $\mathrm{HBu}$ & Ácido Butírico & {$\left[\mathrm{mg} \cdot \mathrm{L}^{-1}\right]$} \\
\hline HIVa & Ácido Isovalérico & {$\left[\mathrm{mg} \cdot \mathrm{L}^{-1}\right]$} \\
\hline $\mathrm{HVa}$ & Ácido Valérico & {$\left[\mathrm{mg} \cdot \mathrm{L}^{-1}\right]$} \\
\hline $\mathrm{HCa}$ & Ácido Capróico & {$\left[\mathrm{mg} \cdot \mathrm{L}^{-1}\right]$} \\
\hline $\mathrm{C}_{\text {Met }}$ & Concentração de metabólitos & {$\left[\mathrm{mg} \cdot \mathrm{L}^{-1}\right]$} \\
\hline $\mathrm{V}_{\mathrm{G}}$ & Volume de biogás total & {$[\mathrm{mL}]$} \\
\hline $\mathrm{V}_{\mathrm{H} 2}$ & Volume de hidrogênio total & {$[\mathrm{mL}]$} \\
\hline $\mathrm{V}_{\mathrm{CO} 2}$ & Volume de dióxido de carbono no biogás & {$[\mathrm{mL}]$} \\
\hline $\mathrm{V}_{\mathrm{CH} 4}$ & Volume de metano no biogás & {$[\mathrm{mL}]$} \\
\hline $\mathrm{C}_{\mathrm{H} 2}$ & Concentração de hidrogênio no biogás & {$\left[\mathrm{mmol} . \mathrm{L}^{-1}\right]$} \\
\hline $\mathrm{C}_{\mathrm{CO} 2}$ & Concentração de dióxido de carbono no biogás & {$\left[\mathrm{mmol} . \mathrm{L}^{-1}\right]$} \\
\hline $\mathrm{C}_{\mathrm{CH} 4}$ & Concentração de metano no biogás & {$\left[\mathrm{mmol} . \mathrm{L}^{-1}\right]$} \\
\hline$t_{C}$ & Tempo de ciclo & [d] ou [dia] \\
\hline $\mathrm{t}$ & Tempo de ensaio/condição ou de monitoramento & [d] ou [dia] \\
\hline $\mathrm{V}_{\mathrm{T}}$ & Volume total de meio líquido presente no biorreator & {$[\mathrm{L}]$} \\
\hline $\mathrm{V}_{\mathrm{F}}$ & $\begin{array}{l}\text { Volume de meio líquido descarregado e alimentado a cada ciclo no } \\
\text { biorreator }\end{array}$ & [L] \\
\hline $\mathrm{COAV}_{\mathrm{STA}}$ & $\begin{array}{l}\text { Carga orgânica aplicada volumétrica afluente em termos de matéria } \\
\text { orgânica (amostras não filtradas) }\end{array}$ & {$\left[\mathrm{kgDQO} \cdot \mathrm{m}^{-3} \cdot \mathrm{d}^{-1}\right]$} \\
\hline $\mathrm{CORV}_{\mathrm{SFE}}$ & $\begin{array}{c}\text { Carga orgânica removida volumétrica efluente em termos de } \\
\text { matéria orgânica (amostras filtradas) }\end{array}$ & {$\left[\mathrm{kgDQO} \cdot \mathrm{m}^{-3} \cdot \mathrm{d}^{-1}\right]$} \\
\hline $\mathrm{COAV}_{\mathrm{CTA}}$ & $\begin{array}{l}\text { Carga orgânica aplicada volumétrica em termos de carboidratos } \\
\text { (amostras não filtradas) }\end{array}$ & {$\left[\operatorname{kgSAC} \cdot \mathrm{m}^{-3} \cdot \mathrm{d}^{-1}\right]$} \\
\hline $\mathrm{CORV}_{\mathrm{CTFE}}$ & $\begin{array}{l}\text { Carga orgânica removida volumétrica em termos de carboidratos } \\
\qquad \text { (amostras filtradas) }\end{array}$ & {$\left[\mathrm{kgSAC} \cdot \mathrm{m}^{-3} \cdot \mathrm{d}^{-1}\right]$} \\
\hline $\mathrm{n}_{\mathrm{H} 2}$ & Vazão diária de hidrogênio & {$\left[\mathrm{mol} . \mathrm{d}^{-1}\right]$} \\
\hline PrM & $\begin{array}{l}\text { Produtividade molar de hidrogênio em relação ao volume de meio } \\
\text { líquido presente no biorreator }\end{array}$ & {$\left[\mathrm{molH}_{2} \cdot \mathrm{m}^{-3} \cdot \mathrm{d}^{-1}\right]$} \\
\hline PrME & $\begin{array}{c}\text { Produtividade de hidrogênio em relação aos sólidos voláteis totais } \\
\text { presentes no biorreator }\end{array}$ & {$\left[\mathrm{molH}_{2} \cdot \mathrm{kgSVT}^{-1} \cdot \mathrm{d}^{-1}\right]$} \\
\hline
\end{tabular}




\begin{tabular}{ccc}
\hline RMCA $_{\mathrm{C}, \mathrm{n}}$ & $\begin{array}{r}\text { Rendimento molar de hidrogênio em relação à carga aplicada de } \\
\text { carboidratos (amostras não filtradas) }\end{array}$ & {$\left[\mathrm{molH}_{2} \cdot \mathrm{kgSAC}^{-1}\right]$} \\
$\mathrm{RMCA}_{\mathrm{S}, \mathrm{n}}$ & $\begin{array}{r}\text { Rendimento molar de hidrogênio em relação à carga aplicada de } \\
\text { matéria orgânica (amostras não filtradas) }\end{array}$ & {$\left[\mathrm{molH}_{2} \cdot \mathrm{kgDQO}^{-1}\right]$} \\
$\mathrm{RMCR}_{\mathrm{C}, \mathrm{n}}$ & $\begin{array}{r}\text { Rendimento molar de hidrogênio em relação à carga removida de } \\
\text { carboidratos (amostras filtradas) }\end{array}$ & {$\left[\mathrm{molH}_{2} \cdot \mathrm{kgSAC}^{-1}\right]$} \\
$\mathrm{RMCR}_{\mathrm{S}, \mathrm{n}}$ & Rendimento molar de hidrogênio em relação à carga aplicada de & \\
& carboidratos (amostras filtradas) & {$\left[\mathrm{molH}_{2} \cdot \mathrm{kgDQO}^{-1}\right]$} \\
\hline
\end{tabular}

\begin{tabular}{cc}
\hline Abreviação & Denominação \\
\hline AnSBBR & Reator anaeróbio operado em batelada sequencial com biomassa \\
& imobilizada (anaerobic sequencing biofilm batch reactor) \\
PEBD & Polietileno de baixa densidade \\
DQO & Demanda Química de Oxigênio) \\
\hline
\end{tabular}




\section{LISTA DE TABELAS}

Tabela 3.1: Rendimento máximo de hidrogênio por mol de açúcar consumido......................32

Tabela 3.2: Efeito do $\mathrm{pH}$ inicial em diferentes estudos e substratos.......................................35

Tabela 4.1: Composição da água residuária sintética a ser utilizada nos ensaios....................48

Tabela 4.2: Resumo dos procedimentos analíticos e frequência de monitoramento................49

Tabela 4.3: Resumos das condições experimentais estudadas................................................54

Tabela 5.1: Série de sólidos afluente e efluente na condição preliminar.................................61

Tabela 5.2: Valores médios dos parâmetros monitorados na condição 1................................64

Tabela 5.3: Concentração dos compostos intermediários na condição 1 ...............................67

Tabela 5.4: Série de sólidos afluente e efluente na condição 1 ..............................................69

Tabela 5.5: Produção e composição do biogás produzido ao longo do ciclo na condição 1 ....74

Tabela 5.6: Valores médios dos parâmetros monitorados na condição 2................................76

Tabela 5.7: Concentração dos compostos intermediários na condição 2.................................79

Tabela 5.8: Série de sólidos afluente e efluente na condição 2 ..............................................81

Tabela 5.9: Produção e composição do biogás produzido ao longo do ciclo na condição $2 . . .86$

Tabela 5.10: Valores médios dos parâmetros monitorados na condição 3..............................88

Tabela 5.11: Concentração dos compostos intermediários na condição 3..............................91

Tabela 5.12: Série de sólidos afluente e efluente na condição 3............................................93

Tabela 5.13: Produção e composição do biogás produzido ao longo do ciclo na

condição 3

Tabela 5.14: Valores médios dos parâmetros monitorados na condição 4

Tabela 5.15: Concentração dos compostos intermediários na condição 4............................103

Tabela 5.16: Série de sólidos afluente e efluente na condição 4

Tabela 5.17: Produção e composição do biogás produzido ao longo do ciclo na

condição 4

Tabela 5.18: Valores médios dos parâmetros monitorados na condição 5

Tabela 5.19: Concentração dos compostos intermediários na condição 5.

Tabela 5.20: Série de sólidos afluente e efluente na condição 5.

Tabela 5.21: Produção e composição do biogás produzido ao longo do ciclo na

condição 5

Tabela 5.22: Valores médios dos parâmetros monitorados na condição 5

Tabela 5.23: Concentração dos compostos intermediários na condição 5. 
Tabela 5.24: Série de sólidos afluente e efluente na condição 5

Tabela 5.25: Produção e composição do biogás produzido ao longo do ciclo na condição 5

Tabela 5.26: Concentração dos compostos intermediários em todas condições.

Tabela 5.27: Equações bioquímicas e equivalente-grama dos compostos em DQO. 141

Tabela 5.28: Valores do balanço de DQO efluente. 141

Tabela 5.29: Composição do biogás produzido em todas condições. 143

Tabela 5.30: Indicadores de produção de biohidrogênio do sistema em todas condições......148 


\section{LISTA DE FIGURAS}

Figura 2.1: Vias de fermentação do hidrogênio (adaptado de TANISHO, 2001)....................31

Figura 2.2: Indicadores de produção de hidrogênio presentes na literatura.............................37

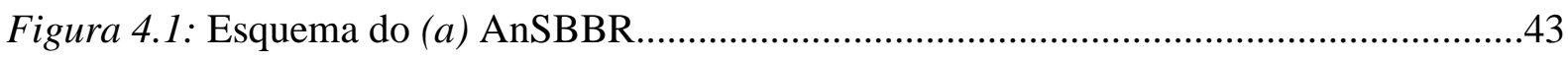

Figura 4.2: Fotografia da montagem experimental.............................................................44

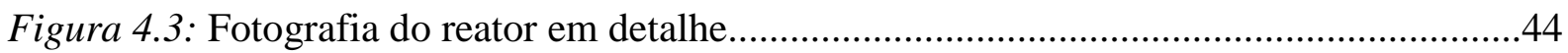

Figura 4.4: Polietileno de baixa densidade (PEBD) utilizado como material suporte..........46

Figura 5.1: Concentração de carboidratos e eficiência de remoção na condição preliminar..

Figura 5.2: Concentração de matéria orgânica (DQO) afluente efluente na condição preliminar..

Figura 5.3: Concentração de ácidos voláteis totais afluente e efluente na condição preliminar......

Figura 5.4: Valores de $\mathrm{pH}$ afluente e efluente na condição preliminar. 62

Figura 5.5: Concentração de carboidratos afluente e efluente para amostras filtradas e não filtradas na condição 1 .

Figura 5.6: Eficiência de remoção de carboidratos para amostras filtradas na condição 1....65

Figura 5.7: Concentração de matéria orgânica (DQO) afluente e efluente para amostras filtradas e não filtradas na condição 1 . .66

Figura 5.8: Eficiência de remoção de matéria orgânica (DQO) para amostras filtradas e não filtradas na condição 1 .66

Figura 5.9: Concentração de ácidos voláteis totais afluente e efluente na condição 1 . 67

Figura 5.10: Valores de $\mathrm{pH}$ afluente e efluente na condição 1. .68

Figura 5.11: Concentração de alcalinidade total afluente e efluente na condição 1 .69

Figura 5.12: Volume total de biogás produzido na condição 1.

Figura 5.13: (a) Concentração de carboidratos e (b) eficiência de remoção para amostras filtradas ao longo do ciclo na condição 1

Figura 5.14: Concentração de matéria orgânica (DQO) para amostras filtradas ao longo do ciclo na condição 1 . 
Figura 5.15: Concentração de ácidos voláteis totais ao longo do ciclo na condição 1 ....71

Figura 5.16: Concentração dos compostos intermediários ao longo do ciclo na

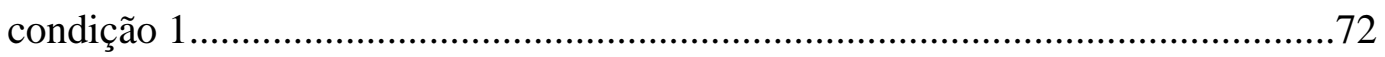

Figura 5.17: Concentração de alcalinidade total ao longo do ciclo na condição 1 ...............72

Figura 5.18: Valores de $\mathrm{pH}$ ao longo do ciclo na condição 1 ................................................73

Figura 5.19: Volume total de biogás produzido ao longo do ciclo na condição 1...............74

Figura 5.20: Volumes de $\mathrm{H}_{2}, \mathrm{CO}_{2}$ e $\mathrm{CH}_{4}$ produzidos ao longo do ciclo na condição 1 ........74

Figura 5.21: Concentração de carboidratos afluente e efluente para amostras filtradas e não filtradas na condição 2 .77

Figura 5.22: Eficiência de remoção de carboidratos para amostras filtradas na condição 2....77

Figura 5.23: Concentração de matéria orgânica (DQO) afluente e efluente para amostras

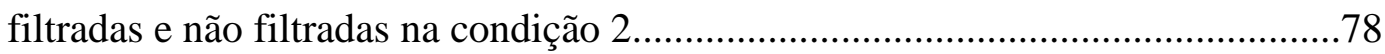

Figura 5.24: Eficiência de remoção de matéria orgânica (DQO) para amostras filtradas e não

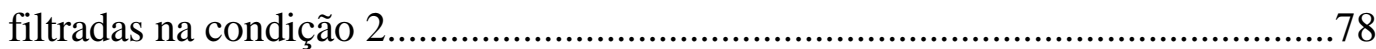

Figura 5.25: Concentração de ácidos voláteis totais afluente e efluente na condição 2......79

Figura 5.26: Valores de $\mathrm{pH}$ afluente e efluente na condição 2. .80

Figura 5.27: Concentração de alcalinidade total afluente e efluente na condição 2..............81

Figura 5.28: Volume toal de biogás produzido na condição 2.

Figura 5.29: (a) Concentração de carboidratos e (b) eficiência de remoção para amostras filtradas ao longo do ciclo na condição 2 82

Figura 5.30: Concentração de matéria orgânica (DQO) para amostras filtradas ao longo do ciclo na condição 2 . .83

Figura 5.31: Concentração de ácidos voláteis totais ao longo do ciclo na condição 2 ........83

Figura 5.32: Concentração dos compostos intermediários ao longo do ciclo na condição 2 ...84

Figura 5.33: Concentração de alcalinidade total ao longo do ciclo na condição 2................84

Figura 5.34: Valores de ao longo do ciclo na condição 2 .85

Figura 5.35: Volume total de biogás produzido ao longo do ciclo na condição 2...............86

Figura 5.36: Volumes de $\mathrm{H}_{2}, \mathrm{CO}_{2}$ e $\mathrm{CH}_{4}$ produzidos ao longo do ciclo na condição 2 ........86

Figura 5.37: Concentração de carboidratos afluente e efluente para amostras filtradas e não filtradas na condição 3 .

Figura 5.38: Eficiência de remoção de carboidratos para amostras filtradas na condição 3 . .89 
Figura 5.39: Concentração de matéria orgânica (DQO) afluente e efluente para amostras filtradas e não filtradas na condição 3 .

Figura 5.40: Eficiência de remoção de matéria orgânica (DQO) para amostras filtradas e não filtradas na condição 3 .

Figura 5.41: Concentração de ácidos voláteis totais afluente e efluente na condição 3......91

Figura 5.42: Valores de $\mathrm{pH}$ afluente e efluente na condição 3. .92

Figura 5.43: Concentração de alcalinidade total afluente e efluente na condição 3. .93

Figura 5.44: Volume total de biogás produzido na condição 3. .93

Figura 5.45: (a) Concentração de carboidratos e (b) eficiência de remoção para amostras filtradas ao longo do ciclo na condição 3 .

Figura 5.46: Concentração de matéria orgânica (DQO) para amostras filtradas ao longo do ciclo na condição 3 .95

Figura 5.47: Concentração de ácidos voláteis totais ao longo do ciclo na condição 3 .95

Figura 5.48: Concentração dos compostos intermediários ao longo do ciclo na condição 3...96

Figura 5.49: Concentração de alcalinidade total ao longo do ciclo na condição 3. .96

Figura 5.50: Valores de $\mathrm{pH}$ ao longo do ciclo na condição 3. .97

Figura 5.51: Volume total de biogás produzido ao longo do ciclo na condição 3 .98

Figura 5.52: Volumes de $\mathrm{H}_{2}, \mathrm{CO}_{2}$ e $\mathrm{CH}_{4}$ produzidos ao longo do ciclo na condição 3........98

Figura 5.53: Concentração de carboidratos afluente e efluente para amostras filtradas e não filtradas na condição 4 ..

Figura 5.54: Eficiência de remoção de carboidratos para amostras filtradas na condição 4 . 101

Figura 5.55: Concentração de matéria orgânica (DQO) afluente e efluente para amostras filtradas e não filtradas na condição 4 . 102

Figura 5.56: Eficiência de remoção de matéria orgânica (DQO) para amostras filtradas e não filtradas na condição 4 102

Figura 5.57: Concentração de ácidos voláteis totais afluente e efluente na condição 4...103

Figura 5.58: Valores de pH afluente e efluente na condição 4 104

Figura 5.59: Concentração de alcalinidade total afluente e efluente na condição 4. .105

Figura 5.60: Volume total de biogás produzido na condição 4. 105

Figura 5.61: (a) Concentração de carboidratos e (b) eficiência de remoção para amostras filtradas ao longo do ciclo na condição 4 . 106 
Figura 5.62: Concentração de matéria orgânica (DQO) para amostras filtradas ao longo do ciclo na condição 4

Figura 5.63: Concentração de ácidos voláteis totais ao longo do ciclo na condição 4....107

Figura 5.64: Concentração dos compostos intermediários ao longo do ciclo na

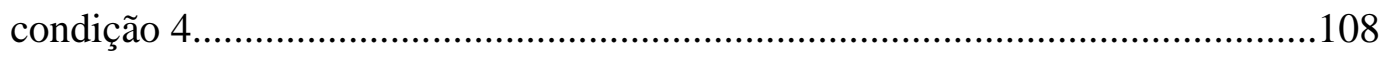

Figura 5.65: Concentração de alcalinidade total ao longo do ciclo na condição 4.............108

Figura 5.66: Valores de pH ao longo do ciclo na condição 4.............................................109

Figura 5.67: Volume total de biogás produzido ao longo do ciclo na condição 4..............110

Figura 5.68: Volumes de $\mathrm{H}_{2}, \mathrm{CO}_{2}$ e $\mathrm{CH}_{4}$ produzidos ao longo do ciclo na condição 4......110

Figura 5.69: Concentração de carboidratos afluente e efluente para amostras filtradas e não filtradas na condição 5 .

Figura 5.70: Eficiência de remoção de carboidratos para amostras filtradas na condição 5 ...

Figura 5.71: Concentração de matéria orgânica (DQO) afluente e efluente para amostras filtradas e não filtradas na condição 5 .

Figura 5.72: Eficiência de remoção de matéria orgânica (DQO) para amostras filtradas e não filtradas na condição 5

Figura 5.73: Concentração de ácidos voláteis totais afluente e efluente na condição 5...115

Figura 5.74: Valores de pH afluente e efluente na condição 5. 116

Figura 5.75: Concentração de alcalinidade total afluente e efluente na condição 5.

Figura 5.76: Volume toal de biogás produzido na condição 5.

Figura 5.77: (a) Concentração de carboidratos e (b) eficiência de remoção para amostras filtradas ao longo do ciclo na condição 5

Figura 5.78: Concentração de matéria orgânica (DQO) para amostras filtradas ao longo do ciclo na condição 5 .

Figura 5.79: Concentração de ácidos voláteis totais ao longo do ciclo na condição 5.....119

Figura 5.80: Concentração dos compostos intermediários ao longo do ciclo na condição 5 .

Figura 5.81: Concentração de alcalinidade total ao longo do ciclo na condição 5. 120

Figura 5.82: Valores de ao longo do ciclo na condição 5

Figura 5.83: Volume total de biogás produzido ao longo do ciclo na condição 5 122

Figura 5.84: Volumes de $\mathrm{H}_{2}, \mathrm{CO}_{2}$ e $\mathrm{CH}_{4}$ produzidos ao longo do ciclo na condição 5....122 
Figura 5.85: Concentração de carboidratos afluente e efluente para amostras filtradas e não filtradas na condição 6

Figura 5.86: Eficiência de remoção de carboidratos para amostras filtradas na condição 6..125

Figura 5.87: Concentração de matéria orgânica (DQO) afluente e efluente para amostras filtradas e não filtradas na condição 6 .

Figura 5.88: Eficiência de remoção de matéria orgânica (DQO) para amostras filtradas e não filtradas na condição 6 . 126

Figura 5.89: Concentração de ácidos voláteis totais afluente e efluente na condição $6 \ldots . .127$

Figura 5.90: Valores de pH afluente e efluente na condição 6. 128

Figura 5.91: Concentração de alcalinidade total afluente e efluente na condição 6. 129

Figura 5.92: Volume total de biogás produzido na condição 6.

Figura 5.93: (a) Concentração de carboidratos e (b) eficiência de remoção para amostras filtradas ao longo do ciclo na condição 6 ...... 130

Figura 5.94: Concentração de matéria orgânica (DQO) para amostras filtradas ao longo do ciclo na condição 6

Figura 5.95: Concentração de ácidos voláteis totais ao longo do ciclo na condição 6. 131

Figura 5.96: Concentração dos compostos intermediários ao longo do ciclo na condição 6 .

Figura 5.97: Concentração de alcalinidade total ao longo do ciclo na condição 6 . 132

Figura 5.98: Valores de pH ao longo do ciclo na condição 6.

Figura 5.99: Volume total de biogás produzido ao longo do ciclo na condição 6.

Figura 5.100: Volumes de $\mathrm{H}_{2}, \mathrm{CO}_{2}$ e $\mathrm{CH}_{4}$ produzidos ao longo do ciclo na condição $6 . . . .134$

Figura 5.101: Concentração de matéria orgânica (DQO) para amostras filtradas e não filtradas em todas as condições.

Figura 5.102: Eficiência de remoção de matéria orgânica (DQO) para amostras filtradas e não filtradas em todas as condições 136

Figura 5.103: Concentração de carboidratos afluente e efluente para amostras filtradas e não filtradas em todas as condições...... 138

Figura 5.104: Eficiência de conversão de carboidratos para amostras filtradas e não filtradas em todas as condições 138

Figura 5.104: Concentração dos compostos intermediários em todas condições. 139

Figura 5.105: Concentração dos compostos intermediários em todas condições. 140

Figura 5.106: Volume total de biogás produzido ao longo do ciclo em todas condições 143 
Figura 5.107: Volumes de $\mathrm{H}_{2}, \mathrm{CO}_{2}$ e $\mathrm{CH}_{4}$ produzidos em todas condições..........................145

Figura 5.108: Exames microbiológicos da biomassa em todas condições. $\quad \ldots \quad 146$ 


\section{Conteúdo}

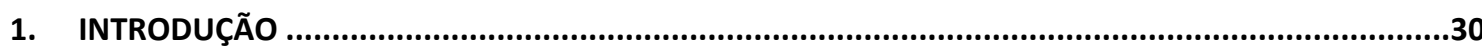

2. OBJETIVOS

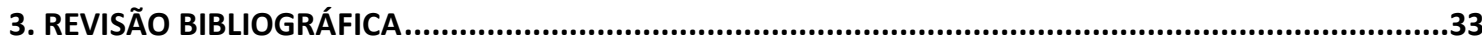

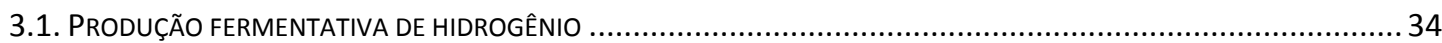

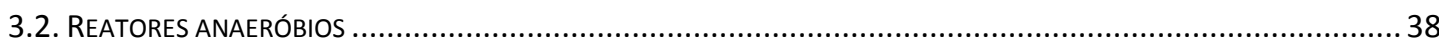

3.3. FATORES INFLUENTES NA PRODUÇÃO DE HIDROGÊNIO EM REATORES ANAERÓBIOS ............................................ 39

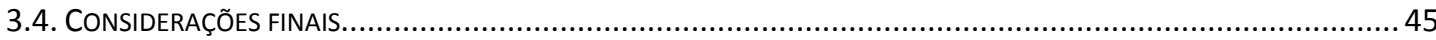

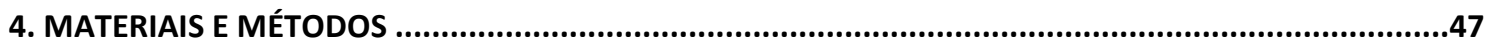

4.1. ANSBBR COM BIOMASSA IMOBILIZADA E RECIRCULAÇÃO DA FASE LÍQUIDA ........................................... 47

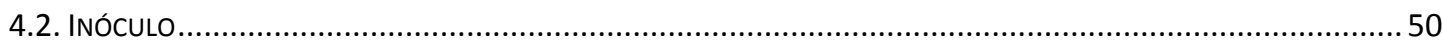

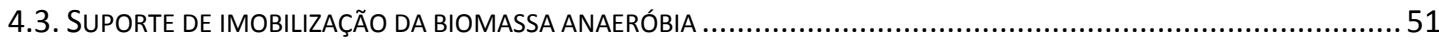

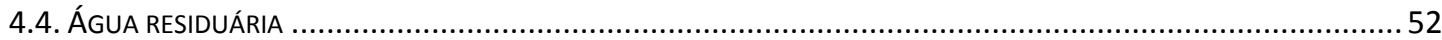

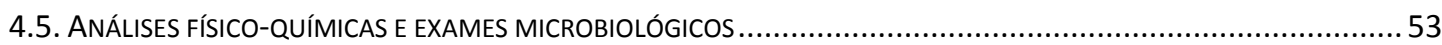

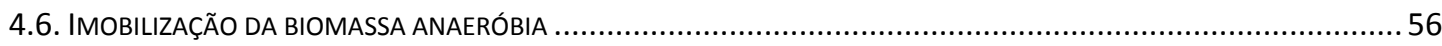

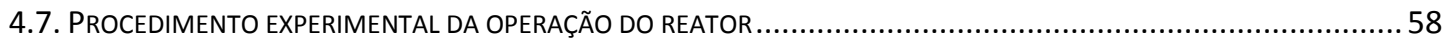

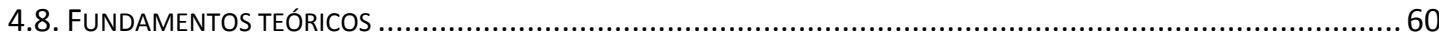

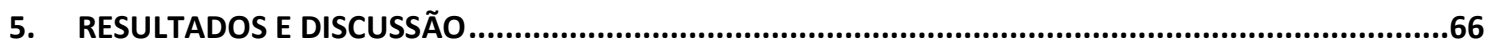

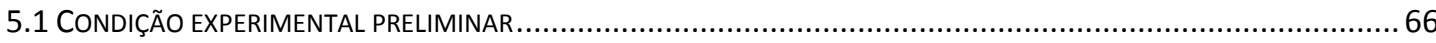

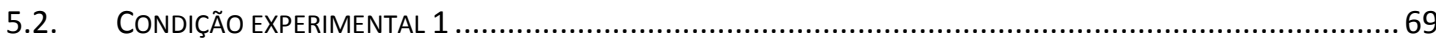

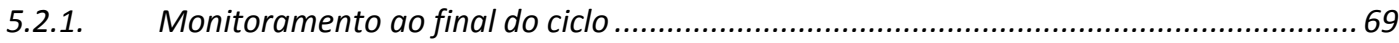

5.2.2. Monitoramento a longo do ciclo ............................................................................. 76

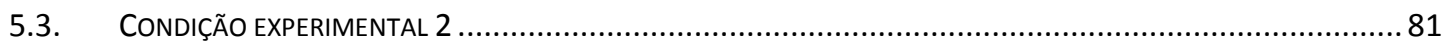

5.3.1. Monitoramento a final do ciclo ............................................................................. 81

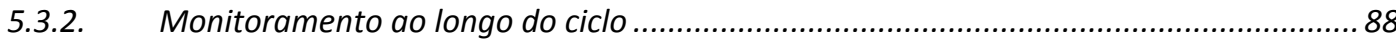

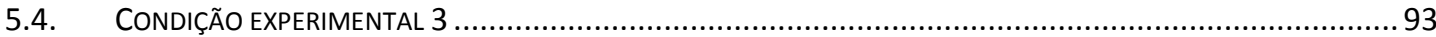

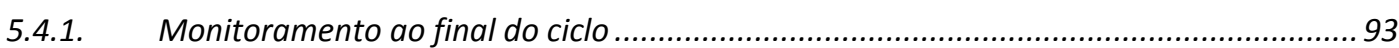

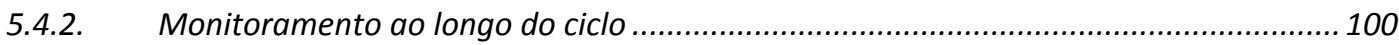

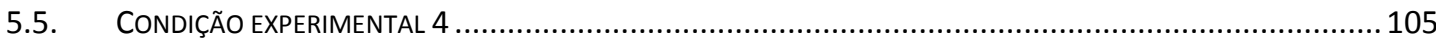

5.5.1. Monitoramento ao final do ciclo ...................................................................... 105

5.5.2. Monitoramento a longo do ciclo ........................................................................... 112

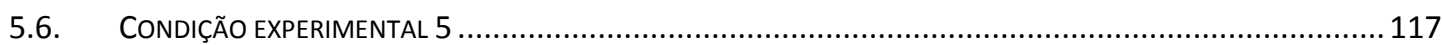

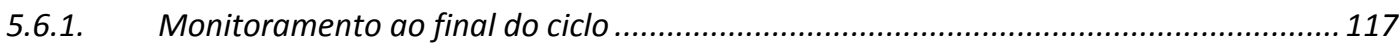

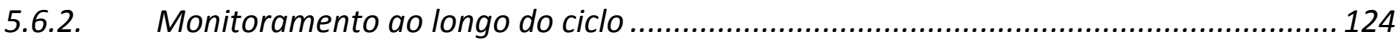




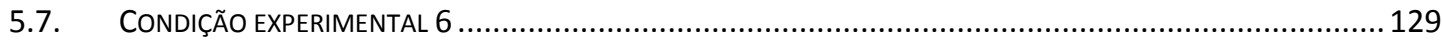

5.7.1. Monitoramento ao final do ciclo ...................................................................... 129

5.7.2. Monitoramento ao longo do ciclo ...................................................................... 136

5.8. ANÁLISE GERAL DAS CONDIÇÕES EXPERIMENTAIS ESTUDADAS..................................................... 141

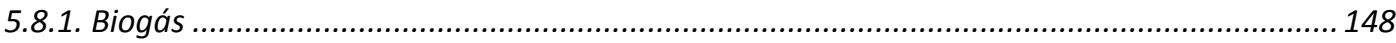

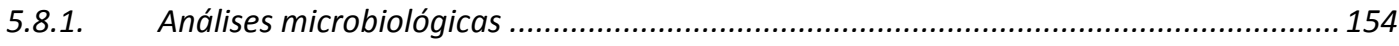

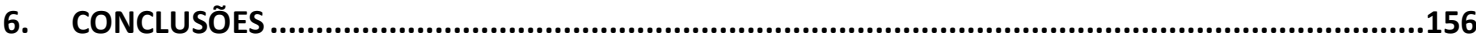

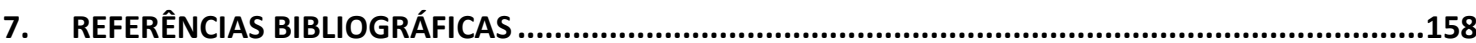




\section{INTRODUÇÃO}

A grande problemática dos combustíveis fósseis juntamente com a questão ambiental, vem direcionando a ciência na busca de novas alternativas energéticas com o intuito da descentralização da produção, diversificando as fontes e os produtos obtidos. Dentro dessa perspectiva o hidrogênio é apontado como um substituto promissor dos combustíveis provenientes do petróleo. A combustão limpa e o grande potencial energético estão entre as vantagens desse combustível, cujos estudos estão direcionados na busca de novas formas de produção em larga escala, tornando-a economicamente viável.

Existem várias formas de se produzir energia via biológica: metano proveniente da digestão (respiração) anaeróbia; o etanol obtido da fermentação alcoólica, amplamente utilizada no Brasil; e o hidrogênio obtido por fermentação de diversos substratos (Tanisho, 2001). A elevada velocidade de produção de hidrogênio, a simples operação e a capacidade de transformar resíduos orgânicos em energia são vantagens da produção de hidrogênio por fermentação (Wang, 2009). O hidrogênio produzido a partir da biomassa e/ou da fração biodegradável de resíduos pode se tornar uma alternativa tecnológica e economicamente viável e, ao mesmo tempo, integrando os princípios do desenvolvimento sustentável, ou seja, contribuindo para as chamadas "tecnologias verdes" (Alves \& Abreu, 2006).

Dentro deste contexto, a produção biológica do hidrogênio tem sido amplamente estudada por alguns grupos de pesquisa e também pelo Laboratório de Processos Biológicos da Escola de Engenharia de São Carlos, utilizando reatores biológicos anaeróbios operados em modo contínuo e tendo como objetivo a otimização das condições operacionais no intuito de melhorar o rendimento destes processos e realizando simultaneamente a adequação 
ambiental dos efluentes líquidos e a produção de bioenergia ( Fernandes et al., 2008; Peixoto et al., 2008; Amorim et al., 2009; Rojas et al., 2010).

Tendo em vista a necessidade de ampliação de diferentes sistemas para produção biológica de hidrogênio e considerando que o Laboratório de Engenharia Bioquímica da Escola de Engenharia Mauá possui experiência na aplicação de reatores operados em batelada e batelada alimentada no intuito de obter adequação ambiental, esse projeto objetiva a verificação das características de um reator operado em batelada sequencial com recirculação da fase líquida e biomassa imobilizada em suporte inerte (AnSBBR) aplicado ao tratamento de uma água residuária sintética a base de sacarose para a produção de biohidrogênio. $\mathrm{O}$ presente estudo teve como objetivos avaliar a influência da carga orgânica, modificada em função da concentração afluente e tempo de ciclo, sobre a eficiência e o fator de conversão (entre a matéria orgânica utilizada e o biohidrogênio produzido) como também a estabilidade das variáveis monitoradas no intuito de se obter um criterioso conhecimento sobre a viabilidade biotecnológica desse sistema. 


\section{OBJETIVOS}

O presente projeto tem como objetivo principal avaliar a aplicação do reator anaeróbio operado em batelada sequencial com biomassa imobilizada em suporte inerte e recirculação da fase líquida (AnSBBR) sobre a produção de biohidrogênio a partir do tratamento de efluente sintético a base de sacarose. A eficiência e o fator de conversão (entre o hidrogênio produzido e a matéria orgânica utilizada) foram analisados em função da variação da carga orgânica, imposta ao sistema modificando-se a concentração afluente e o tempo de ciclo do reator.

Os objetivos específicos foram:

- Avaliar o desempenho do reator através do cálculo de indicadores de rendimento, produtividade para diferentes cargas orgânicas volumétricas aplicadas, implementadas modificando-se a concentração afluente e o tempo de ciclo do AnSBBR;

- Avaliar a composição do biogás produzido em relação ao hidrogênio, metano e dióxido de carbono, a distribuição de ácidos voláteis e solventes produzidos no efluente líquido tratado e a remoção de substrato afluente em cada condição experimental. 


\section{REVISÃO BIBLIOGRÁFICA}

Estudos sobre a influência de variáveis de processo sobre a eficiência e estabilidade do reator anaeróbio operado em batelada sequencial quando aplicado ao tratamento de diferentes efluentes têm sido encontrados em literatura, como os relacionados: (i) ao tipo de mistura, a qual poderá ser implementada por recirculação da fase líquida (Brito et al., 1997; Camargo et al., 2002; Bergamo et al., 2009; Bezerra et al., 2009) ou por agitação mecânica (Angenent et al., 2002; Rodrigues et al., 2003; Rodrigues et al., 2004; Damasceno et al., 2008; Michelan et al., 2009); (ii) ao tempo de enchimento ou estratégia de alimentação (Bagley e Brodkorb, 1999; Shizas e Bagley, 2002; Borges et al., 2004; Orra et al., 2004; Zimmer et al., 2008; Albanez et al., 2009); e (iii) à carga orgânica (Ng, 1989; Massé e Masse, 2000; Chebel et al., 2006; Damasceno et al., 2007; Oliveira et al., 2008; Friedl et al., 2009; Oliveira et al., 2009; Novaes et al., 2010).

Atualmente verifica-se um aumento da potencial aplicação desses reatores na geração de biohidrogênio num contexto amplo no qual as águas residuárias passam a ser tratadas como matéria-prima e não como resíduos de um processo, com o intuito de viabilizar a obtenção de energia a partir do hidrogênio gerado, sendo mantido o objetivo do controle da poluição ambiental com a adequação de todos os resíduos gerados no processo para a disposição no ambiente. Assim, a produção biológica de hidrogênio torna-se uma das mais atrativas, pois é uma tecnologia de baixo custo quando comparada a outras técnicas e requer menos energia para geração, podendo ocorrer por meio de dois processos: fotossíntese e fermentação. A fermentação é tecnicamente mais simples e o hidrogênio pode ser obtido de matéria orgânica presente em águas residuárias. Diversos estudos demonstram a viabilidade 
da utilização do biohidrogênio para geração de energia (Wu et al., 2003; Alzate-Gaviria et al., 2007; Leite et al., 2008).

Neste contexto, diferentes águas residuárias são utilizadas como substrato para a produção de biohidrogênio, nas quais a fonte de matéria orgânica carbonácea consta de sacarose, amido de trigo, fração orgânica de resíduos sólidos, efluente de reatores biológicos, óleos vegetais e resíduos da produção de biodiesel. O objetivo comum de tais estudos consta da avaliação da produtividade de hidrogênio e da estabilidade operacional (Alzate et al., 2007; Jeong et al., 2007; Argun et al., 2008; Lin e Lay, 2004a-b, 2005; O-Thong et al., 2008; Oztekin et al., 2008; Sabourin-Provost et al., 2009; Ito et al., 2005; Nishio e Nakashimada, 2007; Yang et al., 2008) e, além disso, investigam a melhoria da composição das águas residuárias em termos do equilíbrio de nutrientes no intuito de possibilitar acréscimo de produtividade de hidrogênio e, assim, otimizar a aplicação desses diversos efluentes (Lin e Lay, 2005; Argun et al., 2008; Turcot et al., 2008).

\subsection{Produção fermentativa de hidrogênio}

No cenário mundial o hidrogênio é visto como o maior sucessor dos combustíveis fósseis, trazendo consigo vários benefícios sócio-econômicos e ambientais (Das \& Veziroglu, 2007). De um modo geral, quatro processos de produção de hidrogênio são disponíveis atualmente: eletrólise da água; processos termoquímicos; processos radiolíticos; e processos biológicos. As formas convencionais de produção do gás apresentam balanço energético desfavorável, ou seja, o gasto de energia para a produção do gás é maior que a energia obtida com o processo. A partir deste contexto e tendo e vista a produção sustentável do hidrogênio, a produção biológica vem se destacando no cenário científico colocando em conjunto a adequação ambiental de resíduos líquidos e a produção energética em um mesmo sistema. 
A adequação ambiental de efluentes líquidos por processos anaeróbios é realizada por um conjunto de microrganismos através da digestão anaeróbia que pode ser entendida como um ecossistema no qual a diversidade de microrganismos trabalha interativamente na conversão da matéria orgânica a produtos mais simples como gás carbônico, água, gás sulfídrico, e amônia além de gerar novas células bacterianas. Pode ser divida em dois estágios: o primeiro, através de bactérias fermentativas, compostos orgânicos complexos como carboidratos, proteínas e lipídeos são convertidos a ácidos voláteis, alcoóis, hidrogênio e gás carbônico. No segundo estágio os produtos do primeiro estágio são convertidos a gás carbônico e metano por meio das arquéias metanogênicas ((McCarty, 1981; Chernicharo, 1997).

A produção fermentativa do hidrogênio acontece então no primeiro estágio da digestão anaeróbia, mais precisamente na fase acidogênica do processo, através de condições ambientais impostas ao sistema. A fase acidogênica da digestão anaeróbia é realizada por bactérias fermentativas, por exemplo, as bactérias do gênero Clostridium. Essas bactérias têm por característica a formação de esporos e dessa maneira, possuem a característica de serem menos vulneráveis e mais propícias a sobreviverem em ambientes totalmente desfavoráveis. Várias espécies de bactérias foram testadas para a produção de hidrogênio: Enterobacter aerogenes (Tanisho \& Ishiwata, 1993); Klebsiella sp. HE1 (Wu. et al. 2008); Escherchia coli (Turcot, 2007); e Clostridium (Ferchichi, 2005; Liu et al. 2005; Kim et al. 2006; Lin et al. 2007; Ding, 2009). Tendo em vista a baixa velocidade de crescimento das arquéias metanogênicas frente às bactérias fermentativas, e a baixa velocidade de consumo de ácidos orgânicos, esse balanço torna-se limitante do processo de digestão anaeróbia causando a inibição da metanogênese, implicando na produção do biohidrogênio (Chernicharo, 1997).

Três vias de fermentação se destacam no processo de produção de hidrogênio (Tanisho, 2001), conforme mostrado na Figura 3.1. A rota conhecida como via do formiato 
representa a produção de $\mathrm{H}_{2}$ pela decomposição do piruvato a formiato, que após sua decomposição da origem ao $\mathrm{H}_{2}$, sendo que o piruvato pode vir a se decompor à acetil-CoA, que pode se decompor a acetato ou etanol. A segunda rota do hidrogênio ocorre através da oxi-redução do NADH, o qual é produzido na glicólise, conversão de glicose a piruvato; assim como pode ser formado na fermentação do piruvato. De acordo com Tanisho (2001), o rendimento da produção de $\mathrm{H}_{2}$ varia de acordo com as bactérias envolvidas no processo. Para bactérias estritamente anaeróbias espera-se um rendimento máximo de $4 \mathrm{~mol}-\mathrm{H}_{2} / \mathrm{mol}$-glicose, direcionando o metabolismo para a formação de acetato.

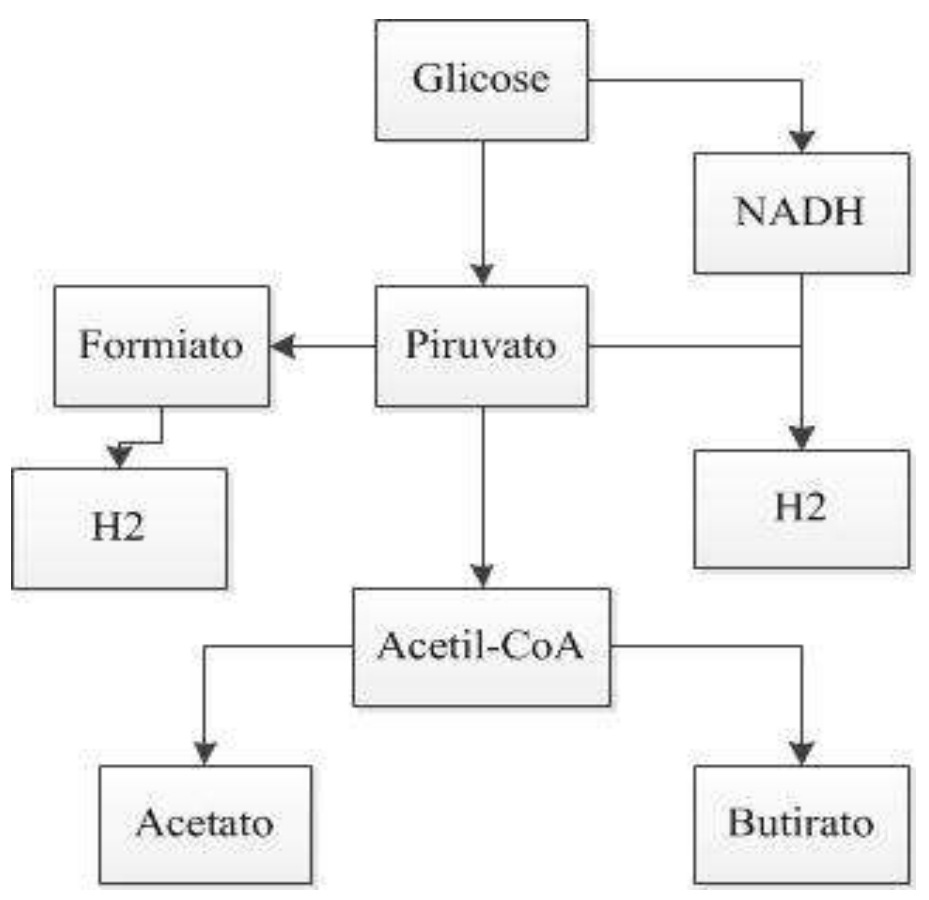

Figura 3.1: Vias de fermentação do hidrogênio (adaptado de TANISHO, 2001).

O rendimento máximo teórico obtido via fermentação, por mol de hexose aplicado, é obtido através da conversão completa da glicose variando de acordo com a rota metabólica predominante no sistema. Do ponto de vista estequiométrico, a fermentação da sacarose formando ácido acético tem um rendimento máximo de 8 mols de $\mathrm{H}_{2}$ por mol de sacarose consumido; já rota fermentativa da sacarose formando ácido butírico tem-se um rendimento 
máximo de 4 mols de $\mathrm{H}_{2}$ por mol de sacarose consumido, conforme mostrado na Tabela 3.1. De uma forma geral, a produção de ácido butírico e ácido acético indicam a produção de $\mathrm{H}_{2}$ no sistema, entretanto a formação de ácido propiônico indica o consumo de $\mathrm{H}_{2}$ (Mandal et al. 2006).

Tabela 3.1: Rendimento máximo de hidrogênio por mol de açúcar consumido.

\begin{tabular}{lcc}
\hline Metabólito & Rota metabólica & mol $\mathrm{H}_{2} /$ mol substrato \\
\hline Ácido acético & $\mathrm{C}_{12} \mathrm{H}_{22} \mathrm{O}_{11}+5 \mathrm{H}_{2} \mathrm{O} \rightarrow 4 \mathrm{CH}_{3} \mathrm{COOH}+4 \mathrm{CO}_{2}+8 \mathrm{H}_{2}$ & 8 \\
Ácido butírico & $\mathrm{C}_{12} \mathrm{H}_{22} \mathrm{O}_{11}+2 \mathrm{H}_{2} \mathrm{O} \rightarrow 2 \mathrm{CH}_{3} \mathrm{CH}_{2} \mathrm{CH}_{2} \mathrm{COOH}+4 \mathrm{CO}_{2}+4 \mathrm{H}_{2}$ & 4 \\
Ácido propiônico & $\mathrm{C}_{6} \mathrm{H}_{12} \mathrm{O}_{6}+2 \mathrm{H}_{2} \rightarrow \mathrm{CH}_{3} \mathrm{CH}_{2} \mathrm{COOH}+2 \mathrm{H}_{2} \mathrm{O}$ & -2 \\
\hline
\end{tabular}

O potencial bioquímico de produção de hidrogênio (BHP) do gênero Clostridium foi testado por LIN et al. (2007). Foram observadas as espécies Clostridium acetobutylicum M121, Clostridium butyricum ATCC19398, Clostridium Tyrobutyricum FYa102 e Clostridium beijerinckii L9. Todas as cepas testadas tiveram capacidade de produzir $\mathrm{H}_{2}$, sendo que o maior rendimento na produção de $\mathrm{H}_{2}$ foi da espécie Clostridium Beijerinckii L9, a qual apresentou os maiores rendimentos durante os experimentos, inclusive na etapa de realimentação do reator com glicose, promovendo a fermentação do substrato adicional e uma conseqüente maior produção do gás. Os principais metabólitos solúveis produzidos foram o butirato e acetato, os quais fazem parte das principais rotas fermentativas produtoras de $\mathrm{H}_{2}$. 


\subsection{Reatores anaeróbios}

Diversas configurações de reatores foram estudas para a produção de biohidrogênio, analisando diferentes características de cada sistema, das quais se pode destacar o reator anaeróbio operado em batelada sequencial com biomassa granulada (ASBR) (Arooj et al. 2008; Lin et al., 2007), reator anaeróbio operado em batelada sequencial com biomassa imobilizada (AnSBBR) (Mohan et al., 2007), reator anaeróbio de leito fixo e fluxo ascendente (Fernandes, 2008; Peixoto, 2008; Rojas, 2010), reator contínuo de mistura completa (CSTR) (Zhang, 2006; Turcot et al., 2008) e UASB (Shida, 2008).

Reatores anaeróbios operados em bateladas sequenciais contendo biomassa imobilizada (AnSBBR) foram estudados para o tratamento de efluentes sintéticos e industriais (Mohan et al., 2006; Frieldl et al., 2009; Flores et al., 2010). Nesses reatores tem-se como característica da operação uma concentração maior de substrato no início do ciclo e consequentemente uma alta velocidade de conversão e uma grande produção de biogás; ao final do ciclo, devido à menor concentração de substrato e uma menor velocidade de conversão há uma menor produção de biogás (Camargo et. al. 2000). Através da inserção de meio suporte inerte no interior do reator para a adesão da biomassa, otimizando a retenção, pode-se não realizar a fase de decantação, reduzindo e o tempo de ciclo além de eliminar as incertezas da granulação da biomassa. Vários materiais suportes são encontrados na literatura podendo destacar espuma de poliuretano (Frieldl et al., 2009), polietileno de baixa densidade (Peixoto, 2008; Fernandes, 2008; Rojas, 2010), carvão ativado (Fernandes, 2008) e argila (Fernandes, 2008). 


\subsection{Fatores influentes na produção de hidrogênio em reatores anaeróbios}

Dentre a bibliografia pesquisada é grande a variedade de fatores ambientais e operacionais influentes na produção biológica de hidrogênio, entre os quais pode se destacar: temperatura, tempo de detenção hidráulica, carga orgânica, pH, tempo de ciclo, consórcios microbiológicos e tipos de água residuária empregada.

ZHANG et al. (2006) estudaram os efeitos do tempo de detenção hidráulica (TDH) na produção de hidrogênio, utilizando um CSTR. Foram testados os TDHs de 6, 8, 10 e 12 horas. Neste estudo a redução do tempo de detenção hidráulica de 8 para 6 horas ocasionou um aumento no rendimento da produção de hidrogênio, variando de 1,6 mol- $\mathrm{H}_{2} / \mathrm{mol}$-glicose para 1,9 mol- $\mathrm{H}_{2} / \mathrm{mol}$-glicose, sendo o último o maior rendimento obtido no experimento. Com os resultados obtidos pode-se verificar que o TDH influencia diretamente as reações de produção de $\mathrm{H}_{2}$ e na seleção hidrodinâmica de microrganismos. A redução do TDH mostrouse capaz de reduzir a diversidade microbiana, eliminando os microrganismos associados a produção de propionato, não afetando a população dominante responsável pela produção de hidrogênio. LIN e CHANG (2004) estudaram a variação de TDH de 60 a 6 horas, obtendo a maior produção específica de $\mathrm{H}_{2}$ para o tempo de 6 horas. Segundo FERNANDES (2008), menores TDHs tem o objetivo de aumentar conversão de sacarose a hidrogênio e reduzir o consumo deste no sistema, sendo observado que a redução do tempo de detenção hidráulica aumentou a produção de hidrogênio, reduziu o volume produzido e a conversão do carboidrato com relação à teoria. AROOJ et. al. (2008) estudou a produção de biohidrogênio em ASBR utilizando amido de milho como substrato, variando os tempos de ciclo de 18 a 4 horas. Essa variação fez com que a biomassa fosse descartada com o efluente, diminuindo de $78 \%$ para $11 \%$ levando o sistema a entrar em colapso. 
Para o processo de produção de hidrogênio devem ser considerados dois pHs distintos: o pH do afluente e o pH de operação do sistema. As bactérias acidogênicas são menos sensíveis a baixos pHs, sendo que as bactérias acidogênicas possuem faixa ótima de crescimento de 5,0 a 6,0. Diversos outros autores pesquisaram a influência do $\mathrm{pH}$ no processo de produção de hidrogênio (Horiuchi et al., 2002; Khanal et al., 2004; Ferchichi et al., 2005), havendo um consenso de que o pH ótimo para a produção de hidrogênio encontra-se na faixa de 5,0 à 6,0. A faixa de pH ótima é explicada pelas diferenças de substratos e inóculos (Wang e Wan, 2008). Vale destacar que os efeitos do $\mathrm{pH}$ em reatores operados em bateladas sequenciais e biomassa imobilizada são pouco relatados, o que demonstra a necessidade deste conhecimento em novos trabalhos. É importante ressaltar que pH abaixo de 4,7 desfavorecem a produção de $\mathrm{H}_{2}$, devido a inibição da atividade da enzima hidrogenase (Wang \& Wan, 2008), A Tabela 3.2 exibe alguns trabalhos da literatura levando em consideração a configuração dos reatores a faixa de $\mathrm{pH}$ considerada no estudo e o rendimento máximo alcançado.

Tabela 3.2: Efeito do $\mathrm{pH}$ inicial em diferentes estudos e substratos *.

\begin{tabular}{|c|c|c|c|c|c|}
\hline \multirow{3}{*}{$\begin{array}{c}\text { Substrato } \\
\text { Sacarose }\end{array}$} & \multirow{3}{*}{$\begin{array}{l}\text { Reator } \\
\text { ASBR }\end{array}$} & \multicolumn{2}{|c|}{ pH } & \multirow[b]{2}{*}{ Rendimento máximo } & \multirow[b]{2}{*}{ Referência } \\
\hline & & Faixa & imo & & \\
\hline & & $4,9-6,7$ & 4,9 & 2,53 $\mathrm{mol}-\mathrm{H}_{2} / \mathrm{mol}$-sacarose & Chen et. al. (2009) \\
\hline Sacarose & Garrafas & $4,5-6,5$ & 4,5 & $214 \mathrm{~mL}-\mathrm{H}_{2} / \mathrm{g}-\mathrm{DQO}$ & Khanal et. al. (2004) \\
\hline Sacarose & Leito fluidizado & fixo & 6,8 & $4,98 \mathrm{~mol}-\mathrm{H}_{2} / \mathrm{mol}$-sacarose & Lin et. al. (2006) \\
\hline Glicose & CSTR & $5,5-6,0$ & 5,3 & $0,51 \mathrm{~mol}-\mathrm{H}_{2} / \mathrm{mol}$-glicose & Arooj et. al. (2008) \\
\hline
\end{tabular}


Como demonstrado anteriormente, de uma maneira geral, os indicadores da produção de biohidrogênio não foram padronizados em literatura, pois os grupos de estudo da produção de biohidrogênio expressam seus resultados de acordo com os indicadores padrões próprios. Essa não padronização torna complexa a comparação entre os diferentes trabalhos dos diferentes grupos, havendo a necessidade de uma série de conversões.

Basicamente os indicadores utilizados na literatura são divididos em três grupos distintos: a produtividade, o rendimento por carga aplicada e o rendimento por carga removida.

A produtividade avalia o volume de hidrogênio produzido (produtividade volumétrica) e a quantidade molar de hidrogênio produzido (produtividade molar) por unidade de tempo e volume total de meio líquido presente no reator. O fato de relacionar o volume do sistema é importante no dimensionamento do reator, podendo-se estimar a produção de um sistema de acordo com as dimensões deste.

O rendimento por carga aplicada ou removida avalia o volume de hidrogênio produzido (rendimento volumétrico) e a quantidade molar de hidrogênio produzido (rendimento molar) por unidade de tempo e carga mássica ou molar aplicada. O grande diferencial desse indicador é o fato de que o mesmo pode ser expresso em duas bases distintas: quantidade de DQO e quantidade de substrato específico, podendo-se estimar a produção de biohidrogênio de acordo com a carga de DQO ou de substrato aplicada ao sistema. Dessa forma, o uso combinado destes indicadores pode levar a uma análise mais detalhada do sistema em questão. A Figura 3.2 demonstra os diferentes indicadores utilizados na literatura e os seus fundamentos teóricos. 


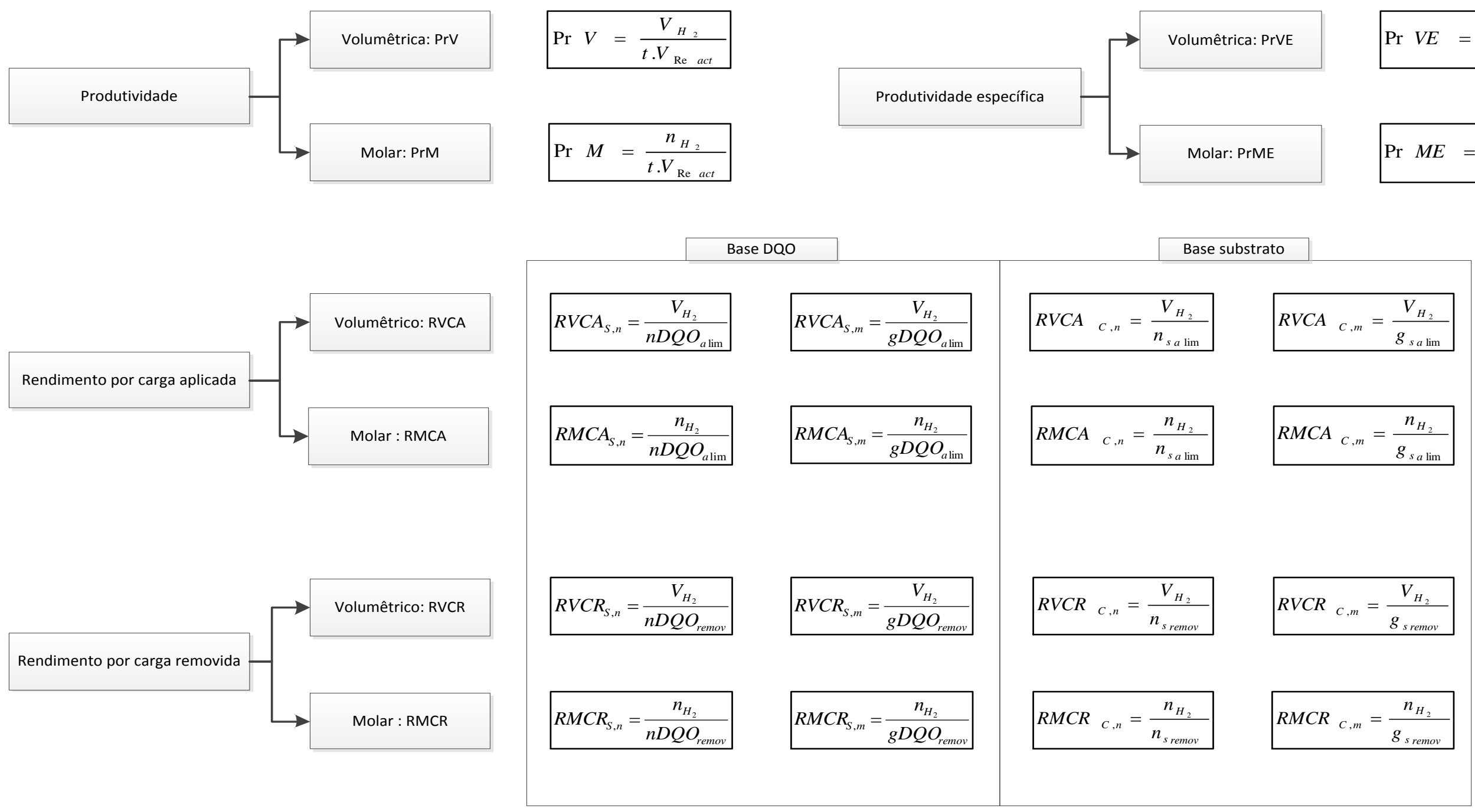

Figura 3.2: Indicadores de produção de hidrogênio presentes na literatura. 
KHANAL et al. (2004) estudaram os efeitos do $\mathrm{pH}$ inicial e operacional. Foram monitorados a produção de hidrogênio, as variações do $\mathrm{pH}$ e ácidos orgânicos formados no processo, observando-se que o $\mathrm{pH}$ inicial abaixo de 4,5 gera um longo período de adaptação das bactérias (fase lag) o que prejudica a produção de biohidrogênio. Por outro lado, para o pH inicial de 4,5 foi encontrado o maior potencial específico de produção de hidrogênio, porém com menor velocidade de produção específica. A velocidade de produção específica de hidrogênio foi maior para a faixa de pH 5,5-5,7. CHEN et. al. (2009) utilizaram um ASBR com sacarose como substrato para a produção de biohidrogênio e analisaram os efeitos da variação do $\mathrm{pH}$ e da duração do ciclo de operação. O intervalo de $\mathrm{pH}$ avaliado foi de 4,9 a 6,7, sendo monitorado por um controlador apenas na fase de reação através da adição de acido clorídrico ou uma mistura de hidróxidos para corrigir possíveis variações. O tempo de ciclo foi fixado em 16 horas. O rendimento máximo de hidrogênio de 2,53 mol/mol-sacarose consumida ocorreu em pH 4,9, sendo que este pH apresentou a menor eficiência de remoção de carboidratos (aproximadamente 56\%), enquanto que para os outros valores de $\mathrm{pH}$ a remoção chegou a aproximadamente $100 \%$.

Outro fator ambiental importante na operação de reatores anaeróbios é a temperatura. As variações de temperatura do meio estão intimamente ligadas à velocidade das reações, químicas e bioquímicas, e diretamente associadas à atividade microbiana e a solubilidade do gás $\mathrm{H}_{2}$ no meio aquoso. Os microrganismos envolvidos na digestão anaeróbia não possuem meios de controle da temperatura interna das células, ficando expostos às oscilações da temperatura do ambiente externo. LIN e CHANG (2004) trabalharam com um fermentador inoculado com lodo de esgoto, dominado por espécies de Clostridium, visando à comparação de sistemas operados em temperaturas constantes $\left(35^{\circ} \mathrm{C}\right)$ e ambientes não controladas (15$34^{\circ} \mathrm{C}$ ), constataram que em temperatura ambiente ocorre uma redução na produção de hidrogênio de aproximadamente $30 \%$. 
De acordo com VAZQUEZ et al. (2008) a espécie dominante no reator dependerá das características de operação do sistema como $\mathrm{pH}$, temperatura, pressão de $\mathrm{H}_{2}$, e tempo de detenção hidráulica. Atualmente, existem diversos tipos de pré-tratamentos de lodo, dos quais pode-se citar o tratamento ácido, básico, térmico e aeração. WANG e WAN (2008) fizeram uma comparação entre os métodos para o pré-tratamento de inóculo para verificar o rendimento da produção de $\mathrm{H}_{2}$. $\mathrm{O}$ experimento foi realizado a temperatura constante de $35^{\circ} \mathrm{C}$ e $\mathrm{pH}$ 7,0. Todos os métodos de pré tratamento proporcionaram um aumento no rendimento da produção de $\mathrm{H}_{2}$ quando comparados a um lodo não tratado (controle). Após 36 horas, o método térmico obteve a maior concentração de biomassa $2739 \mathrm{mg} . \mathrm{L}^{-1}$, maior eficiência na degradação do substrato $97 \%$, o maior potencial de produção de $\mathrm{H}_{2} 215,4 \mathrm{~mL}$ e a maior velocidade de produção de $\mathrm{H}_{2}$ 120,4 $\mathrm{mL} \cdot \mathrm{h}^{-1}$. De acordo com os autores, o pré-tratamento térmico do lodo é um método fácil e prático para o enriquecimento com bactérias produtoras de $\mathrm{H}_{2}$. MOHAN et. al. (2007) utilizou de uma sequência mista alternada de métodos de prétratamento para o enriquecimento de lodo metanogênico proveniente de um UASB. A amostra de lodo foi desidratada e encubada para cultivo. Foram alternados o tratamento térmico $\left(100^{\circ} \mathrm{C}\right)$ e ácido (ácido ortofosfato com $\left.\mathrm{pH} 3,0\right)$. Essa seleção de bactérias foi inoculada ao reator no $3^{\circ}$ ciclo de operação, obtendo-se como resultado um aumento da velocidade de produção de $\mathrm{H}_{2}$ e constatado um volume de 2,05 mmol.dia ${ }^{-1}$ e produção volumétrica de $1464,3 \mathrm{mmol} \cdot \mathrm{m}^{-3} \cdot \mathrm{dia}^{-1}$. Tais mudanças indicam que o enriquecimento do reator com o lodo pré-tratado aumenta a produção especifica de $\mathrm{H}_{2}$.

A grande maioria dos estudos realizados para a produção de hidrogênio utilizou águas residuárias sintéticas balanceadas de modo que as necessidades minerais dos microrganismos fossem supridas e os mesmos trabalhassem de forma otimizada. Assim, vários estudos utilizam na composição do afluente a sacarose (Kim et al., 2006; Wu et al., 2008) e glicose (Horiuchi et al., 2002; Lin et al., 2007; Shida, 2008; Turcot et al., 2008) como a principal 
fonte de carbono. Entretanto, alguns autores realizaram estudos com efluente industrial para a produção de hidrogênio, como por exemplo: efluente de indústria de refrigerante (Peixoto, 2008), vinhaça (Fernandes, 2008), glicerol (Seifert, et al. 2007; Silva et al., 2009) e soro de leite. Diferentes inóculos aplicados a produção de biohidrogênio, levam a uma discordância na literatura referente à carga orgânica ideal aplicada. Tal discordância deve se ao fato de substratos complexos apresentarem efeitos diferenciados para a produção de biohidrogênio (Wang et al., 2009).

A variação da carga orgânica aplicada foi verificada por BHASKAR et al. (2008), utilizando um AnSBBR tratando água residuária sintética a base de sacarose variando a carga orgânica entre 6,3 a 7,9 kgDQO. $\mathrm{m}^{-3} \mathrm{~d}^{-1}$. A faixa de $\mathrm{pH}$ considerada como ótima foi de 5,5 a 6,0, sendo encontrado para a carga orgânica de $6,3 \mathrm{kgDQO} \cdot \mathrm{m}^{-3} \mathrm{~d}^{-1}$ a maior eficiência de remoção de substrato e rendimento de hidrogênio de 13,44 mol- $\mathrm{H}_{2} \cdot \mathrm{kgDQO}_{\mathrm{R}}{ }^{-1} \cdot \mathrm{d}^{-1} \cdot \mathrm{O}$ aumento da carga orgânica aplicada de 6,3 para 7,9 kgDQO. $\mathrm{m}^{-3} \mathrm{~d}^{-1}$ ocasionou a redução no rendimento de $\mathrm{H}_{2}$ de 13,44 para 6,06 mol- $\mathrm{H}_{2} \cdot \mathrm{kgDQO}_{\mathrm{R}}{ }^{-1} \cdot \mathrm{d}^{-1}$ e na eficiência de remoção de DQO de 22,6 à $17,2 \%$

\subsection{Considerações finais}

Os trabalhos encontrados em literatura sobre a produção de biohidrogênio por processos fermentativos em biorreatores operados nos modos contínuos e descontínuos, utilizando como substrato fontes sintéticas e industriais, com ênfases nos conhecimentos fundamentais e tecnológicos mostram a importância da implementação do estudo sobre a aplicação do reator anaeróbio operado em bateladas sequenciais devido ao fácil controle

operacional resultante da forma descontínua de operar. Nesse contexto, verifica-se a importância de utilizar biomassa imobilizada em suporte inerte para facilitar a retenção dos 
microrganismos responsáveis pelas biotransformações, analisando a influência da carga orgânica pela modificação da concentração afluente e tempo total de ciclo sobre a produtividade e os rendimentos do sistema, alimentando o biorreator com substrato sintético a base de sacarose no intuito de serem obtidos resultados que contribuam para o conhecimento fundamental desse sistema, ou seja, a análise da produção de biohidrogênio e dos produtos intermediários e suas possíveis rotas metabólicas, mantendo-se constantes outras variáveis como temperatura e $\mathrm{pH}$. 


\section{MATERIAIS E MÉTODOS}

\subsection{AnSBBR com biomassa imobilizada e recirculação da fase líquida}

As Figuras 4.1 a 4.3 mostram esquema e fotografia do sistema utilizado para a produção de biohidrogênio a partir do tratamento anaeróbio de efluente sintético a base de sacarose. O reator foi constituído por um frasco de acrílico cilíndrico com as seguintes dimensões: $540 \mathrm{~mm}$ de altura, $100 \mathrm{~mm}$ de diâmetro externo e 3,5 $\mathrm{mm}$ de espessura de parede. A parte inferior do reator foi composta por um compartimento de $40 \mathrm{~mm}$ de altura destinado a favorecer a distribuição da água residuária e, na parte superior, um compartimento com 60 mm de altura utilizado como câmara coletora de biogás $\left(\mathrm{H}_{2}, \mathrm{CH}_{4} \mathrm{e} \mathrm{CO}_{2}\right)$. Dessa forma, o volume total do reator foi de 4,3 L (volume vazio).

O suporte de imobilização da biomassa foi acondicionado entre telas de aço Inox - 314, revestidas na parte superior por telas de PVC, dividindo a altura de $540 \mathrm{~mm}$ do reator em 5 estágios para evitar a compactação do leito e a passagem das partículas de suporte entre os estágios.

O sistema de recirculação foi composto $(i)$ por um reservatório lateral, o qual continha um volume de 2,9 L (volume vazio), constituído por um frasco de acrílico cilíndrico com as seguintes dimensões: $430 \mathrm{~mm}$ de altura, $100 \mathrm{~mm}$ de diâmetro externo e 3,5 mm de espessura de parede; e (ii) de uma bomba peristáltica com vazão ajustável, marca Ismatec modelo MCP, com vazão máxima de 52,3 L.h ${ }^{-1}$. Um tubo graduado de $100 \mathrm{~mL}$ foi interligado ao sistema de recirculação para medidas da vazão de recirculação. Dessa forma, o volume total resultante da soma do volume do reator $(4,3 \mathrm{~L})$ e do reservatório $(2,9 \mathrm{~L})$ foi de 7,2 L. 
Uma unidade de controle foi utilizada para automatizar as operações de carga, descarga e recirculação.

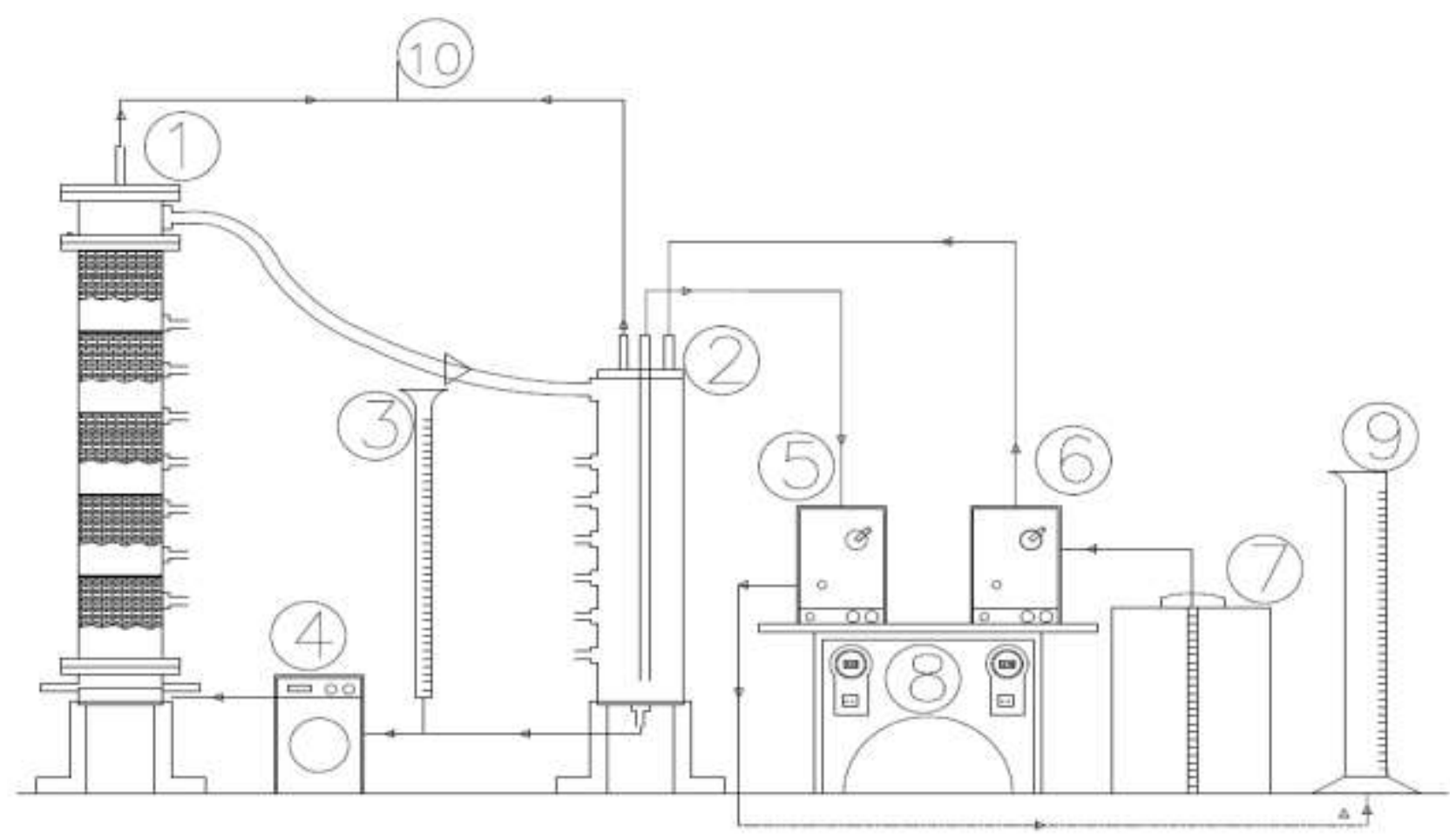

(a)
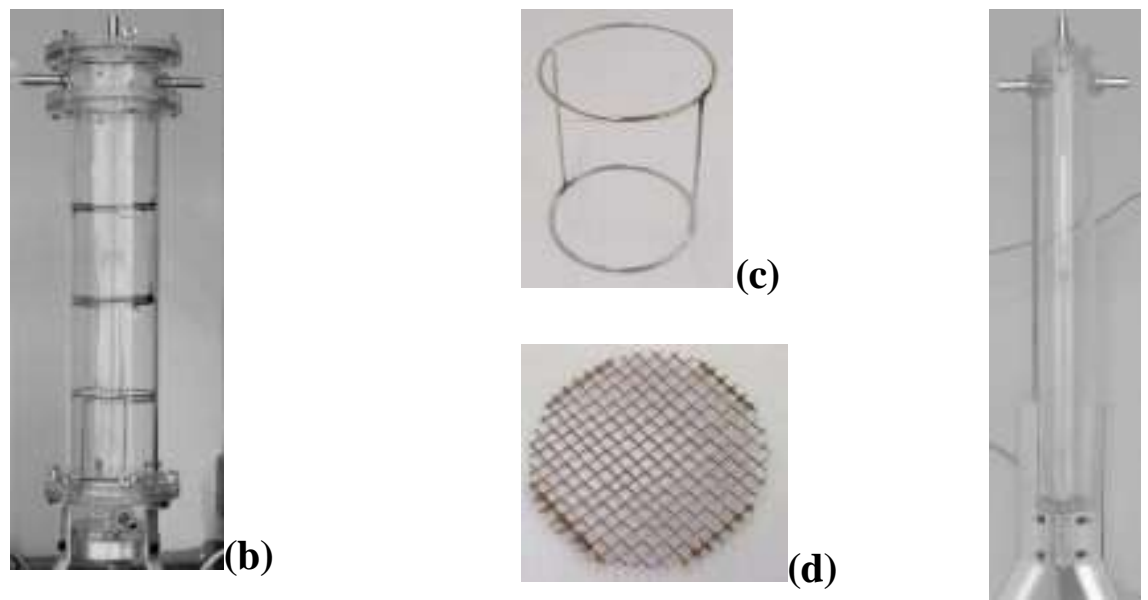

(e)

Figura 4.1: Esquema do (a) AnSBBR com recirculação utilizado nos ensaios e detalhes do $(b)$ reator, $(c)$ suporte da tela de aço, $(d)$ tela de aço e $(e)$ reservatório

[Notação: 1 - reator contendo biomassa imobilizada; 2 - reservatório lateral; 3 - medidor de vazão; 4 bomba de recirculação; 5 - bomba de descarga; 6 - bomba de alimentação; 7 - reservatório de água residuária; 8 - unidades de controle; 9 - Proveta de coleta do efluente; 10 - saída do biogás]. 


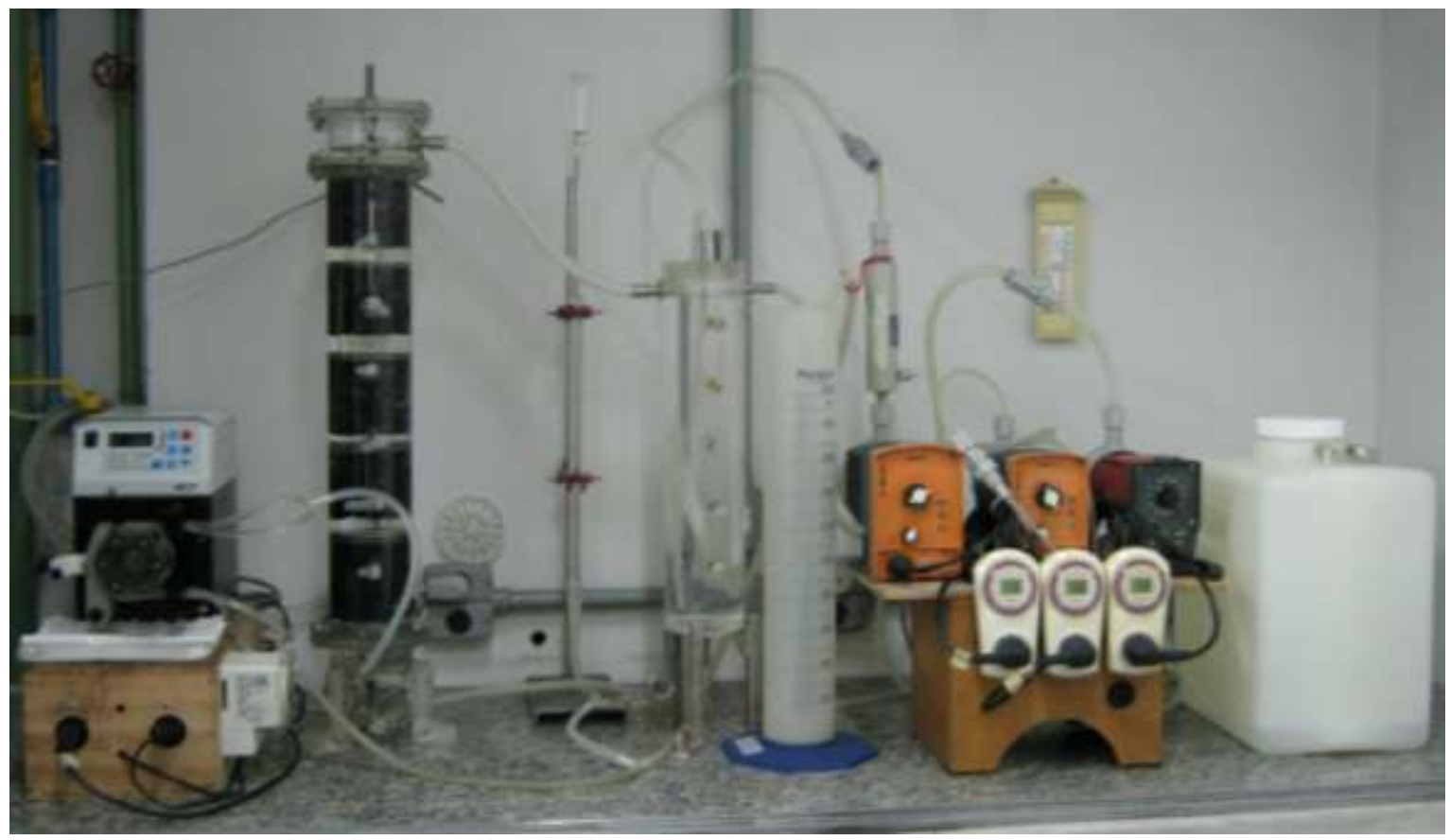

Figura 4.2: Fotografia da montagem experimental.

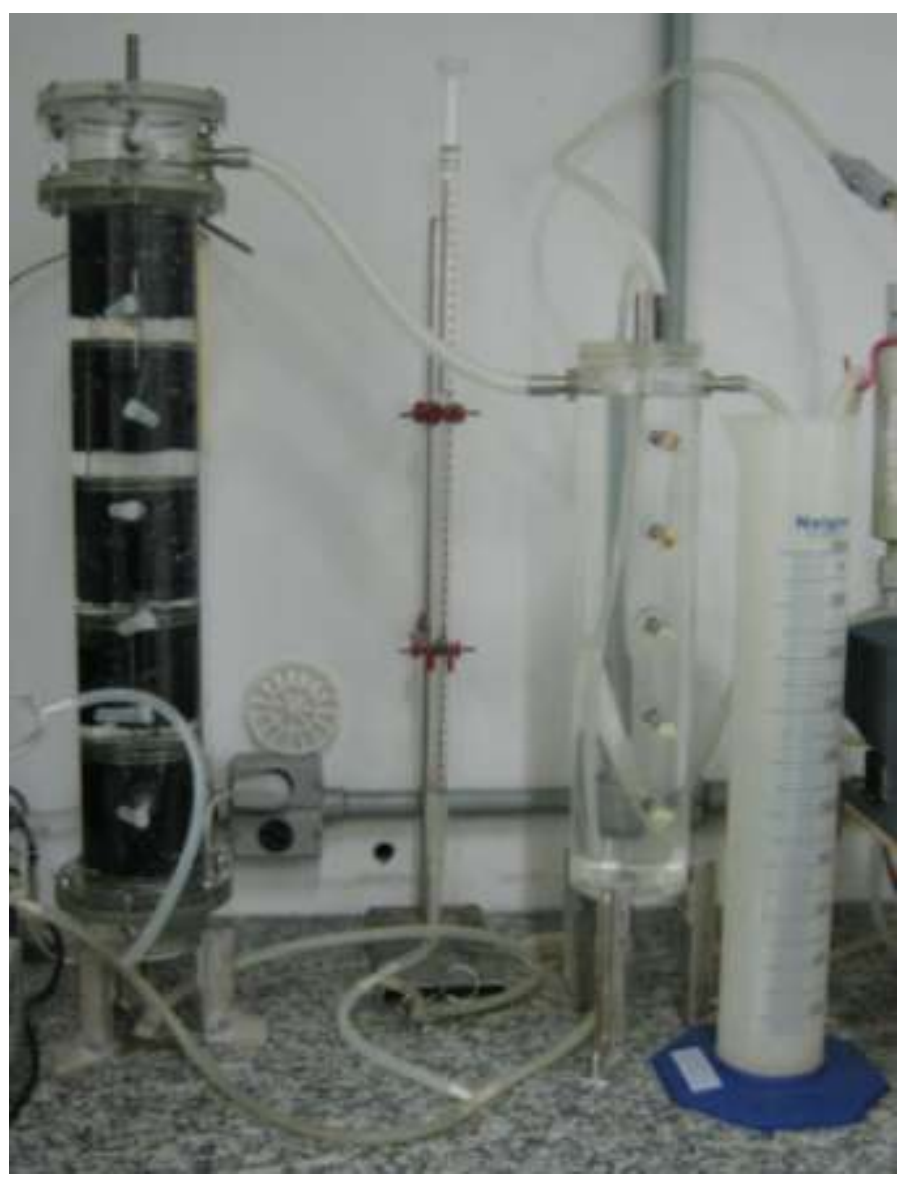

Figura 4.3: Fotografia do reator em detalhe. 
A alimentação e descarga foram realizadas por bombas tipo diafragma marca Prominent ${ }^{\circledR}$, modelos Beta/5 (com capacidade de até 30 L.h ${ }^{-1}$ ) e Concept/0223 (com capacidade de até $23 \mathrm{~L} \cdot \mathrm{h}^{-1}$ ), respectivamente, auxiliadas por um sistema de automação composto por temporizadores marca Coel ${ }^{\circledR}$, modelo RTST/20.

O reator foi colocado em uma câmara mantida a $30 \pm 1{ }^{\circ} \mathrm{C}$, onde a manutenção da temperatura foi realizada por um sistema composto de sensor, controlador (Novus ${ }^{\circledR}$, modelo N480), ventilador e resistência elétrica.

\subsection{Inóculo}

O inóculo utilizado nos experimentos (volume de $2 \mathrm{~L}$ ) foi proveniente de reator anaeróbio de manta de lodo e escoamento ascendente (UASB), tratando água residuária de abatedouro de aves (Dacar Industrial S.A.), sediada em Tietê-SP. Este inóculo apresentou valores de concentração de sólidos totais (ST) e de sólidos voláteis totais (SVT) próximos a 62 e 51 g.L. $\mathrm{L}^{-1}$, respectivamente.

O ensaio foi iniciado com um inóculo formado por lodo anaeróbio "in natura" proveniente de reator tipicamente metanogênico, ou seja, contendo um diversificado consórcio microbiano com microrganismos acidogênicos, acetogênicos e metanogênicos. Assim, a partir das condições experimentais impostas, ocorreu a adaptação do lodo no sentido do enriquecimento de microrganismos produtores de bio-hidrogênio, geralmente do gênero

\section{Clostridium.}




\subsection{Suporte de imobilização da biomassa anaeróbia}

Como suporte de imobilização da biomassa foi utilizado polietileno de baixa densidade (PEBD), em detalhe na Figura 4.4, obtido como produto do processo de reciclagem de resíduos plásticos. As partículas possuíam aproximadamente $5 \mathrm{~mm}$ de comprimento por 3 mm de diâmetro.

Para maior caracterização do material suporte foi calculada a densidade aparente e real do material, através da imersão de uma massa conhecida do material em uma proveta graduada com volume de água conhecido, sendo encontrado a densidade aparente de 470 g.L $\mathrm{L}^{-}$

1 e densidade real de 825 g. $\mathrm{L}^{-1}$ Com esses valores da densidade foi realizado o cálculo da porosidade do leito, sendo obtido o valor de $43 \%$.

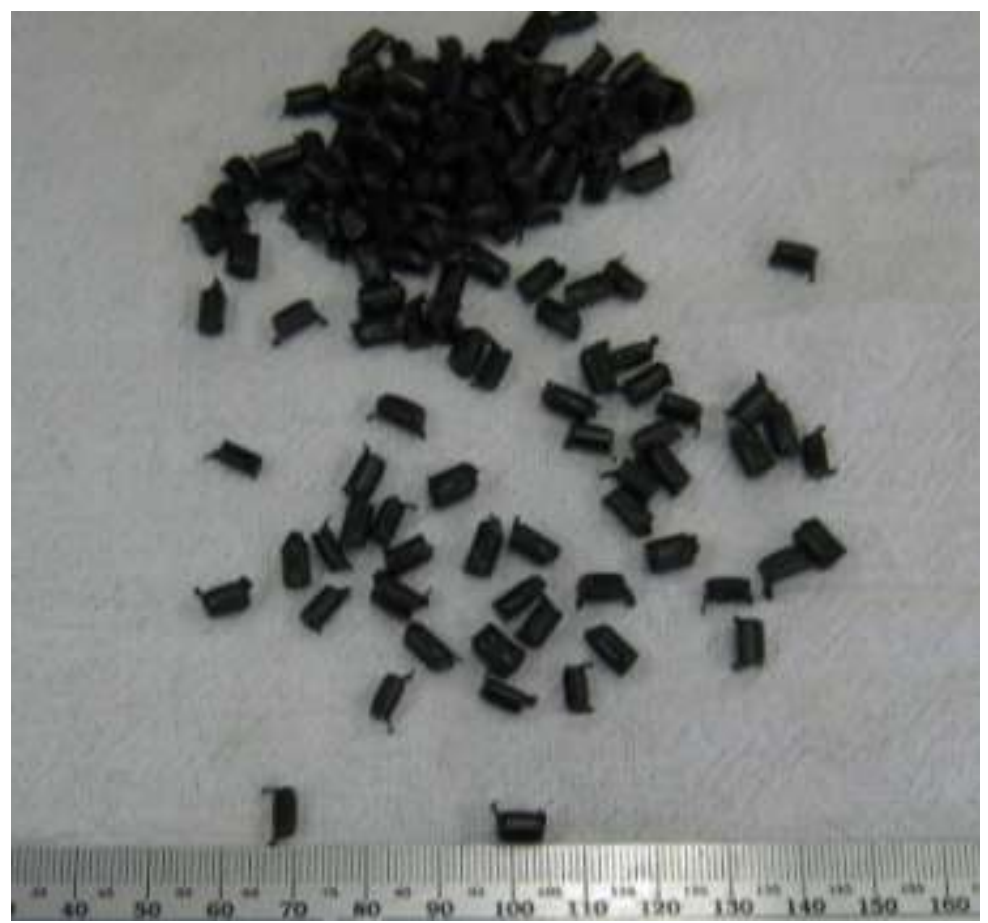

Figura 4.4: Polietileno de baixa densidade (PEBD) utilizado como material suporte. 


\section{4. Água residuária}

A água residuária utilizada foi formulada a base de sacarose como fonte de carbono e energia, fixando-se a razão entre a fonte de carbono e a fonte de nitrogênio-uréia $(\mathrm{C} / \mathrm{N})$ em aproximadamente 140, pH inicial igual a 6,5 e razão DQO/P menor que 500 (1000:2). A Tabela 4.1 descreve a composição da água residuária para uma concentração em termos de DQO igual a 1000 mg.L ${ }^{-1}$ (Del Nery, 1987).

A relação $\mathrm{C} / \mathrm{N}(\mathrm{g}-\mathrm{C} / \mathrm{g}-\mathrm{N})$ foi calculada de acordo com a porcentagem em massa de carbono e nitrogênio dos elementos sacarose (glicose-frutose $-\mathrm{C}_{12} \mathrm{H}_{22} \mathrm{O}_{11}-144 \mathrm{~g}-\mathrm{C} / 342 \mathrm{~g}$ sacarose) e uréia $\left(\mathrm{CH}_{4} \mathrm{~N}_{2} \mathrm{O}-28 \mathrm{~g}-\mathrm{N} / 60 \mathrm{~g}\right.$-uréia), que constituíram parte do meio. Assim, a relação $\mathrm{C} / \mathrm{N}$ a ser utilizada nesse estudo foi:

$$
893 / 5,8=(893 \cdot 144 / 342) /(5,8 \cdot 28 / 60)=376,0 / 2,7=139,3 \mathrm{~g}-\mathrm{C} / \mathrm{g}-\mathrm{N}
$$

A relação $\mathrm{C} / \mathrm{P}$ (g-C/g-P) foi calculada de acordo com a porcentagem em massa de carbono e fósforo dos elementos sacarose (glicose-frutose $-\mathrm{C}_{12} \mathrm{H}_{22} \mathrm{O}_{11}-144 \mathrm{~g}-\mathrm{C} / 342 \mathrm{~g}$ sacarose $)$ e sais de fósforo $\left(\mathrm{KH}_{2} \mathrm{PO}_{4}-31 \mathrm{~g}-\mathrm{P} / 136 \mathrm{~g}-\mathrm{KH}_{2} \mathrm{PO}_{4} ; \mathrm{K}_{2} \mathrm{HPO}_{4}-31 \mathrm{~g}-\mathrm{P} / 174 \mathrm{~g}-\mathrm{K}_{2} \mathrm{HPO}_{4}\right.$; $\left.\mathrm{Na}_{2} \mathrm{HPO}_{4}-31 \mathrm{~g}-\mathrm{P} / 142 \mathrm{~g}-\mathrm{Na}_{2} \mathrm{HPO}_{4}\right)$, que constituíram parte do meio. Assim, a relação C/P a ser utilizada nesse estudo foi:

- Em termos de C: $(893 \cdot 144 / 342) /(5,36 \cdot 31 / 136+1,30 \cdot 31 / 174+2,70 \cdot 31 / 142)$

$$
=376,0 / 2,04=184,3 \mathrm{~g}-\mathrm{C} / \mathrm{g}-\mathrm{P}
$$

- Em termos de DQO: (1000) / (5,36·31/136 + 1,30·31/174 + 2,70·31/142)

$$
=1000 / 2,04=490,2 \mathrm{~g}-\mathrm{DQO} / \mathrm{g}-\mathrm{P}
$$


Tabela 4.1: Composição da água residuária sintética a ser utilizada nos ensaios *.

\begin{tabular}{|c|c|}
\hline Composto & Concentração $\left(\mathrm{mg} \mathrm{L}^{-1}\right)$ \\
\hline Sacarose & 893,0 \\
\hline (relação teórica: 1000 mg-DQO = 893 mg-sacarose) & $\left(1000 \mathrm{mgDQO} \cdot \mathrm{L}^{-1}\right)$ \\
\hline Uréia $\left(\mathrm{CH}_{4} \mathrm{~N}_{2} \mathrm{O}\right)$ & 5,8 \\
\hline Sulfato de níquel $\left(\mathrm{NiSO}_{4} \cdot 6 \mathrm{H}_{2} \mathrm{O}\right)$ & 0,50 \\
\hline Sulfato ferroso $\left(\mathrm{FeSO}_{4} \cdot 7 \mathrm{H}_{2} \mathrm{O}\right)$ & 2,50 \\
\hline Cloreto férrico $\left(\mathrm{FeCl}_{3} \cdot 6 \mathrm{H}_{2} \mathrm{O}\right)$ & 0,25 \\
\hline Cloreto de cálcio $\left(\mathrm{CaCl}_{2} \cdot 2 \mathrm{H}_{2} \mathrm{O}\right)$ & 2,06 \\
\hline Cloreto de cobalto $\left(\mathrm{CoCl}_{2} \cdot 6 \mathrm{H}_{2} \mathrm{O}\right)$ & 0,04 \\
\hline Dióxido de selênio $\left(\mathrm{SeO}_{2}\right)$ & 0,04 \\
\hline Fosfato de potássio monobásico $\left(\mathrm{KH}_{2} \mathrm{PO}_{4}\right)$ & 5,36 \\
\hline Fosfato de potássio dibásico $\left(\mathrm{K}_{2} \mathrm{HPO}_{4}\right)$ & 1,30 \\
\hline Fosfato de sódio dibásico $\left(\mathrm{Na}_{2} \mathrm{HPO}_{4}\right)$ & 2,70 \\
\hline Bicarbonato de sódio $\left(\mathrm{NaHCO}_{3}\right)$ & 500,0 \\
\hline
\end{tabular}

\subsection{Análises físico-químicas e exames microbiológicos}

O monitoramento do reator foi efetuado medindo-se, em amostras do afluente e do efluente, as concentrações de matéria orgânica nas formas não filtrada $\left(\mathrm{C}_{\mathrm{ST}}\right)$ e filtrada $\left(\mathrm{C}_{\mathrm{SF}}\right)$ (como demanda química de oxigênio - DQO), alcalinidade parcial (AP), alcalinidade intermediária (AI), alcalinidade total (AT), alcalinidade a bicarbonato (AB), ácidos voláteis totais (AVT), sólidos totais (ST), sólidos totais voláteis (STV), sólidos suspensos totais (SST) e sólidos suspensos voláteis (SSV), além da medida do $\mathrm{pH}$ e do volume de meio alimentado/descarregado. Tais análises foram, realizadas de acordo com o Standard Methods 
for the Examination of Water and Wastewater (1995), considerando também o método proposto por Dilallo e Albertson (1961), o qual foi modificado por Ripley et al. (1986) na determinação da alcalinidade, e o método de Dubois (1956) para a determinação dos carboidratos totais (CT). Esses parâmetros foram monitorados como mostrado na Tabela 4.2.

Tabela 4.2: Resumo dos procedimentos analíticos e frequência de monitoramento.

\begin{tabular}{cccc}
\hline Parâmetro & Amostra & Frequência de & Método \\
& & monitoramento & \\
\hline DQO & Afluente e efluente & diariamente & Standard Methods (1998) \\
Carboidratos & Afluente e efluente & diariamente & Dubois et. al., 1956 \\
Sólidos Suspensos & Afluente e efluente & 2 vezes por semana & Standard Methods (1998) \\
Volume de biogás & Saída de gás & 2 vezes por semana & Medidor de gás Ritter \\
pH & Afluente e efluente & Diariamente & Standard Methods (1998) \\
Alcalinidade & Afluente e efluente & Diariamente & Standard Methods (1998) \\
V & Gás de Saída & 3 vezes por condição & Cromatografia gasosa \\
Ácidos voláteis & Saída de gás & 3 vezes por condição & Cromatografia gasosa \\
Alcoóis & Saída de gás & 3 vezes por condição & Cromatografia gasosa \\
Vazão recirculação & Bureta & 1 vez por semana & Bureta \\
\hline
\end{tabular}

Os compostos intermediários do metabolismo anaeróbio (acetona, metanol, etanol, nbutanol, ácidos acético, propiônico, butírico, iso-butírico, valérico, iso-valérico e capróico) foram analisados por cromatografia em fase gasosa, pelo método "head-space", utilizando um cromatógrafo Agilent Technologies ${ }^{\circledR}$ modelo 7890 GC System com injetor automático (fase líquida e "head space") GC Sampler 80, equipado com detector de ionização de chama e coluna HP-Innowax com $30 \mathrm{~m} \times 0,25 \mathrm{~mm} \times 0,25 \mu \mathrm{m}$ de espessura do filme. $\mathrm{O}$ gás de arraste utilizado foi o hidrogênio com vazão de $1,56 \mathrm{~mL} \cdot \mathrm{min}^{-1}$, a temperatura do injetor foi de $250^{\circ} \mathrm{C}$, 
a razão de "split" 10 e o volume de injeção de $1 \mu \mathrm{L}$. A temperatura do forno foi programada da seguinte forma: em $35^{\circ} \mathrm{C}$ por $0 \mathrm{~min}, 2^{\circ} \mathrm{C} \cdot \mathrm{min}^{-1}$ até $38^{\circ} \mathrm{C} ; 10^{\circ} \mathrm{C} \cdot \mathrm{min}^{-1}$ até $75^{\circ} \mathrm{C} ; 35^{\circ} \mathrm{C} \cdot \mathrm{min}^{-1}$ até $120^{\circ} \mathrm{C}$ por 2 minutos; $10^{\circ} \mathrm{C} \cdot \mathrm{min}^{-1}$ até $170^{\circ} \mathrm{C}$ por 2 minutos. A temperatura do detector foi de $280^{\circ} \mathrm{C}$ com fluxo de ar sintético de $300 \mathrm{~mL} / \mathrm{min}$ e vazão de "make up" de nitrogênio de 30 $\mathrm{mL} / \mathrm{min}$. Foi utilizado nessa análise o método "head-space", utilizando como padrão interno o ácido crotônico (na determinação dos ácidos voláteis) e isobutanol (na determinação da acetona e alcoóis).

A composição do biogás formado pelo metabolismo anaeróbio (hidrogênio, metano e dióxido de carbono) foi analisada por cromatografia em fase gasosa utilizando-se um cromatógrafo Agilent Technologies ${ }^{\circledR}$ modelo 7890 GC System equipado com detector de condutividade térmica e coluna GS-Carbonplot Agilent com $30 \mathrm{~m} \times 0,53 \mathrm{~mm} \times 3,0 \mu \mathrm{m}$ de espessura do filme. O gás de arraste utilizado foi o argônio com vazão de 3,67 $\mathrm{mL} / \mathrm{min}$, a temperatura do injetor foi de $185^{\circ} \mathrm{C}$, a razão de "split" de 10 e o volume de injeção de 200 $\mu \mathrm{L}$. A temperatura do forno foi programada da seguinte forma: em $40^{\circ} \mathrm{C}$ por $5 \mathrm{~min}$, de $40^{\circ} \mathrm{C}$ à $60^{\circ} \mathrm{C}$ em $5^{\circ} \mathrm{C} / \mathrm{min}$, de $60^{\circ} \mathrm{C}$ à $95^{\circ} \mathrm{C}$ em $25^{\circ} \mathrm{C} / \mathrm{min}$, de $95^{\circ} \mathrm{C}$ à $200^{\circ} \mathrm{C}$ em $5^{\circ} \mathrm{C} / \mathrm{min}$. A temperatura do detector foi de $150^{\circ} \mathrm{C}$, com vazão de "make up" de argônio de $8,33 \mathrm{~mL} / \mathrm{min}$. O volume produzido foi aferido por meio de medidor de gás Rittter modelo MilligasCounter.

Ao final de cada condição operacional foram retiradas do reator amostras de biomassa para exame microbiológico. As amostras foram examinadas em lâminas de vidro cobertas com filme de Ágar a $2 \%$, por microscopia óptica comum e de contraste de fase por fluorescência, utilizando microscópio Olympus ${ }^{\circledR}$ modelo BX41, com sistema de câmera digital Optronics e aquisição de imagens feita pelo software Image Pro-Plus ${ }^{\circledR}$ versão 4.5.0. Os exames microbiológicos foram úteis para avaliação de possíveis mudanças na morfologia microbiana em função das condições do estudo. 


\subsection{Imobilização da biomassa anaeróbia}

O lodo anaeróbio foi imobilizado em partículas polietileno de baixa densidade (PEBD), conforme metodologia proposta por Zaiat et al. (1994). Foram utilizados $1,5 \mathrm{~kg}$ de material suporte divididos em 5 porções com $300 \mathrm{~g}$ cada. As partículas de PEBD foram colocadas em recipientes e o lodo foi adicionado até que todas as partículas estivessem em contato com ele. Este contato se deu por 2 horas. Decorrido este período, as matrizes com as células aderidas foram colocadas no interior do reator preenchendo os cinco estágios, em seguida foi adicionado meio (o mesmo a ser utilizado nos experimentos) para lavagem dos sólidos fracamente aderidos. $\mathrm{O}$ meio foi drenado e o inóculo encontrou-se pronto para o início dos ensaios.

A quantificação da biomassa presente no biorreator foi feita a cada duas condições experimentais. O procedimento constou, inicialmente, de desmontar o biorreator e retirar todo suporte inerte (SI) presente no reator juntamente com a biomassa aderida e/ou retida (B). O meio líquido contido nessa denominada "mistura total suporte inerte + biomassa" foi drenado naturalmente e a medida da massa total foi realizada ( $\left.\mathrm{M}_{\mathrm{T}-\mathrm{SI}+\mathrm{B}}\right)$. Após homogeneização da "mistura total suporte inerte + biomassa", foi retirada uma amostra denominada "mistura amostra suporte inerte + biomassa" $\left(\mathrm{M}_{\mathrm{A}-\mathrm{SI}+\mathrm{B}}\right)$, na qual foi medida a massa e feita uma lavagem com água destilada no intuito de separar o suporte inerte da biomassa. $\mathrm{O}$ suporte inerte separado foi levado à estufa $\left(103^{\circ} \mathrm{C}\right)$ por $24 \mathrm{~h}$ para secagem e posterior resfriamento em dessecador para medida da massa $\left(\mathrm{M}_{\mathrm{A}-\mathrm{SI}}\right)$. A biomassa separada foi quantificada $\left(\mathrm{M}_{\mathrm{A}-\mathrm{B}}\right)$, na forma de sólidos voláteis totais da amostra (estufa a $103^{\circ} \mathrm{C}$ por $24 \mathrm{~h}$ e posteriormente em mufla a $550^{\circ} \mathrm{C}$ por $2 \mathrm{~h}$ ).

Dessa forma, foi possível quantificar a biomassa presente no biorreator de três formas: 
(i) quantidade total de biomassa presente no biorreator $\left(\mathrm{M}_{\mathrm{SVT}}\right)$, calculada pela relação dos sólidos voláteis totais da amostra $\left(\mathrm{M}_{\mathrm{A}-\mathrm{B}}\right)$ e as massas da "mistura total suporte inerte + biomassa" ( $\left.\mathrm{M}_{\mathrm{T}-\mathrm{SI}+\mathrm{B}}\right)$ e da "mistura amostra suporte inerte + biomassa" ( $\left.\mathrm{M}_{\mathrm{A}-\mathrm{SI}+\mathrm{B}}\right)$, através da seguinte equação $\mathrm{M}_{\mathrm{SVT}}=\mathrm{M}_{\mathrm{A}-\mathrm{B}} \cdot \mathrm{M}_{\mathrm{T}-\mathrm{SI}+\mathrm{B}} / \mathrm{M}_{\mathrm{A}-\mathrm{SI}+\mathrm{B}}$;

(ii) relação entre a quantidade total da biomassa e a quantidade total de suporte inerte presentes no biorreator $\left(\mathrm{C}^{\prime}{ }_{\mathrm{X}-\mathrm{SVT}}\right)$, calculada pela relação entre os sólidos voláteis totais $\left(\mathrm{M}_{\mathrm{A}-\mathrm{B}}\right)$ e a massa de suporte da amostra $\left(\mathrm{M}_{\mathrm{A}-\mathrm{SI}}\right)$, através da seguinte equação $\mathrm{C}^{\prime}{ }_{\mathrm{X}-\mathrm{SVT}}=\mathrm{M}_{\mathrm{A}-\mathrm{B}} / \mathrm{M}_{\mathrm{A}-\mathrm{SI}}$;

(iii) relação entre a quantidade total de biomassa e o volume de meio líquido contido no reator $\left(\mathrm{C}_{\mathrm{X}-\mathrm{SVT}}\right)$, calculada pela relação entre os sólidos voláteis totais $\left(\mathrm{M}_{\mathrm{A}-\mathrm{B}}\right)$ e o volume de meio líquido contido no biorreator $\left(V_{R}\right)$, através da seguinte equação $C_{X-S V T}=M_{A-B} / V_{R}$.

Essas três formas de quantificar a biomassa aderida e/ou retida no biorreator possuem importâncias distintas e complementares. A primeira maneira (item i) informa sobre a quantidade total de biomassa que ficou aderida e/ou retida no biorreator ao longo da condição experimental, sendo um indicativo da eficiência da configuração do biorreator em reter a biomassa, a qual considera o modo de mistura (agitação ou recirculação da fase líquida), o tipo e concentração da água residuária utilizada (qualidade e quantidade de substrato) e o modo de operação (batelada, batelada alimentada ou contínuo). Portanto, essa variável permite calcular as variáveis de projeto denominadas de "específicas" (cargas orgânicas aplicadas e removidas), ou seja, aquelas que não dependem do volume (denominadas de volumétricas) de meio, mas da biomassa presente no sistema. Entretanto, por ser uma grandeza extensiva, ou seja, depender do "tamanho do sistema", existe a necessidade do cálculo efetuado pelas duas maneiras seguintes. Assim, tem-se a segunda maneira (item ii) que relaciona a variável extensiva anterior com a massa de suporte inerte, sendo esta uma grandeza intensiva, ou seja, não depende do "tamanho do sistema". A aplicação desta variável contribui para a estimativa da massa de suporte inerte necessária para um projeto de 
biorreator em diferente escala. De forma análoga, a terceira maneira (item iii) que relaciona a variável extensiva (item i) com o volume de meio líquido presente no sistema é também uma grandeza intensiva. A aplicação desta variável pode contribuir para a interpretação e/ou comparação de resultados obtidos em diferentes biorreatores, pois está relacionada com a concentração de substrato (relação entre massa de substrato e volume de meio líquido) que é a forma intrinsicamente importante para relacionar as reações do metabolismo celular com o crescimento dos microrganismos (formação daqueles que melhor se adaptaram às condições ambientais impostas), o aproveitamento de nutrientes (substrato alimentado ao biorreator), a formação/consumo de intermediários (ácidos e solventes) e a liberação do produto final (biohidrogênio).

\subsection{Procedimento experimental da operação do reator}

Os ensaios foram realizados utilizando-se diferentes cargas orgânicas volumétricas modificadas em função da concentração afluente, de 3600 e $5200 \mathrm{mgDQO} . \mathrm{L}^{-1}$, e do tempo de ciclo, de 4, 3 e 2 h, ou seja, 6, 8 e 12 ciclos diários, conforme mostrado na Tabela 4.3. 
Tabela 4.3: Resumos das condições experimentais estudadas.

\begin{tabular}{cccc}
\hline Ensaio & $\begin{array}{c}\text { Concentração } \\
\left(\operatorname{mgDQO} . \mathrm{L}^{-1}\right)\end{array}$ & $\begin{array}{c}\text { Tempo de ciclo } \\
(\mathrm{h})\end{array}$ & $\begin{array}{c}\text { Carga orgânica } \\
\text { volumétrica } \\
\left(\mathrm{gDQO} . \mathrm{L}^{-1} \cdot \mathrm{d}^{-1}\right)\end{array}$ \\
\hline 1 & 3600 & 4,0 & 9,0 \\
2 & 3600 & 3,0 & 12,0 \\
3 & 5400 & 4,0 & 13,5 \\
4 & 5400 & 3,0 & 18,8 \\
5 & 3600 & 2,0 & 18,0 \\
6 & 5400 & 2,0 & 27,0 \\
\hline
\end{tabular}

O volume útil total do sistema reator e reservatório $(4,3+2,9=7,2 \mathrm{~L})$ foi composto em um volume de 2,6 L de meio que ficavam retidos no sistema, 1,9 $\mathrm{L}$ de meio tratado por ciclo (volume carregado no início do ciclo e descarregado no final do ciclo) e 1,8 L de material suporte, sendo o volume restante de $0,9 \mathrm{~L}$ destinado a coleta de biogás $(0,2 \mathrm{~L}$ na parte superior do reator e $0,7 \mathrm{~L}$ na parte superior do reservatório).

A operação do reator foi realizada da seguinte maneira: no primeiro ciclo foram alimentados 4,5 L ao sistema (2,6 L de meio no reator e 1,9 L de meio no reservatório) em 20 min, sendo que o reator foi previamente preparado com o suporte inerte e biomassa (inóculo). Após o término da alimentação a vazão de recirculação $\left(20\right.$ L.h ${ }^{-1}$ - velocidade de recirculação de $0,2 \mathrm{~cm} \cdot \mathrm{s}^{-1}$ ) foi ligada. No final do ciclo, cuja duração foi em função da condição experimental em estudo, a recirculação foi desligada e foram descarregados $1,9 \mathrm{~L}$ de meio em $10 \mathrm{~min}$, sendo que 2,6 L de volume residual foram mantidos no reator (além dos 1,8 $\mathrm{L}$ de suporte inerte). Logo após essa descarga, um novo ciclo teve início, no qual houve alimentação de 1,9 L de meio em 10 min e a recirculação foi ligada. Ao término do ciclo, a recirculação foi interrompida e, em seguida, iniciou-se a descarga em 10 min. Assim, os 
ciclos foram repetidos, caracterizando as bateladas sequenciais.

Uma vez atingida a estabilidade nas condições experimentais, ou seja, as variáveis monitoradas apresentaram valores aproximadamente (10\%) constantes, foram obtidos perfis ao longo do ciclo de operação de algumas das variáveis monitoradas. Nestes perfis foram retiradas amostras ao longo do tempo de operação de um ciclo. As variáveis de interesse foram: concentrações de matéria orgânica na forma filtrada, de ácidos voláteis totais, de metabólitos intermediários (acetona, ácidos voláteis e alcoóis), de biogás (composição e produção), além do $\mathrm{pH}$. Desta forma, foi possível obter uma melhor compreensão das rotas metabólicas ao longo de um ciclo. As amostras retiradas para obtenção do perfil anteriormente citado foram colhidas em intervalos de tempo, ao longo do ciclo, de $30 \mathrm{~min}$. $\mathrm{O}$ volume total retirado nas amostragens foi de no máximo $300 \mathrm{~mL}$, ou seja, menos que $10 \%$ do volume de meio reacional do sistema. Após cada operação, amostras do lodo foram retiradas do reator para análise microbiológica. Dessa forma, uma nova condição experimental foi implementada alterando-se a concentração afluente ou o tempo de ciclo do reator.

Os resultados experimentais obtidos no monitoramento do sistema e nos perfis ao longo de um ciclo, em cada condição operacional, foram analisados considerando-se a influência das variáveis estudadas sobre a estabilidade e o desempenho do processo, além do fator de conversão entre hidrogênio formado e matéria orgânica consumida. Além disso, as análises microbiológicas terão utilidade para avaliação das mudanças na morfologia microbiana.

\subsection{Fundamentos teóricos}

As variáveis utilizadas para o monitoramento do reator foram calculadas de acordo com as equações descritas. A eficiência de remoção de matéria orgânica total $\left(\varepsilon_{\mathrm{ST}}\right)$ no sistema foi calculada pela Equação (4.2), na qual $\mathrm{C}_{\mathrm{SAFL}}$ é a concentração de matéria orgânica total no 
afluente e $\mathrm{C}_{\mathrm{ST}}$ é a concentração de matéria orgânica total no efluente.

$$
\varepsilon_{\mathrm{ST}}(\%)=\frac{\mathrm{C}_{\mathrm{SAFL}}-\mathrm{C}_{\mathrm{ST}}}{\mathrm{C}_{\mathrm{SAFL}}} \cdot 100
$$

A eficiência de remoção de matéria orgânica filtrada $\left(\varepsilon_{\mathrm{SF}}\right)$ foi calculada pela Equação (4.3), na qual $\mathrm{C}_{\mathrm{SF}}$ é a concentração de matéria orgânica filtrada no efluente.

$$
\varepsilon_{\mathrm{SF}}(\%)=\frac{\mathrm{C}_{\mathrm{SAFL}}-\mathrm{C}_{\mathrm{SF}}}{\mathrm{C}_{\mathrm{SAFL}}} \cdot 100
$$

A eficiência de remoção de matéria orgânica filtrada (ع) para os perfis ao longo do ciclo foi calculada pela Equação (4.4), na qual $\mathrm{C}_{\mathrm{SAFL} 0}$ é a concentração de matéria orgânica filtrada no interior do reator no início do ciclo (tempo zero), ou seja, a concentração de matéria orgânica no reator após a diluição inicial do afluente.

$$
\varepsilon(\%)=\frac{\mathrm{C}_{\mathrm{SAFLO}}-\mathrm{C}_{\mathrm{SF}}}{\mathrm{C}_{\mathrm{SAFL} 0}} \cdot 100
$$

A carga orgânica aplicada volumétrica (COAV), expressa em $\mathrm{kgDQO} \cdot \mathrm{m}^{-3} \cdot \mathrm{d}^{-1}$, foi definida como sendo a quantidade de matéria orgânica aplicada ao reator por unidade de tempo e por volume de meio do reator. Para reatores operados em batelada pode ser calculada pela Equação (4.5), na qual $\mathrm{V}_{\mathrm{A}}$ é o volume de água residuária alimentada no ciclo, $\mathrm{N}$ é o número de ciclos por dia, $C_{S A F L}$ é a concentração de matéria orgânica no afluente e $V_{R}$ é o 
volume de água residuária no reator.

$$
C O A V=\frac{\boldsymbol{w}_{A} \cdot N \stackrel{-}{-} C_{S A F L}}{V_{R}}
$$

A carga orgânica aplicada específica (COAE), expressa em $\mathrm{kgSAC}_{\mathrm{gSVT}} \mathrm{g}^{-1} \cdot \mathrm{d}^{-1}$, foi definida como sendo a quantidade de matéria orgânica aplicada ao reator por unidade de tempo e por massa de sólidos totais voláteis no reator. Para reatores operados em batelada pode ser calculada pela Equação (4.6), na qual $\mathrm{M}_{\mathrm{SvT}}$ é a massa de sólidos voláteis totais no interior do reator.

$$
\mathrm{COAE}=\frac{\mathbf{v}_{\mathrm{A}} \cdot \mathrm{N}-\mathrm{C}_{\mathrm{SAFL}}}{\mathrm{M}_{\mathrm{SVT}}}
$$

A carga orgânica removida volumétrica $\left(\mathrm{CORV}_{\mathrm{SF}}\right)$, expressa em $\mathrm{kgDQO} \cdot \mathrm{m}^{-3} \cdot \mathrm{d}^{-1}$, para amostras filtradas, foi definida como sendo a quantidade de matéria orgânica removida pelo reator por unidade de tempo e por volume de meio do reator. Para reatores operados em batelada pode ser calculada pela Equação (4.7).

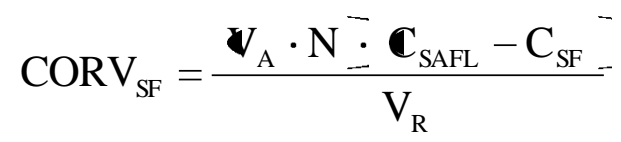

A carga orgânica removida específica $\left(\mathrm{CORE}_{\mathrm{SF}}\right)$, expressa em $\mathrm{kgDQO} . \mathrm{gSVT}^{-1} \cdot \mathrm{d}^{-1}$, para amostras filtradas, foi definida como sendo a quantidade de matéria orgânica removida pelo 
reator por unidade de tempo e por massa de sólidos totais voláteis no reator. Para reatores operados em batelada pode ser calculada pela Equação (4.8), na qual $\mathrm{M}_{\mathrm{SvT}}$ é a massa de sólidos voláteis totais no interior do reator.

$$
\mathrm{CORE}_{\mathrm{SF}}=\frac{\mathbf{v}_{\mathrm{A}} \cdot \mathrm{N} \doteq \mathbf{c}_{\mathrm{SAFL}}-\mathrm{C}_{\mathrm{SF}}}{\mathrm{M}_{\mathrm{SVT}}}
$$

A produtividade molar $(\mathrm{PrM})$, expressa em $\mathrm{molH}_{2} \cdot \mathrm{m}^{-3} \cdot \mathrm{d}^{-1}$, foi definida pela relação entre hidrogênio produzido por unidade de tempo e o volume útil do reator. Para reatores operados em batelada sequenciais pode ser calculada pela equação (4.9), na qual $\mathrm{n}_{\mathrm{H}_{2}}$ representa o numero de moles de hidrogênio produzido durante o ciclo.

$$
\operatorname{Pr} \mathrm{M}=\frac{\mathrm{N} \cdot \mathrm{n}_{\mathrm{H}_{2}}}{\mathrm{~V}_{\mathrm{u}}}
$$

A produtividade molar específica (PrME), expressa em mol. $\mathrm{molH}_{2} \cdot \mathrm{kgSVT}^{-1} \cdot \mathrm{d}^{-1}$, foi definida pela relação entre hidrogênio produzido por unidade de tempo e a massa de sólidos voláteis totais no interior do reator, podendo ser calculada pela equação (4.10).

$$
\operatorname{PrME}=\frac{\mathrm{N} \cdot \mathrm{n}_{\mathrm{H}_{2}}}{\mathrm{M}_{\mathrm{SVT}}}
$$

O rendimento molar por carga aplicada entre o hidrogênio produzido e matéria orgânica aplicada pode ser calculado com base na DQO $\left(\mathrm{RMCA}_{\mathrm{S}, \mathrm{m}}\right)$, expressa em 
$\mathrm{molH}_{2} \cdot \mathrm{kgDQO}^{-1}$, pela equação (4.11).

$$
R M C A_{S, m}=\frac{n_{H_{2}}}{N \cdot V_{A} \cdot C_{S T, A}}
$$

O rendimento molar por carga aplicada entre o hidrogênio produzido e matéria orgânica aplicada pode ser calculado com base na sacarose $\left(\mathrm{RMCA}_{\mathrm{C}, \mathrm{m}}\right)$, expressa em $\mathrm{molH}_{2} \cdot \mathrm{kgSAC}^{-1}$ pela equação (4.12).

$$
R M C A_{C, m}=\frac{n_{H_{2}}}{N \cdot V_{A} \cdot C_{C T, A}}
$$

O rendimento molar por carga removida entre o hidrogênio produzido e matéria orgânica aplicada foi calculado com base na DQO $\left(\mathrm{RMCR}_{\mathrm{S}, \mathrm{m}}\right)$, expressa em molH $2 \cdot \mathrm{kgDQO}^{-1}$, pela equação (4.13).

$$
R M C R_{S, m}=\frac{n_{H_{2}}}{N \cdot V_{A} \cdot \mathbf{C}_{S T, A}-C_{S F, E}}
$$

O rendimento molar por carga removida entre o hidrogênio produzido e matéria orgânica aplicada foi calculado com base na sacarose $\left(\mathrm{RMCR}_{\mathrm{C}, \mathrm{m}}\right)$, expressa em $\mathrm{molH}_{2} \cdot \mathrm{molSAC}^{-1}$, pela equação (4.14).

$$
R M C R_{C, m}=\frac{n_{H_{2}}}{N \cdot V_{A} \cdot \mathbf{C}_{C T, A}-C_{C F, E}}
$$


Estes parâmetros utilizados durante o período de monitoramento do sistema, fornecendo subsídios para a discussão do trabalho com base na literatura pertinente. 


\section{RESULTADOS E DISCUSSÃO}

No presente capitulo serão apresentados e discutidos os resultados obtidos na condição preliminar e nas seis condições experimentais realizadas no projeto.

\subsection{Condição experimental preliminar}

A montagem do sistema e o período seguinte, até a estabilização do reator, foram considerados como fase preliminar do projeto. Coube a esta fase o ajuste das análises das variáveis a serem monitoradas, montagem e correção de vazamentos gasosos no "headspace" do reator. Os resultados obtidos nessa fase foram importantes para o melhor conhecimento do sistema e estabilização dos parâmetros para a aplicação das condições de fato elaboradas.

A Figura 5.1 demonstra os valores da concentração afluente e efluente de carboidratos nos sistema. A eficiência de remoção de sacarose foi, em média, de $98 \%$ para as amostras filtradas, sendo a média de concentração afluente de $3298 \mathrm{mgSAC} . \mathrm{L}^{-1}$ e para o efluente de 67,5 mgSAC. $\mathrm{L}^{-1} \cdot \mathrm{L}^{-1}$. Os altos valores de eficiência de remoção de sacarose nesse período mostram a rápida adaptação do inóculo ao substrato e as condições ambientais impostas.

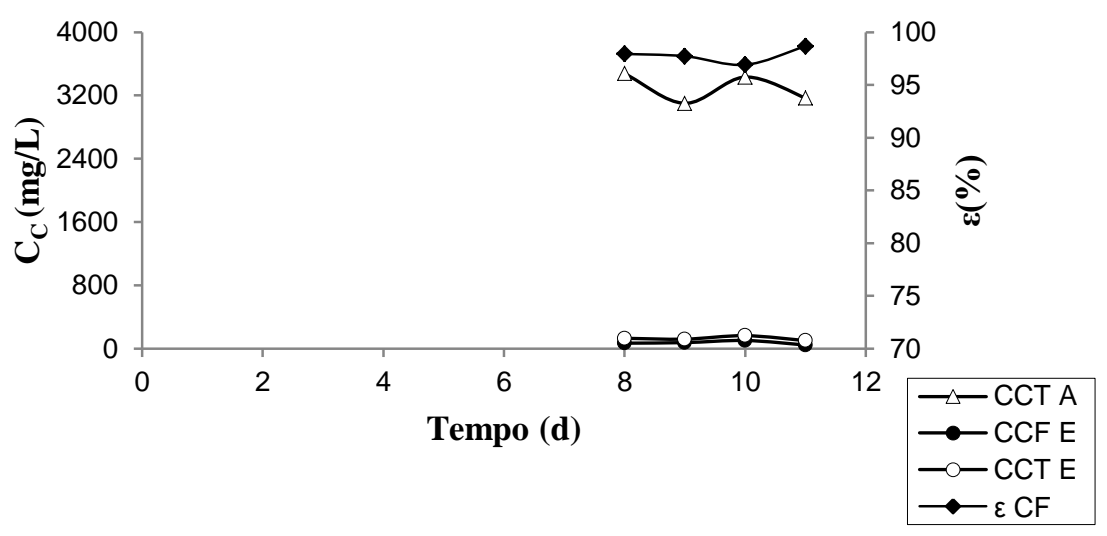

Figura 5.1: Concentração de carboidratos e eficiência de remoção na condição preliminar. 
A Figura 5.2 mostra que a concentração de matéria orgânica efluente foi, em média, de $2852 \mathrm{mgDQO} . \mathrm{L}^{-1}$ com desvio padrão de $114 \mathrm{mgDQO} . \mathrm{L}^{-1}$, eficiência média de remoção de $23 \%$ com relação às amostras filtradas.

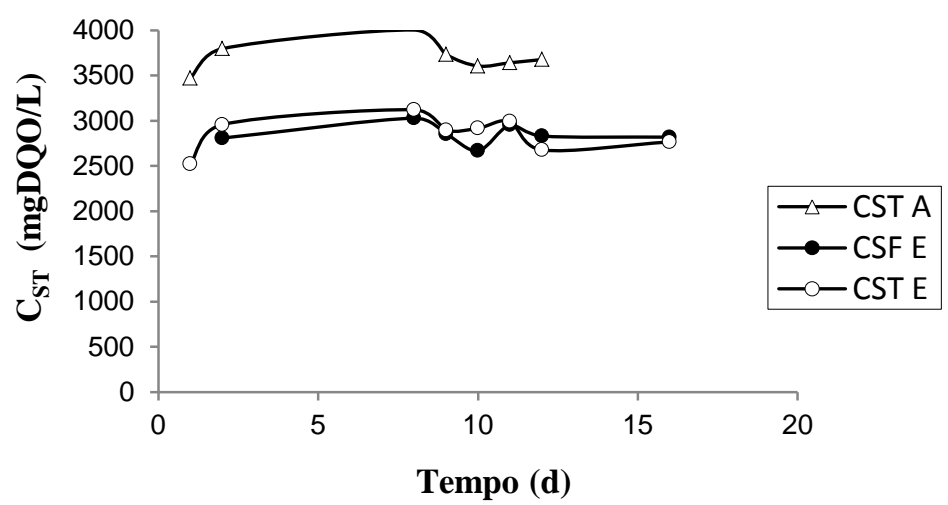

Figura 5.2: Concentração de matéria orgânica (DQO) afluente efluente na condição preliminar.

A Figura 5.3 mostra o acúmulo de ácidos voláteis totais no interior do reator durante a fase preliminar. A média de concentração efluente foi de $803 \mathrm{mgHAc} . \mathrm{L}^{-1}$, obtendo-se o valor máximo de 925 mgHAc. $\mathrm{L}^{-1}$.

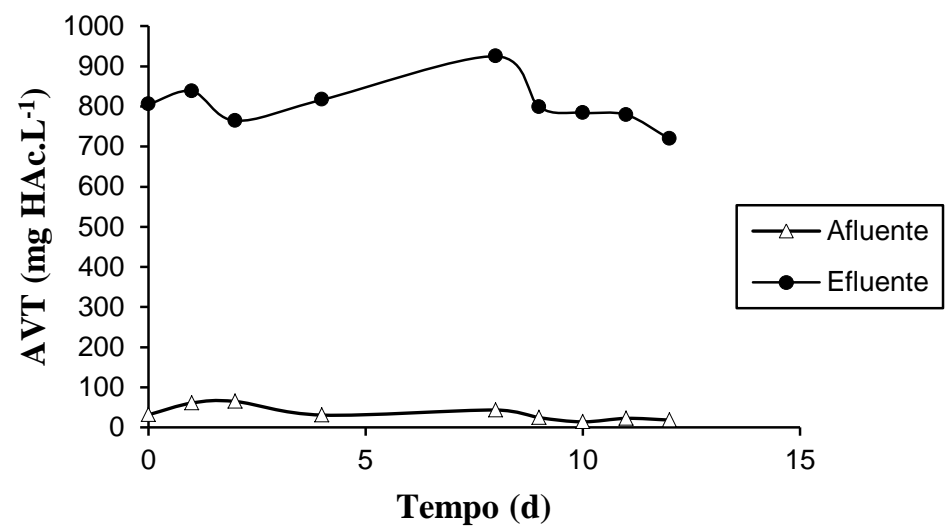

Figura 5.3: Concentração de ácidos voláteis totais afluente e efluente na condição preliminar. 
A produção de ácidos voláteis totais provocou uma redução no $\mathrm{pH}$ como pode ser observado na Figura 5.4. A média dos valores de $\mathrm{pH}$ efluente durante a fase preliminar foi de 4,7, atingindo o valor mínimo de 4,5.

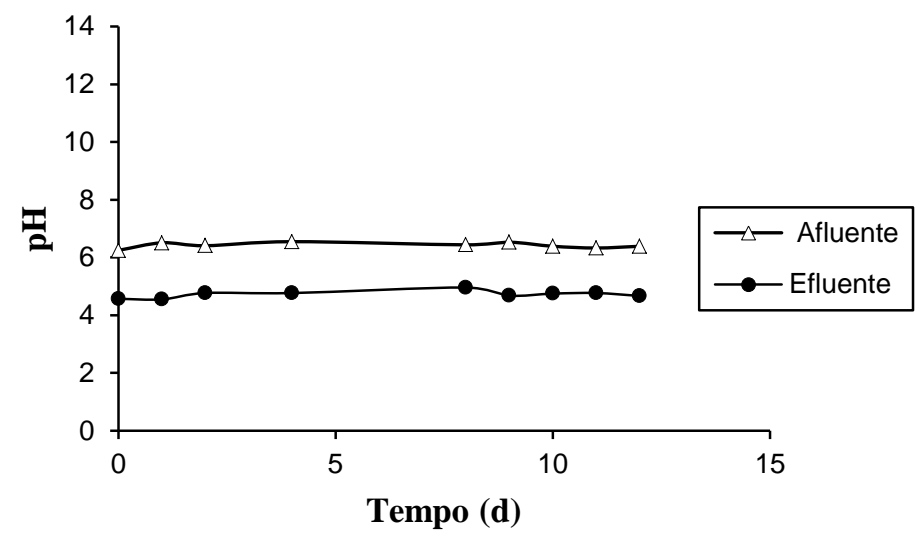

Figura 5.4: Valores de $\mathrm{pH}$ afluente e efluente na condição preliminar.

A Tabela 5.1 mostra os valores da série de sólidos para o afluente e efluente, sendo observado uma variação de $54 \mathrm{mg} . \mathrm{L}^{-1}$ entre os sólidos em suspensão voláteis afluente e efluente, cujas concentrações foram de 90 e 144 para o afluente e efluente, respectivamente.

Tabela 5.1: Série de sólidos afluente e efluente na condição preliminar.

\begin{tabular}{lcccc}
\hline & $\begin{array}{c}\text { ST } \\
\left(\mathrm{mg} . \mathrm{L}^{-1}\right)\end{array}$ & $\begin{array}{c}\text { SVT } \\
\left(\mathrm{mg} . \mathrm{L}^{-1}\right)\end{array}$ & $\begin{array}{c}\text { SST } \\
\left(\mathrm{mg} . \mathrm{L}^{-1}\right)\end{array}$ & $\begin{array}{c}\text { SSV } \\
\left(\mathrm{mg} . \mathrm{L}^{-1}\right)\end{array}$ \\
\hline Afluente & $5282 \pm 274$ & $3120 \pm 1332$ & $84 \pm 3$ & $90 \pm 17$ \\
Efluente & $3107 \pm 27$ & $1869 \pm 61$ & $113 \pm 38$ & $144 \pm 90,5$ \\
\hline
\end{tabular}

*Número de amostras consideradas $=2$. 


\subsection{Condição experimental 1}

\subsubsection{Monitoramento ao final do ciclo}

Nessa condição experimental o reator foi operado em bateladas sequenciais com COAV nominal de $9 \mathrm{kgDQO} \cdot \mathrm{m}^{-3} \cdot \mathrm{d}^{-1}$ e duração do ciclo de 4 horas por um período de 29 dias. A Tabela 5.2 mostra as variáveis monitoradas e seus respectivos valores médios.

A Figura 5.5 exibe os valores da concentração de carboidratos afluente e efluente (para amostras filtradas e não filtradas). A média da concentração afluente foi de $3230 \mathrm{mgSAC} . \mathrm{L}^{-1}$, enquanto que a concentração residual foi de $39 \mathrm{mgSAC} . \mathrm{L}^{-1}$. A média da eficiência de remoção com base em amostras filtradas foi de 99\%, sendo que a Figura 5.9 exibe o comportamento ao longo da operação.

A Figura 5.6 mosta os valores da eficiência de remoção de carboidratos, pela qual pode ser obseravada a estabilidade do processo durante todo o período, alcançando-se uma média de remoção de $99 \%$.

A média da concentração de matéria orgânica afluente foi de $3671 \mathrm{mgDQO} . \mathrm{L}^{-1}$ e as análises de efluente feitas em amostras filtradas e não filtradas resultaram em médias de 2985 e 3067 mgDQO.L ${ }^{-1}$, respectivamente, cujos valores são mostrados na Figura 5.7. A eficiência de remoção de DQO mostrou-se relativamente baixa, $19 \%$ em média, durante toda a condição, cujos valores podem ser observados na Figura 5.8. 
Tabela 5.2: Valores médios dos parâmetros monitorados da condição 1.

\begin{tabular}{|c|c|c|c|c|c|c|c|c|c|c|c|c|c|}
\hline \multirow{2}{*}{$\frac{\text { Parâmetro }}{\mathrm{C}_{\mathrm{ST}}}$} & & \multicolumn{3}{|c|}{ Afluente } & \multicolumn{9}{|c|}{ Efluente } \\
\hline & {$\left[\mathrm{mgDQO} . \mathrm{L}^{-1}\right]$} & 3671 & \pm & 149 & $(2$ & 25 & ) & 3067 & \pm & 136 & c & 25 & ) \\
\hline$\varepsilon_{\mathrm{ST}}$ & {$[\%]$} & - & & - & & & & 16 & \pm & 4 & ( & 25 & ) \\
\hline $\mathrm{C}_{\mathrm{SF}}$ & {$\left[\mathrm{mgDQO} . \mathrm{L}^{-1}\right]$} & - & & - & & & & 2985 & \pm & 223 & ( & 25 & ) \\
\hline$\varepsilon_{\mathrm{SF}}$ & {$[\%]$} & - & & - & & & & 19 & \pm & 6 & ( & 25 & ) \\
\hline $\mathrm{C}_{\mathrm{CT}}$ & {$\left[\mathrm{mgSAC} \cdot \mathrm{L}^{-1}\right]$} & 3230 & \pm & 129 & $(2$ & 25 & ) & 59 & \pm & 21 & c & 25 & ) \\
\hline $\mathrm{C}_{\mathrm{CF}}$ & {$\left[\mathrm{mgSAC} . \mathrm{L}^{-1}\right]$} & - & & - & & & & 39 & \pm & 11 & c & 25 & ) \\
\hline$\varepsilon_{\mathrm{CT}}$ & {$[\%]$} & - & & - & & & & 98 & \pm & 1 & c & 25 & ) \\
\hline$\varepsilon_{\mathrm{CF}}$ & {$[\%]$} & - & & - & & & & 99 & \pm & 1 & ( & 25 & ) \\
\hline AVT & {$\left[\mathrm{mgHAc} . \mathrm{L}^{-1}\right]$} & 25 & \pm & 85 & $(2$ & 22 & ) & 660 & \pm & 89 & c & 22 & ) \\
\hline $\mathrm{AT}$ & {$\left[\mathrm{mgCaCO}_{3} \cdot \mathrm{L}^{-1}\right]$} & 357 & \pm & 5 & $(2$ & 22 & ) & 173 & \pm & 83 & c & 22 & ) \\
\hline $\mathrm{pH}$ & & 6,4 & \pm & 0,1 & $(2$ & 22 & ) & 4,7 & \pm & 0,2 & ( & 22 & ) \\
\hline ST & {$\left[\mathrm{mg} . \mathrm{L}^{-1}\right]$} & 4678 & \pm & 326 & c & 7 & ) & 2484 & \pm & 678 & c & 7 & ) \\
\hline SVT & {$\left[\mathrm{mg} . \mathrm{L}^{-1}\right]$} & 3693 & \pm & 387 & c & 7 & ) & 1577 & \pm & 571 & c & 7 & ) \\
\hline SST & {$\left[\mathrm{mg} \cdot \mathrm{L}^{-1}\right]$} & 75 & \pm & 29,7 & c & 7 & ) & 110 & \pm & 31 & c & 7 & ) \\
\hline SSV & {$\left[\mathrm{mg} . \mathrm{L}^{-1}\right]$} & 39 & \pm & 36 & c & 7 & ) & 87 & \pm & 40 & c & 7 & ) \\
\hline $\mathrm{V}_{\mathrm{G}}$ & {$[\mathrm{mL}]$} & - & & - & & & & 952 & \pm & 166 & ( & 3 & ) \\
\hline $\mathrm{V}_{\mathrm{H} 2}$ & {$[\mathrm{~mL}]$} & - & & - & & & & 343 & \pm & 32 & ( & 3 & ) \\
\hline$C^{\prime}{ }_{X-S V T}$ & [g.g-suporte $\left.{ }^{-1}\right]$ & 0,015 & & & & & & & & & & & \\
\hline $\mathrm{C}_{\mathrm{X} \text {-SVT }}$ & {$\left[\mathrm{g} . \mathrm{L}^{-1}\right]$} & 4,95 & & & & & & & & & & & \\
\hline $\mathrm{COAV}_{\mathrm{STA}}$ & {$\left[\mathrm{kgDQO} \cdot \mathrm{m}^{-3} \cdot \mathrm{d}^{-1}\right]$} & 9,3 & & - & & & & - & & - & & & \\
\hline $\mathrm{CORV}_{\mathrm{SFE}}$ & {$\left[\mathrm{kgDQO} \cdot \mathrm{m}^{-3} \cdot \mathrm{d}^{-1}\right]$} & - & & — & & & & 1,7 & & - & & & \\
\hline $\operatorname{COAV}_{\mathrm{CTA}}$ & {$\left[\mathrm{kgSAC} \cdot \mathrm{m}^{-3} \cdot \mathrm{d}^{-1}\right]$} & 8,2 & & — & & & & - & & - & & & \\
\hline $\mathrm{CORV}_{\mathrm{CTFE}}$ & {$\left[\mathrm{kgSAC} \cdot \mathrm{m}^{-3} \cdot \mathrm{d}^{-1}\right]$} & - & & - & & & & 8,1 & & - & & & \\
\hline $\mathrm{M}_{\mathrm{SVT}}$ & {$[\mathrm{g}]$} & - & & - & & & & 22,3 & \pm & 0,5 & ( & 3 & ) \\
\hline $\mathrm{n}_{\mathrm{H} 2}$ & {$\left[\mathrm{molH}_{2} \cdot \mathrm{d}^{-1}\right]$} & - & & - & & & & 0,15 & & - & & & \\
\hline PrM & {$\left[\mathrm{molH}_{2} \cdot \mathrm{m}^{-3} \cdot \mathrm{d}^{-1}\right]$} & 21,0 & & — & & & & - & & - & & & \\
\hline PrME & {$\left[\mathrm{molH}_{2} \cdot \mathrm{kgSVT}^{-1} \cdot \mathrm{d}^{-1}\right]$} & 6,87 & & — & & & & - & & - & & & \\
\hline $\mathrm{RMCA}_{\mathrm{C}, \mathrm{m}}$ & {$\left[\mathrm{molH}_{2} \cdot \mathrm{kgSAC}^{-1}\right]$} & 4,16 & & - & & & & - & & - & & & \\
\hline $\mathrm{RMCA}_{\mathrm{S}, \mathrm{m}}$ & {$\left[\mathrm{molH}_{2} \cdot \mathrm{kgDQO}^{-1}\right]$} & 3,66 & & - & & & & - & & - & & & \\
\hline $\mathrm{RMCR}_{\mathrm{C}, \mathrm{m}}$ & {$\left[\mathrm{molH}_{2} \cdot \mathrm{kgSAC}^{-1}\right]$} & - & & - & & & & 4,21 & & - & & & \\
\hline $\mathrm{RMCR}_{\mathrm{S}, \mathrm{m}}$ & {$\left[\mathrm{molH}_{2} \cdot \mathrm{kgDQO}^{-1}\right]$} & - & & - & & & & 19,6 & & - & & & \\
\hline $\mathrm{V}_{\mathrm{T}}$ & {$[\mathrm{L}]$} & 4,5 & \pm & 0,1 & $(2$ & 25 & ) & - & & - & & & \\
\hline $\mathrm{V}_{\mathrm{F}}$ & {$[\mathrm{L}]$} & 1,9 & \pm & 0,1 & ( & 25 & ) & - & & - & & & \\
\hline
\end{tabular}




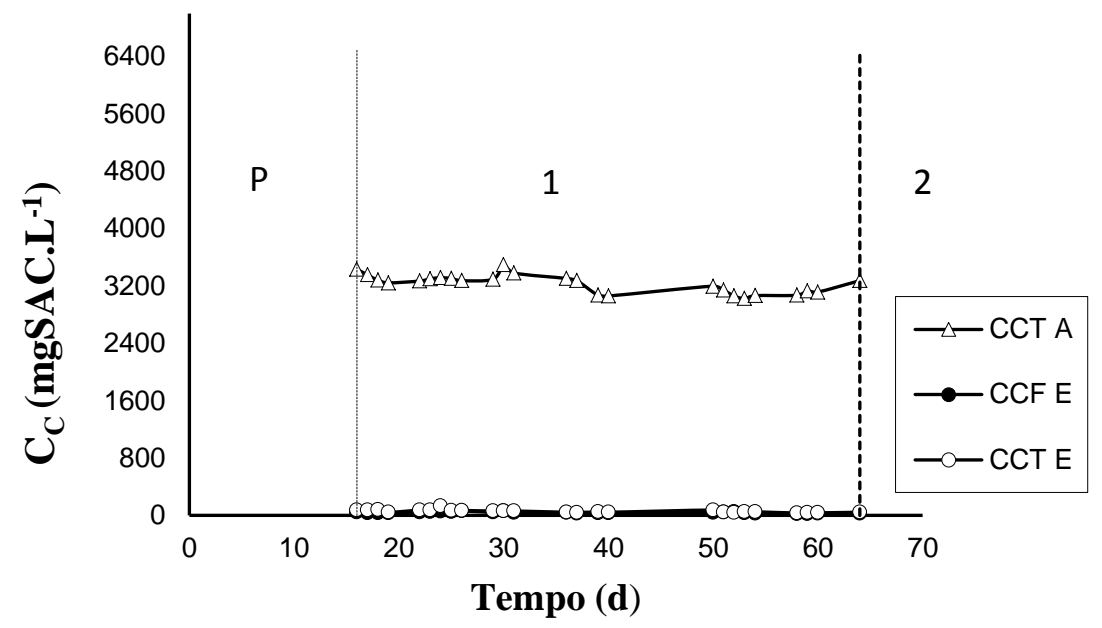

Figura 5.5: Concentração de carboidratos afluente e efluente para amostras filtradas e não filtradas na condição 1 .

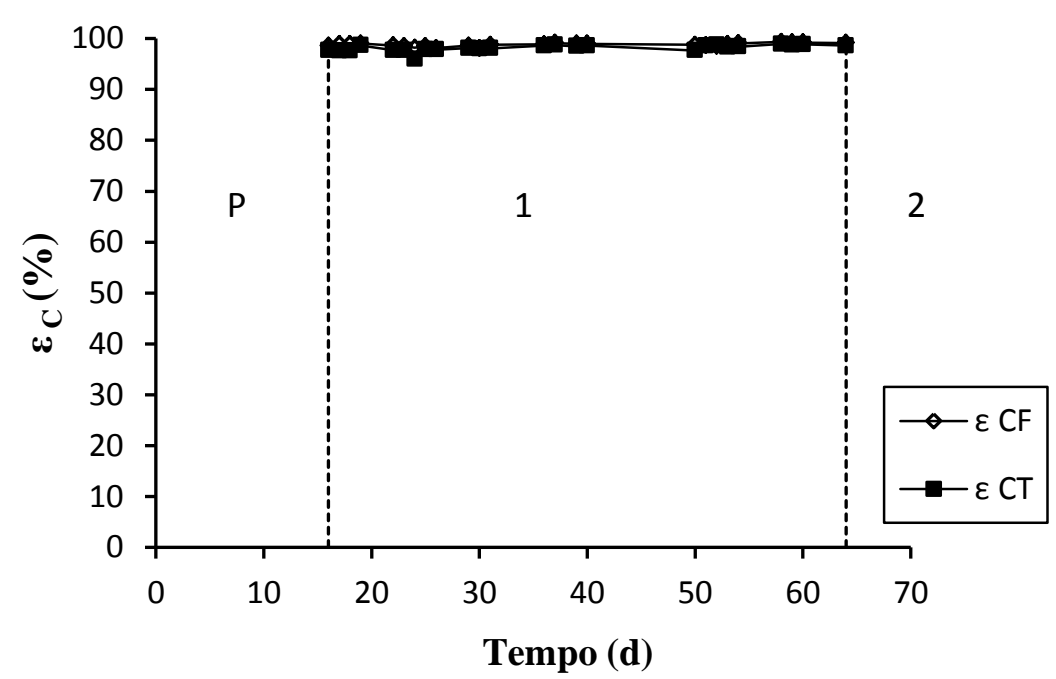

Figura 5.6: Eficiência de remoção de carboidratos para amostras filtradas na condição 1. 


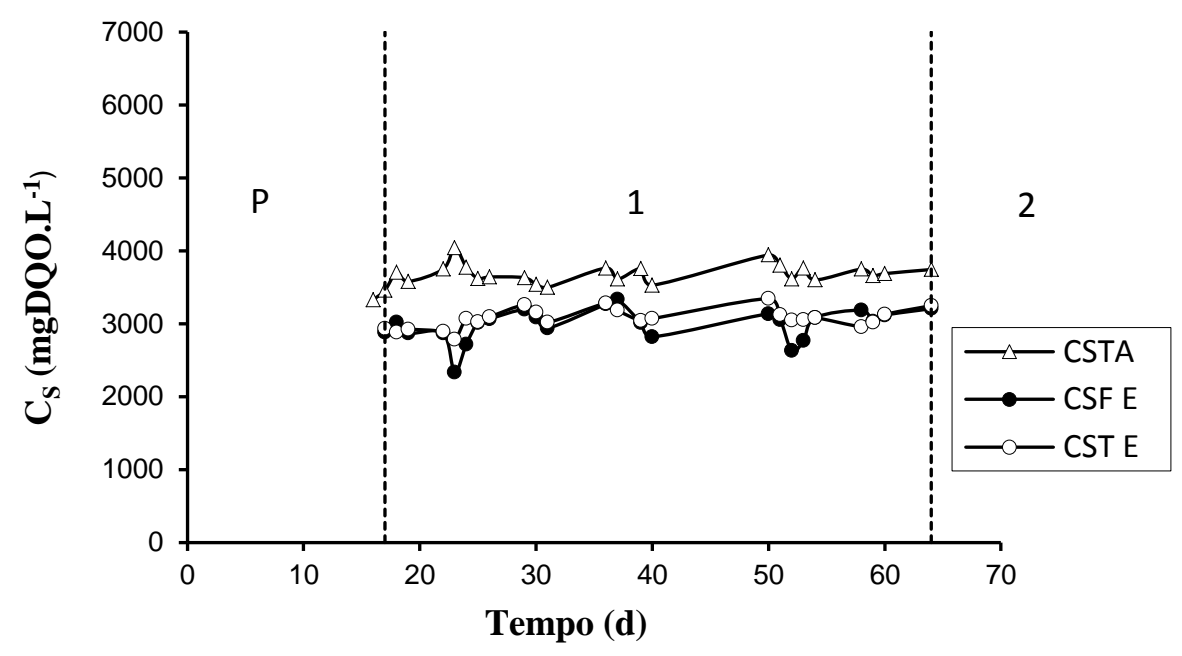

Figura 5.7: Concentração de matéria orgânica (DQO) afluente e efluente para amostras filtradas e não filtradas na condição 1 .

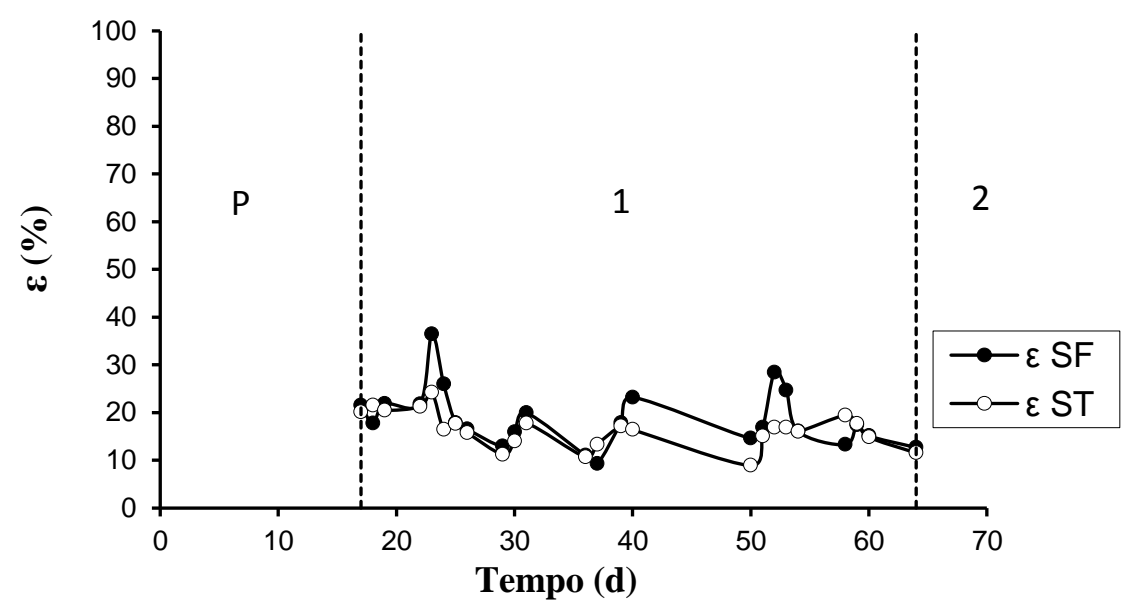

Figura 5.8: Eficiência de remoção de matéria orgânica (DQO) para amostras filtradas e não filtradas na condição 1 . 
A Tabela 5.3 apresenta os valores da concentração média dos compostos intermediários, obtidos em triplicata, contidos no efluente do sistema. O método cromatográfico aplicado não detectou acetona e metanol. A Figura 5.9 a concentração dos ácidos no efluente e afluente. A concentração média de ácidos no efluente foi de 660 mgHAc. $\mathrm{L}^{-1}$ enquanto que no afluente foi de $25 \mathrm{mgHAc} . \mathrm{L}^{-1}$.

Tabela 5.3: Concentração dos produtos intermediários da condição 1.

\begin{tabular}{|c|c|c|c|c|c|c|c|}
\hline \multirow{3}{*}{$\begin{array}{c}\text { Produtos } \\
\text { intermediários }\end{array}$} & \multicolumn{6}{|c|}{ Concentração média } & \multirow{3}{*}{$\begin{array}{c}\begin{array}{c}\text { Porcentagem } \\
(\%)\end{array} \\
0,0\end{array}$} \\
\hline & \multicolumn{3}{|c|}{$\mathrm{mg} \cdot \mathrm{L}^{-1}$} & \multicolumn{3}{|c|}{ mmol.L $\mathrm{L}^{-1}$} & \\
\hline & - & \pm & - & - & \pm & - & \\
\hline Metanol & - & \pm & - & - & \pm & - & 0,0 \\
\hline Etanol & 376,1 & \pm & 29,6 & 8,1 & \pm & 0,6 & 97,4 \\
\hline n-Butanol & 10,1 & \pm & 0,4 & 0,1 & \pm & 0,0 & 2,6 \\
\hline Acético & 326,1 & \pm & 43,6 & 5,4 & \pm & 0,7 & 23,3 \\
\hline Porpiônico & 78,0 & \pm & 3,2 & 1,1 & \pm & 0,0 & 5,6 \\
\hline Isobutírico & 254,6 & \pm & 50,5 & 2,9 & \pm & 0,6 & 18,2 \\
\hline Butírico & 438,9 & \pm & 64,2 & 5,0 & \pm & 0,7 & 31,4 \\
\hline Isovalérico & 11,1 & \pm & 1,3 & 0,1 & \pm & 0,0 & 0,8 \\
\hline Valérico & 46,0 & \pm & 8,4 & 0,4 & \pm & 0,1 & 3,3 \\
\hline Capróico & 242,0 & \pm & 71,2 & 2,1 & \pm & 0,6 & 17,3 \\
\hline
\end{tabular}

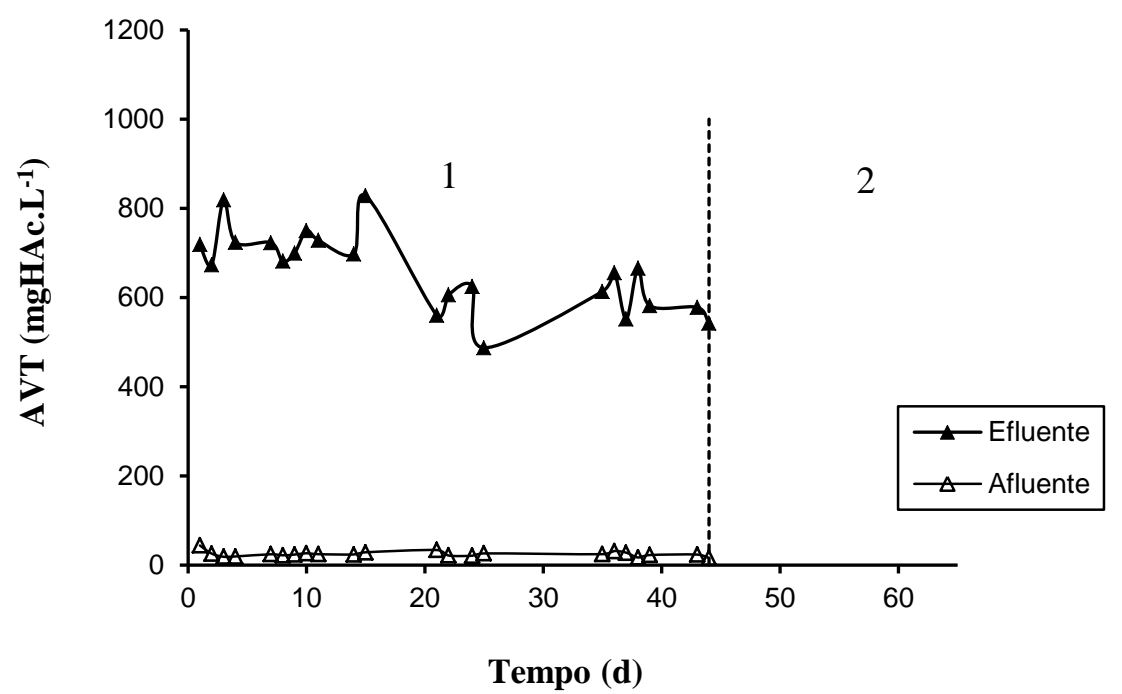

Figura 5.9: Concentração de ácidos voláteis totais afluente e efluente na condição 1. 
O acúmulo de ácidos orgânicos no interior do reator provocaram a redução instantânea do $\mathrm{pH}$ assim que o afluente entrava em contato com o meio líquido residual no interior do reator. A Figura 5.10 apresenta os valores de $\mathrm{pH}$, afluente e efluente, ao longo do período experimental. O valor médio do $\mathrm{pH}$ afluente foi de 6,4 e de 4,7 para o efluente.

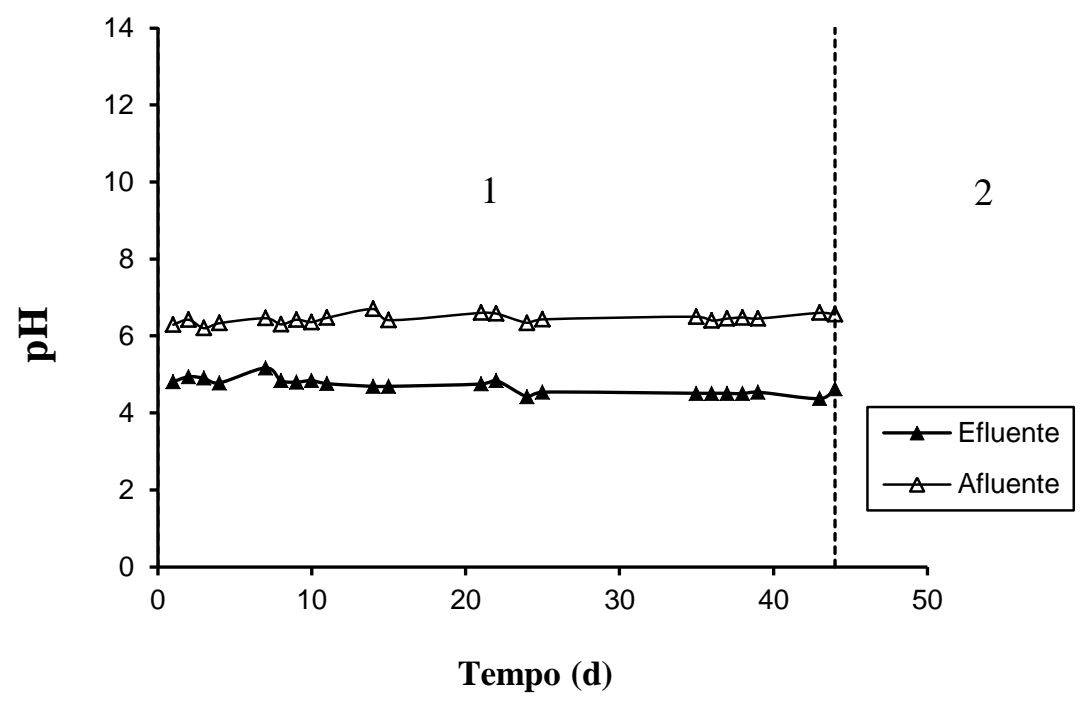

Figura 5.10: Valores de pH afluente e efluente na condição 1.

A Figura 5.11 apresenta as concentrações, afluente e efluente, da alcalinidade total que apresentaram valores médios de 359 e $169 \mathrm{mgCaCO}_{3} \cdot \mathrm{L}^{-1}$ para o afluente e efluente, respectivamente.

O monitoramento da série de sólidos é mostrado na Tabela 5.4, cujos valores indicam um baixo teor de SSV no efluente e afluente.

A produção do biogás, em aspecto quantitativo, pode ser observada na Figura 5.12. A de produção média foi de $893 \mathrm{~mL}$ (CNTP). 


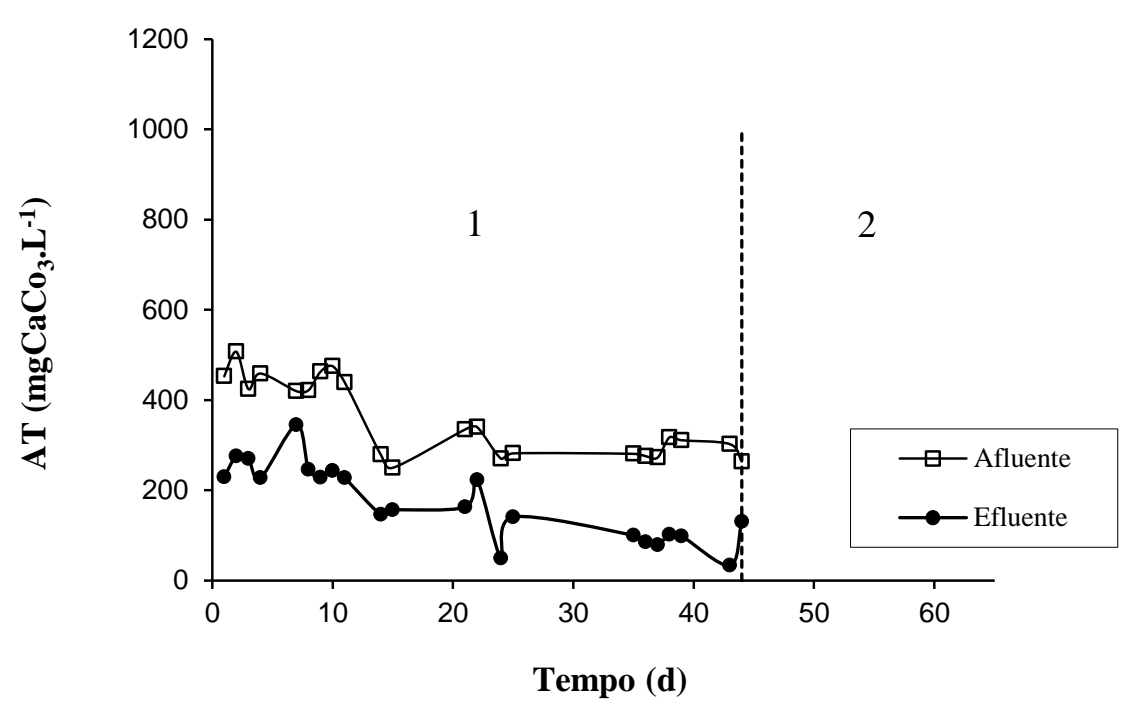

Figura 5.11: Concentração de alcalinidade total afluente e efluente na condição 1.

Tabela 5.4: Série de sólidos afluente e efluente na condição 1.

\begin{tabular}{lcccc}
\hline & $\begin{array}{c}\mathrm{ST} \\
\left(\mathrm{mg} . \mathrm{L}^{-1}\right)\end{array}$ & $\begin{array}{c}\mathrm{SVT} \\
\left(\mathrm{mg} . \mathrm{L}^{-1}\right)\end{array}$ & $\begin{array}{c}\text { SST } \\
\left(\mathrm{mg} . \mathrm{L}^{-1}\right)\end{array}$ & $\begin{array}{c}\text { SSV } \\
\left(\mathrm{mg.L}^{-1}\right)\end{array}$ \\
\hline Afluente & $4678 \pm 326$ & $3693 \pm 387$ & $75 \pm 30$ & $39 \pm 36$ \\
Efluente & $2484 \pm 677$ & $1577 \pm 571$ & $109 \pm 31$ & $87 \pm 40$ \\
\hline \multicolumn{5}{c}{ *Número de amostras consideradas $=7}$.
\end{tabular}

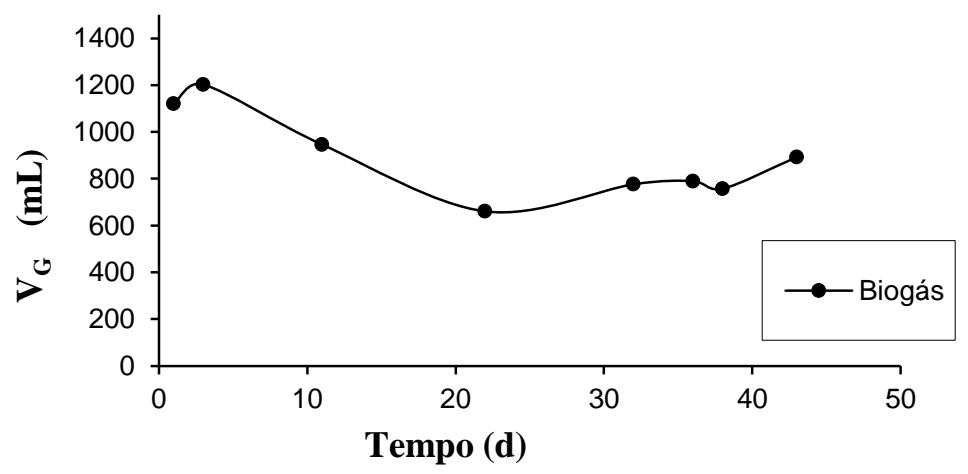

Figura 5.12: Volume total de biogás produzido na condição 1. 


\subsubsection{Monitoramento ao longo do ciclo}

A Figura 5.13 apresenta os valores de carboidratos ao longo do perfil de operação. No tempo inicial o valor da concentração é de 2018 mgSAC. $\mathrm{L}^{-1}$. A redução imediata da concentração deve-se ao volume residual de meio existente no interior do recipiente de recirculação. Como pode ser observado na Figura 5.13(a) e 5.13(b), após 1,5 horas de ciclo praticamente todo substrato é removido, atingindo uma eficiência de $98 \%$ com um residual de $32 \mathrm{mgSAC} . \mathrm{L}^{-1}$ ao final das 4 horas de ciclo.

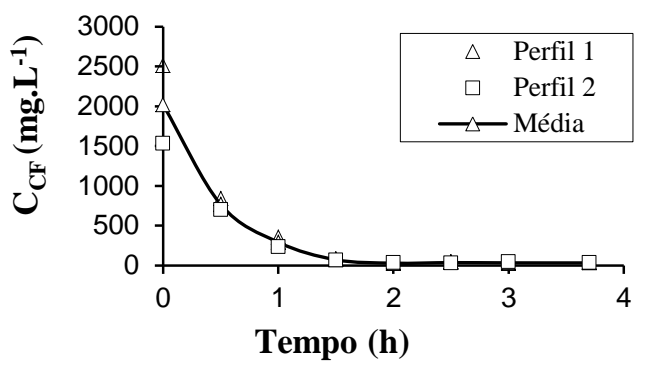

(a)

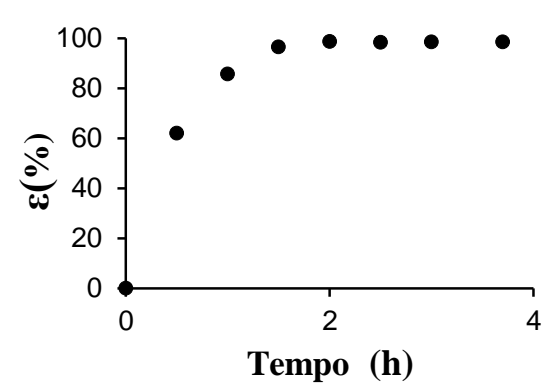

(b)

Figura 5.13: (a) Concentração de carboidratos e (b) eficiência de remoção para amostras filtradas ao longo do ciclo na condição 1 .

A Figura 5.14 representa o comportamento da matéria orgânica ao longo do ciclo. No inicio do ciclo, a concentração é de 3366 mgDQO.L $\mathrm{L}^{-1}$ ocorrendo uma redução até o tempo de 1,5 horas de ciclo e chegando ao valor de $2995 \mathrm{mgDQO} . \mathrm{L}^{-1}$ no último ponto do ciclo. 


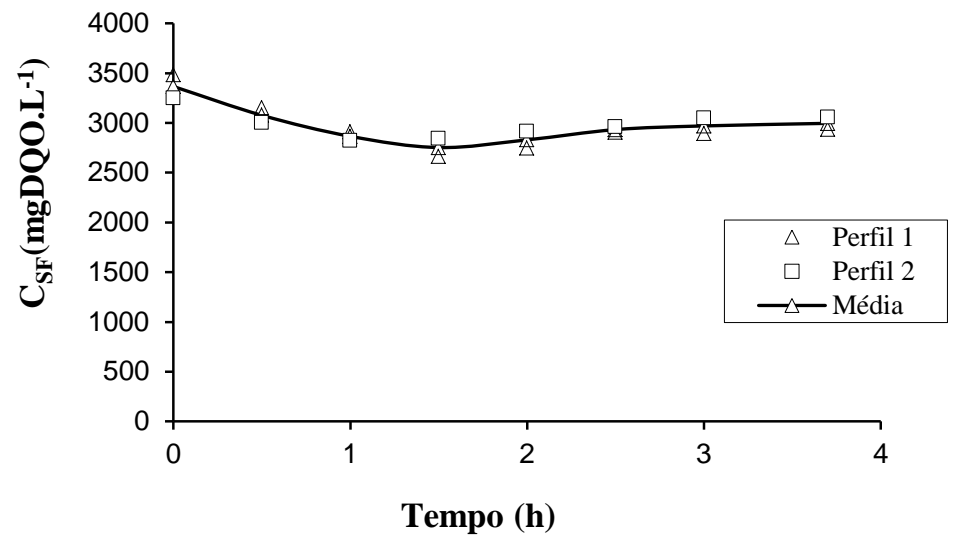

Figura 5.14: Concentração de matéria orgânica (DQO) para amostras filtradas ao longo do ciclo na condição 1 .

A produção de ácidos voláteis totais ao longo do ciclo é representada na Figura 5.15. No tempo inicial a concentração é de $135 \mathrm{mgHAc} . \mathrm{L}^{-1}$, tendo um crescimento acentuado em 1,5 horas, atingindo o valor de 653 mgHAc. $\mathrm{L}^{-1}$, seguido de um aumento menos acentuado, chegando ao valor de $729 \mathrm{mgHAc} \mathrm{L}^{-1}$ ao final do ciclo. A média da concentração de ácidos voláteis totais ao longo do ciclo foi de $572 \mathrm{mgHAc} . \mathrm{L}^{-1}$.

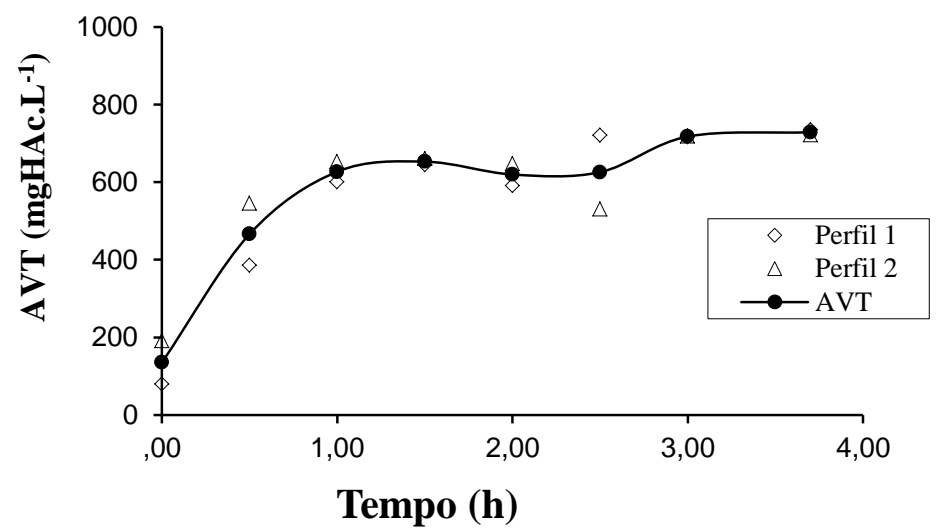

Figura 5.15: Concentração de ácidos voláteis totais ao longo do ciclo na condição 1. 
A Figura 5.16 permite observar a predominância dos ácidos butírico e acético com concentrações de 438,9 mg.L $\mathrm{L}^{-1}$ 326,1 mg.L $\mathrm{L}^{-1}$, respectivamente. A Figura 5.17 apresenta o comportamento da alcalinidade total ao longo do ciclo, sendo que no inicio do ciclo a alcalinidade é de $207 \mathrm{mgCaCO}_{3}$, atingindo $193 \mathrm{mgCaCO}_{3}$ após 4 horas de ciclo.

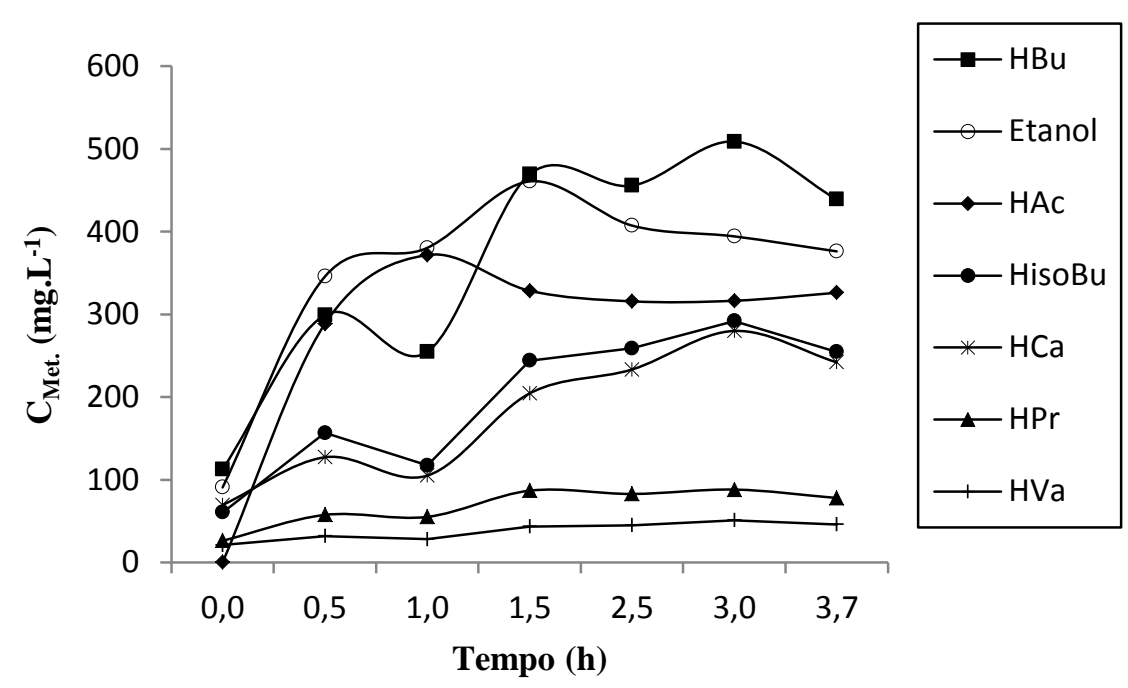

Figura 5.16: Concentração dos compostos intermediários ao longo do ciclo na condição 1.

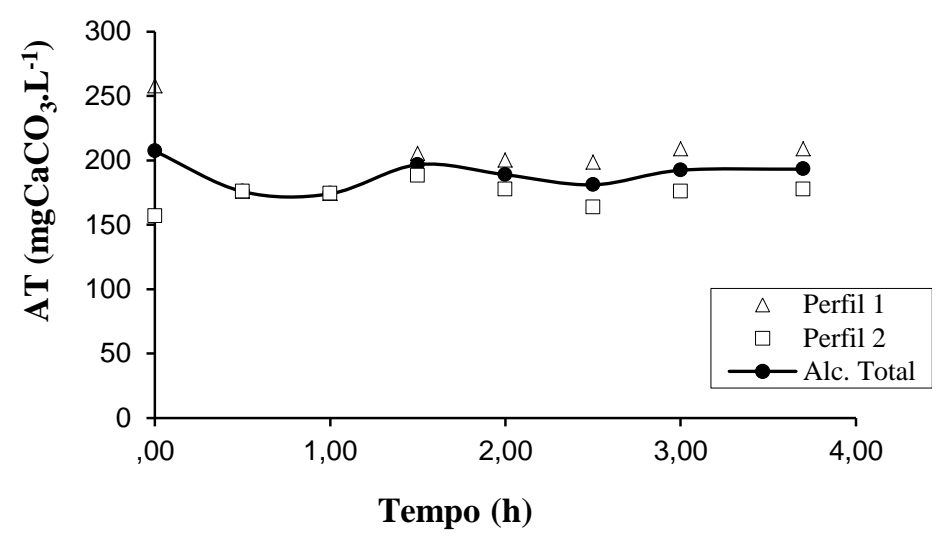

Figura 5.17: Concentração de alcalinidade total ao longo do ciclo na condição 1. 
$\mathrm{O}$ perfil dos valores de $\mathrm{pH}$ mostrados na Figura 5.18 indicam que o valor inicial de 6,5 é reduzido ao valor de 4,9 devido aos ácidos voláteis no interior do reator, mantendo-se constante durante todo o ciclo, demonstrando a estabilidade do mesmo.

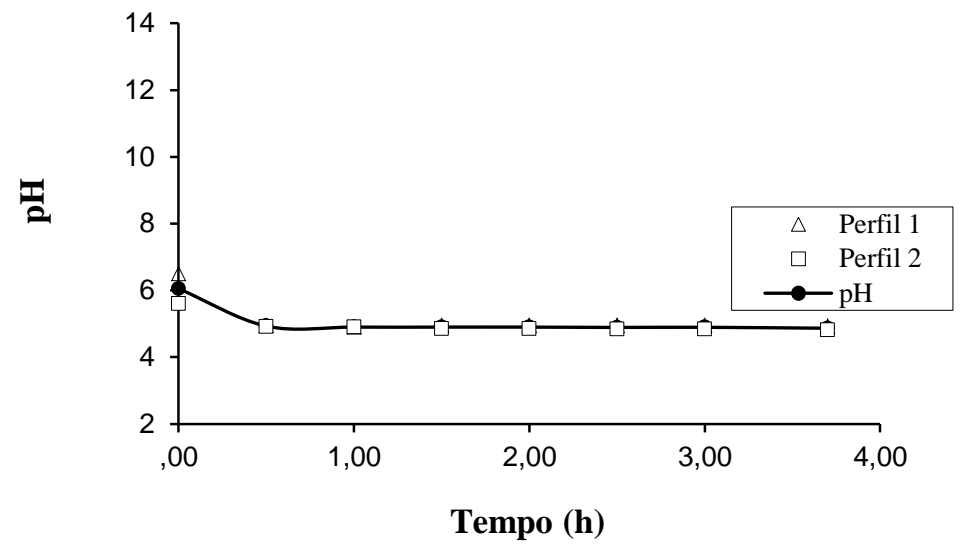

Figura 5.18: Valores de pH ao longo do ciclo na condição 1.

A Figura 5.19 permite observar que a produção do biogás é crescente no início do ciclo (1,5 horas), atingindo o valor médio de $839 \mathrm{~mL}$ (CNTP), seguido de um crescimento menos acentuado e atingindo $878 \mathrm{~mL}$ (CNTP) em 2,5 horas, ficando estagnada após esse período. A Tabela 5.5 resume os valores da produção, fração molar e os volumes individuais da mistura do biogás. A Figura 5.20 apresenta os volumes de $\mathrm{H}_{2}, \mathrm{CO}_{2}$ e $\mathrm{CH}_{4}$ produzidos durante o ciclo. Nos primeiros 30 minutos são produzidos $147 \mathrm{~mL}$ de $\mathrm{H}_{2}$, atingindo o valor máximo de 310 $\mathrm{mL}$ ao final das 4 horas de ciclo. Não foi detectado metano. 
Tabela 5.5: Produção e composição do biogás produzido ao longo do ciclo na condição 1.

\begin{tabular}{ccccccccccc}
\hline $\begin{array}{c}\text { Tempo } \\
(\mathrm{h})\end{array}$ & $\begin{array}{c}\mathrm{V}_{\mathrm{G}} \\
(\mathrm{mL}-\mathrm{CNTP})\end{array}$ & \multicolumn{3}{c}{$\mathrm{C}_{\mathrm{G}}\left(\mathrm{mmol. \textrm {L } ^ { - 1 } )}\right.$} & \multicolumn{3}{c}{ Fração Molar (\%) } & \multicolumn{3}{c}{ Volume (mL-CNTP) } \\
& & $\mathrm{H}_{2}$ & $\mathrm{CO}_{2}$ & $\mathrm{CH}_{4}$ & $\mathrm{H}_{2}$ & $\mathrm{CO}_{2}$ & $\mathrm{CH}_{4}$ & $\mathrm{H}_{2}$ & $\mathrm{CO}_{2}$ & $\mathrm{CH}_{4}$ \\
\hline 0,0 & 0 & 0,0 & 0,0 & 0,0 & 0 & 0 & 0 & 0 & 0 & 0 \\
0,5 & 488 & 2,8 & 6,4 & 0,0 & 30 & 70 & 0 & 146 & 342 & 0 \\
1,0 & 754 & 6,6 & 9,2 & 0,0 & 42 & 58 & 0 & 257 & 497 & 0 \\
1,5 & 839 & 7,8 & 10,2 & 0,0 & 43 & 57 & 0 & 294 & 545 & 0 \\
2,0 & 869 & 7,6 & 10,6 & 0,0 & 42 & 58 & 0 & 306 & 563 & 0 \\
2,5 & 878 & 7,2 & 10,4 & 0,0 & 41 & 59 & 0 & 310 & 568 & 0 \\
3,0 & 878 & 7,1 & 11,0 & 0,0 & 39 & 61 & 0 & 310 & 568 & 0 \\
3,7 & 878 & 5,5 & 9,8 & 0,0 & 36 & 64 & 0 & 310 & 568 & 0 \\
\hline
\end{tabular}

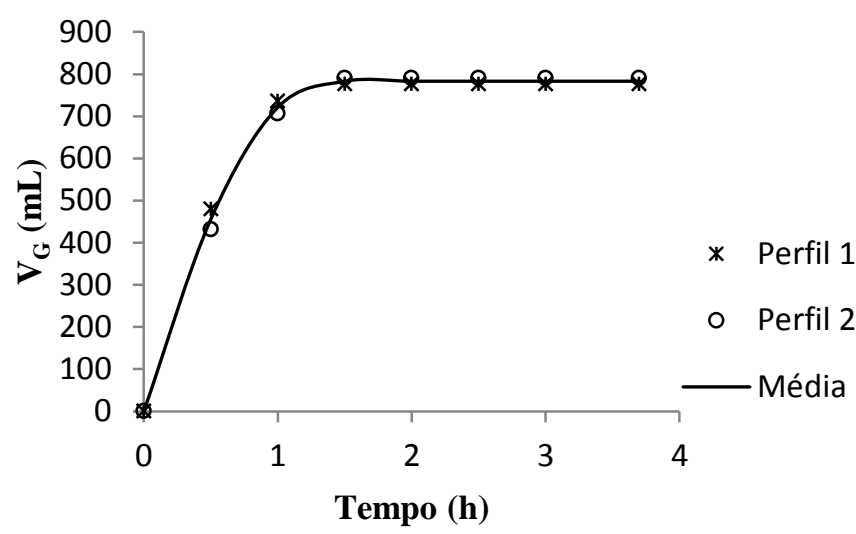

Figura 5.19: Volume total de biogás produzido ao longo do ciclo na condição 1.

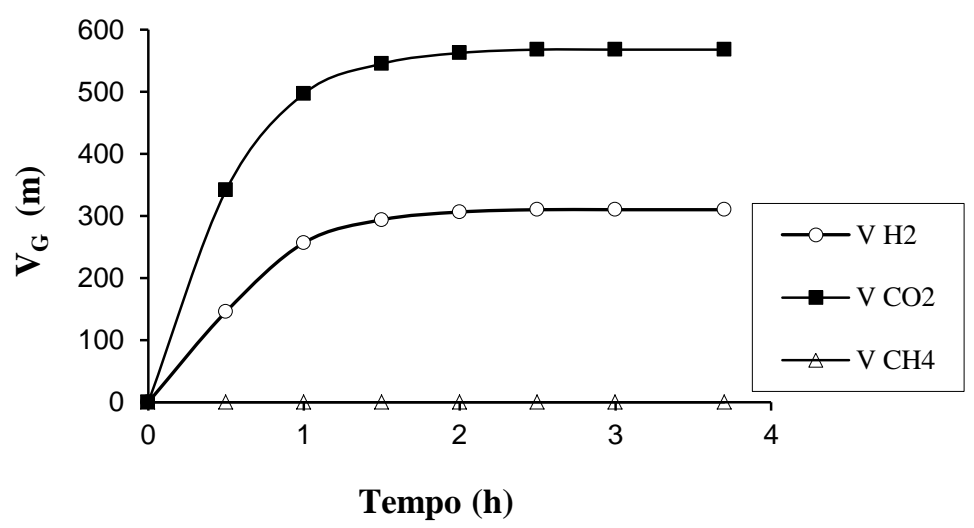

Figura 5.20: Volumes de $\mathrm{H}_{2}, \mathrm{CO}_{2}$ e $\mathrm{CH}_{4}$ produzidos ao longo do ciclo na condição 1. 


\subsection{Condição experimental 2}

\subsubsection{Monitoramento ao final do ciclo}

Nessa condição experimental o reator foi operado em bateladas sequenciais com COAV nominal de $12 \mathrm{kgDQO} \cdot \mathrm{m}^{-3} \cdot \mathrm{d}^{-1}$ e duração do ciclo de 3 horas por um período de 29 dias. A Tabela 5.6 ilustra as variáveis monitoradas e seus respectivos valores médios.

A Figura 5.21 exibe os valores da concentração de carboidratos afluente e efluente (amostras filtradas e não filtradas). A média da concentração afluente foi de $3182 \mathrm{mgSAC}$.L $^{-}$ ${ }^{1}$, enquanto que a concentração residual foi de $39 \mathrm{mgSAC} . \mathrm{L}^{-1}$. A média da eficiência de remoção com base em amostras filtradas foi de 99\%, sendo que a Figura 5.21 exibe o comportamento ao longo da operação.

A Figura 5.22 mosta os valores da eficiência de remoção de carboidratos, pela qual pode ser obseravada a estabilidade do processo durante todo o período, alcançando uma média de remoção de $99 \%$.

A média da concentração de matéria orgânica afluente foi de $3673 \mathrm{mgDQO} \cdot \mathrm{L}^{-1}$ e as análises de efluente feitas em amostras filtradas e não filtradas resultaram em médias de 3152 e $3215 \mathrm{mgDQO} . \mathrm{L}^{-1}$, respectivamente, cujos valores são mostrados na Figura 5.23. A eficiência de remoção de DQO, com relação a amostras filtradas e não filtradas, mostrou-se relativamente baixa, 14 e $13 \%$ em média, respectivamente, cujos valores podem ser observados na Figura 5.24. 
Tabela 5.6: Valores médios dos parâmetros monitorados na condição 2.

\begin{tabular}{|c|c|c|c|c|c|c|c|c|c|c|c|c|c|}
\hline \multirow{2}{*}{$\frac{\text { Parâmetro }}{\mathrm{C}_{\mathrm{ST}}}$} & & \multicolumn{3}{|c|}{ Afluente } & \multicolumn{9}{|c|}{ Efluente } \\
\hline & {$\left[\mathrm{mgDQO} \cdot \mathrm{L}^{-1}\right]$} & 3673 & \pm & 149 & c & 25 & ) & 3216 & \pm & 190 & ( & 25 & $\overline{3}$ \\
\hline$\varepsilon_{\mathrm{ST}}$ & {$[\%]$} & - & & - & & & & 12 & \pm & 5 & ( & 25 & ) \\
\hline $\mathrm{C}_{\mathrm{SF}}$ & {$\left[\mathrm{mgDQO} \cdot \mathrm{L}^{-1}\right]$} & - & & - & & & & 3152 & \pm & 151 & ( & 25 & ) \\
\hline$\varepsilon_{\mathrm{SF}}$ & {$[\%]$} & - & & - & & & & 14 & \pm & 4 & c & 25 & ) \\
\hline $\mathrm{C}_{\mathrm{CT}}$ & {$\left[\mathrm{mgSAC} \cdot \mathrm{L}^{-1}\right]$} & 3182 & \pm & 102 & ( & 25 & ) & 69 & \pm & 27 & ( & 25 & ) \\
\hline $\mathrm{C}_{\mathrm{CF}}$ & {$\left[\mathrm{mgSAC} . \mathrm{L}^{-1}\right]$} & - & & - & & & & 32 & \pm & 4 & c & 25 & ) \\
\hline$\varepsilon_{\mathrm{CT}}$ & {$[\%]$} & - & & - & & & & 98 & \pm & 1 & ( & 25 & ) \\
\hline$\varepsilon_{\mathrm{CF}}$ & {$[\%]$} & - & & - & & & & 99 & \pm & 1 & ( & 25 & ) \\
\hline AVT & {$\left[\mathrm{mgHAc} . \mathrm{L}^{-1}\right]$} & 26 & \pm & 6 & c & 22 & ) & 707 & \pm & 102 & ( & 22 & ) \\
\hline AT & {$\left[\mathrm{mgCaCO}_{3} \cdot \mathrm{L}^{-1}\right]$} & 549 & \pm & 55 & c & 22 & ) & 316 & \pm & 50 & ( & 22 & ) \\
\hline $\mathrm{pH}$ & & 7,3 & \pm & 0,1 & c & 22 & ) & 5,0 & \pm & 0,1 & ( & 22 & ) \\
\hline ST & {$\left[\mathrm{mg} . \mathrm{L}^{-1}\right]$} & 4169 & \pm & 268 & c & 7 & ) & 1676 & \pm & 1099 & ( & 7 & ) \\
\hline SVT & {$\left[\mathrm{mg} . \mathrm{L}^{-1}\right]$} & 3475 & \pm & 249 & c & 7 & ) & 1512 & \pm & 281 & ( & 7 & ) \\
\hline SST & {$\left[\mathrm{mg} . \mathrm{L}^{-1}\right]$} & 79 & \pm & 11 & c & 7 & ) & 4242 & \pm & 7072 & ( & 7 & ) \\
\hline SSV & {$\left[\mathrm{mg} \cdot \mathrm{L}^{-1}\right]$} & 51 & \pm & 18 & c & 7 & ) & 247 & \pm & 182 & c & 7 & ) \\
\hline $\mathrm{V}_{\mathrm{G}}$ & {$[\mathrm{mL}]$} & - & & - & & & & 836 & \pm & 29 & ( & 3 & ) \\
\hline $\mathrm{V}_{\mathrm{H} 2}$ & {$[\mathrm{~mL}]$} & - & & - & & & & 277 & \pm & 25 & ( & 3 & ) \\
\hline $\mathrm{C}_{\mathrm{X} \text {-SVT }}^{\prime}$ & [g.g-suporte ${ }^{-1}$ ] & 0,015 & & & & & & & & & & & \\
\hline $\mathrm{C}_{\mathrm{X} \text {-svT }}$ & {$\left[\mathrm{g} . \mathrm{L}^{-1}\right]$} & 4,95 & & & & & & & & & & & \\
\hline $\mathrm{COAV}_{\mathrm{STA}}$ & {$\left[\mathrm{kgDQO} \cdot \mathrm{m}^{-3} \cdot \mathrm{d}^{-1}\right]$} & 12,4 & & - & & & & - & & - & & & \\
\hline $\mathrm{CORV}_{\mathrm{SFE}}$ & {$\left[\mathrm{kgDQO} \cdot \mathrm{m}^{-3} \cdot \mathrm{d}^{-1}\right]$} & - & & - & & & & 1,8 & & - & & & \\
\hline $\mathrm{COAV}_{\mathrm{CTA}}$ & {$\left[\mathrm{kgSAC} \cdot \mathrm{m}^{-3} \cdot \mathrm{d}^{-1}\right]$} & 10,7 & & - & & & & - & & - & & & \\
\hline $\mathrm{CORV}_{\mathrm{CTFE}}$ & {$\left[\mathrm{kgSAC} \cdot \mathrm{m}^{-3} \cdot \mathrm{d}^{-1}\right]$} & - & & - & & & & 10,6 & & - & & & \\
\hline $\mathrm{M}_{\mathrm{SVT}}$ & {$[\mathrm{g}]$} & - & & - & & & & 22,3 & \pm & 0,5 & ( & 3 & ) \\
\hline $\mathrm{n}_{\mathrm{H} 2}$ & {$\left[\mathrm{molH}_{2} \cdot \mathrm{d}^{-1}\right]$} & - & & - & & & & 0,12 & & - & & & \\
\hline PrM & {$\left[\mathrm{molH}_{2} \cdot \mathrm{m}^{-3} \cdot \mathrm{d}^{-1}\right]$} & 16,9 & & - & & & & - & & - & & & \\
\hline PrME & {$\left[\mathrm{molH}_{2} \cdot \mathrm{kgSVT}^{-1} \cdot \mathrm{d}^{-1}\right]$} & 5,54 & & - & & & & - & & - & & & \\
\hline $\mathrm{RMCA}_{\mathrm{C}, \mathrm{m}}$ & {$\left[\mathrm{molH}_{2} \cdot \mathrm{kgSAC}^{-1}\right]$} & 2,55 & & - & & & & - & & - & & & \\
\hline $\mathrm{RMCA}_{\mathrm{S}, \mathrm{m}}$ & {$\left[\mathrm{molH}_{2} \cdot \mathrm{kgDQO}^{-1}\right]$} & 2,21 & & - & & & & - & & - & & & \\
\hline $\mathrm{RMCR}_{\mathrm{C}, \mathrm{m}}$ & {$\left[\mathrm{molH}_{2} \cdot \mathrm{kgSAC}^{-1}\right]$} & - & & - & & & & 2,58 & & - & & & \\
\hline $\mathrm{RMCR}_{\mathrm{S}, \mathrm{m}}$ & {$\left[\mathrm{molH}_{2} \cdot \mathrm{kgDQO}^{-1}\right]$} & - & & - & & & & 15,6 & & - & & & \\
\hline $\mathrm{V}_{\mathrm{T}}$ & {$[\mathrm{L}]$} & 4,5 & \pm & 0,1 & c & 25 & ) & - & & - & & & \\
\hline $\mathrm{V}_{\mathrm{F}}$ & {$[\mathrm{L}]$} & 1,9 & \pm & 0,1 & ( & 25 & ) & - & & - & & & \\
\hline
\end{tabular}




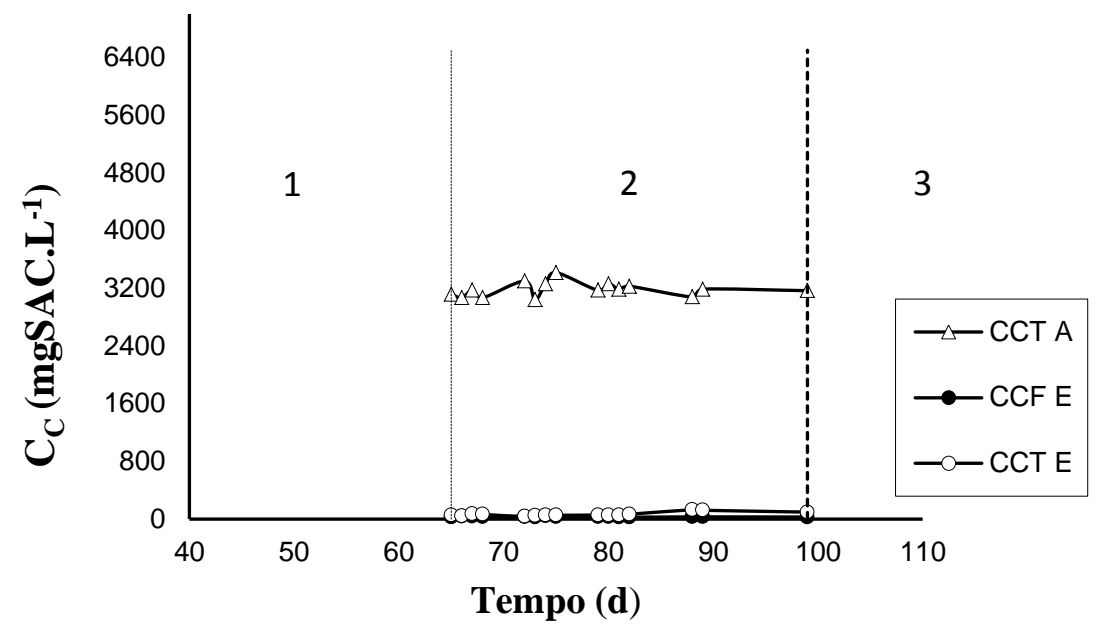

Figura 5.21: Concentração de carboidratos afluente e efluente para amostras filtradas e não filtradas na condição 2.

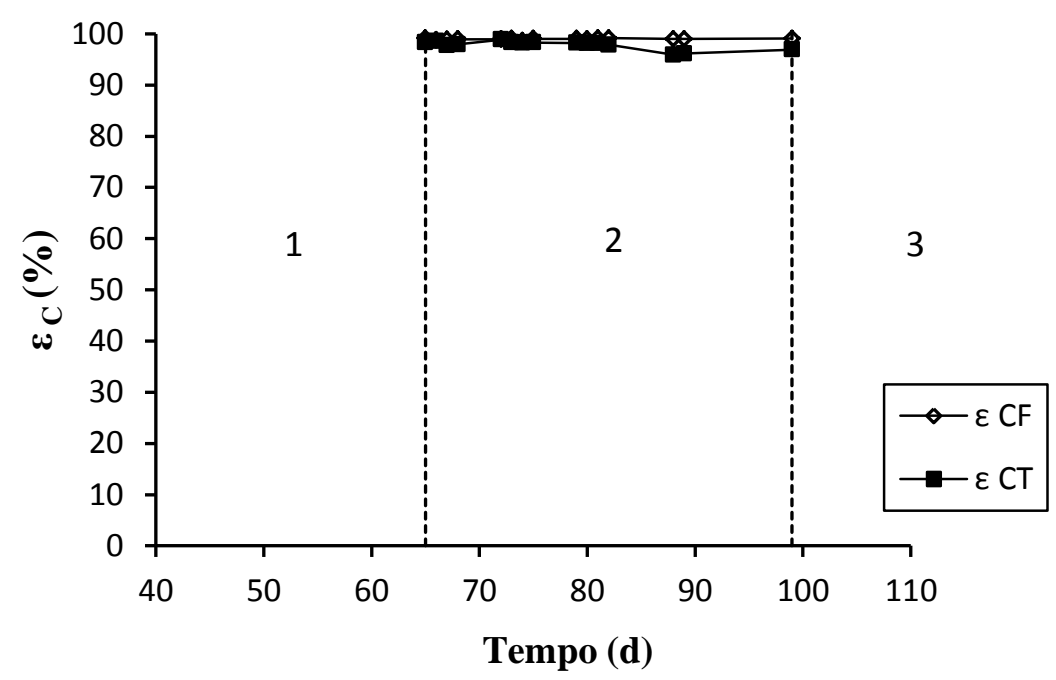

Figura 5.22: Eficiência de remoção de carboidratos para amostras filtradas na condição 2. 


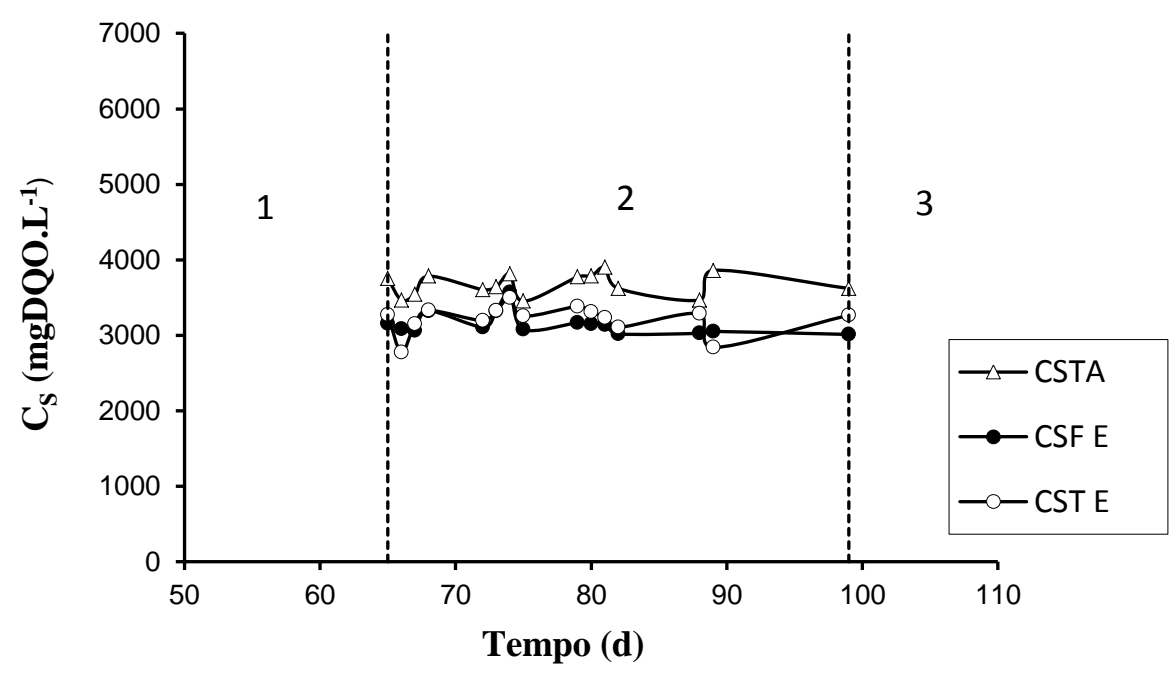

Figura 5.23: Concentração de matéria orgânica (DQO) afluente e efluente para amostras filtradas e não filtradas na condição 2 .

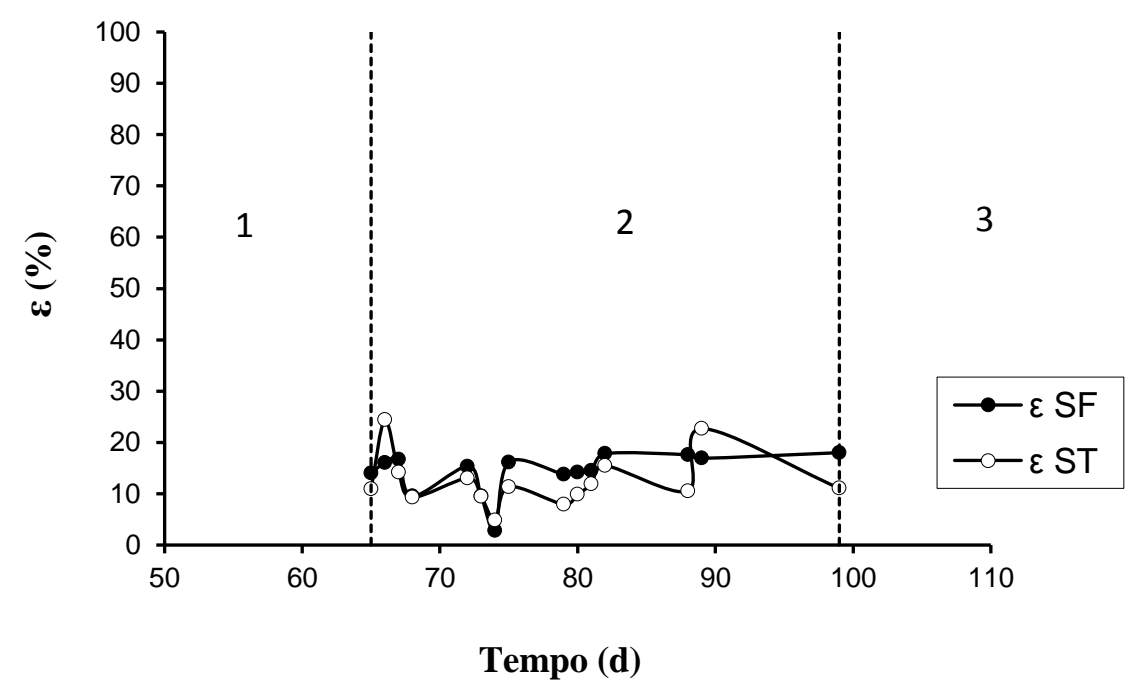

Figura 5.24: Eficiência de remoção de matéria orgânica (DQO) para amostras filtradas e não filtradas na condição 2 . 
A Tabela 5.7 apresenta os valores da concentração média dos compostos intermediários, obtidos em triplicata, contidos no efluente do sistema. O método cromatográfico aplicado não detectou acetona e metanol. A Figura 5.25 mostra a concentração dos ácidos no efluente e afluente. A concentração média de ácidos no efluente foi de $679 \mathrm{mgHAc} . \mathrm{L}^{-1}$ enquanto que no afluente foi de $24 \mathrm{mgHAc} . \mathrm{L}$.

Tabela 5.7: Concentração dos compostos intermediários na condição 2.

\begin{tabular}{|c|c|c|c|c|c|c|c|}
\hline \multirow{3}{*}{$\begin{array}{c}\begin{array}{c}\text { Produtos } \\
\text { intermediários }\end{array} \\
\text { Acetona }\end{array}$} & \multicolumn{6}{|c|}{ Concentração média } & \multirow{3}{*}{$\begin{array}{c}\begin{array}{c}\text { Porcentagem } \\
(\%)\end{array} \\
0,0\end{array}$} \\
\hline & \multicolumn{3}{|c|}{$\mathrm{mg} . \mathrm{L}^{-1}$} & \multicolumn{3}{|c|}{ mmol.L $\mathrm{L}^{-1}$} & \\
\hline & - & \pm & - & - & \pm & - & \\
\hline Metanol & - & \pm & - & - & \pm & - & 0,0 \\
\hline Etanol & 202,2 & \pm & 0,8 & 4,3 & \pm & 0,0 & 97,1 \\
\hline n-Butanol & 6,0 & \pm & 0,1 & 0,1 & \pm & 0,0 & 2,9 \\
\hline Acético & 623,0 & \pm & 3,5 & 10,4 & \pm & 0,1 & 44,0 \\
\hline Porpiônico & 55,2 & \pm & 10,2 & 0,7 & \pm & 0,1 & 3,9 \\
\hline Isobutírico & 131,5 & \pm & 43,8 & 1,5 & \pm & 0,5 & 9,3 \\
\hline Butírico & 267,2 & \pm & 74,5 & 3,0 & \pm & 0,8 & 18,9 \\
\hline Isovalérico & 10,2 & \pm & 1,2 & 0,1 & \pm & 0,0 & 0,7 \\
\hline Valérico & 47,4 & \pm & 10,5 & 0,5 & \pm & 0,1 & 3,3 \\
\hline Capróico & 282,1 & \pm & 67,4 & 2,4 & \pm & 0,6 & 19,9 \\
\hline
\end{tabular}

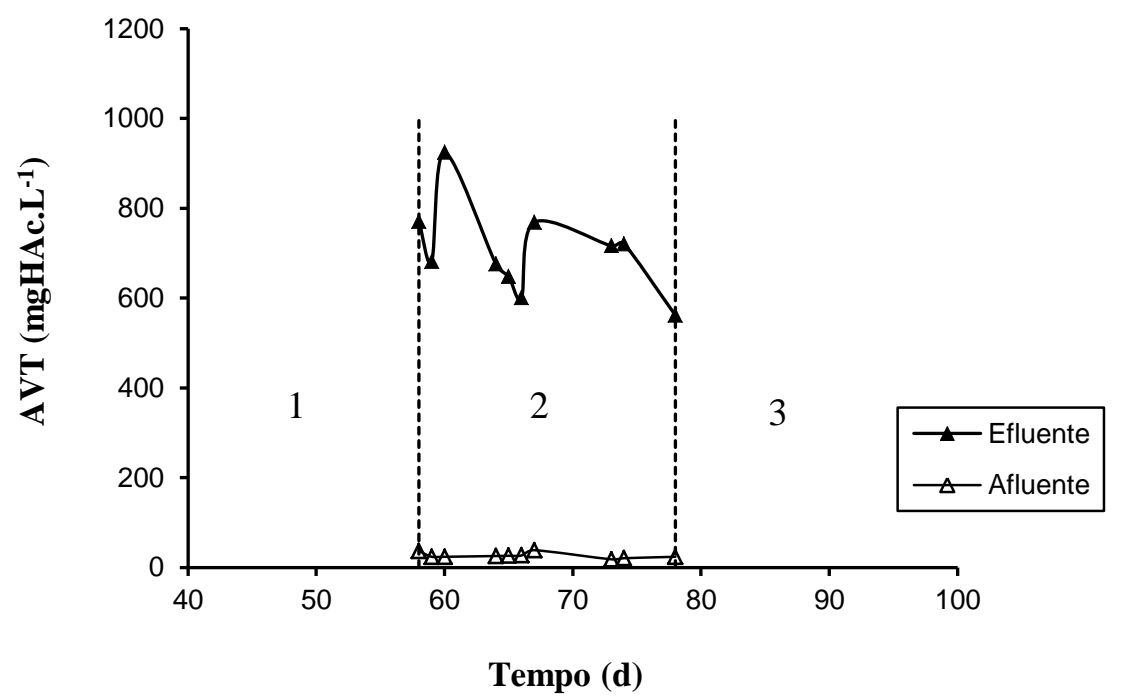

Figura 5.25: Concentração de ácidos voláteis totais afluente e efluente na condição 2. 
O acúmulo de ácidos orgânicos no interior do reator provocaram a redução instantânea do $\mathrm{pH}$ assim que o afluente entrava em contato com o meio residual no interior do reator. A Figura 5.26, apresenta os valores de $\mathrm{pH}$, afluente e efluente, ao longo do período experimental. $\mathrm{O}$ valor médio do $\mathrm{pH}$ afluente foi de 7,3 e de 4,9 para o efluente.

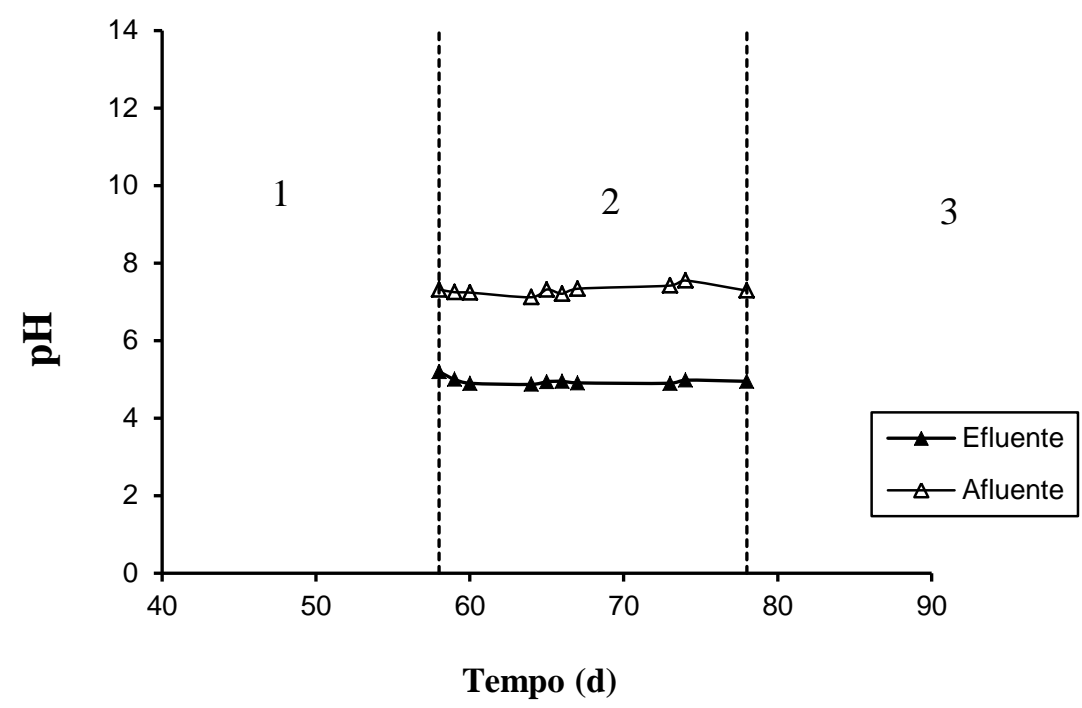

Figura 5.26: Valores de $\mathrm{pH}$ afluente e efluente na condição 2.

A Figura 5.27 apresenta as concentrações, afluente e efluente, da alcalinidade ao longo da operação. Os valores médios de alcalinidade foi de 550 e $316 \mathrm{mgCaCO}_{3} \cdot \mathrm{L}^{-1}$ para o afluente e efluente, respectivamente.

O monitoramento da série de sólidos é mostrado na Tabela 5.8, cujos valores indicam um baixo teor de SSV no efluente e afluente.

A produção do biogás, em aspecto quantitativo, pode ser observada na Figura 5.28. A média de produção foi de 784 mL (CNTP). 


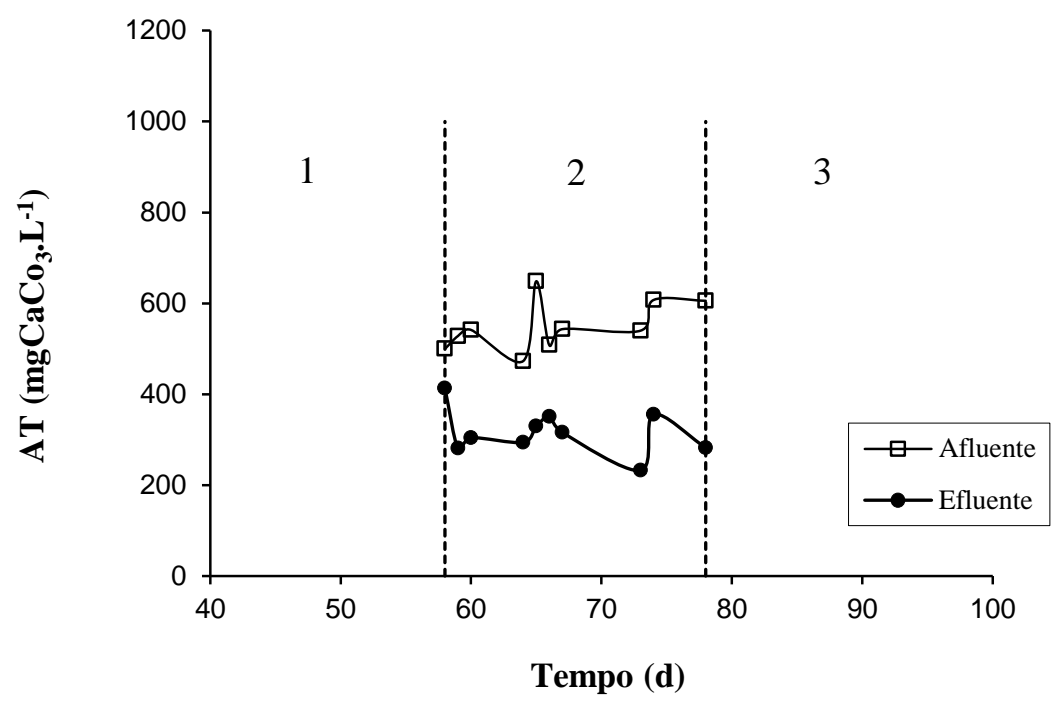

Figura 5.27: Concentração de alcalinidade total afluente e efluente na condição 2.

Tabela 5.8: Série de sólidos afluente e efluente na condição 2.

\begin{tabular}{lcccc}
\hline & $\begin{array}{c}\mathrm{ST} \\
\left(\mathrm{mg} . \mathrm{L}^{-1}\right)\end{array}$ & $\begin{array}{c}\mathrm{SVT} \\
\left(\mathrm{mg} . \mathrm{L}^{-1}\right)\end{array}$ & $\begin{array}{c}\mathrm{SST} \\
\left(\mathrm{mg} . \mathrm{L}^{-1}\right)\end{array}$ & $\begin{array}{c}\mathrm{SSV} \\
\left(\mathrm{mg}^{-1} \mathrm{~L}^{-1}\right)\end{array}$ \\
\hline Afluente & $4418 \pm 184$ & $3608 \pm 68$ & $129 \pm 78$ & $45 \pm 28$ \\
Efluente & $2165 \pm 277$ & $1512 \pm 281$ & $150 \pm 71$ & $247 \pm 182$ \\
\hline \multicolumn{5}{c}{ *Número de amostras consideradas $=3}$.
\end{tabular}

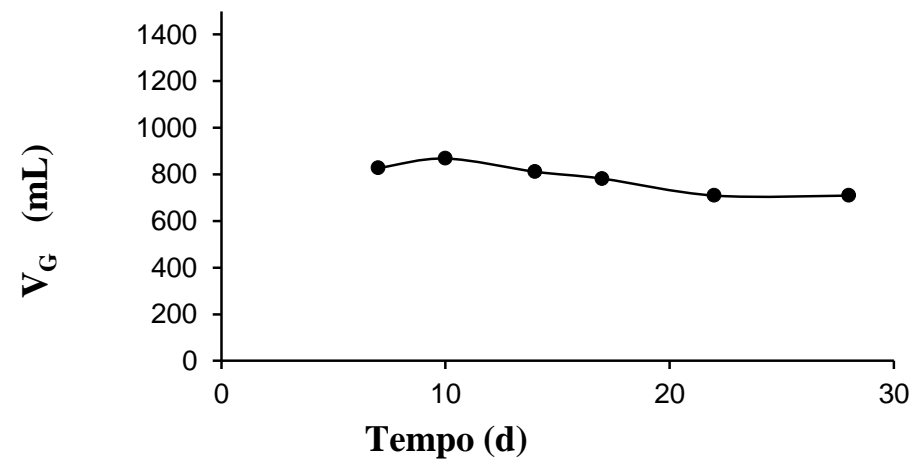

Figura 5.28: Volume total de biogás produzido na condição 2. 


\subsubsection{Monitoramento ao longo do ciclo}

A Figura 5.29 apresenta os valores de carboidratos ao longo do perfil de operação. No tempo inicial o valor da concentração é de 2619 mgSAC. $\mathrm{L}^{-1}$. A redução imediata da concentração inicial deve-se ao volume residual de meio existente no interior do recipiente de recirculação. Como pode ser observado na Figura 5.29(a) e 5.29(b), após 1,5 horas de ciclo praticamente todo o substrato é removido, atingindo uma eficiência de $99 \%$ com um residual de $33 \mathrm{mgSAC} . \mathrm{L}^{-1}$ ao final das 4 horas de ciclo.

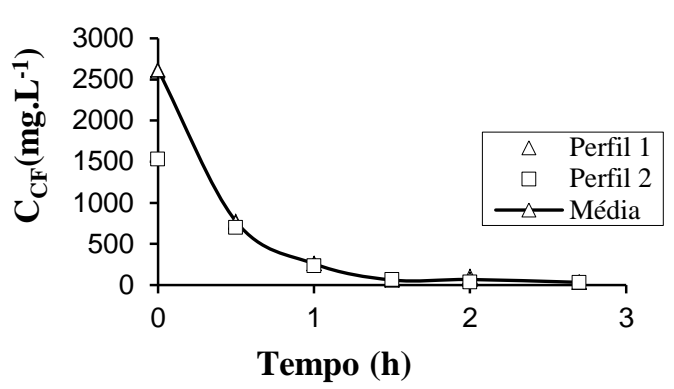

(a)

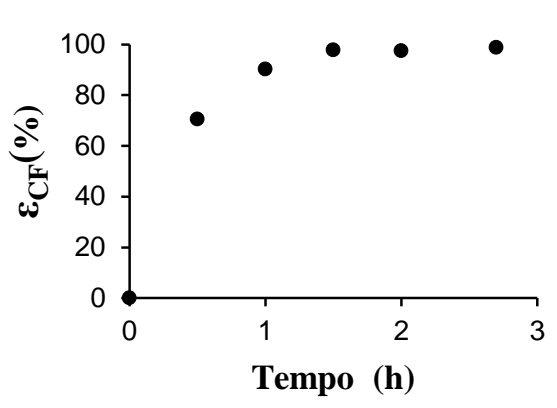

(b)

Figura 5.29: (a) Concentração de carboidratos e (b) eficiência de remoção para amostras filtradas ao longo do ciclo na condição 2 .

A Figura 5.30 representa o comportamento da matéria orgânica ao longo do ciclo. No inicio do ciclo, a concentração é de $3664 \mathrm{mgDQO} . \mathrm{L}^{-1}$ reduzindo a $2883 \mathrm{mgDQO} . \mathrm{L}^{-1}$ em 1 hora de ciclo, após esse período, há um ligeiro aumento até o último ponto do ciclo, chegando ao valor de $2988 \mathrm{mgDQO} \cdot \mathrm{L}^{-1}$. 


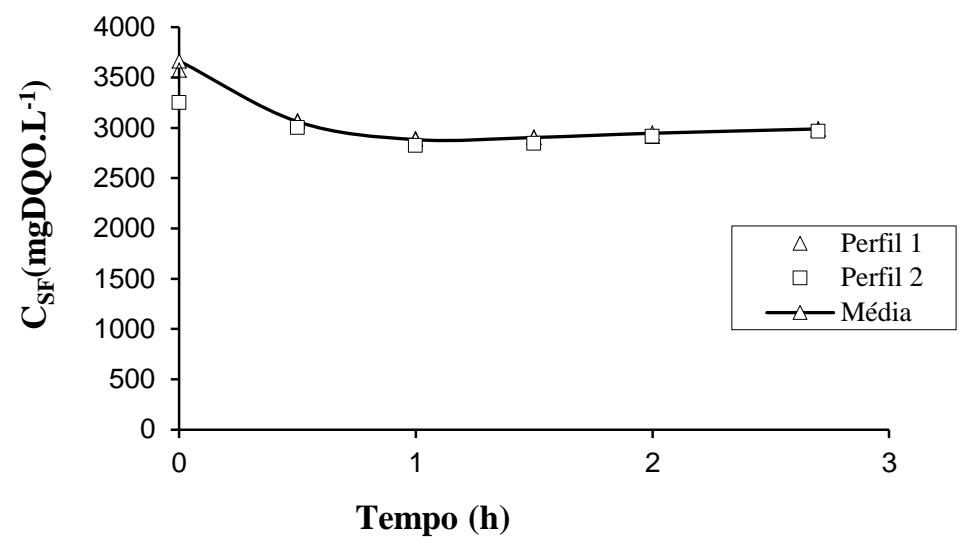

Figura 5.30: Concentração de matéria orgânica (DQO) para amostras filtradas ao longo do ciclo na condição 2 .

A produção de ácidos voláteis é representada na Figura 5.31. No tempo inicial a concentração de ácidos é de 107 mgHAc. $\mathrm{L}^{-1}$, tendo um crescimento acentuado em 1,5 horas, atingindo o valor de $723 \mathrm{mgHAc} . \mathrm{L}^{-1}$, seguido de um aumento menos acentuado, chegando ao valor de $799 \mathrm{mgHAc} . \mathrm{L}^{-1}$ ao final do ciclo. A média da concentração de ácidos voláteis ao longo do ciclo foi de $573 \mathrm{mgHAc} . \mathrm{L}^{-1}$.

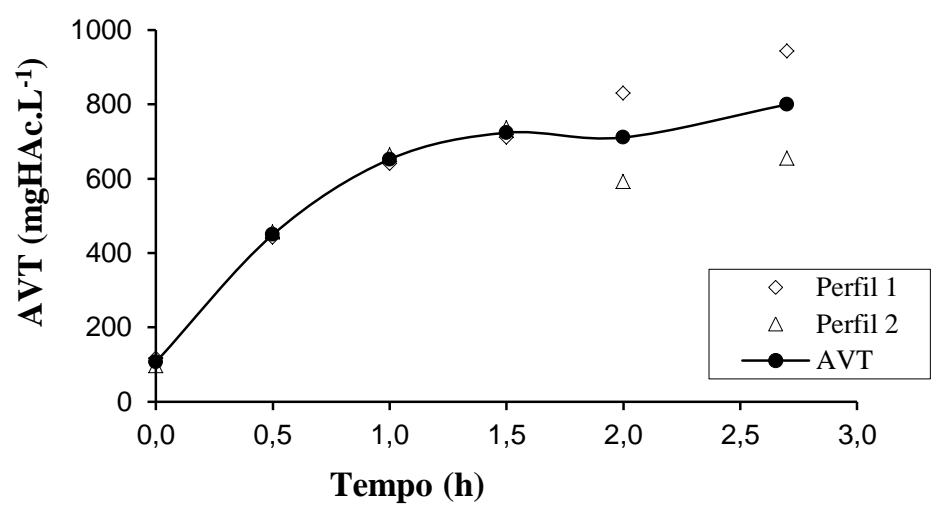

Figura 5.31: Concentração de ácidos voláteis totais ao longo do ciclo na condição 2. 


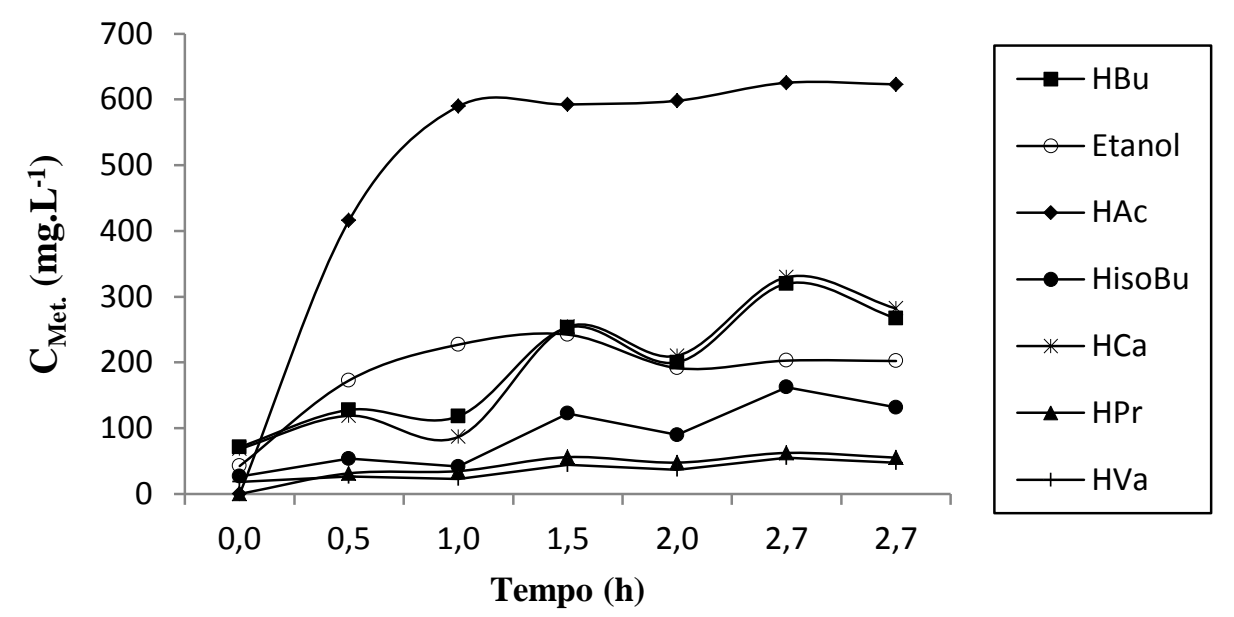

Figura 5.32: Concentração dos compostos intermediários ao longo do ciclo na condição 2.

A Figura 5.32 permite observar a predominância do ácido acético, mostrando um crescimento acentuado em 1 hora de ciclo, chegando a $590 \mathrm{mg} . \mathrm{L}^{-1}$, e estabilizando a partir desse ponto, atingindo o valor de $623 \mathrm{mg} . \mathrm{L}^{-1}$ ao final do ciclo de 3 horas. A Figura 5.33 apresenta o comportamento da alcalinidade ao longo do ciclo. No inicio do ciclo a alcalinidade é de $525 \mathrm{mgCaCO} \cdot \mathrm{L}^{-1}$, reduzindo para $330 \mathrm{mgCaCO}_{3} \cdot \mathrm{L}^{-1}$ em 1 hora de ciclo, permanecendo estável até o término do ciclo de 3 horas.

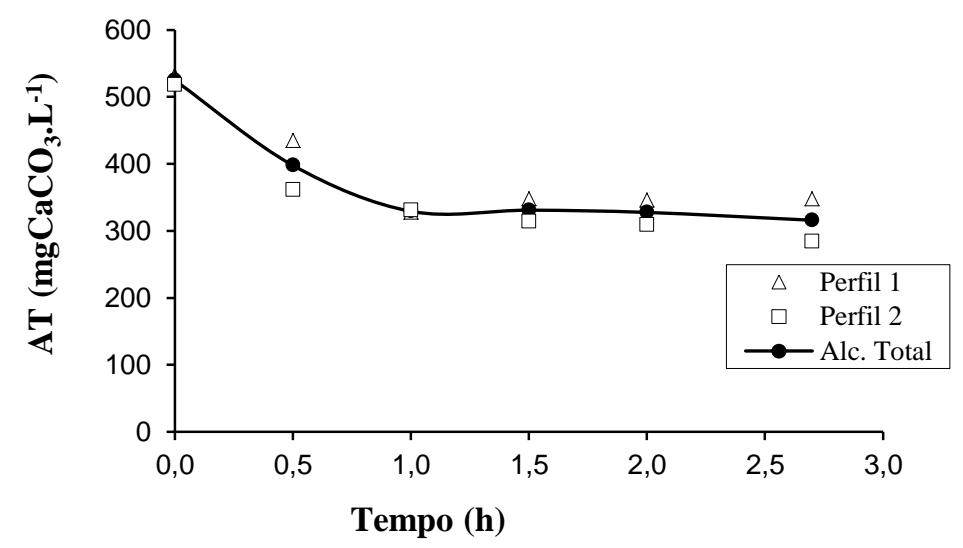

Figura 5.33: Concentração de alcalinidade total ao longo do ciclo na condição 2. 
$\mathrm{O}$ perfil dos valores de $\mathrm{pH}$ mostrados na Figura 5.34 indicam que o valor inicial de 6,5 é reduzido ao valor de 4,9 devido aos ácidos voláteis no interior do reator, mantendo-se constante durante todo o ciclo, demonstrando a estabilidade do mesmo.

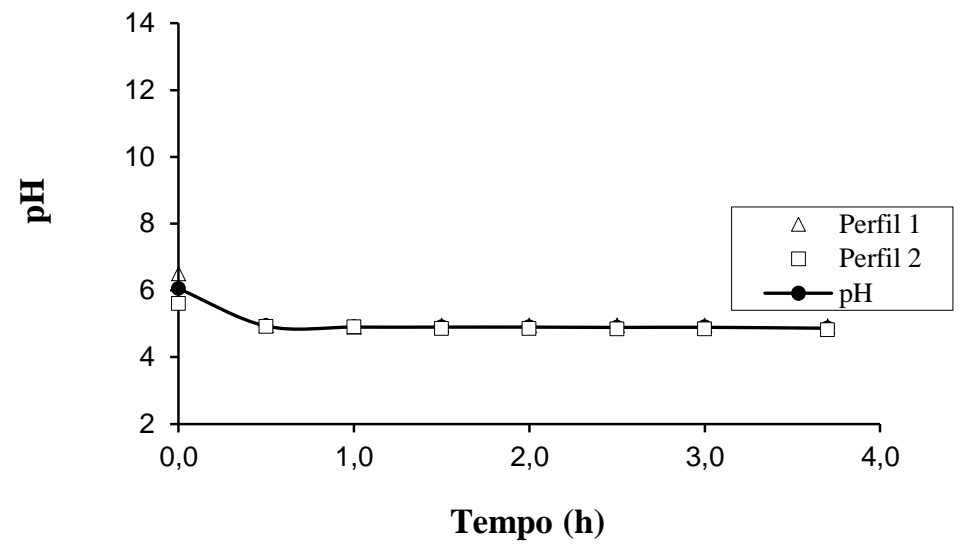

Figura 5.34: Valores de pH ao longo do ciclo na condição 2.

A Figura 5.35 permite observar que a produção do biogás é crescente no início do ciclo (1 hora), atingindo o valor médio de $805 \mathrm{~mL}$ (CNTP), seguido de um crescimento menos acentuado e atingindo $847 \mathrm{~mL}$ (CNTP) ao final do ciclo. A Tabela 5.9 resume os valores da produção, concentração, fração molar e os volumes individuais da mistura gasosa. A Figura 5.20 apresenta os volumes de $\mathrm{H}_{2}, \mathrm{CO}_{2}$ e $\mathrm{CH}_{4}$ produzidos durante o ciclo. Nos primeiros 30 minutos são produzidos $153 \mathrm{~mL}$ de $\mathrm{H}_{2}$, atingindo o valor máximo de $261 \mathrm{~mL}$ ao final das 3 horas de ciclo. Não foi detectado metano. 
Tabela 5.9: Produção e composição do biogás produzido ao longo do ciclo na condição 2.

\begin{tabular}{ccccccccccc}
\hline $\begin{array}{c}\text { Tempo } \\
(\mathrm{h})\end{array}$ & $\begin{array}{c}\mathrm{V}_{\mathrm{G}} \\
(\mathrm{mL}-\mathrm{CNTP})\end{array}$ & \multicolumn{3}{c}{$\mathrm{C}_{\mathrm{G}}\left(\mathrm{mmol} . \mathrm{L}^{-1}\right)$} & \multicolumn{3}{c}{ Fração Molar $(\%)$} & \multicolumn{3}{c}{ Volume $(\mathrm{mL})$} \\
\hline 0,0 & 0 & 0,0 & 0,0 & 0,0 & 0 & 0 & 0 & 0 & 0 & 0 \\
0,5 & 526 & 2,8 & 6,9 & 0,0 & 30 & 70 & 0 & 152 & 374 & 0 \\
1,0 & 739 & 5,1 & 6,6 & 0,0 & 42 & 58 & 0 & 245 & 494 & 0 \\
1,5 & 783 & 5,7 & 11,0 & 0,0 & 43 & 57 & 0 & 2601 & 523 & 0 \\
2,0 & 784 & 6,0 & 11,5 & 0,0 & 42 & 58 & 0 & 261 & 524 & 0 \\
2,7 & 784 & 6,0 & 11,7 & 0,0 & 41 & 59 & 0 & 261 & 524 & 0 \\
\hline
\end{tabular}

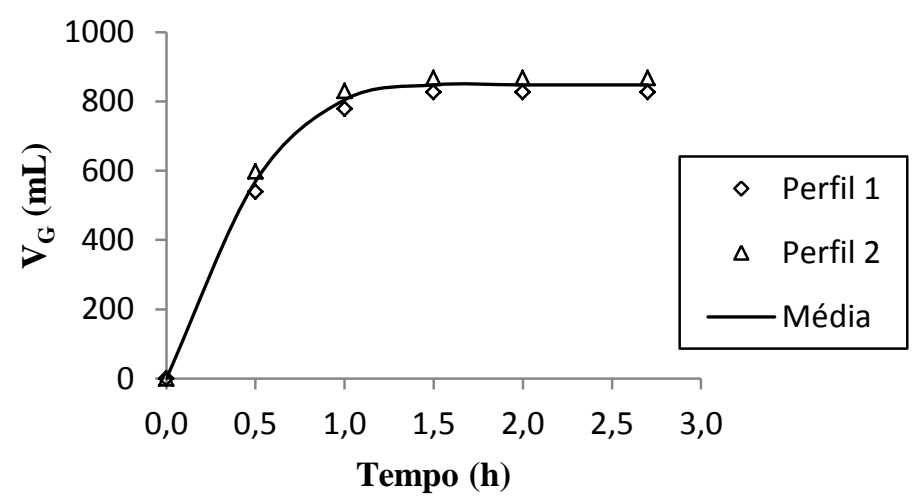

Figura 5.35: Volume total de biogás produzido ao longo do ciclo na condição 2.

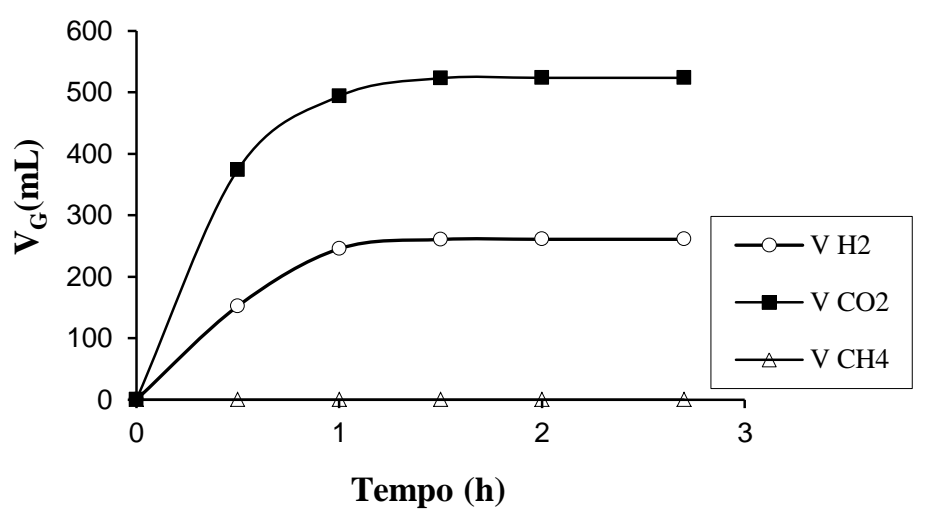

Figura 5.36: Volumes de $\mathrm{H}_{2}, \mathrm{CO}_{2}$ e $\mathrm{CH}_{4}$ produzidos ao longo do ciclo na condição 2. 


\subsection{Condição experimental 3}

\subsubsection{Monitoramento ao final do ciclo}

$\mathrm{Na}$ condição experimental 3 o reator foi operado em bateladas sequenciais com COAV nominal de $13,5 \mathrm{kgDQO} \cdot \mathrm{m}^{-3} \cdot \mathrm{d}^{-1}$ e duração do ciclo de 4 horas por um período de 41 dias. A Tabela 5.10 mostra as variáveis monitoradas e seus respectivos valores médios.

A Figura 5.37 exibe os valores da concentração de carboidratos afluente e efluente (amostras filtradas e não filtradas). A média da concentração afluente foi de $5043 \mathrm{mgSAC} . \mathrm{L}^{-1}$ enquanto que a concentração residual foi de $144 \mathrm{mgSAC} . \mathrm{L}^{-1}$. A média da eficiência de remoção com base em amostras filtradas foi de 99\%, sendo que a Figura 5.38 exibe o comportamento ao longo da operação.

A Figura 5.38 mosta os valores da eficiência de remoção de carboidratos pela qual pode ser obseravada a estabilidade do processo durante todo o período alcançando uma média de remoção de $99 \%$.

A média da concentração de matéria orgânica afluente foi de $5448 \mathrm{mgDQO} \cdot \mathrm{L}^{-1}$ e as análises de efluente feitas em amostras filtradas e não filtradas resultaram em médias de concentração de 4442 e 4653 mgDQO.L ${ }^{-1}$, respectivamente, cujos valores são mostrados na Figura 5.39. A eficiência de remoção de DQO, com relação a amostras filtradas e não filtradas, mostrou-se relativamente baixa, 19 e $15 \%$ em média, respectivamente, cujos valores podem ser observados na Figura 5.24. 
Tabela 5.10: Valores médios dos parâmetros monitorados na condição 3.

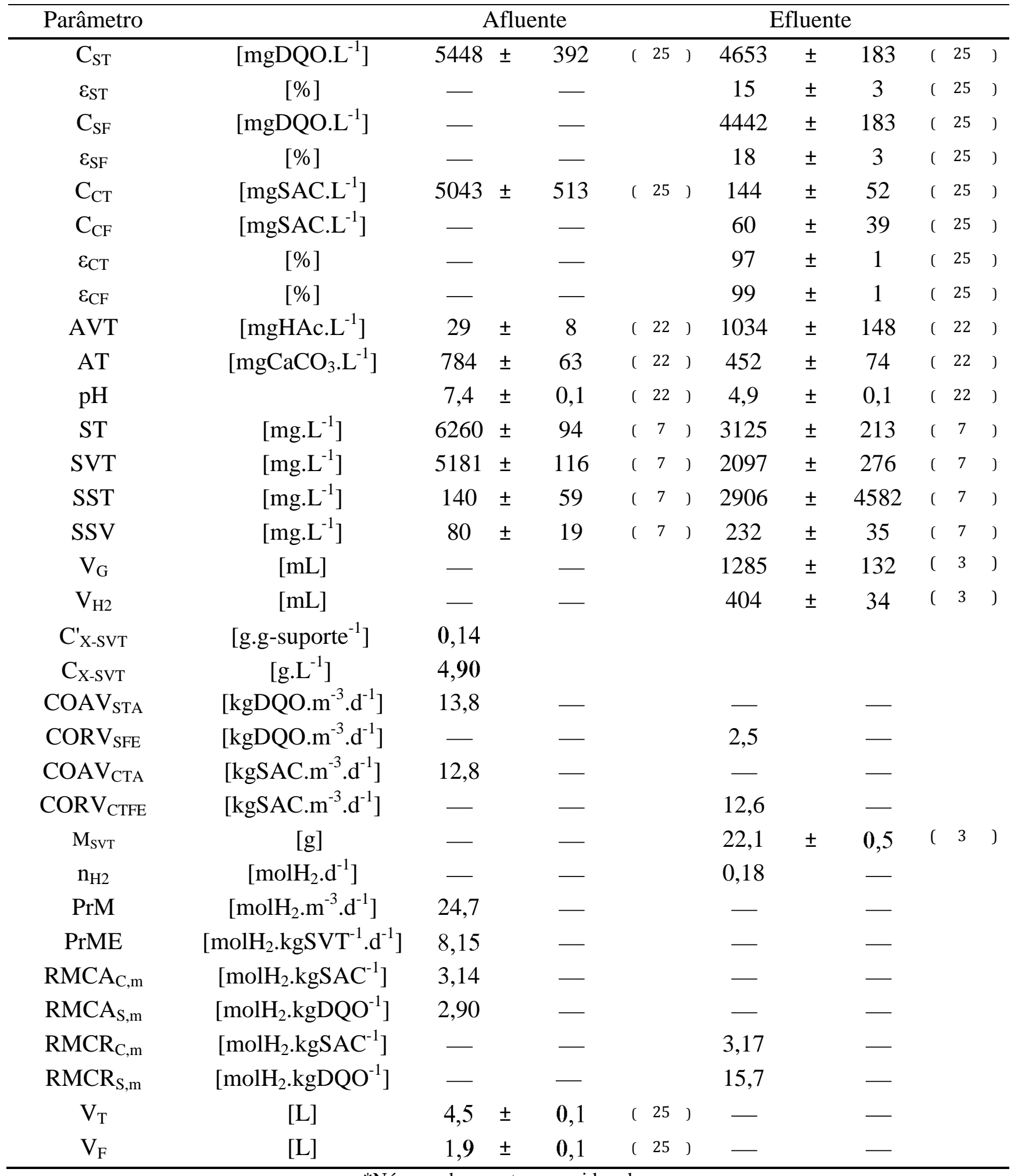

*Número de amostras consideradas. 


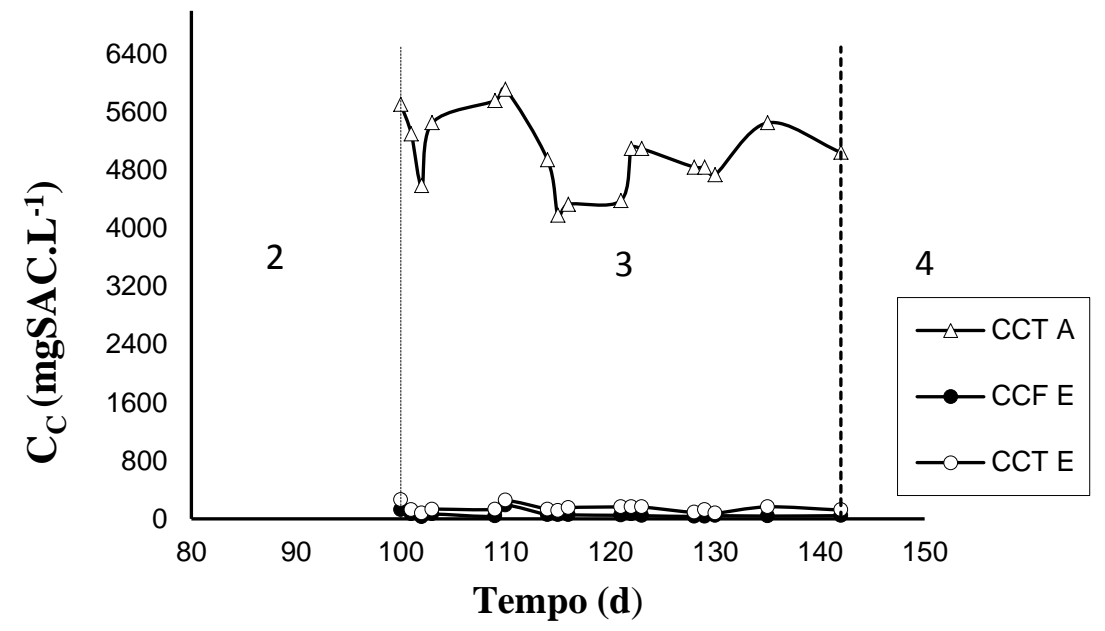

Figura 5.37: Concentração de carboidratos afluente e efluente para amostras filtradas e não filtradas na condição 3.

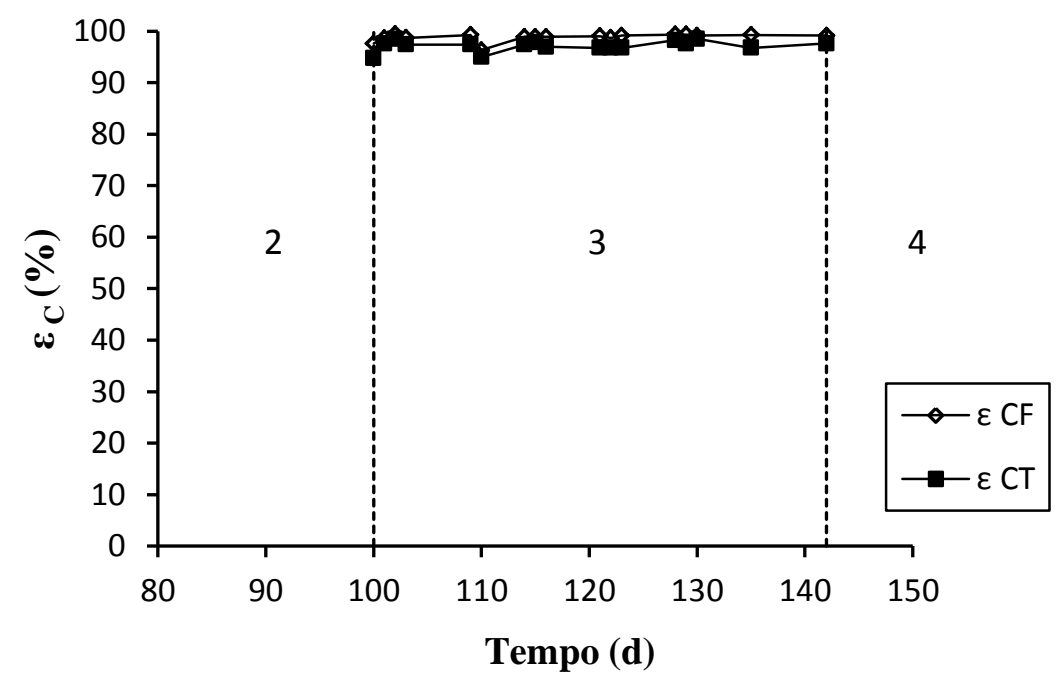

Figura 5.38: Eficiência de remoção de carboidratos para amostras filtradas na condição 3. 


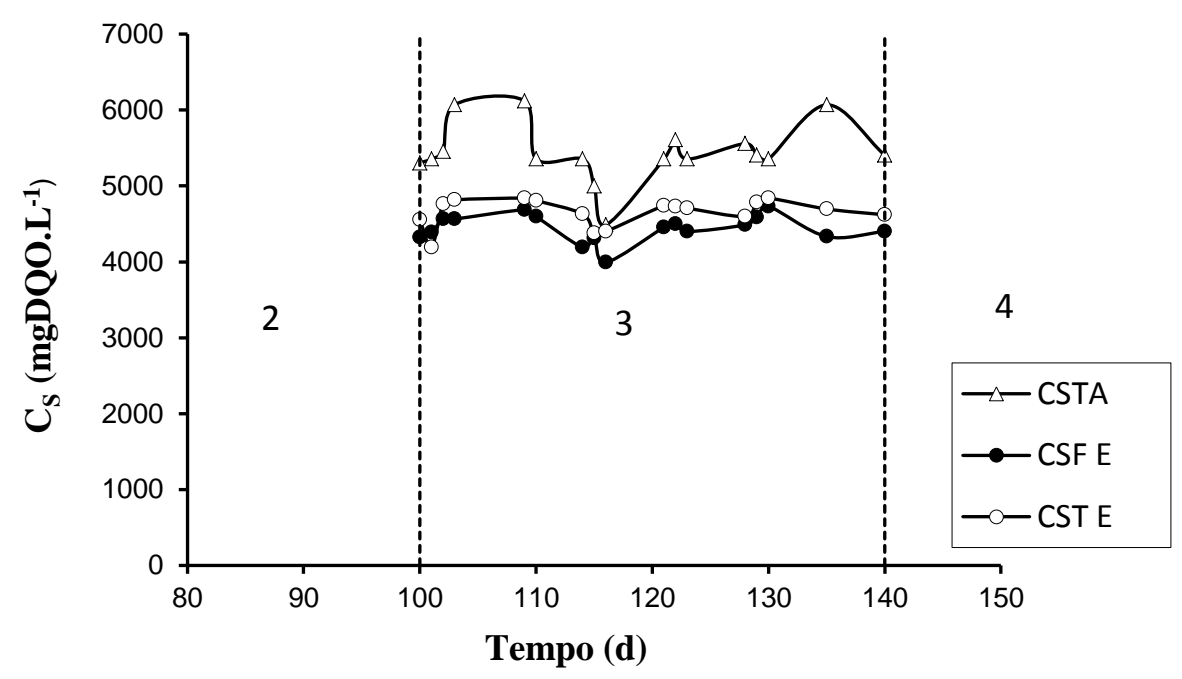

Figura 5.39: Concentração de matéria orgânica (DQO) afluente e efluente para amostras filtradas e não filtradas na condição 3 .

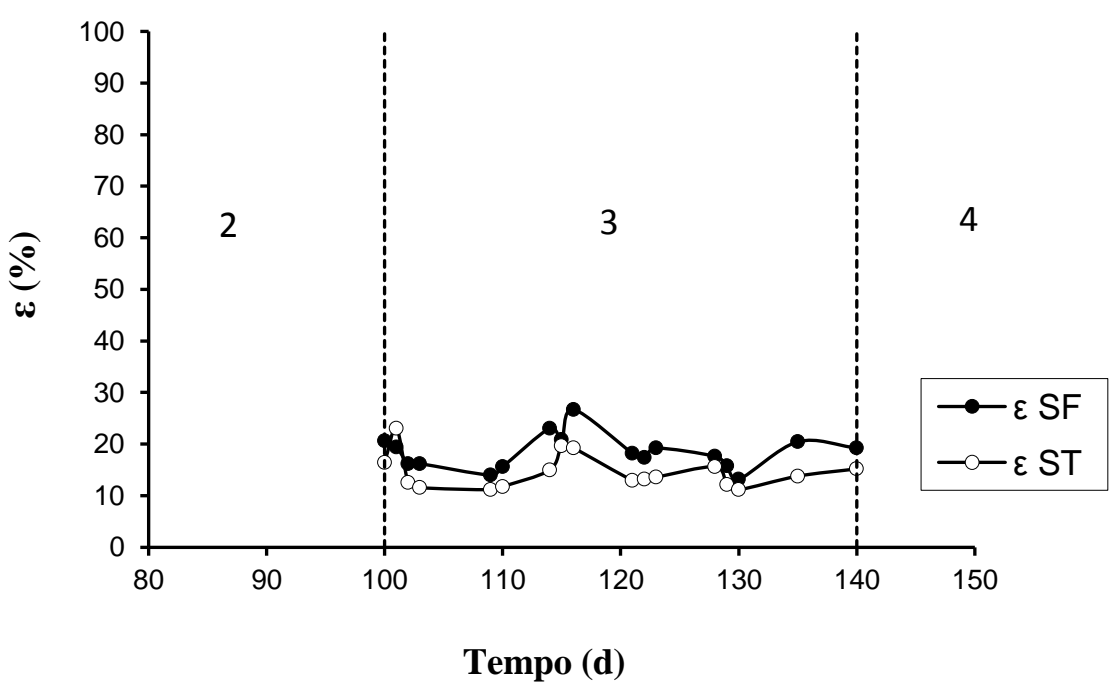

Figura 5.40: Eficiência de remoção de matéria orgânica (DQO) para amostras filtradas e não filtradas na condição 3 . 
A Tabela 5.11 apresenta os valores da concentração média dos compostos intermediários, obtidos em triplicata, contidos no efluente do sistema. O método cromatográfico aplicado não detectou acetona e metanol. A Figura 5.41 mostra a a concentração dos ácidos no efluente e afluente. A concentração média de ácidos no efluente foi de $1034 \mathrm{mgHAc} . \mathrm{L}^{-1}$ enquanto que no afluente foi de $29 \mathrm{mgHAc} . \mathrm{L}^{-1}$.

Tabela 5.11: Concentração dos compostos intermediários na condição 3.

\begin{tabular}{|c|c|c|c|c|c|c|c|}
\hline \multirow{3}{*}{$\begin{array}{c}\text { Produtos } \\
\text { intermediários }\end{array}$} & \multicolumn{6}{|c|}{ Concentração média } & \multirow{3}{*}{$\begin{array}{c}\text { Porcentagem } \\
(\%)\end{array}$} \\
\hline & \multicolumn{3}{|c|}{$\mathrm{mg} \cdot \mathrm{L}^{-1}$} & \multicolumn{3}{|c|}{ mmol.L $\mathrm{L}^{-1}$} & \\
\hline & - & \pm & - & - & \pm & - & \\
\hline Metanol & - & \pm & - & - & \pm & - & 0,0 \\
\hline Etanol & 367,0 & \pm & 23,6 & 7,9 & \pm & 0,5 & 98,6 \\
\hline n-Butanol & 5,1 & \pm & 0,1 & 0,1 & \pm & 0,0 & 1,4 \\
\hline Acético & 800,0 & \pm & 14,1 & 13,3 & \pm & 0,2 & 58,0 \\
\hline Porpiônico & 54,7 & \pm & 1,0 & 0,7 & \pm & 0,0 & 4,0 \\
\hline Isobutírico & 87,0 & \pm & 2,8 & 1,0 & \pm & 0,0 & 6,3 \\
\hline Butírico & 211,0 & \pm & 7,1 & 2,4 & \pm & 0,1 & 15,3 \\
\hline Isovalérico & 8,8 & \pm & 0,1 & 0,1 & \pm & 0,0 & 0,6 \\
\hline Valérico & 36,4 & \pm & 1,2 & 0,4 & \pm & 0,0 & 2,6 \\
\hline Capróico & 181,4 & \pm & 13,6 & 1,6 & \pm & 0,1 & 13,1 \\
\hline
\end{tabular}

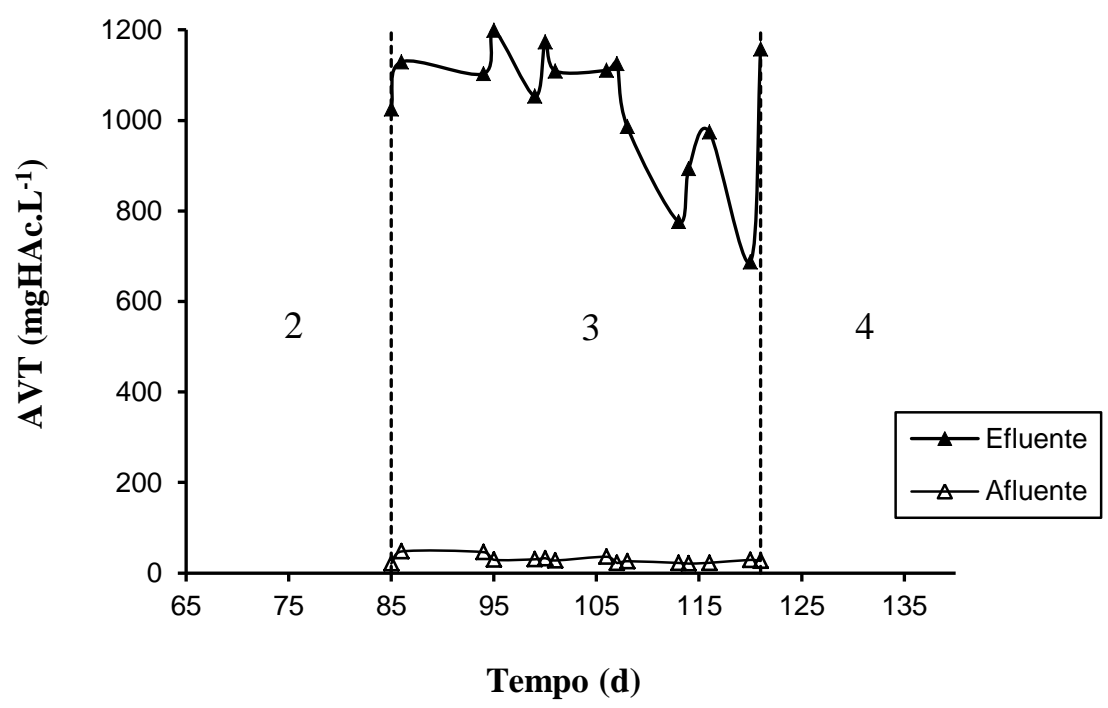

Figura 5.41: Concentração de ácidos voláteis totais afluente e efluente na condição 3. 
O acúmulo de ácidos orgânicos no interior do reator provocaram a redução instantânea do $\mathrm{pH}$ assim que o afluente entrava em contato com o meio residual no interior do reator. A Figura 5.42, apresenta os valores de $\mathrm{pH}$, afluente e efluente, ao longo do período experimental. O valor médio do $\mathrm{pH}$ afluente foi de 7,35 e de 4,9 para o efluente.

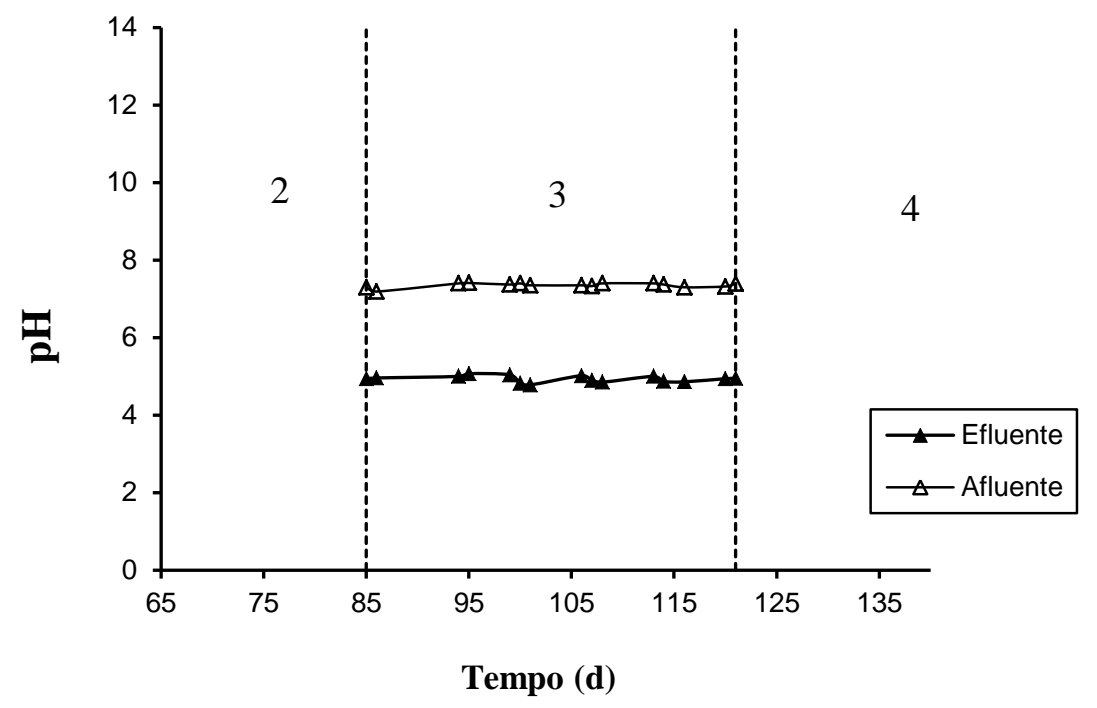

Figura 5.42: Valores de pH afluente e efluente na condição 3.

A Figura 5.27 apresenta as concentrações, afluente e efluente, da alcalinidade ao longo da operação. Os valores médios de alcalinidade foi de 550 e $316 \mathrm{mgCaCO}_{3} \cdot \mathrm{L}^{-1}$ para o afluente e efluente, respectivamente.

O monitoramento da série de sólidos é mostrado na Tabela 5.12, cujos valores indicam um baixo teor de SSV no efluente e afluente.

A produção do biogás, em aspecto quantitativo, pode ser observada na Figura 5.44. A média de produção foi de $1201 \mathrm{~mL}$ (CNTP). 


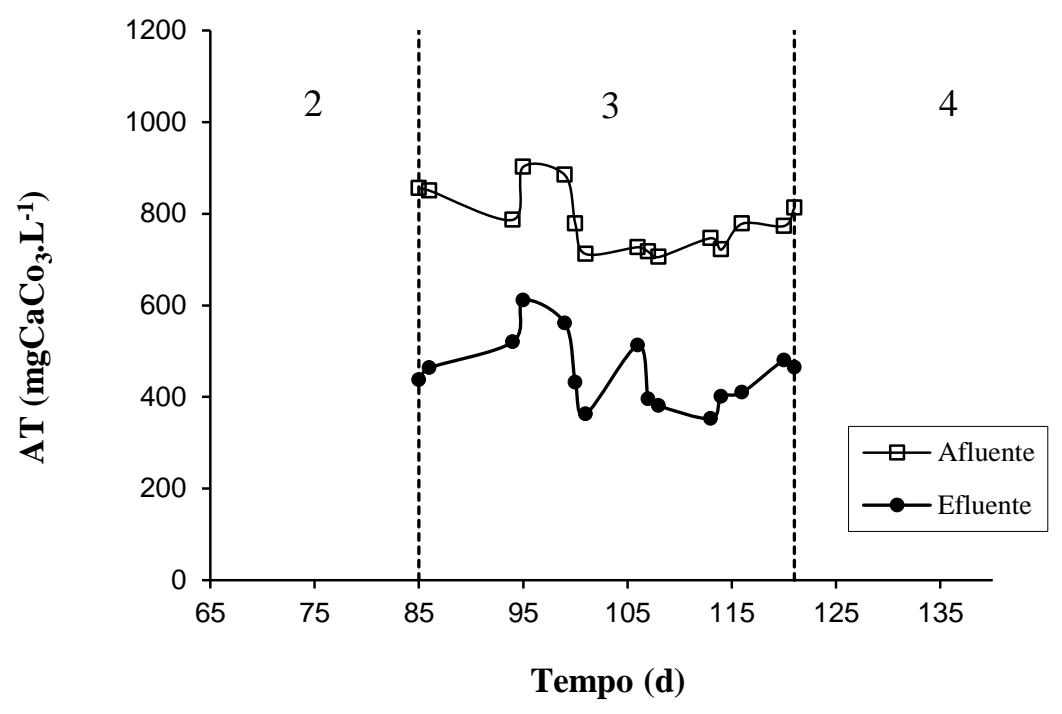

Figura 5.43: Concentração de alcalinidade total afluente e efluente na condição 3.

Tabela 5.12: Série de sólidos afluente e efluente na condição 3.

\begin{tabular}{lcccr}
\hline & $\begin{array}{c}\mathrm{ST} \\
\left(\mathrm{mg} . \mathrm{L}^{-1}\right)\end{array}$ & $\begin{array}{c}\mathrm{SVT} \\
\left(\mathrm{mg} . \mathrm{L}^{-1}\right)\end{array}$ & $\begin{array}{c}\text { SST } \\
\left(\mathrm{mg} . \mathrm{L}^{-1}\right)\end{array}$ & \multicolumn{1}{c}{$\begin{array}{c}\text { SSV } \\
\left(\mathrm{mg} . \mathrm{L}^{-1}\right)\end{array}$} \\
\hline Afluente & $6260 \pm 94$ & $5181 \pm 276$ & $140 \pm 59$ & $80 \pm 19$ \\
Efluente & $3090 \pm 213$ & $2097 \pm 276$ & $239 \pm 65$ & $232 \pm 35$ \\
\hline \multicolumn{5}{c}{ *Número de amostras consideradas $=3}$.
\end{tabular}

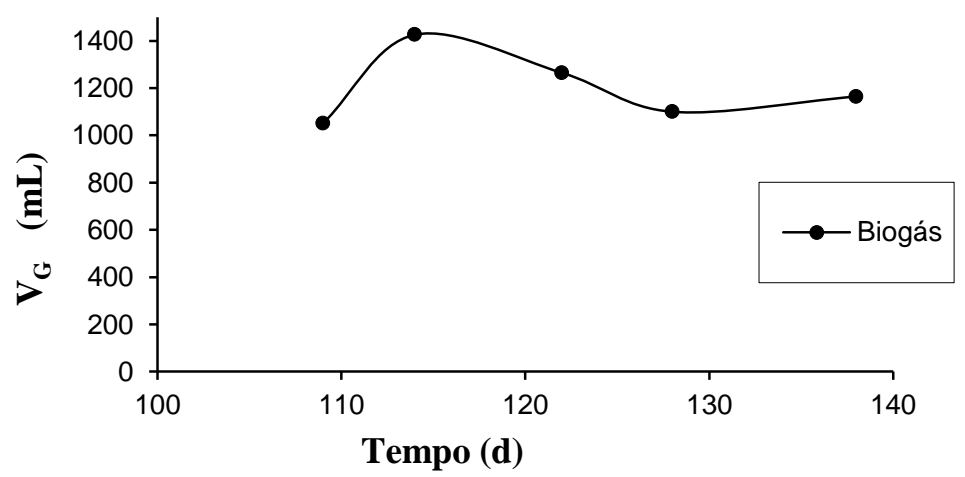

Figura 5.44: Volume total de biogás produzido na condição 3. 


\subsubsection{Monitoramento ao longo do ciclo}

A Figura 5.45 apresenta os valores de carboidratos ao longo do perfil de operação. No tempo inicial o valor da concentração é de $3371 \mathrm{mgSAC} . \mathrm{L}^{-1}$. A redução imediata da concentração inicial deve-se ao volume residual de meio existente no interior do recipiente de recirculação. Como pode ser observado na Figura 5.45(a) e 5.45(b) após 3 horas de ciclo praticamente todo substrato é removido, atingindo uma eficiência de $99 \%$ com um residual de 16 mgSAC.L ${ }^{-1}$ ao final das 4 horas de ciclo.

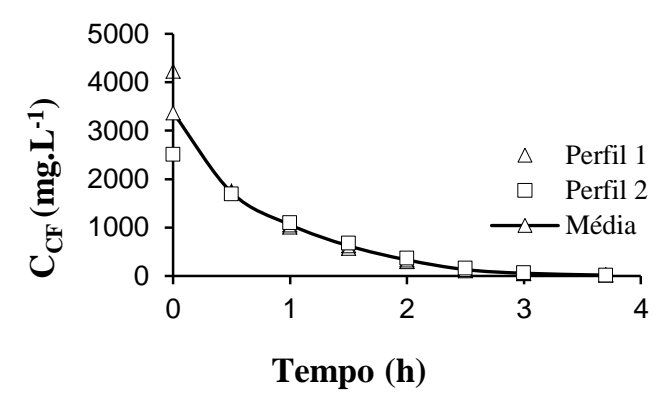

(a)

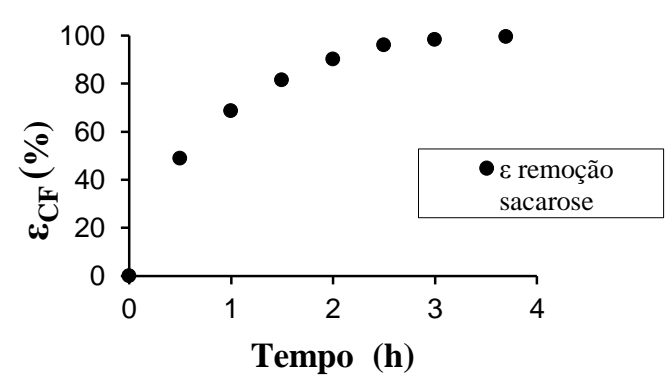

(b)

Figura 5.45: (a) Concentração de carboidratos e (b) eficiência de remoção para amostras filtradas ao longo do ciclo na condição 3.

A Figura 5.46 representa o comportamento da matéria orgânica ao longo do ciclo. No inicio do ciclo a concentração é de $5431 \mathrm{mgDQO} . \mathrm{L}^{-1}$ reduzindo a $4152 \mathrm{mgDQO} . \mathrm{L}^{-1}$ em 2,5 horas, após esse período, há um ligeiro aumento até o último ponto do ciclo chegando ao valor de $4268 \mathrm{mgDQO} \cdot \mathrm{L}^{-1}$. 


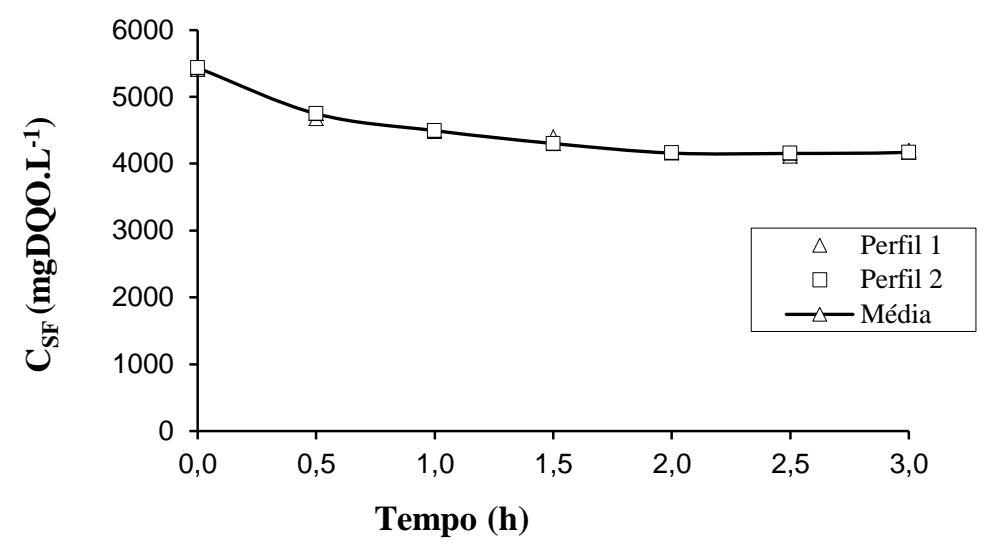

Figura 5.46: Concentração de matéria orgânica (DQO) para amostras filtradas ao longo do ciclo na condição 3 .

A produção de ácidos voláteis é representada na Figura 5.47. No tempo inicial a concentração de ácidos é de $242 \mathrm{mgHAc.L^{-1 }}$, tendo um crescimento acentuado em 1,5 horas de ciclo e atingindo o valor de 758 mgHAc. $\mathrm{L}^{-1}$, seguido de um aumento menos acentuado, chegando ao valor de 914 mgHAc. $\mathrm{L}^{-1}$ com 3 horas de ciclo. A média da concentração de ácidos voláteis ao longo do ciclo foi de $705 \mathrm{mgHAc} . \mathrm{L}^{-1}$.

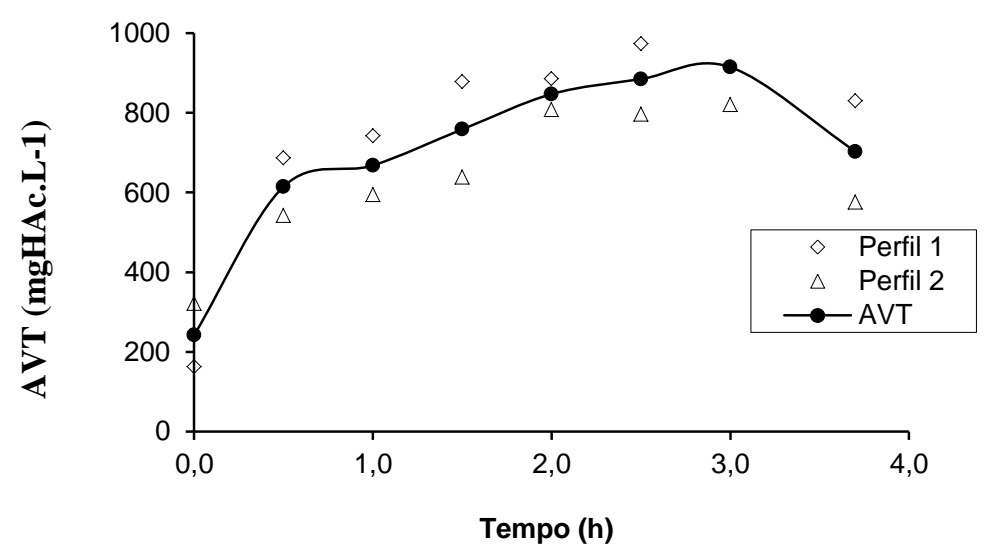

Figura 5.47: Concentração de ácidos voláteis totais ao longo do ciclo na condição 3. 


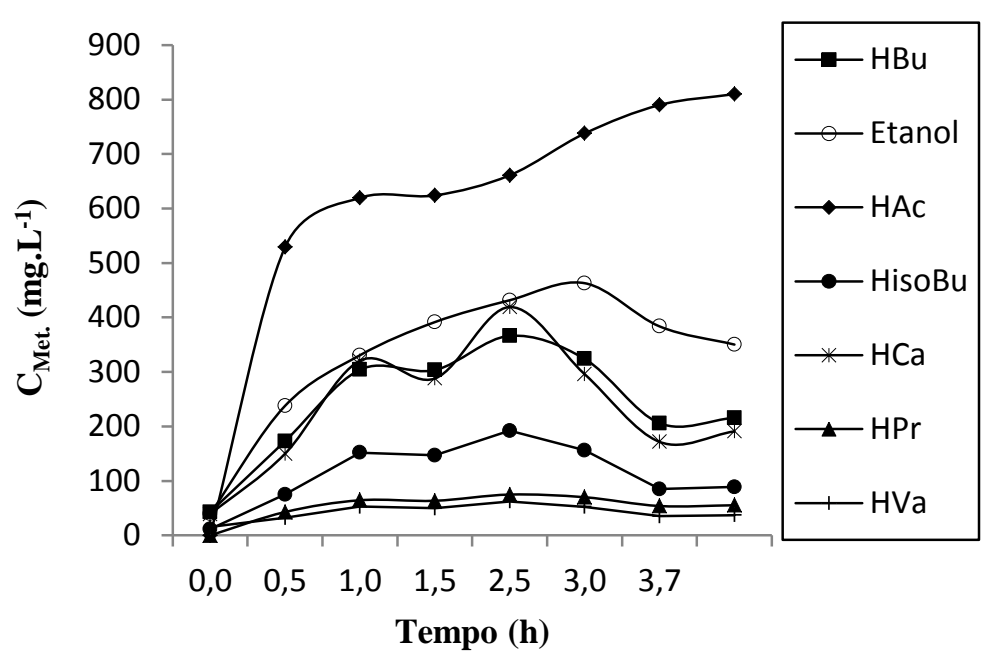

Figura 5.48: Concentração dos compostos intermediários ao longo do ciclo na condição 3.

A Figura 5.48 permite observar a predominância do ácido acético, mostrando um crescimento acentuado em 0,5 hora de ciclo, chegando a $529 \mathrm{mg} . \mathrm{L}^{-1}$ e mantendo um crescimento menor a partir desse ponto, atingindo o valor de $810 \mathrm{mg} . \mathrm{L}^{-1}$ ao final do ciclo de 4 horas. A Figura 5.49 apresenta o comportamento da alcalinidade ao longo do ciclo. No inicio do ciclo a alcalinidade é de $715 \mathrm{mgCaCO}_{3} \cdot \mathrm{L}^{-1}$, atingindo $481 \mathrm{mgCaCO}_{3} \cdot \mathrm{L}^{-1}$ em 3 horas de ciclo, ocorrendo um ligeiro aumento até o término do ciclo de 4 horas.

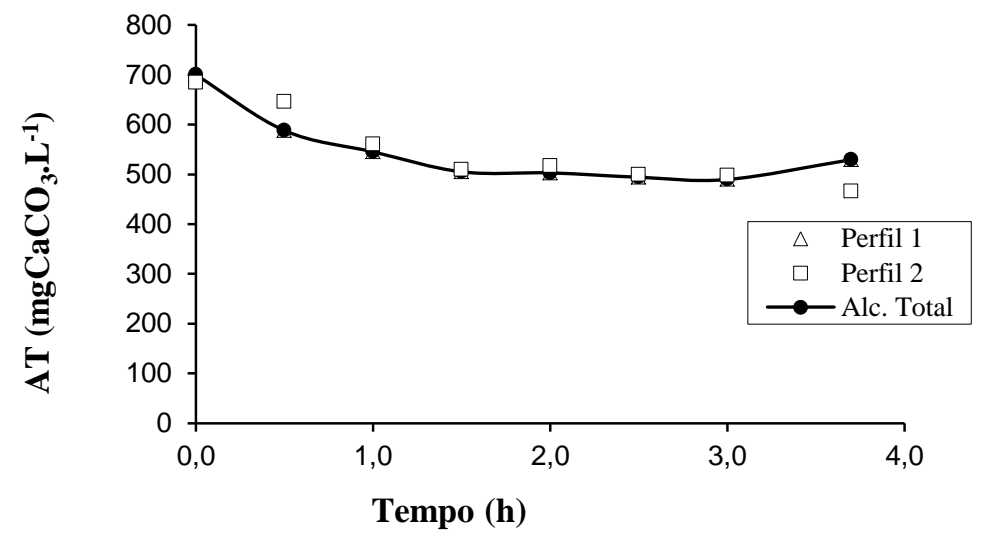

Figura 5.49: Concentração de alcalinidade total ao longo do ciclo na condição 3. 
O perfil dos valores de $\mathrm{pH}$ mostrados na Figura 5.50 indicam que o valor inicial de 7,2 é reduzido ao valor de 5,7 devido aos ácidos voláteis no interior do reator, mantendo-se constante durante todo o ciclo, demonstrando a estabilidade do mesmo.

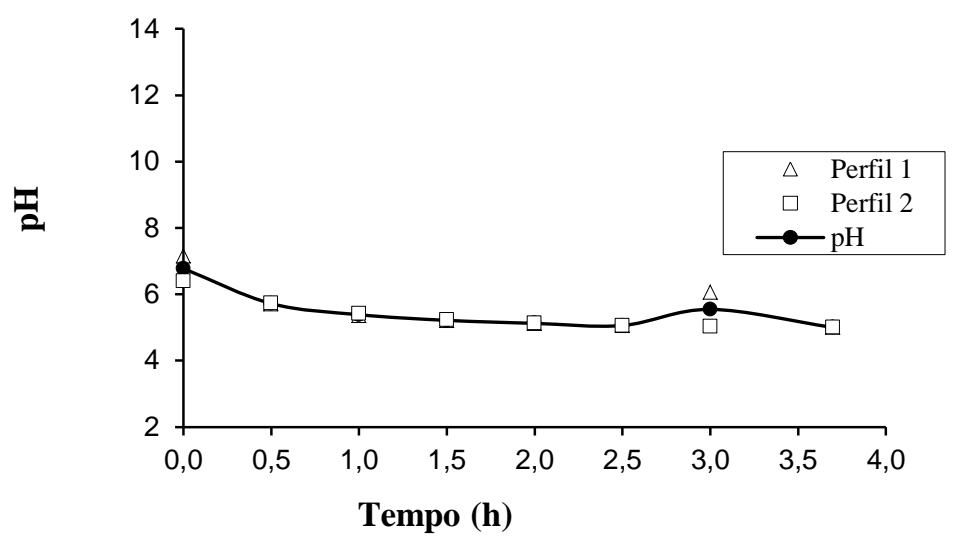

Figura 5.50: Valores de pH ao longo do ciclo na condição 3.

A Figura 5.50 permite observar que a produção do biogás é crescente em 1,5 horas de ciclo, atingindo o valor médio de $1102 \mathrm{~mL}$ (CNTP) nesse ponto, seguido de um crescimento menos acentuado e atingindo $1285 \mathrm{~mL}(\mathrm{CNTP})$ ao final do ciclo. A Tabela 5.13 resume os valores da produção, concentração, fração molar e volumes individuais da mistura gasosa. A Figura 5.51 apresenta os volumes de $\mathrm{H}_{2}, \mathrm{CO}_{2}$ e $\mathrm{CH}_{4}$ produzidos durante o ciclo. Nos primeiros 30 minutos são produzidos $124 \mathrm{~mL}$ de $\mathrm{H}_{2}$, atingindo o valor máximo de $404 \mathrm{~mL}$ ao final das 4 horas de ciclo. Não foi detectado metano. 
Tabela 5.13: Produção e composição do biogás produzido ao longo do ciclo na condição 3.

\begin{tabular}{ccccccccccc}
\hline $\begin{array}{c}\text { Tempo } \\
(\mathrm{h})\end{array}$ & $\begin{array}{c}\mathrm{V}_{\mathrm{G}} \\
(\mathrm{mL}-\mathrm{CNTP})\end{array}$ & \multicolumn{3}{c}{$\mathrm{C}_{\mathrm{G}}\left(\mathrm{mmol} . \mathrm{L}^{-1}\right)$} & \multicolumn{3}{c}{ Fração Molar (\%) } & \multicolumn{3}{c}{ Volume (mL - CNTP) } \\
& & $\mathrm{H}_{2}$ & $\mathrm{CO}_{2}$ & $\mathrm{CH}_{4}$ & $\mathrm{H}_{2}$ & $\mathrm{CO}_{2}$ & $\mathrm{CH}_{4}$ & $\mathrm{H}_{2}$ & $\mathrm{CO}_{2}$ & $\mathrm{CH}_{4}$ \\
\hline 0,0 & 0,0 & 0,0 & 0,0 & 0,0 & 0 & 0 & 0 & 0,0 & 0,0 & 0 \\
0,5 & 510 & 2,8 & 8,6 & 0,0 & 24 & 76 & 0 & 124 & 387 & 0 \\
1,0 & 873 & 6,1 & 11,5 & 0,0 & 35 & 65 & 0 & 250 & 624 & 0 \\
1,5 & 1102 & 7,9 & 13,3 & 0,0 & 37 & 63 & 0 & 335 & 767 & 0 \\
2,0 & 1227 & 8,5 & 14,1 & 0,0 & 38 & 62 & 0 & 382 & 845 & 0 \\
2,5 & 1276 & 9,1 & 15,1 & 0,0 & 38 & 62 & 0 & 400 & 876 & 0 \\
3,0 & 1285 & 8,8 & 14,9 & 0,0 & 37 & 63 & 0 & 404 & 881 & 0 \\
3,7 & 1285 & 8,9 & 15,3 & 0,0 & 37 & 63 & 0 & 404 & 881 & 0 \\
\hline
\end{tabular}

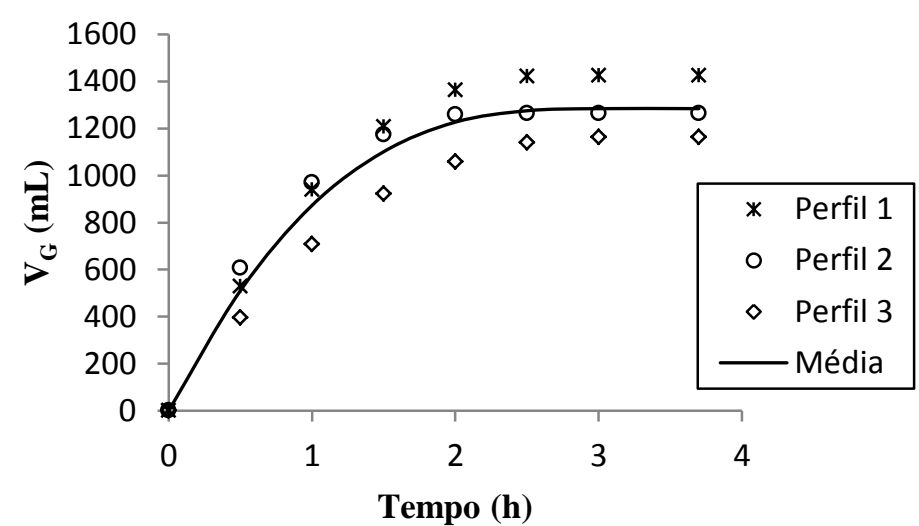

Figura 5.51: Volume total de biogás produzido ao longo do ciclo na condição 3.

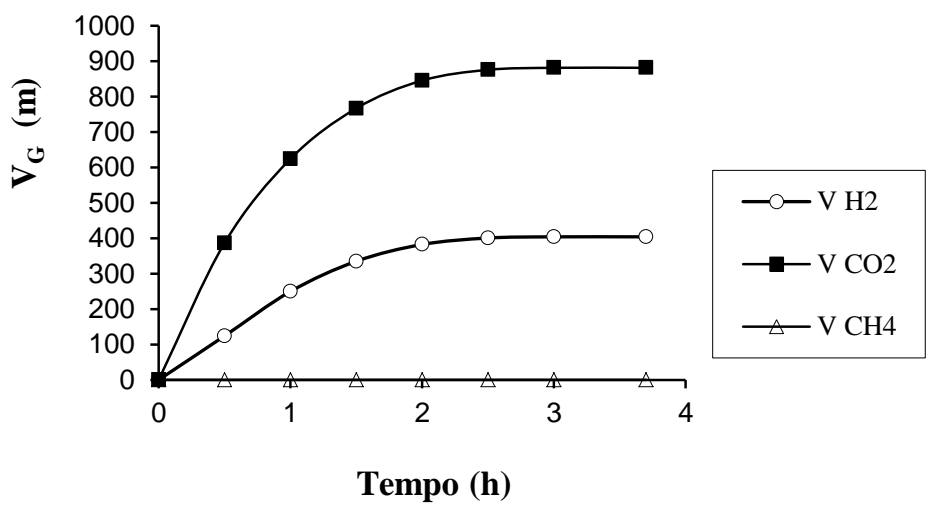

Figura 5.52: Volumes de $\mathrm{H}_{2}, \mathrm{CO}_{2}$ e $\mathrm{CH}_{4}$ produzidos ao longo do ciclo na condição 3. 


\subsection{Condição experimental 4}

\subsubsection{Monitoramento ao final do ciclo}

Na condição experimental 4 o reator foi operado em bateladas sequenciais com COAV nominal de $13,5 \mathrm{kgDQO} \cdot \mathrm{m}^{-3} \cdot \mathrm{d}^{-1}$ e duração do ciclo de 3 horas por um período de 30 dias. A Tabela 5.14 mostra as variáveis monitoradas e seus respectivos valores médios.

A Figura 5.53 exibe os valores da concentração de carboidratos afluente e efluente (amostras filtradas e não filtradas). A média da concentração afluente foi de $4277 \mathrm{mgSAC} . \mathrm{L}^{-1}$ enquanto que a concentração residual foi de $125 \mathrm{mgSAC} . \mathrm{L}^{-1}$. A média da eficiência de com base em amostras filtradas foi de $99 \%$, sendo que a Figura 5.54 exibe o comportamento ao longo da operação.

A Figura 5.54 mosta os valores da eficiência de remoção de carboidratos. Pode ser obseravada a estabilidade do processo durante todo o período alcançando uma média de remoção de $99 \%$.

A média da concentração de matéria orgânica afluente foi de $5064 \mathrm{mgDQO} \cdot \mathrm{L}^{-1}$ e as análises de efluente em amostras filtradas e não filtradas resultaram em médias de concentração de 3995 e 4406 mgDQO.L $L^{-1}$, respectivamente, cujos valores são mostrados na Figura 5.55. A eficiência de remoção de DQO, com relação a amostras filtradas e não filtradas, mostrou-se relativamente baixa, 20 e 13\% em média, respectivamente, cujos valores podem ser observados na Figura 5.56. 
Tabela 5.14: Valores médios dos parâmetros monitorados na condição 4.

\begin{tabular}{|c|c|c|c|c|c|c|c|c|c|c|c|c|c|}
\hline \multirow{2}{*}{$\frac{\text { Parâmetro }}{\mathrm{C}_{\mathrm{ST}}}$} & & \multicolumn{3}{|c|}{ Afluente } & \multicolumn{9}{|c|}{ Efluente } \\
\hline & {$\left[\mathrm{mgDQO} \cdot \mathrm{L}^{-1}\right]$} & 5064 & \pm & 465 & ( & 25 & ) & 4406 & \pm & 364 & ( & 25 & ) \\
\hline$\varepsilon_{\mathrm{ST}}$ & {$[\%]$} & - & & - & & & & 13 & \pm & 5 & ( & 25 & ) \\
\hline $\mathrm{C}_{\mathrm{SF}}$ & {$\left[\mathrm{mgDQO} . \mathrm{L}^{-1}\right]$} & - & & - & & & & 3995 & \pm & 292 & c & 25 & ) \\
\hline$\varepsilon_{\mathrm{SF}}$ & {$[\%]$} & - & & - & & & & 20 & \pm & 5 & ( & 25 & ) \\
\hline $\mathrm{C}_{\mathrm{CT}}$ & {$\left[\mathrm{mgSAC} \cdot \mathrm{L}^{-1}\right]$} & 4277 & \pm & 403 & ( & 25 & ) & 125 & \pm & 13 & c & 25 & ) \\
\hline $\mathrm{C}_{\mathrm{CF}}$ & {$\left[\mathrm{mgSAC} \cdot \mathrm{L}^{-1}\right]$} & - & & - & & & & 42 & \pm & 10 & c & 25 & ) \\
\hline$\varepsilon_{\mathrm{CT}}$ & {$[\%]$} & - & & - & & & & 97 & \pm & 2 & ( & 25 & ) \\
\hline$\varepsilon_{\mathrm{CF}}$ & {$[\%]$} & - & & - & & & & 99 & \pm & 2 & ( & 25 & ) \\
\hline AVT & {$\left[\mathrm{mgHAc} . \mathrm{L}^{-1}\right]$} & 45 & \pm & 20 & ( & 22 & ) & 1059 & \pm & 159 & ( & 22 & ) \\
\hline $\mathrm{AT}$ & {$\left[\mathrm{mgCaCO}_{3} \cdot \mathrm{L}^{-1}\right]$} & 842 & \pm & 47 & ( & 22 & ) & 465 & \pm & 32 & ( & 22 & ) \\
\hline $\mathrm{pH}$ & & 7,4 & \pm & 0,1 & ( & 22 & ) & 4,9 & \pm & 0,1 & ( & 22 & ) \\
\hline ST & {$\left[\mathrm{mg} . \mathrm{L}^{-1}\right]$} & 5589 & \pm & 1469 & ( & 7 & ) & 3953 & \pm & 1679 & ( & 7 & ) \\
\hline SVT & {$\left[\mathrm{mg} . \mathrm{L}^{-1}\right]$} & 4503 & \pm & 1478 & c & 7 & ) & 2790 & \pm & 1672 & ( & 7 & ) \\
\hline SST & {$\left[\mathrm{mg} . \mathrm{L}^{-1}\right]$} & 164 & \pm & 75 & c & 7 & ) & 213 & \pm & 85 & c & 7 & ) \\
\hline SSV & {$\left[\mathrm{mg} . \mathrm{L}^{-1}\right]$} & 124 & \pm & 61 & c & 7 & ) & 177 & \pm & 101 & c & 7 & ) \\
\hline $\mathrm{V}_{\mathrm{G}}$ & {$[\mathrm{mL}]$} & - & & - & & & & 1489 & \pm & 37 & c & 3 & ) \\
\hline $\mathrm{V}_{\mathrm{H} 2}$ & {$[\mathrm{~mL}]$} & - & & - & & & & 420 & \pm & 39 & c & 3 & ) \\
\hline $\mathrm{C}^{\prime}{ }_{\mathrm{X}-\mathrm{SVT}}$ & [g.g-suporte ${ }^{-1}$ ] & 0,14 & & & & & & & & & & & \\
\hline $\mathrm{C}_{\mathrm{X}-\mathrm{SVT}}$ & {$\left[\mathrm{g} . \mathrm{L}^{-1}\right]$} & 4,90 & & & & & & & & & & & \\
\hline COAV $_{\text {STA }}$ & {$\left[\mathrm{kgDQO} \cdot \mathrm{m}^{-3} \cdot \mathrm{d}^{-1}\right]$} & 17,1 & & - & & & & - & & - & & & \\
\hline $\mathrm{CORV}_{\mathrm{SFE}}$ & {$\left[\mathrm{kgDQO} \cdot \mathrm{m}^{-3} \cdot \mathrm{d}^{-1}\right]$} & - & & - & & & & 3,6 & & - & & & \\
\hline COAV $_{\text {CTA }}$ & {$\left[\mathrm{kgSAC} \cdot \mathrm{m}^{-3} \cdot \mathrm{d}^{-1}\right]$} & 14,4 & & - & & & & - & & - & & & \\
\hline $\mathrm{CORV}_{\mathrm{CTFE}}$ & {$\left[\mathrm{kgSAC} \cdot \mathrm{m}^{-3} \cdot \mathrm{d}^{-1}\right]$} & - & & - & & & & 14,3 & & - & & & \\
\hline $\mathrm{M}_{\mathrm{SVT}}$ & {$[\mathrm{g}]$} & - & & - & & & & 22,1 & \pm & 0,5 & ( & 3 & ) \\
\hline $\mathrm{n}_{\mathrm{H} 2}$ & {$\left[\mathrm{molH}_{2} \cdot \mathrm{d}^{-1}\right]$} & - & & - & & & & 0,19 & & - & & & \\
\hline PrM & {$\left[\mathrm{molH}_{2} \cdot \mathrm{m}^{-3} \cdot \mathrm{d}^{-1}\right]$} & 25,7 & & - & & & & - & & - & & & \\
\hline PrME & {$\left[\mathrm{molH}_{2} \cdot \mathrm{kgSVT}^{-1} \cdot \mathrm{d}^{-1}\right]$} & 8,47 & & - & & & & - & & - & & & \\
\hline $\mathrm{RMCA}_{\mathrm{C}, \mathrm{m}}$ & {$\left[\mathrm{molH}_{2} \cdot \mathrm{kgSAC}^{-1}\right]$} & 2,88 & & - & & & & - & & - & & & \\
\hline $\mathrm{RMCA}_{\mathrm{S}, \mathrm{m}}$ & {$\left[\mathrm{molH}_{2} \cdot \mathrm{kgDQO}^{-1}\right]$} & 2,43 & & - & & & & - & & - & & & \\
\hline $\mathrm{RMCR}_{\mathrm{C}, \mathrm{m}}$ & {$\left[\mathrm{molH}_{2} \cdot \mathrm{kgSAC}^{-1}\right]$} & - & & - & & & & 2,91 & & - & & & \\
\hline $\mathrm{RMCR}_{\mathrm{S}, \mathrm{m}}$ & {$\left[\mathrm{molH}_{2} \cdot \mathrm{kgDQO}^{-1}\right]$} & - & & - & & & & 11,5 & & - & & & \\
\hline $\mathrm{V}_{\mathrm{T}}$ & [L] & 4,5 & \pm & 0,1 & ( & 25 & ) & - & & - & & & \\
\hline $\mathrm{V}_{\mathrm{F}}$ & {$[\mathrm{L}]$} & 1,9 & \pm & 0,1 & ( & 25 & ) & - & & - & & & \\
\hline
\end{tabular}

*Número de amostras consideradas. 


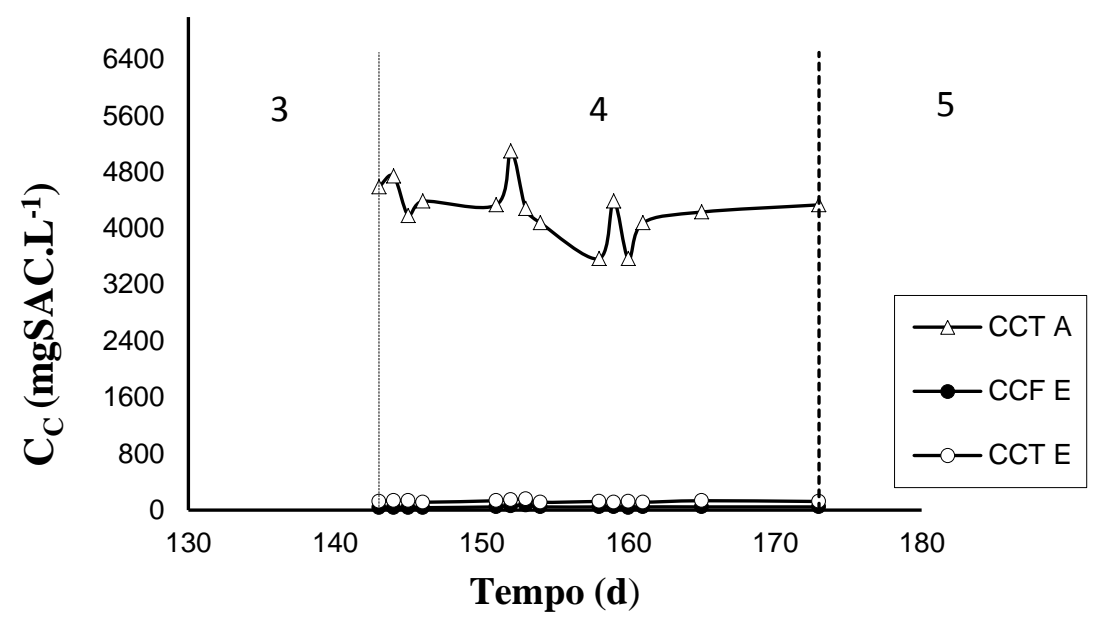

Figura 5.53: Concentração de carboidratos afluente e efluente para amostras filtradas e não filtradas na condição 4.

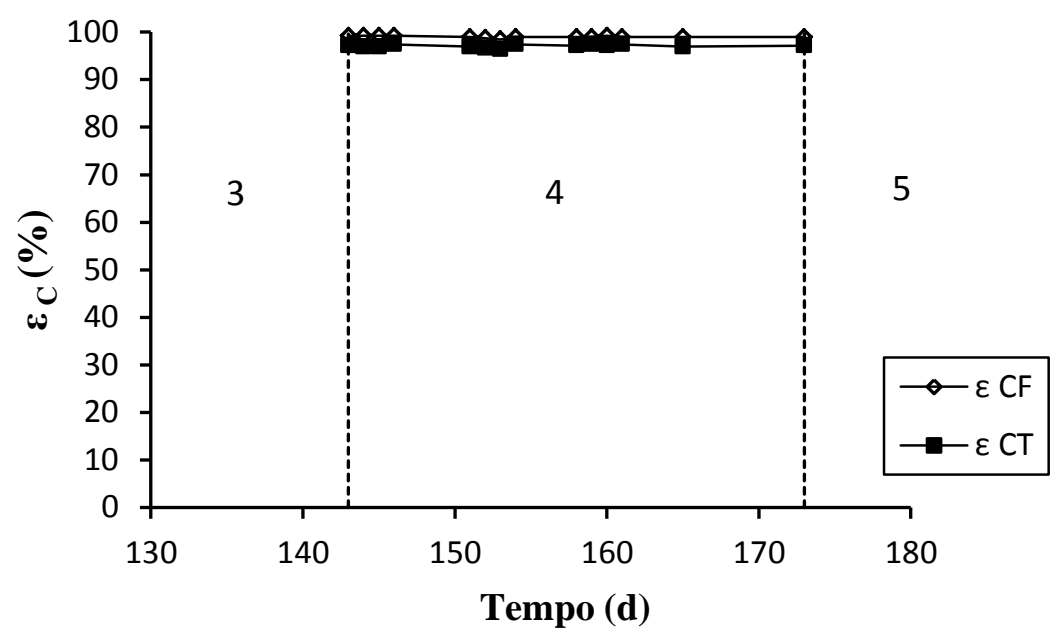

Figura 5.54: Eficiência de remoção de carboidratos para amostras filtradas na condição 4. 


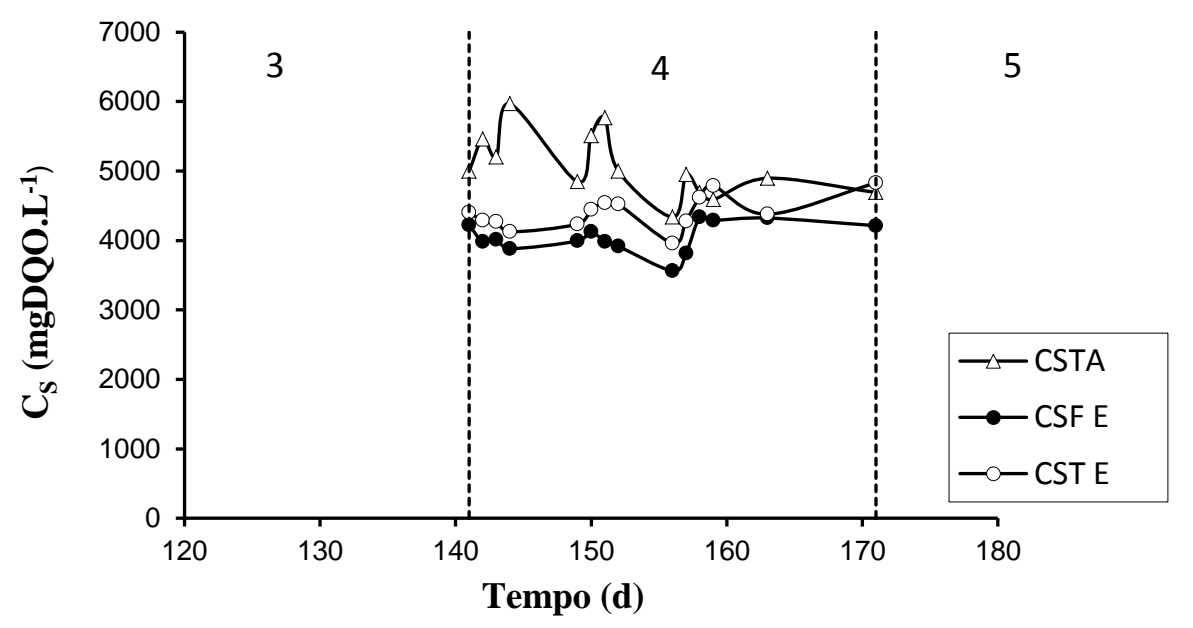

Figura 5.55: Concentração de matéria orgânica (DQO) afluente e efluente para amostras filtradas e não filtradas na condição 4 .

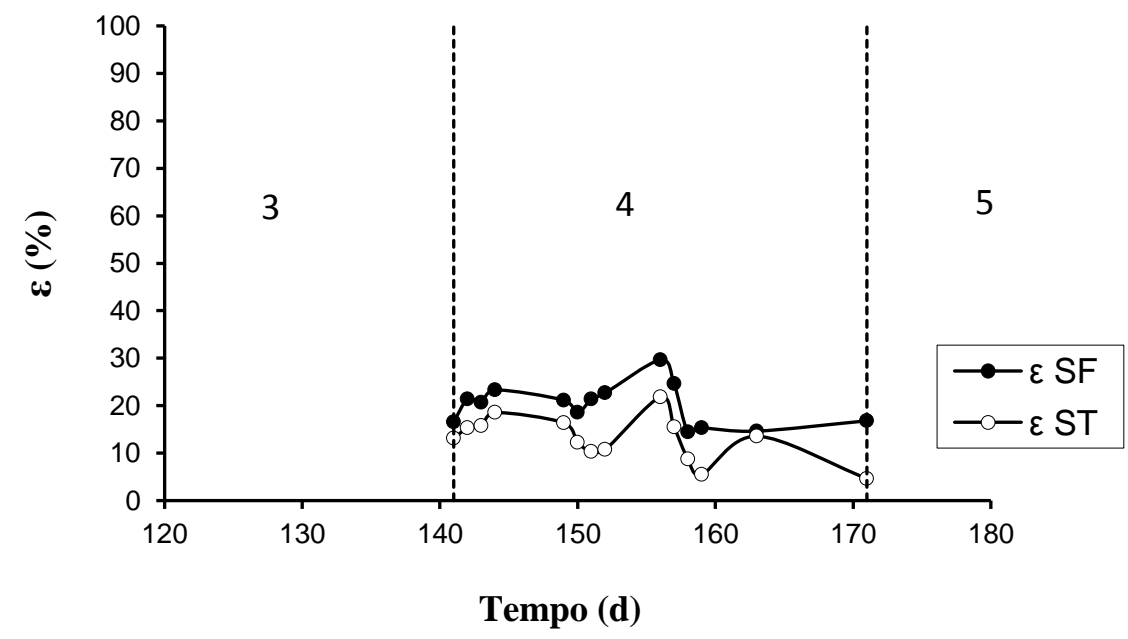

Figura 5.56: Eficiência de remoção de matéria orgânica (DQO) para amostras filtradas e não filtradas na condição 4. 
A Tabela 5.14 apresenta os valores da concentração média dos compostos intermediários, obtidos em triplicata, contidos no efluente do sistema. O método cromatográfico aplicado não detectou acetona e metanol. A Figura 5.58 mostra a concentração dos ácidos no efluente e afluente. A concentração média de ácidos no efluente foi de $1034 \mathrm{mgHAc} . \mathrm{L}^{-1}$ enquanto que no afluente foi de $29 \mathrm{mgHAc} . \mathrm{L}^{-1}$.

Tabela 5.15: Concentração dos compostos intermediários na condição 4.

\begin{tabular}{|c|c|c|c|c|c|c|c|}
\hline \multirow{3}{*}{$\begin{array}{c}\begin{array}{c}\text { Produtos } \\
\text { intermediários }\end{array} \\
\text { Acetona }\end{array}$} & \multicolumn{6}{|c|}{ Concentração média } & \multirow{3}{*}{$\begin{array}{c}\begin{array}{c}\text { Porcentagem } \\
(\%)\end{array} \\
0,0\end{array}$} \\
\hline & \multicolumn{3}{|c|}{$\mathrm{mg} . \mathrm{L}^{-1}$} & \multicolumn{3}{|c|}{ mmol.L $\mathrm{L}^{-1}$} & \\
\hline & - & \pm & - & - & \pm & - & \\
\hline Metanol & - & \pm & - & - & \pm & - & 0,0 \\
\hline Etanol & 623,5 & \pm & 42,6 & 13,4 & \pm & 0,9 & 99,1 \\
\hline n-Butanol & 5,6 & \pm & 0,1 & 0,1 & \pm & 0,0 & 0,9 \\
\hline Acético & 1060,5 & \pm & 71,4 & 17,7 & \pm & 1,2 & 61,1 \\
\hline Porpiônico & 139,6 & \pm & 11,9 & 1,9 & \pm & 0,2 & 8,0 \\
\hline Isobutírico & 14,0 & \pm & 1,8 & 0,2 & \pm & 0,0 & 0,8 \\
\hline Butírico & 319,5 & \pm & 48,8 & 3,6 & \pm & 0,6 & 18,4 \\
\hline Isovalérico & 8,7 & \pm & 0,8 & 0,1 & \pm & 0,0 & 0,5 \\
\hline Valérico & 44,0 & \pm & 6,4 & 0,4 & \pm & 0,1 & 2,5 \\
\hline Capróico & 150,6 & \pm & 32,0 & 1,3 & \pm & 0,3 & 8,7 \\
\hline
\end{tabular}

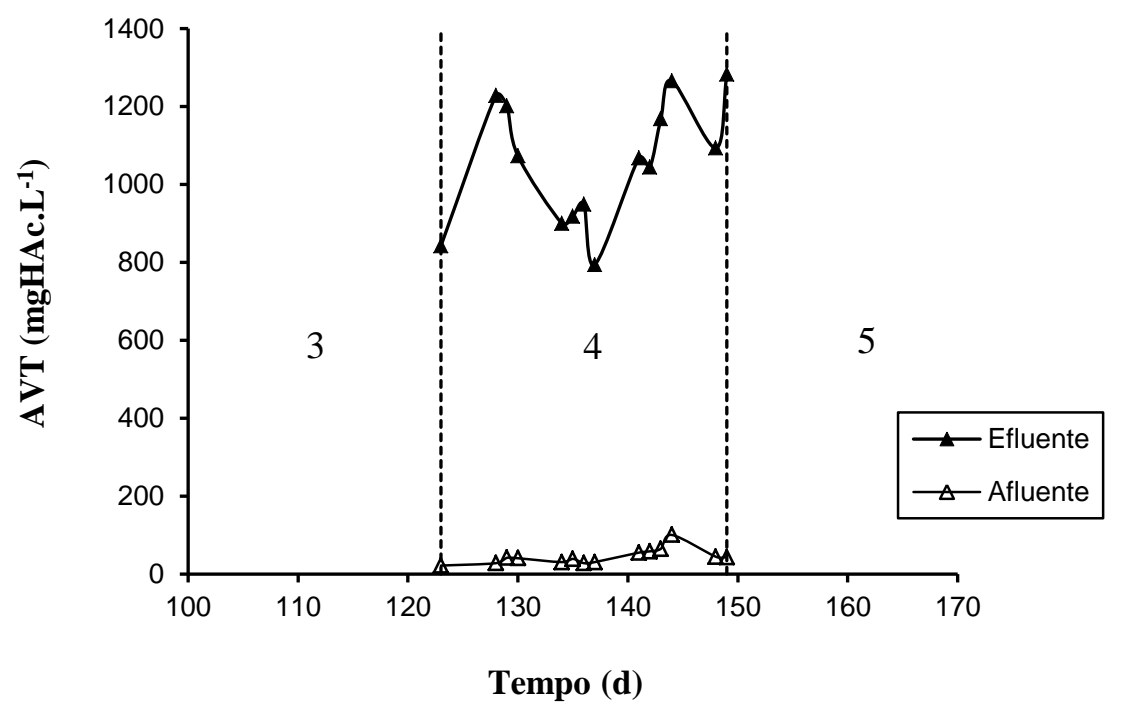

Figura 5.57: Concentração de ácidos voláteis totais afluente e efluente na condição 4. 
O acúmulo de ácidos orgânicos no interior do reator provocaram a redução instantânea do $\mathrm{pH}$ assim que o afluente entrava em contato com o meio residual no interior do reator. A Figura 5.58, apresenta os valores de $\mathrm{pH}$, afluente e efluente, ao longo do período experimental. O valor médio do $\mathrm{pH}$ afluente foi de 7,4 e de 4,9 para o efluente.

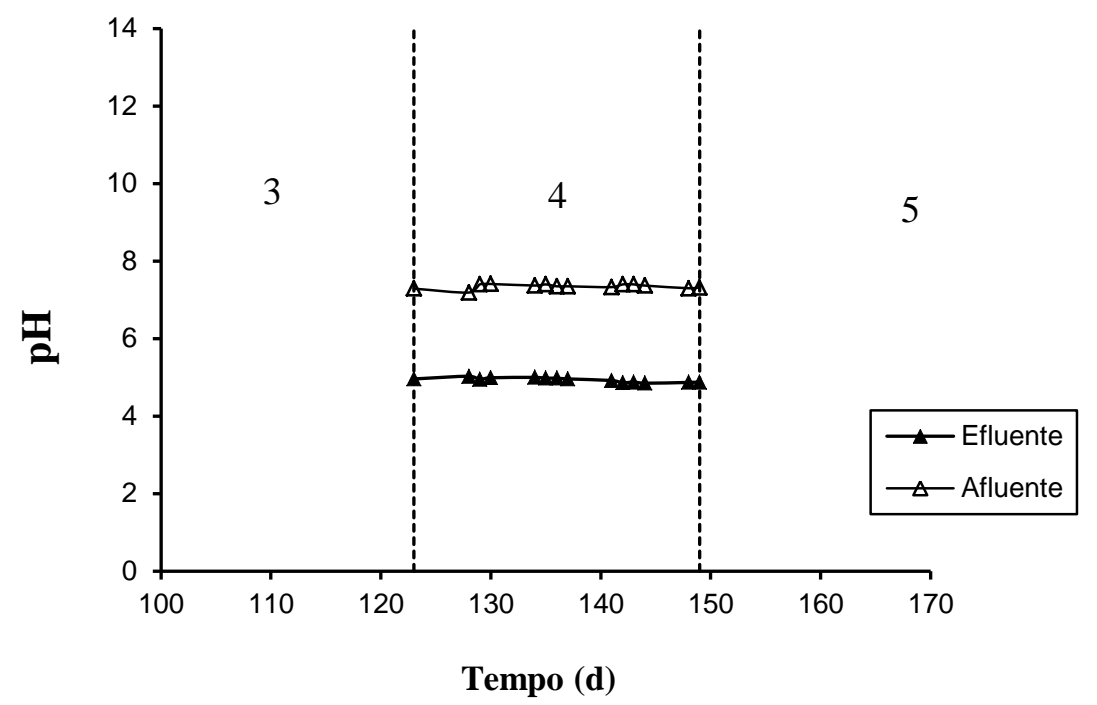

Figura 5.58: Valores de $\mathrm{pH}$ afluente e efluente na condição 4.

A Figura 5.59 apresenta as concentrações, afluente e efluente, da alcalinidade ao longo da operação. Os valores médios de alcalinidade foram de 842 e $465 \mathrm{mgCaCO}_{3} \cdot \mathrm{L}^{-1}$ para o afluente e efluente, respectivamente.

O monitoramento da série de sólidos é mostrado na Tabela 5.16, cujos valores indicam um baixo teor de SSV no efluente e afluente.

A produção do biogás, em aspecto quantitativo, pode ser observada na Figura 5.60. A média de produção foi de $1149 \mathrm{~mL}(\mathrm{CNTP})$. 


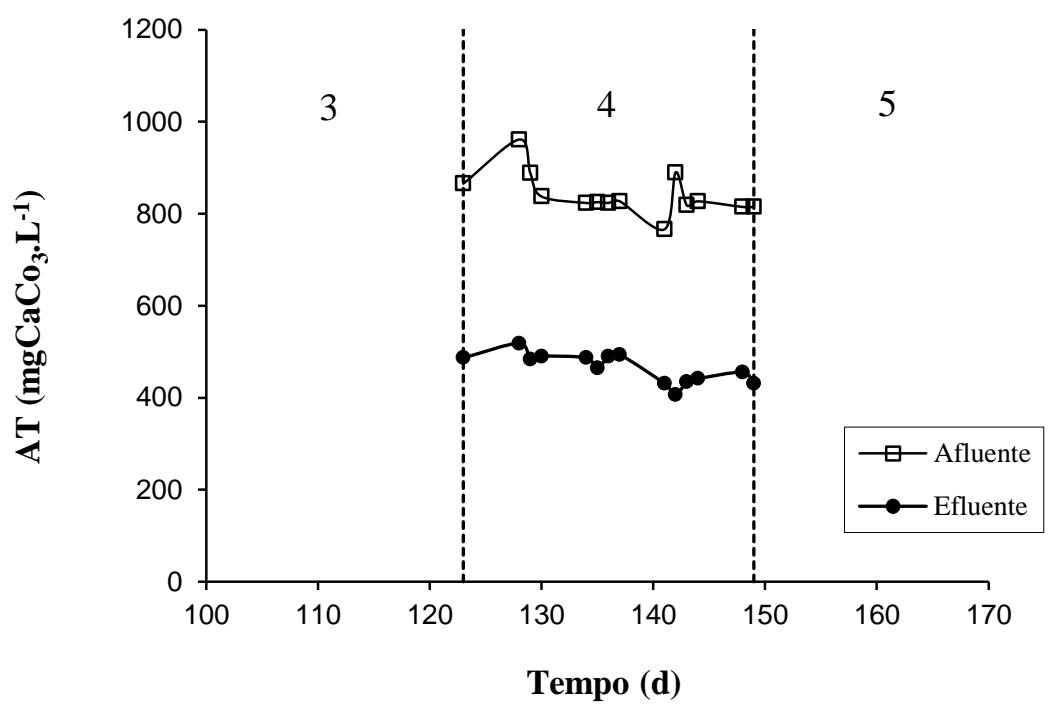

Figura 5.59: Concentração de alcalinidade total afluente e efluente na condição 4.

Tabela 5.16: Série de sólidos afluente e efluente na condição 4.

\begin{tabular}{lcccc}
\hline & $\begin{array}{c}\text { ST } \\
\left(\mathrm{mg} . \mathrm{L}^{-1}\right)\end{array}$ & $\begin{array}{c}\text { SVT } \\
\left(\mathrm{mg} . \mathrm{L}^{-1}\right)\end{array}$ & $\begin{array}{c}\text { SST } \\
\left(\mathrm{mg} . \mathrm{L}^{-1}\right)\end{array}$ & $\begin{array}{c}\text { SSV } \\
\left(\mathrm{mg} . \mathrm{L}^{-1}\right)\end{array}$ \\
\hline Afluente & $6320 \pm 164$ & $5237 \pm 191$ & $131 \pm 45$ & $102 \pm 52$ \\
Efluente & $3120 \pm 254$ & $1961 \pm 2686$ & $247 \pm 62$ & $217 \pm 75$ \\
\hline \multicolumn{5}{c}{ *Número de amostras consideradas $=3}$.
\end{tabular}

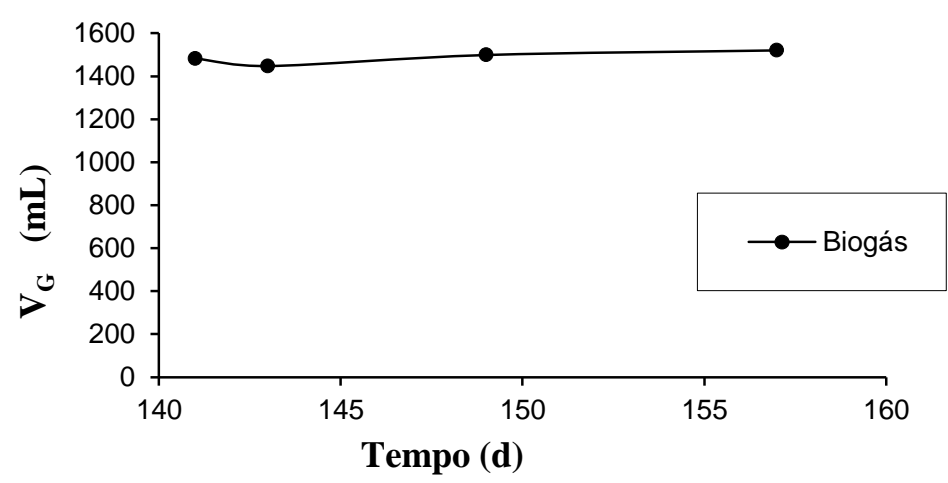

Figura 5.60: Volume total de biogás produzido na condição 4. 


\subsubsection{Monitoramento ao longo do ciclo}

A Figura 5.61 apresenta os valores de carboidratos ao longo do perfil de operação. No tempo inicial o valor da concentração é de $4156 \mathrm{mgSAC} . \mathrm{L}^{-1}$. A redução imediata da concentração inicial deve-se ao volume residual de meio existente no interior do recipiente de recirculação. Como pode ser observado na Figura 5.61(a) e 5.61(b), após 2 horas de ciclo praticamente todo o substrato é removido, atingindo uma eficiência de $98 \%$ com um residual de $30 \mathrm{mgSAC} . \mathrm{L}^{-1}$ ao final das 3 horas de ciclo.

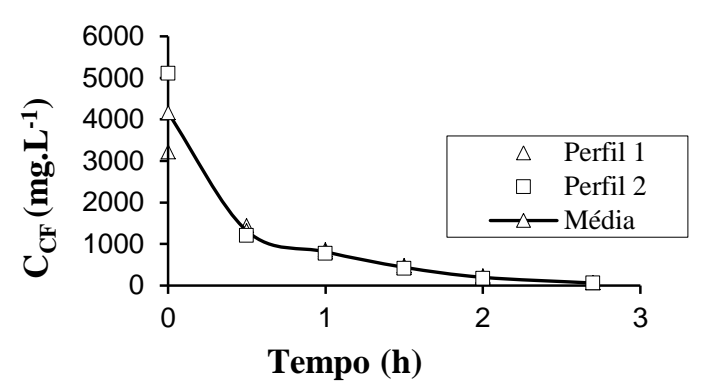

(a)

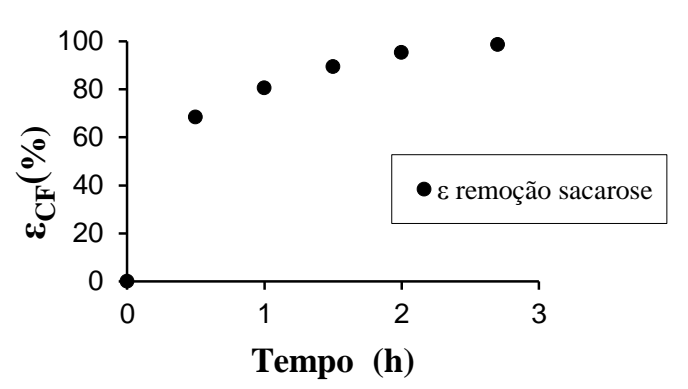

(b)

Figura 5.61: (a) Concentração de carboidratos e (b) eficiência de remoção para amostras filtradas ao longo do ciclo na condição 4 .

A Figura 5.62 representa o comportamento da matéria orgânica ao longo do ciclo. No inicio do ciclo, a concentração é de $4671 \mathrm{mgDQO} . \mathrm{L}^{-1}$ e reduzindo a 3877 mgDQO.L ${ }^{-1}$ em 1 hora de ciclo, chegando a atingir $3239 \mathrm{mgDQO} . \mathrm{L}^{-1}$.em 3 horas de ciclo. 


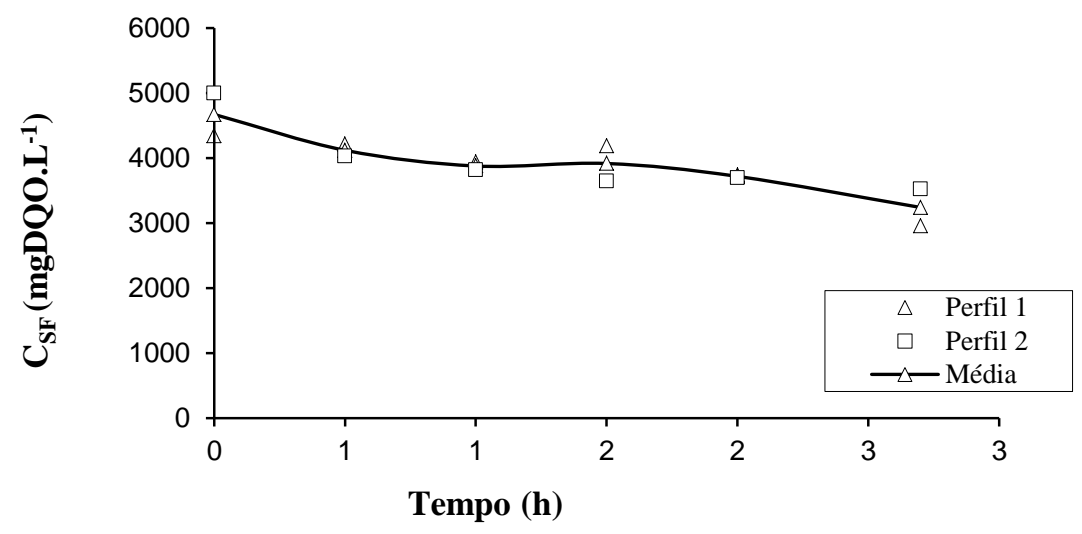

Figura 5.62: Concentração de matéria orgânica (DQO) para amostras filtradas ao longo do ciclo na condição 4.

A produção de ácidos voláteis é representada na Figura 5.63. No tempo inicial a concentração de ácidos é de 153 mgHAc.L ${ }^{-1}$, tendo um crescimento acentuado em 1,5 horas e atingindo o valor de $982 \mathrm{mgHAc} . \mathrm{L}^{-1}$, seguido de um aumento menos acentuado, chegando ao valor de 1143 mgHAc. $\mathrm{L}^{-1}$ com 3 horas de ciclo. A média da concentração de ácidos voláteis ao longo do ciclo foi de $820 \mathrm{mgHAc} . \mathrm{L}^{-1}$.

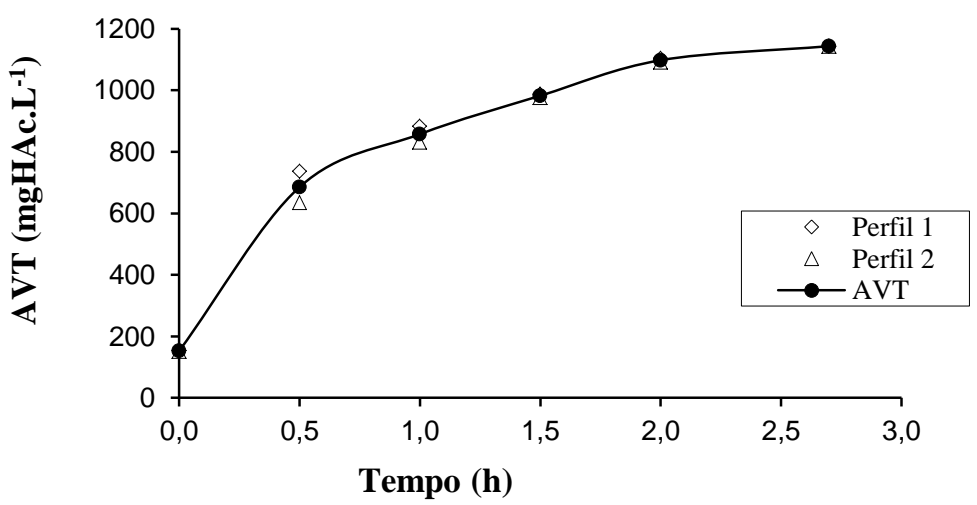

Figura 5.63: Concentração de ácidos voláteis totais ao longo do ciclo na condição 4. 


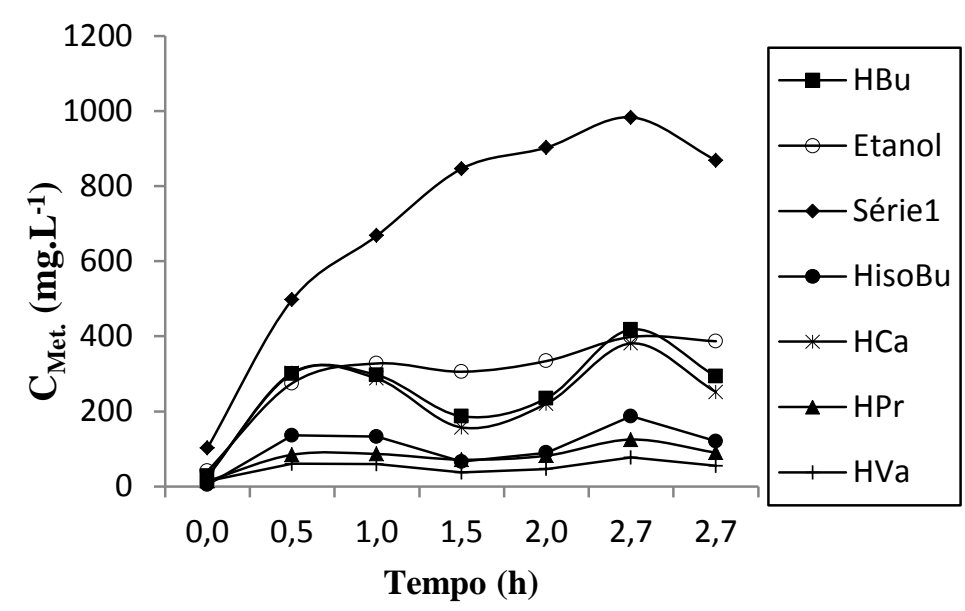

Figura 5.64: Concentração dos compostos intermediários ao longo do ciclo na condição 4.

A Figura 5.64 permite observar a predominância do ácido acético, mostrando um crescimento acentuado em 1,5 horas de ciclo, chegando a $846 \mathrm{mg} . \mathrm{L}^{-1}$ e mantendo um crescimento menor a partir desse ponto, atingindo o valor de $926 \mathrm{mg} . \mathrm{L}^{-1}$ ao final do ciclo de 3 horas. A Figura 5.65 apresenta o comportamento da alcalinidade total ao longo do ciclo. No inicio do ciclo a alcalinidade é de $715 \mathrm{mgCaCO}_{3} \cdot \mathrm{L}^{-1}$, atingindo $481 \mathrm{mgCaCO}_{3} \cdot \mathrm{L}^{-1} \mathrm{em} 3$ horas de ciclo, ocorrendo um ligeiro aumento até o término do ciclo de 4 horas.

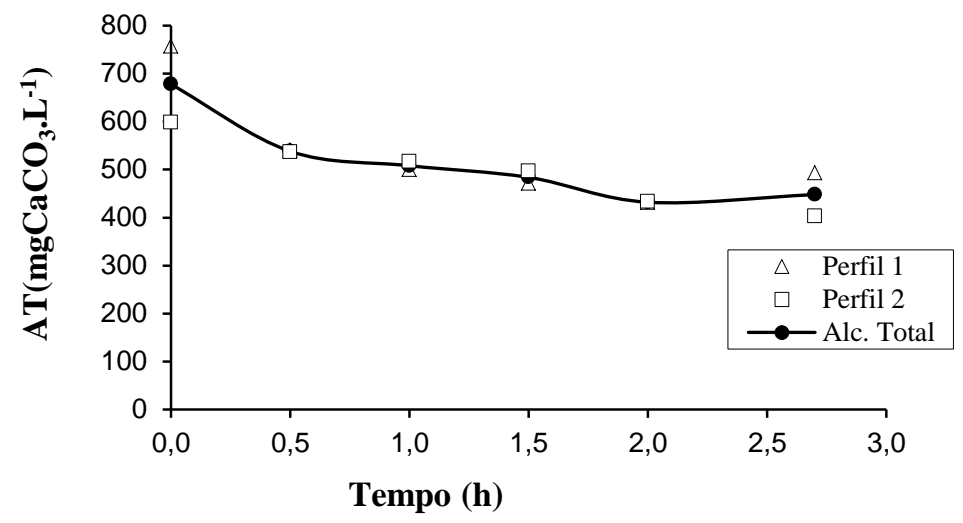

Figura 5.65: Concentração de alcalinidade total ao longo do ciclo na condição 4. 
O perfil dos valores de $\mathrm{pH}$ mostrados na Figura 5.66 indicam que o valor inicial de 7,2 é reduzido ao valor de 5,7 devido aos ácidos voláteis no interior do reator, mantendo-se constante durante todo o ciclo, demonstrando a estabilidade do mesmo.

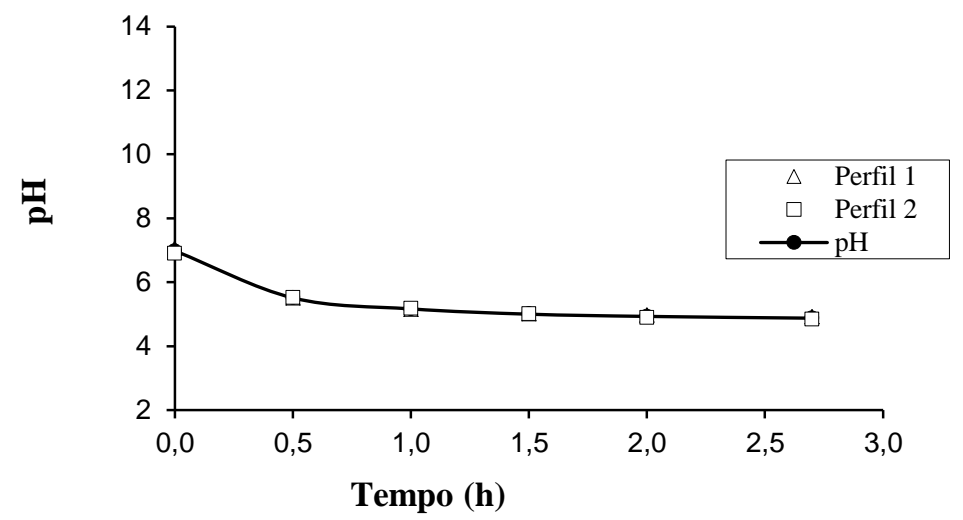

Figura 5.66: Valores de pH ao longo do ciclo na condição 4.

A Figura 5.67 permite observar que a produção do biogás é crescente no iníco do ciclo (2 horas), atingindo o valor médio de $1421 \mathrm{~mL}$ (CNTP) seguido de um crescimento menos acentuado e atingindo $1489 \mathrm{~mL}(\mathrm{CNTP})$ ao final do ciclo. A Tabela 5.17 resume os valores da produção do biogás, concentração, fração molar e volumes individuais da mistura gasosa. A Figura 5.68 apresenta os volumes de $\mathrm{H}_{2}, \mathrm{CO}_{2}$ e $\mathrm{CH}_{4}$ produzidos durante o ciclo. Nos primeiros 30 minutos são produzidos $137 \mathrm{~mL}$ de $\mathrm{H}_{2}$, atingindo o valor máximo de $420 \mathrm{~mL}$ ao final das 3 horas de ciclo. Não foi detectado metano. 
Tabela 5.17: Produção e composição do biogás produzido ao longo do ciclo na condição 4.

\begin{tabular}{ccccccccccc}
\hline $\begin{array}{c}\text { Tempo } \\
(\mathrm{h})\end{array}$ & $\begin{array}{c}\mathrm{V}_{\mathrm{G}} \\
(\mathrm{mL}-\mathrm{CNTP})\end{array}$ & \multicolumn{3}{c}{$\mathrm{C}_{\mathrm{G}}\left(\mathrm{mmol} \cdot \mathrm{L}^{-1}\right)$} & \multicolumn{3}{c}{ Fração Molar $(\%)$} & \multicolumn{3}{c}{ Volume $(\mathrm{mL}-\mathrm{CNTP})$} \\
& & $\mathrm{H}_{2}$ & $\mathrm{CO}_{2}$ & $\mathrm{CH}_{4}$ & $\mathrm{H}_{2}$ & $\mathrm{CO}_{2}$ & $\mathrm{CH}_{4}$ & $\mathrm{H}_{2}$ & $\mathrm{CO}_{2}$ & $\mathrm{CH}_{4}$ \\
\hline 0,0 & 0 & 0,0 & 0,0 & 0,0 & 0 & 0 & 0 & 0 & 0 & 0 \\
0,5 & 590 & 2,5 & 8,3 & 0,0 & 23 & 77 & 0 & 137 & 453 & 0 \\
1,0 & 1003 & 5,3 & 12,2 & 0,0 & 30 & 70 & 0 & 262 & 741 & 0 \\
1,5 & 1266 & 6,6 & 13,8 & 0,0 & 32 & 68 & 0 & 347 & 919 & 0 \\
2,0 & 1421 & 7,2 & 14,7 & 0,0 & 33 & 67 & 0 & 398 & 1023 & 0 \\
2,7 & 1489 & 7,0 & 14,8 & 0,0 & 32 & 68 & 0 & 420 & 1069 & 0 \\
\hline
\end{tabular}

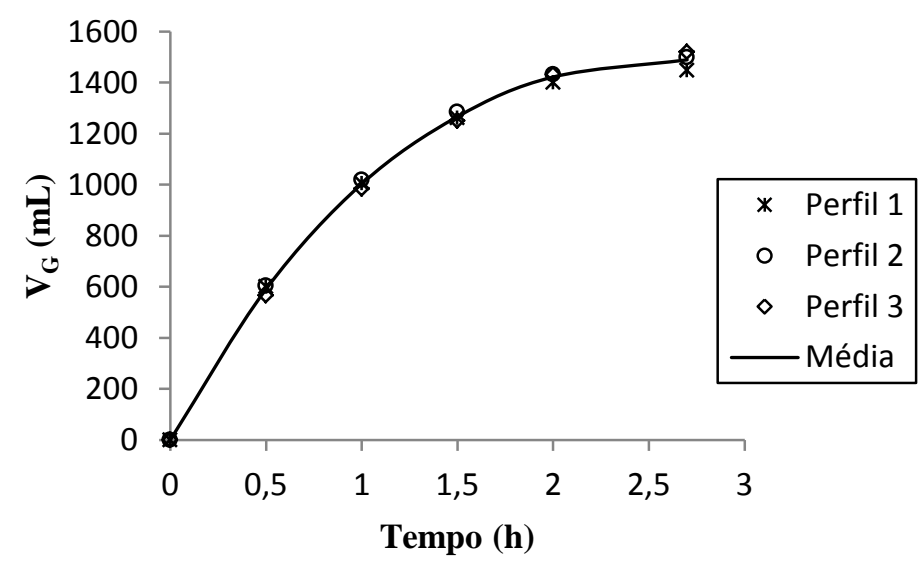

Figura 5.67: Volume total de biogás produzido ao longo do ciclo na condição 4.

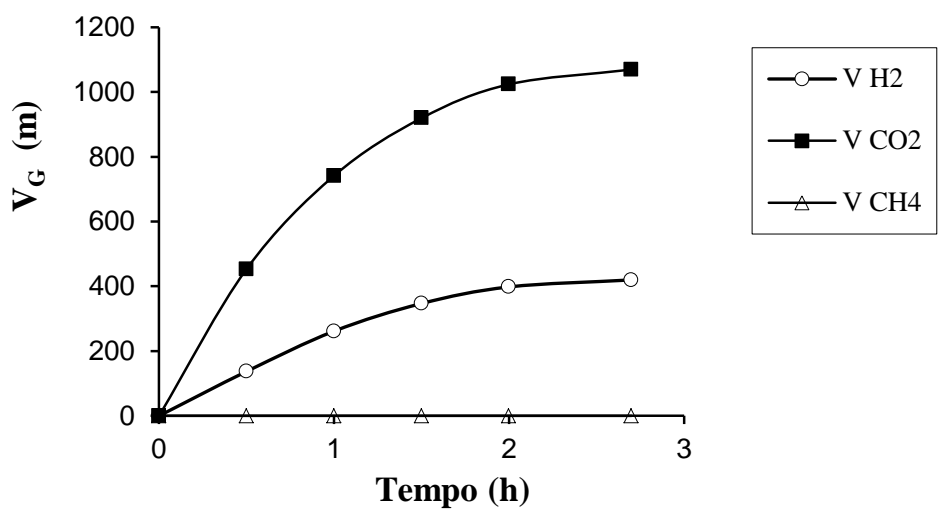

Figura 5.68: Volumes de $\mathrm{H}_{2}, \mathrm{CO}_{2}$ e $\mathrm{CH}_{4}$ produzidos ao longo do ciclo na condição 4. 


\subsection{Condição experimental 5}

\subsubsection{Monitoramento ao final do ciclo}

Na condição experimental 5 o reator foi operado em bateladas sequenciais com COAV nominal teórica de $18 \mathrm{kgDQO} \cdot \mathrm{m}^{-3} \cdot \mathrm{d}^{-1}$ e duração do ciclo de 2 horas por um período de 25 dias. A Tabela 5.17 ilustra as variáveis monitoradas e seus respectivos valores médios.

A Figura 5.69 exibe os valores da concentração de carboidratos afluente e efluente (amostras filtradas e não filtradas). A média da concentração afluente foi de 4277 mgSAC.L' ${ }^{1}$, enquanto que a concentração residual foi de $125 \mathrm{mgSAC} . \mathrm{L}^{-1}$. A média da eficiência de remoção com base em amostras filtradas foi de 99\%, sendo que Figura 5.54 exibe o comportamento ao longo da operação.

A Figura 5.70 exibe os valores da eficiência de remoção de carboidratos. Pode ser obseravada uma maior variação no início de operação e posteriormente uma estabilidade do processo, alcançando uma média total de remoção de $95 \%$.

A média da concentração de matéria orgânica afluente foi de $3759 \mathrm{mgDQO} \cdot \mathrm{L}^{-1}$ e as análises de efluente feitas em amostras filtradas e não filtradas resultaram em médias de concentração de 3190 e 3037 mgDQO.L $L^{-1}$, respectivamente, cujos valores são mostrados na Figura 5.71. 
Tabela 5.18: Valores médios dos parâmetros monitorados na condição 5.

\begin{tabular}{|c|c|c|c|c|c|c|c|c|c|c|c|c|c|}
\hline \multirow{2}{*}{$\frac{\text { Parâmetro }}{\mathrm{C}_{\mathrm{ST}}}$} & & \multicolumn{3}{|c|}{ Afluente } & \multicolumn{9}{|c|}{ Efluente } \\
\hline & {$\left[\mathrm{mgDQO} \cdot \mathrm{L}^{-1}\right]$} & 3759 & \pm & 150 & & 25 & ) & 3190 & \pm & 254 & ( & 25 & 5 \\
\hline$\varepsilon_{\mathrm{ST}}$ & {$[\%]$} & - & & - & & & & 15 & \pm & 7 & ( & 25 & ) \\
\hline $\mathrm{C}_{\mathrm{SF}}$ & {$\left[\mathrm{mgDQO} . \mathrm{L}^{-1}\right]$} & - & & - & & & & 3037 & \pm & 283 & ( & 25 & $5)$ \\
\hline$\varepsilon_{\mathrm{SF}}$ & {$[\%]$} & - & & - & & & & 19 & \pm & 8 & ( & & ) \\
\hline $\mathrm{C}_{\mathrm{CT}}$ & {$\left[\mathrm{mgSAC} . \mathrm{L}^{-1}\right]$} & 3647 & \pm & 221 & ( & 25 & ) & 252 & \pm & 172 & ( & 25 & ) \\
\hline $\mathrm{C}_{\mathrm{CF}}$ & {$\left[\mathrm{mgSAC} \cdot \mathrm{L}^{-1}\right]$} & - & & - & & & & 185 & \pm & 152 & ( & 25 & $5)$ \\
\hline$\varepsilon_{\mathrm{CT}}$ & {$[\%]$} & - & & - & & & & 93 & \pm & 5 & ( & & ) \\
\hline$\varepsilon_{\mathrm{CF}}$ & {$[\%]$} & - & & - & & & & 95 & \pm & 4 & ( & & ) \\
\hline AVT & {$\left[\mathrm{mgHAc} . \mathrm{L}^{-1}\right]$} & 31 & \pm & 12 & ( & 22 & ) & 678 & \pm & 88 & c & 22 & ) \\
\hline AT & {$\left[\mathrm{mgCaCO}_{3} \cdot \mathrm{L}^{-1}\right]$} & 570 & \pm & 23 & ( & 22 & ) & 296 & \pm & 49 & ( & 22 & ) \\
\hline $\mathrm{pH}$ & & 7,3 & \pm & 0,2 & ( & 22 & ) & 5,0 & \pm & 0,2 & ( & 22 & ) \\
\hline ST & {$\left[\mathrm{mg} . \mathrm{L}^{-1}\right]$} & 4114 & \pm & 5044 & c & 7 & ) & 2585 & \pm & 453 & ( & 7 & ) \\
\hline SVT & {$\left[\mathrm{mg} . \mathrm{L}^{-1}\right]$} & 874 & \pm & 4870 & c & 7 & ) & 1859 & \pm & 249 & ( & 7 & ) \\
\hline SST & {$\left[\mathrm{mg} \cdot \mathrm{L}^{-1}\right]$} & 68 & \pm & 19 & $c$ & 7 & ) & 143 & \pm & 94 & c & 7 & ) \\
\hline SSV & {$\left[\mathrm{mg} . \mathrm{L}^{-1}\right]$} & 45 & \pm & 10 & c & 7 & ) & 131 & \pm & 58 & ( & 7 & ) \\
\hline $\mathrm{V}_{\mathrm{G}}$ & {$[\mathrm{mL}]$} & - & & - & & & & 939 & \pm & 34 & ( & 3 & ) \\
\hline $\mathrm{V}_{\mathrm{H} 2}$ & {$[\mathrm{~mL}]$} & - & & - & & & & 298 & \pm & 27 & ( & 3 & ) \\
\hline $\mathrm{C}_{\mathrm{X} \text {-SVT }}^{\prime}$ & [g.g-suporte ${ }^{-1}$ ] & 0,15 & & & & & & & & & & & \\
\hline $\mathrm{C}_{\mathrm{X}-\mathrm{SVT}}$ & {$\left[\mathrm{g} . \mathrm{L}^{-1}\right]$} & 5,15 & & & & & & & & & & & \\
\hline COAV $_{\text {STA }}$ & {$\left[\mathrm{kgDQO} \cdot \mathrm{m}^{-3} \cdot \mathrm{d}^{-1}\right]$} & 19,0 & & - & & & & - & & - & & & \\
\hline $\mathrm{CORV}_{\mathrm{SFE}}$ & {$\left[\mathrm{kgDQO} \cdot \mathrm{m}^{-3} \cdot \mathrm{d}^{-1}\right]$} & - & & - & & & & 3,7 & & - & & & \\
\hline $\mathrm{COAV}_{\mathrm{CTA}}$ & {$\left[\mathrm{kgSAC} \cdot \mathrm{m}^{-3} \cdot \mathrm{d}^{-1}\right]$} & 18,5 & & - & & & & - & & - & & & \\
\hline $\mathrm{CORV}_{\mathrm{CTFE}}$ & {$\left[\mathrm{kgSAC} \cdot \mathrm{m}^{-3} \cdot \mathrm{d}^{-1}\right]$} & - & & - & & & & 17,5 & & - & & & \\
\hline $\mathrm{M}_{\mathrm{SVT}}$ & {$[\mathrm{g}]$} & - & & - & & & & 23,2 & \pm & 0,5 & ( & 3 & ) \\
\hline $\mathrm{n}_{\mathrm{H} 2}$ & {$\left[\mathrm{molH}_{2} \cdot \mathrm{d}^{-1}\right]$} & - & & - & & & & 0,13 & & - & & & \\
\hline PrM & {$\left[\mathrm{molH}_{2} \cdot \mathrm{m}^{-3} \cdot \mathrm{d}^{-1}\right]$} & 18,2 & & - & & & & - & & - & & & \\
\hline PrME & {$\left[\mathrm{molH}_{2} \cdot \mathrm{kgSVT}^{-1} \cdot \mathrm{d}^{-1}\right]$} & 5,73 & & - & & & & - & & - & & & \\
\hline $\mathrm{RMCA}_{\mathrm{C}, \mathrm{m}}$ & {$\left[\mathrm{molH}_{2} \cdot \mathrm{kgSAC}^{-1}\right]$} & 1,60 & & - & & & & - & & - & & & \\
\hline $\mathrm{RMCA}_{\mathrm{S}, \mathrm{m}}$ & {$\left[\mathrm{molH}_{2} \cdot \mathrm{kgDQO}^{-1}\right]$} & 1,55 & & - & & & & - & & - & & & \\
\hline $\mathrm{RMCR}_{\mathrm{C}, \mathrm{m}}$ & {$\left[\mathrm{molH}_{2} \cdot \mathrm{kgSAC}^{-1}\right]$} & - & & - & & & & 1,69 & & & & & \\
\hline $\mathrm{RMCR}_{\mathrm{S}, \mathrm{m}}$ & {$\left[\mathrm{molH}_{2} \cdot \mathrm{kgDQO}^{-1}\right]$} & - & & - & & & & 8,09 & - & - & & & \\
\hline $\mathrm{V}_{\mathrm{T}}$ & {$[\mathrm{L}]$} & 4,5 & \pm & 0,1 & ( & 25 & ) & & - & - & & & \\
\hline $\mathrm{V}_{\mathrm{F}}$ & {$[\mathrm{L}]$} & 1,9 & \pm & 0,1 & ( & 25 & ) & & - & - & & & \\
\hline
\end{tabular}

*Número de amostras consideradas. 


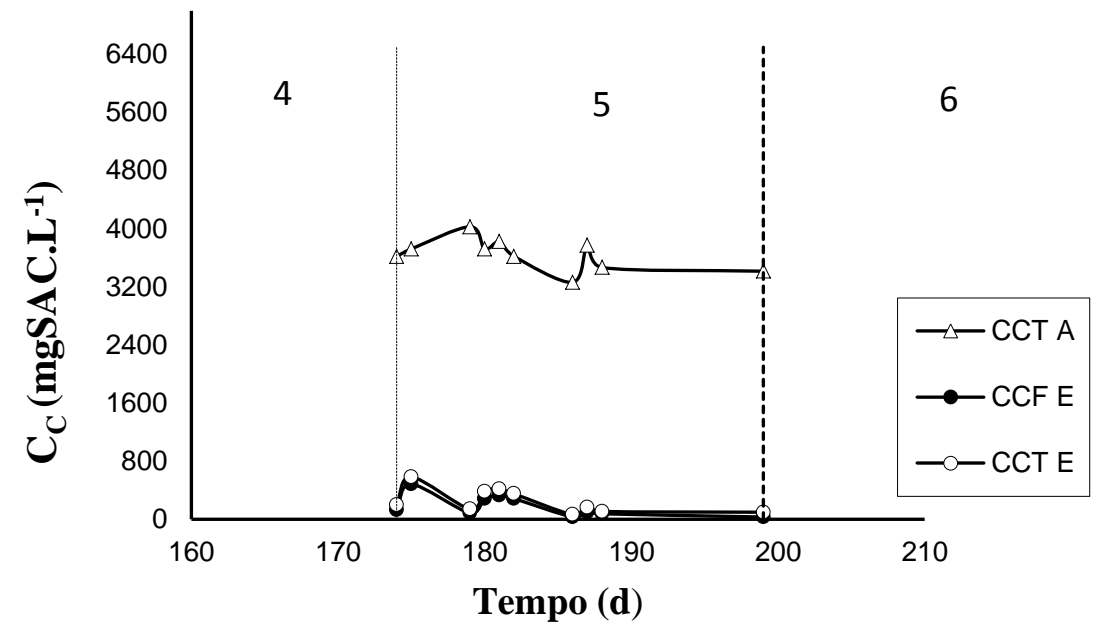

Figura 5.69: Concentração de carboidratos afluente e efluente para amostras filtradas e não filtradas na condição 5 .

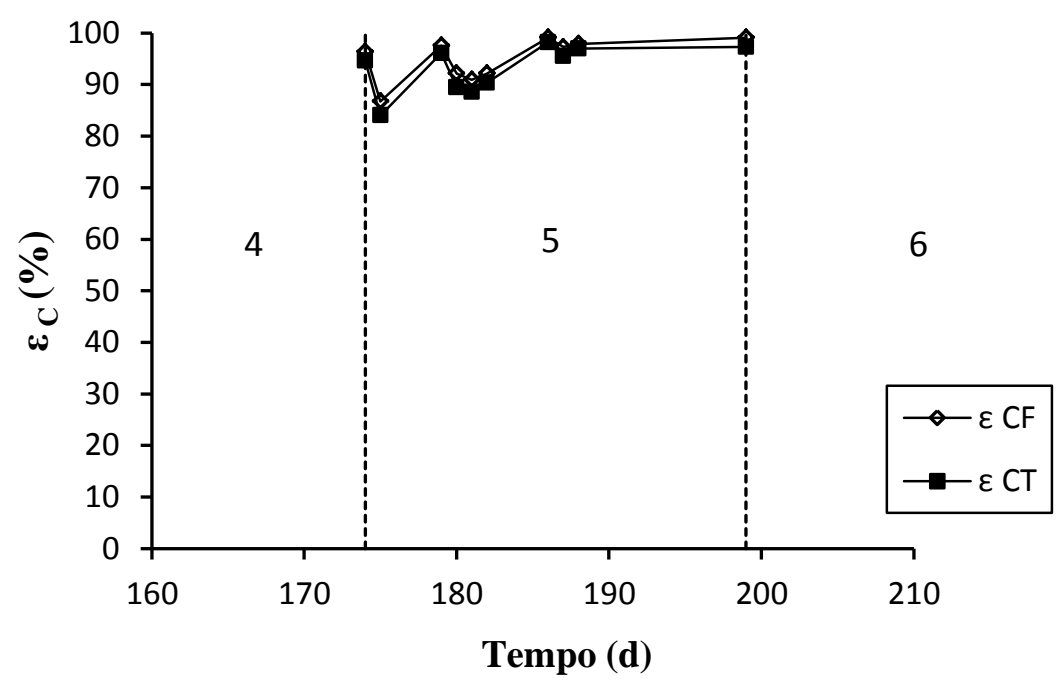

Figura 5.70: Eficiência de remoção de carboidratos para amostras filtradas na condição 5. 


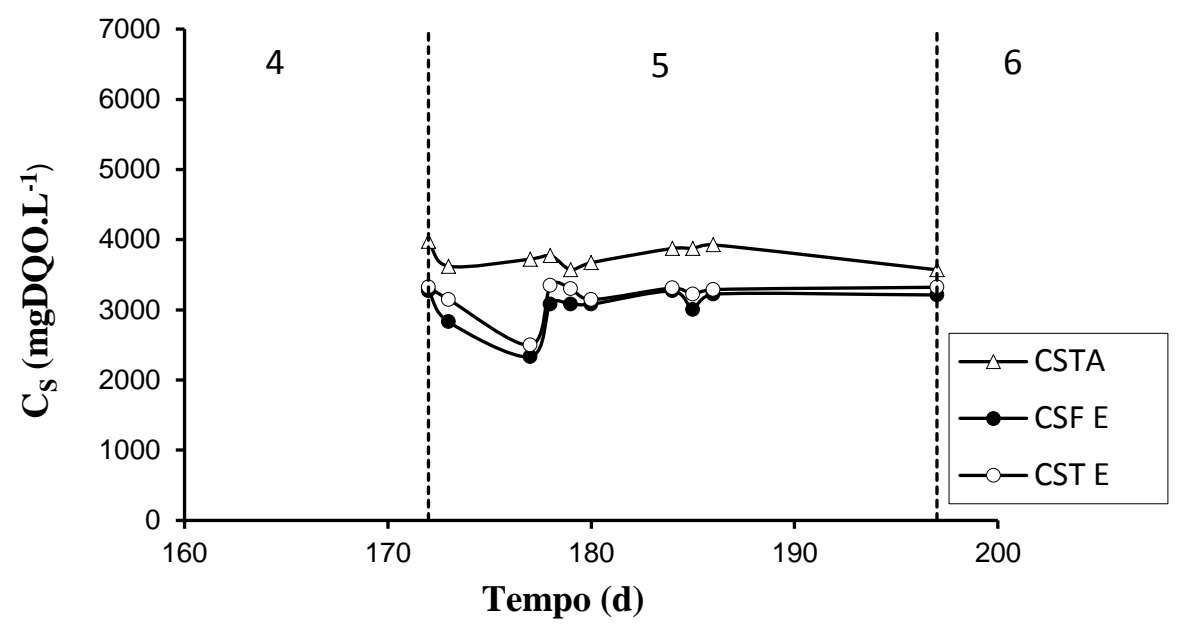

Figura 5.71: Concentração de matéria orgânica (DQO) afluente e efluente para amostras filtradas e não filtradas na condição 5 .

A eficiência de remoção de DQO, com relação a amostras filtradas e não filtradas, mostrou-se relativamente baixa, 19 e $15 \%$ em média, respectivamente, cujos valores podem ser observados na Figura 5.72.

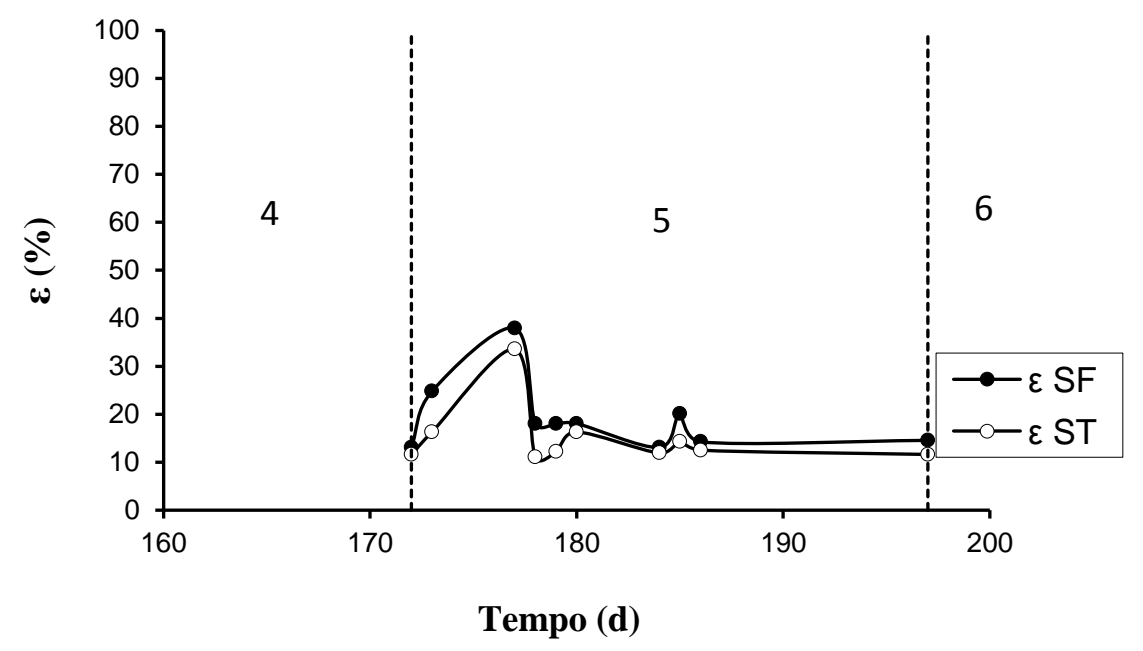

Figura 5.72: Eficiência de remoção de matéria orgânica (DQO) para amostras filtradas e não filtradas na condição 5 . 
A Tabela 5.18 apresenta os valores da concentração média dos compostos intermediários, obtidos em triplicata, contidos no efluente do sistema. O método cromatográfico aplicado não detectou acetona e metanol. A Figura 5.73 mostra a concentração dos ácidos no efluente e afluente. A concentração média de ácidos no efluente foi de $678 \mathrm{mgHAc} . \mathrm{L}^{-1}$ enquanto que no afluente foi de $31 \mathrm{mgHAc} . \mathrm{L}^{-1}$.

Tabela 5.19: Concentração dos compostos intermediários na condição 5.

\begin{tabular}{|c|c|c|c|c|c|c|c|}
\hline \multirow{3}{*}{$\begin{array}{c}\text { Produtos } \\
\text { intermediários }\end{array}$} & \multicolumn{6}{|c|}{ Concentração média } & \multirow{3}{*}{$\begin{array}{c}\text { Porcentagem } \\
(\%)\end{array}$} \\
\hline & \multicolumn{3}{|c|}{$\mathrm{mg} \cdot \mathrm{L}^{-1}$} & \multicolumn{3}{|c|}{ mmol.L $\mathrm{L}^{-1}$} & \\
\hline & - & \pm & - & - & \pm & - & \\
\hline Metanol & - & \pm & - & - & \pm & - & 0,0 \\
\hline Etanol & 333,8 & \pm & 70,3 & 7,1 & \pm & 1,5 & 98,7 \\
\hline n-Butanol & 4,5 & \pm & 0,1 & 0,1 & \pm & 0,0 & 1,3 \\
\hline Acético & 778,6 & \pm & 76,9 & 13,0 & \pm & 1,3 & 51,8 \\
\hline Porpiônico & 144,1 & \pm & 33,4 & 1,9 & \pm & 0,5 & 9,6 \\
\hline Isobutírico & 48,9 & \pm & 24,3 & 0,6 & \pm & 0,3 & 3,3 \\
\hline Butírico & 300,0 & \pm & 109,7 & 3,4 & \pm & 1,2 & 20,0 \\
\hline Isovalérico & 9,7 & \pm & 1,9 & 0,1 & \pm & 0,0 & 0,6 \\
\hline Valérico & 59,6 & \pm & 21,4 & 0,6 & \pm & 0,2 & 4,0 \\
\hline Capróico & 161,0 & \pm & 68,9 & 1,4 & \pm & 0,6 & 10,7 \\
\hline
\end{tabular}

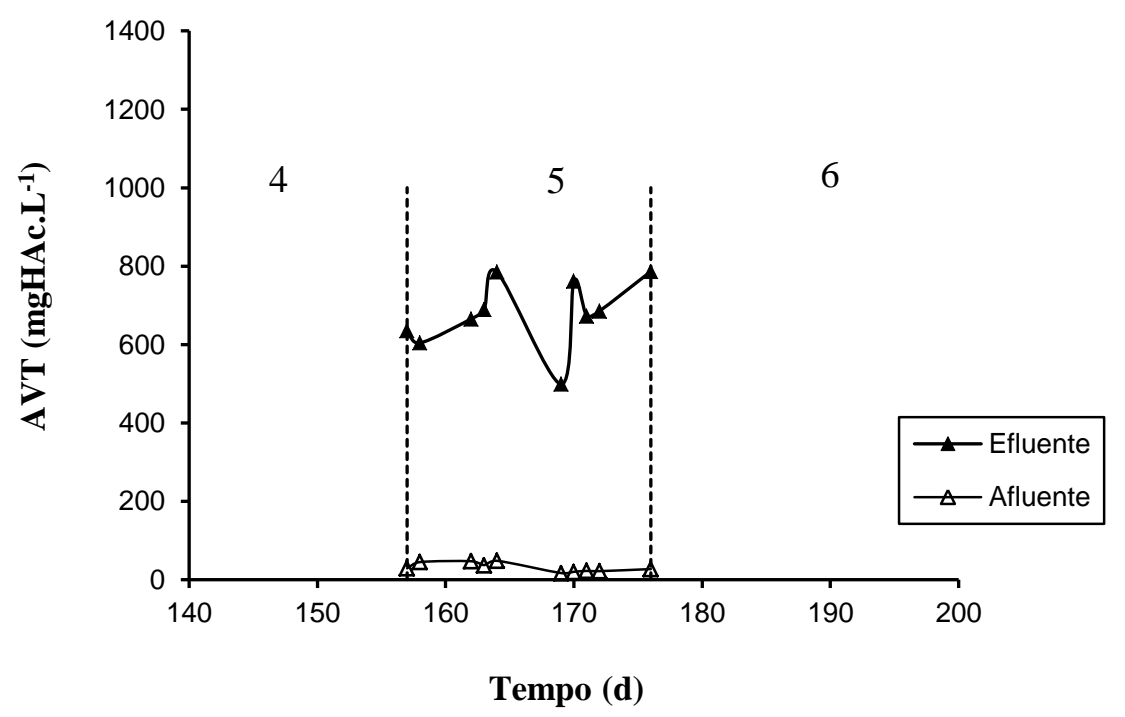

Figura 5.73: Concentração de ácidos voláteis totais afluente e efluente na condição 5. 
O acúmulo de ácidos orgânicos no interior do reator provocaram a redução instantânea do $\mathrm{pH}$ assim que o afluente entrava em contato com o meio residual no interior do reator. A Figura 5.74, apresenta os valores de $\mathrm{pH}$, afluente e efluente, ao longo do período experimental. O valor médio do $\mathrm{pH}$ afluente foi de 7,3 e de 5,0 para o efluente.

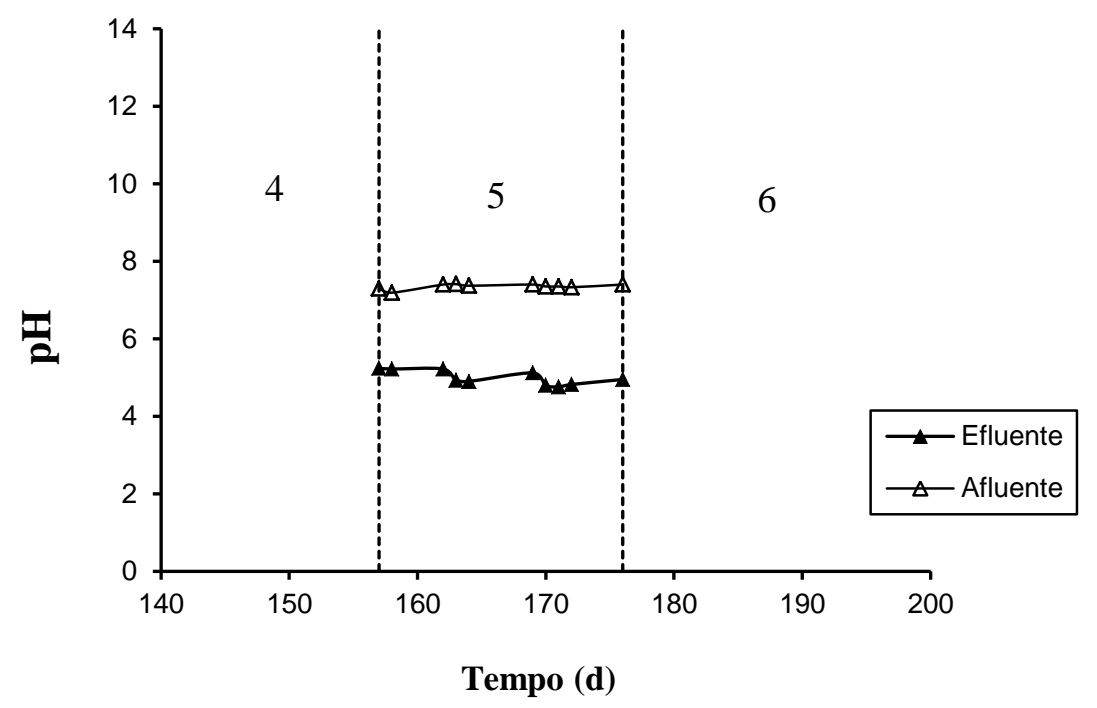

Figura 5.74: Valores de pH afluente e efluente na condição 5.

A Figura 5.75 apresenta as concentrações, afluente e efluente, da alcalinidade ao longo da operação. Os valores médios de alcalinidade foram de 570 e $296 \mathrm{mgCaCO}_{3} \cdot \mathrm{L}^{-1}$ para o afluente e efluente, respectivamente.

O monitoramento da série de sólidos é mostrado na Tabela 5.20, cujos valores indicam um baixo teor de SSV no efluente e afluente.

A produção do biogás, em aspecto quantitativo, pode ser observada na Figura 5.76. A média de produção foi de 866 mL (CNTP). 


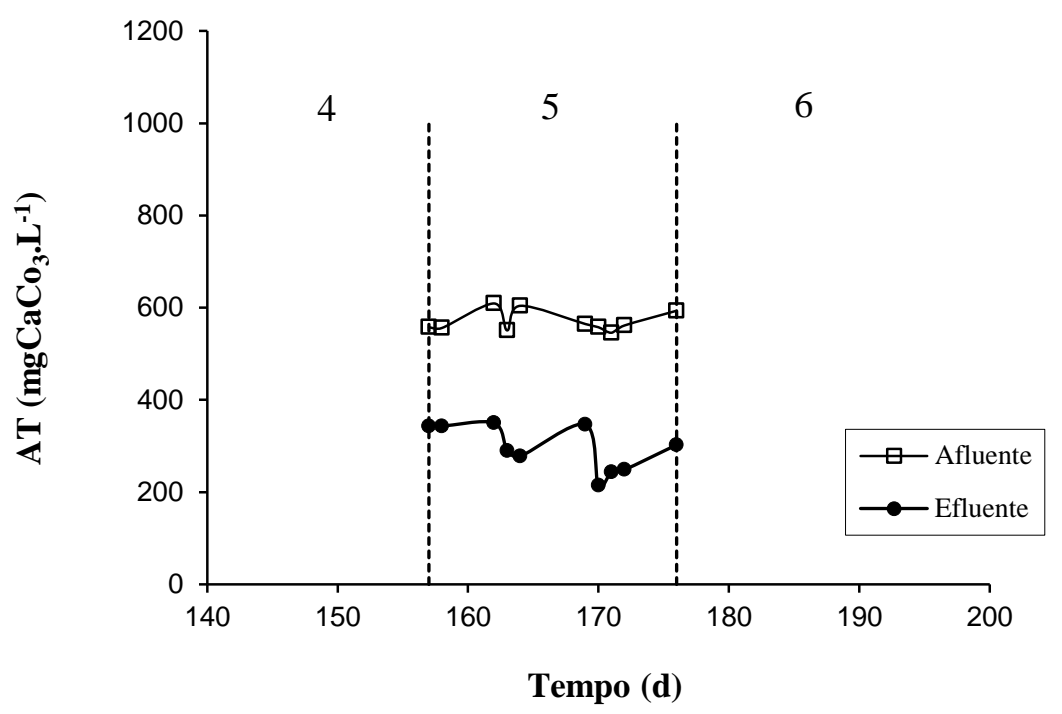

Figura 5.75: Concentração de alcalinidade total afluente e efluente na condição 4.

Tabela 5.20: Série de sólidos afluente e efluente na condição 5.

\begin{tabular}{lcccc}
\hline & $\begin{array}{c}\mathrm{ST} \\
\left(\mathrm{mg} . \mathrm{L}^{-1}\right)\end{array}$ & $\begin{array}{c}\mathrm{SVT} \\
\left(\mathrm{mg} . \mathrm{L}^{-1}\right)\end{array}$ & $\begin{array}{c}\mathrm{SST} \\
\left(\mathrm{mg} . \mathrm{L}^{-1}\right)\end{array}$ & $\begin{array}{c}\mathrm{SSV} \\
\left(\mathrm{mg.L}^{-1}\right)\end{array}$ \\
\hline Afluente & $5155 \pm 190$ & $3686 \pm 79$ & $74 \pm 23$ & $40 \pm 2,8$ \\
Efluente & $2584 \pm 453$ & $1858 \pm 249$ & $143 \pm 94$ & $13 \pm 57$ \\
\hline \multicolumn{5}{c}{}
\end{tabular}

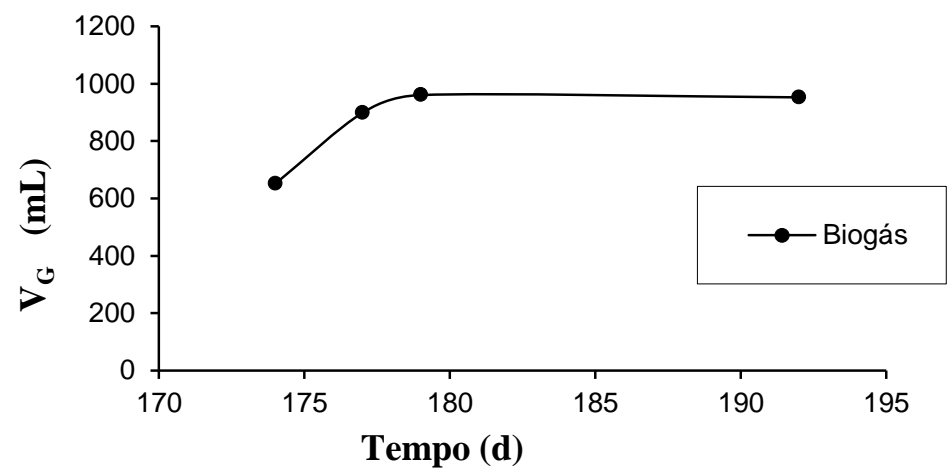

Figura 5.76: Volume total de biogás produzido na condição 5. 


\subsubsection{Monitoramento ao longo do ciclo}

A Figura 5.77 apresenta os valores da concentração de carboidratos ao longo do perfil de operação. No tempo inicial o valor da concentração é de $3468 \mathrm{mgSAC} . \mathrm{L}^{-1}$. A redução imediata da concentração inicial deve-se ao volume residual de meio existente no interior do recipiente de recirculação. Como pode ser observado na Figura 5.77(a) e 5.77(b), após uma 1,3 horas de ciclo praticamente todo substrato é removido, atingindo uma eficiência de $99 \%$ com um residual de $55 \mathrm{mgSAC} . \mathrm{L}^{-1}$ ao final das 2 horas de ciclo.

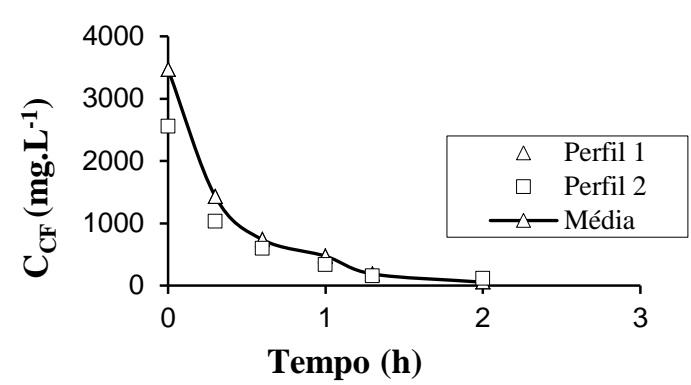

(a)

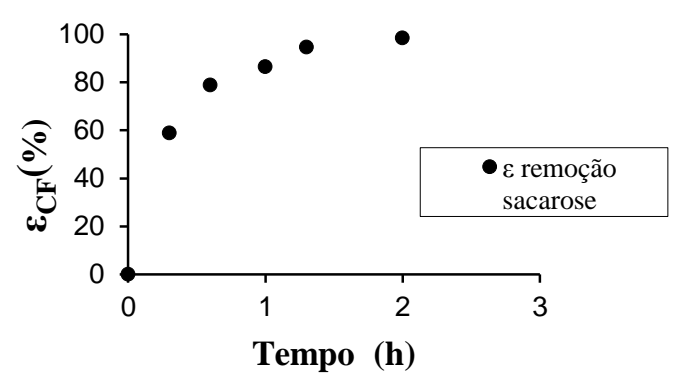

(b)

Figura 5.77: (a) Concentração de carboidratos e (b) eficiência de remoção para amostras filtradas ao longo do ciclo na condição 5 .

A Figura 5.78 representa o comportamento da matéria orgânica ao longo do ciclo. No inicio do ciclo a concentração é de $3468 \mathrm{mgDQO} . \mathrm{L}^{-1}$ reduzindo a $3080 \mathrm{mgDQO} . \mathrm{L}^{-1}$ em 1 hora de ciclo e chegando a 3915 mgDQO. $\mathrm{L}^{-1}$ em 2 horas de ciclo. 


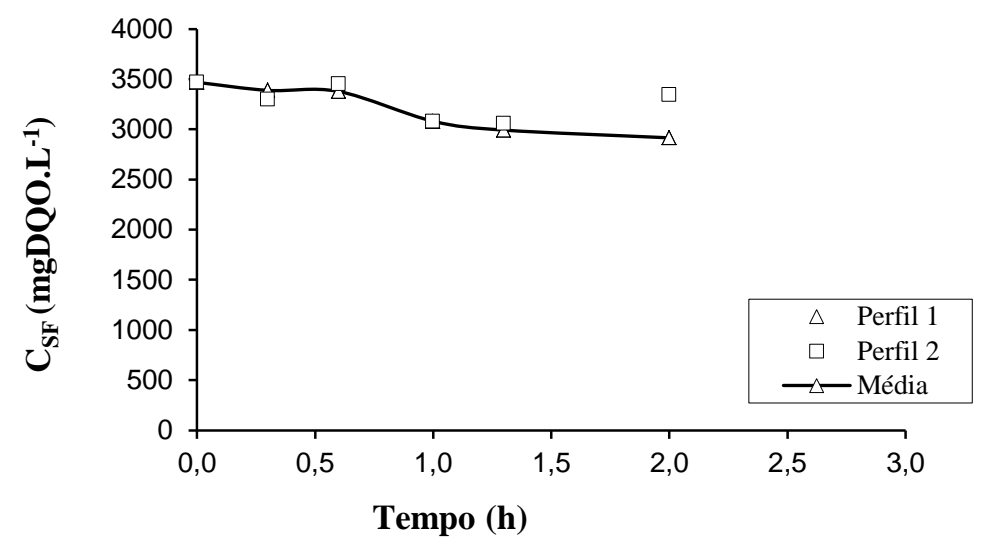

Figura 5.78: Concentração de matéria orgânica (DQO) para amostras filtradas ao longo do ciclo na condição 5 .

A produção de ácidos voláteis é representada na Figura 5.79. No tempo inical a concentração de ácidos é de 200 mgHAc. $\mathrm{L}^{-1}$, tendo um crescimento acentuado em 0,5 hora e atingindo o valor de $760 \mathrm{mgHAc} . \mathrm{L}^{-1}$, seguido de um aumento menos acentuado, chegando ao valor de $821 \mathrm{mgHAc.L^{-1 }}$ com 2 horas de ciclo. A média da concentração de ácidos voláteis ao longo do ciclo foi de $668 \mathrm{mgHAc} . \mathrm{L}^{-1}$.

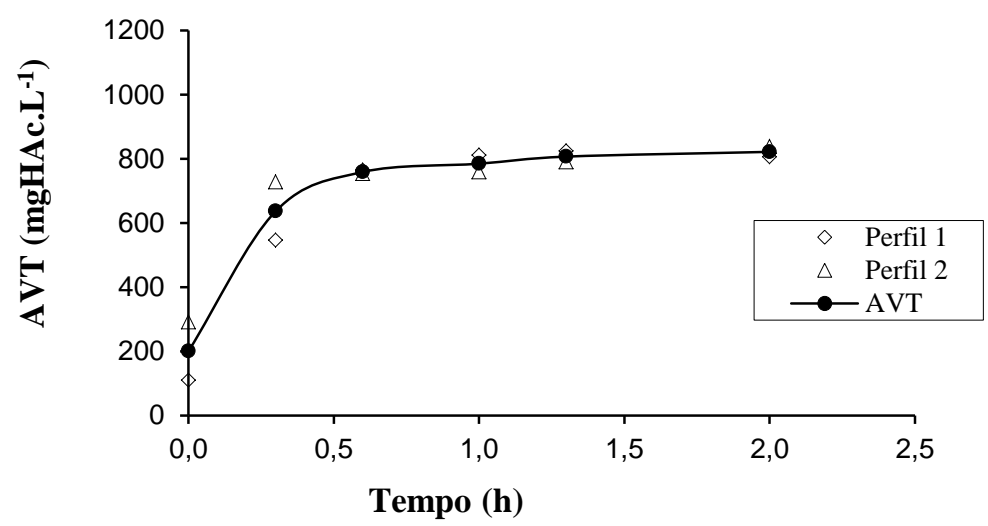

Figura 5.79: Concentração de ácidos voláteis totais ao longo do ciclo na condição 5. 


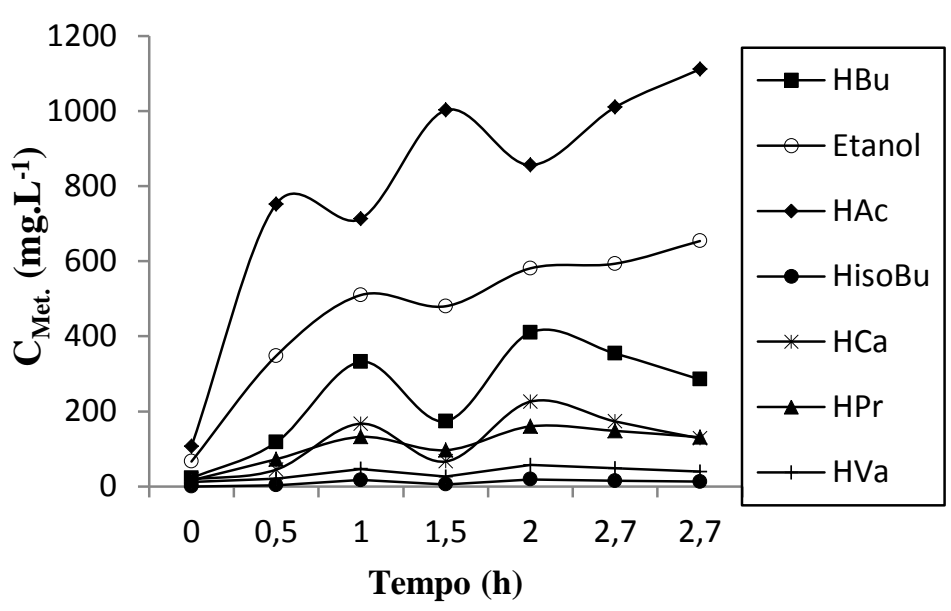

Figura 5.80: Concentração dos compostos intermediários ao longo do ciclo na condição 5.

A Figura 5.80 permite observar a predominância do ácido acético, mostrando um crescimento acentuado nos 0,6 hora de ciclo, chegando a $657 \mathrm{mg} . \mathrm{L}^{-1}$ e mantendo um crescimento menor a partir desse ponto, atingindo o valor de $833 \mathrm{mg} . \mathrm{L}^{-1}$ ao final do ciclo de 2 horas. A Figura 5.81 apresenta o comportamento da alcalinidade total ao longo do ciclo. No inicio do ciclo a alcalinidade é de $449 \mathrm{mgCaCO} 3 . \mathrm{L}^{-1}$, ocorrendo uma redução nos primeiros 20 minutos e atingindo o valor de $230 \mathrm{mgCaCO}_{3} \cdot \mathrm{L}^{-1}$ ao final do ciclo de 2 horas.

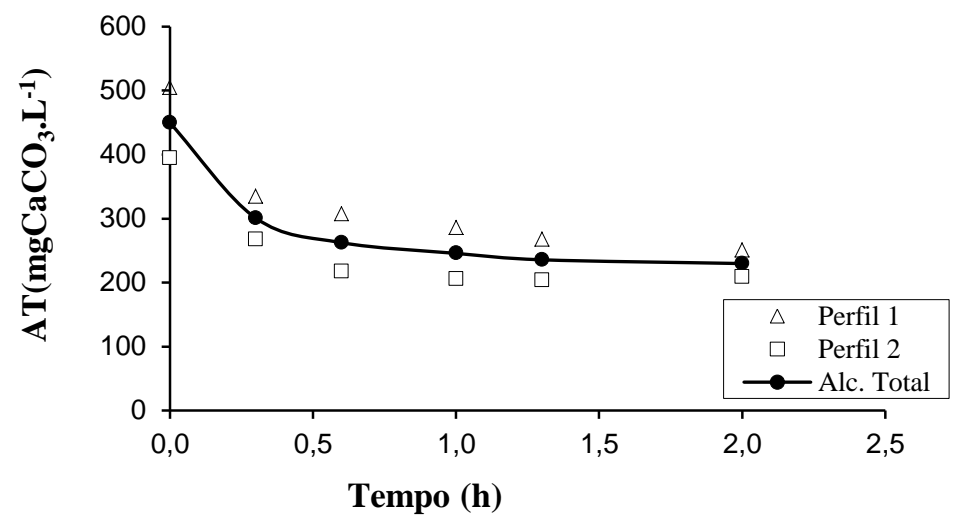

Figura 5.81: Concentração de alcalinidade total ao longo do ciclo na condição 5. 
O perfil dos valores de $\mathrm{pH}$ mostrados na Figura 5.18 indicam que o valor inicial de 6,7 é reduzido ao valor de 5,1 devido aos ácidos voláteis no interior do reator, mantendo-se constante durante todo o ciclo, demonstrando a estabilidade do mesmo.

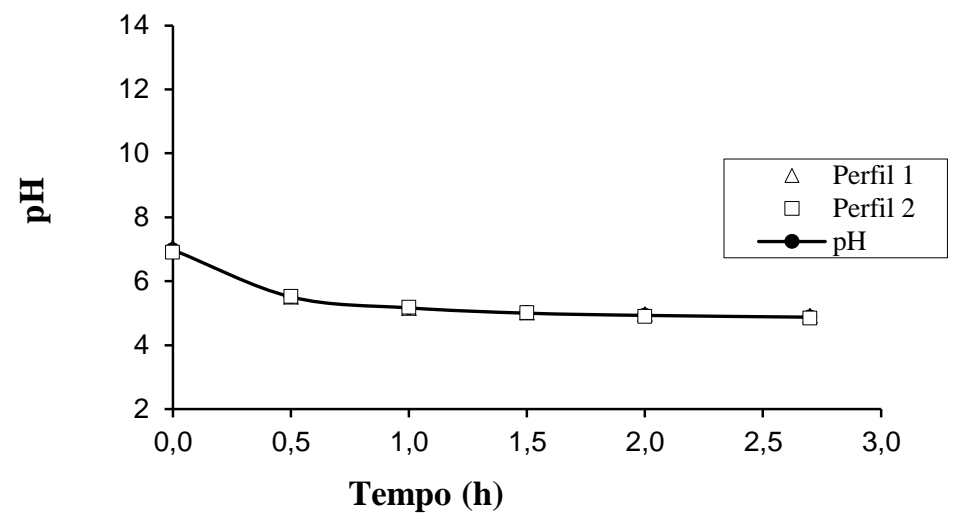

Figura 5.82: Valores de pH ao longo do ciclo na condição 5.

A Figura 5.83 permite observar que a produção do biogás é crescente durante todo o ciclo e atingindo o valor máximo de939 mL (CNTP) ao final do ciclo. A Tabela 5.21 resume os valores da produção do biogás, concentração, fração molar e volumes individuais da mistura gasosa. A Figura 5.84 apresenta os volumes de $\mathrm{H}_{2}, \mathrm{CO}_{2}$ e $\mathrm{CH}_{4}$ produzidos durante o ciclo. Nos primeiros 40 minutos são produzidos $148 \mathrm{~mL}$ de $\mathrm{H}_{2}$, atingindo o valor máximo de $298 \mathrm{~mL}$ ao final das 2 horas de ciclo. Não foi detectado metano.

Tabela 5.21: Produção e composição do biogás produzido ao longo do ciclo na condição 5.

\begin{tabular}{ccccccccccc}
\hline \multirow{2}{*}{ Tempo (h) } & \multirow{2}{*}{$\mathrm{V}_{\mathrm{G}}(\mathrm{mL})$} & \multicolumn{3}{c}{$\mathrm{C}_{\mathrm{G}}\left(\mathrm{mmol} . \mathrm{L}^{-1}\right)$} & \multicolumn{3}{c}{ Fração Molar (\%) } & \multicolumn{3}{c}{ Volume (mL) } \\
& & $\mathrm{H}_{2}$ & $\mathrm{CO}_{2}$ & $\mathrm{CH}_{4}$ & $\mathrm{H}_{2}$ & $\mathrm{CO}_{2}$ & $\mathrm{CH}_{4}$ & $\mathrm{H}_{2}$ & $\mathrm{CO}_{2}$ & $\mathrm{CH}_{4}$ \\
\hline 0,0 & 0 & 0,0 & 0,0 & 0,0 & 0 & 0 & 0 & 0 & 0 & 0 \\
0,3 & 312 & 1,7 & 5,7 & 0,0 & 23 & 77 & 0 & 71 & 242 & 0 \\
0,6 & 551 & 3,7 & 7,7 & 0,0 & 33 & 67 & 0 & 149 & 403 & 0 \\
1,0 & 728 & 5,9 & 9,6 & 0,0 & 38 & 62 & 0 & 216 & 512 & 0 \\
1,3 & 853 & 6,7 & 11,5 & 0,0 & 37 & 63 & 0 & 262 & 591 & 0 \\
1,7 & 939 & 7,0 & 11,0 & 0,0 & 39 & 61 & 0 & 298 & 641 & 0 \\
\hline
\end{tabular}




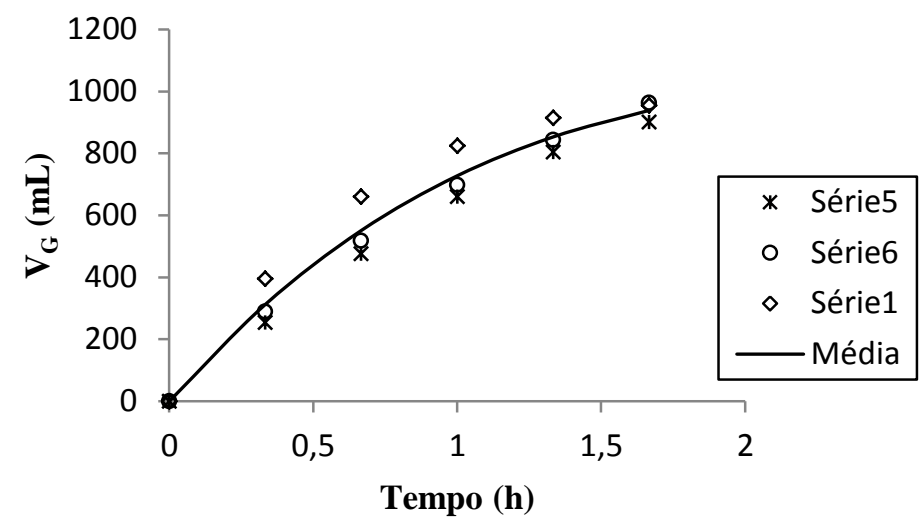

Figura 5.83: Volume total de biogás produzido ao longo do ciclo na condição 5.

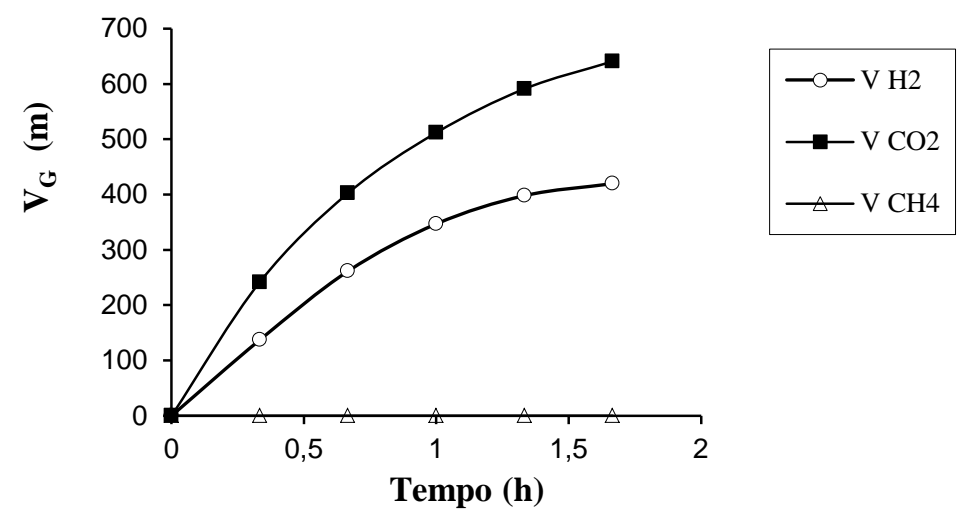

Figura 5.84: Volumes de $\mathrm{H}_{2}, \mathrm{CO}_{2}$ e $\mathrm{CH}_{4}$ produzidos ao longo do ciclo na condição 5. 


\subsection{Condição experimental 6}

\subsubsection{Monitoramento ao final do ciclo}

Na condição experimental 6 o reator foi operado em bateladas sequenciais com COAV nominal teórica de $27 \mathrm{kgDQO} \cdot \mathrm{m}^{-3} \cdot \mathrm{d}^{-1} \mathrm{e}$ duração do ciclo de 2 horas por um período de 25 dias. A Tabela 5.22 ilustra as variáveis monitoradas e seus respectivos valores médios.

A Figura 5.85 exibe os valores da concentração de carboidratos afluente e efluente (amostras filtradas e não filtradas). A média da concentração afluente foi de 5245 mgSAC.L'

${ }^{1}$, enquanto que a concentração residual para amostras filtradas foi de $345 \mathrm{mgSAC} . \mathrm{L}^{-1}$. A média da eficiência de remoção com base em amostras filtradas foi de $94 \%$, sendo que a Figura 5.86 exibe o comportamento ao longo da operação.

A Figura 5.86 exibe os valores da eficiência de remoção de carboidratos. Pode ser obseravada uma redução na eficiência do sistema, obtendo-se uma média de remoção de $94 \%$.

A média da concentração de matéria orgânica afluente foi de $5657 \mathrm{mgDQO} . \mathrm{L}^{-1}$ e as análises de efluente feitas em amostras filtradas e não filtradas resultaram em médias de concentração de 4661 e 4917 mgDQO.L $L^{-1}$, respectivamente, cujos valores são mostrados na Figura 5.87. A eficiência de remoção de DQO, com relação a amostras filtradas e não filtradas, mostrou-se relativamente baixa, 16 e 12\% em média, respectivamente, cujos valores podem ser observados na Figura 5.88. 
Tabela 5.22: Valores médios dos parâmetros monitorados na condição 6.

\begin{tabular}{|c|c|c|c|c|c|c|c|c|c|c|c|c|c|}
\hline \multirow{2}{*}{$\frac{\text { Parâmetro }}{\mathrm{C}_{\mathrm{ST}}}$} & & \multicolumn{3}{|c|}{ Afluente } & \multicolumn{9}{|c|}{ Efluente } \\
\hline & {$\left[\mathrm{mgDQO} \cdot \mathrm{L}^{-1}\right]$} & 5657 & \pm & 333 & ( & 25 & ) & 4917 & \pm & 284 & ( & 25 & ) \\
\hline$\varepsilon_{\mathrm{ST}}$ & {$[\%]$} & - & & - & & & & 12 & \pm & 5 & ( & 25 & ) \\
\hline $\mathrm{C}_{\mathrm{SF}}$ & {$\left[\mathrm{mgDQO} . \mathrm{L}^{-1}\right]$} & - & & - & & & & 4661 & \pm & 250 & ( & 25 & ) \\
\hline$\varepsilon_{\mathrm{SF}}$ & {$[\%]$} & - & & - & & & & 17 & \pm & 4 & ( & 25 & ) \\
\hline $\mathrm{C}_{\mathrm{CT}}$ & {$\left[\mathrm{mgSAC} . \mathrm{L}^{-1}\right]$} & 5245 & \pm & 284 & ( & 25 & ) & 398 & \pm & 282 & ( & 25 & ) \\
\hline $\mathrm{C}_{\mathrm{CF}}$ & {$\left[\mathrm{mgSAC} \cdot \mathrm{L}^{-1}\right]$} & - & & - & & & & 345 & \pm & 272 & ( & 25 & ) \\
\hline$\varepsilon_{\mathrm{CT}}$ & {$[\%]$} & - & & - & & & & 93 & \pm & 5 & ( & 25 & ) \\
\hline$\varepsilon_{\mathrm{CF}}$ & [\%] & - & & - & & & & 94 & \pm & 5 & ( & 25 & ) \\
\hline AVT & {$\left[\mathrm{mgHAc} . \mathrm{L}^{-1}\right]$} & 28 & \pm & 6 & ( & 22 & ) & 894 & \pm & 125 & ( & 22 & ) \\
\hline AT & {$\left[\mathrm{mgCaCO}_{3} \cdot \mathrm{L}^{-1}\right]$} & 777 & \pm & 21 & c & 22 & ) & 328 & \pm & 58 & ( & 22 & ) \\
\hline $\mathrm{pH}$ & & 7,3 & \pm & 0,1 & ( & 22 & ) & 4,8 & \pm & 0,1 & ( & 22 & ) \\
\hline ST & {$\left[\mathrm{mg} . \mathrm{L}^{-1}\right]$} & 6622 & \pm & 314 & ( & 7 & ) & 3382 & \pm & 153 & ( & 7 & ) \\
\hline SVT & {$\left[\mathrm{mg} . \mathrm{L}^{-1}\right]$} & 5681 & \pm & 291 & ( & 7 & ) & 2423 & \pm & 176 & ( & 7 & ) \\
\hline SST & {$\left[\mathrm{mg} . \mathrm{L}^{-1}\right]$} & 79 & \pm & 25 & ( & 7 & ) & 146 & \pm & 30 & c & 7 & ) \\
\hline SSV & {$\left[\mathrm{mg} . \mathrm{L}^{-1}\right]$} & 48 & \pm & 25 & ( & 7 & ) & 105 & \pm & 31 & c & 7 & ) \\
\hline $\mathrm{V}_{\mathrm{G}}$ & {$[\mathrm{mL}]$} & - & & - & & & & 1619 & \pm & 16 & ( & 3 & ) \\
\hline $\mathrm{V}_{\mathrm{H} 2}$ & {$[\mathrm{~mL}]$} & - & & - & & & & 457 & \pm & 38 & ( & 3 & ) \\
\hline $\mathrm{C}_{\mathrm{X} \text {-SVT }}^{\prime}$ & [g.g-suporte ${ }^{-1}$ ] & 0,15 & & & & & & & & & & & \\
\hline $\mathrm{C}_{\mathrm{X}-\mathrm{SVT}}$ & {$\left[\mathrm{g} . \mathrm{L}^{-1}\right]$} & 5,15 & & & & & & & & & & & \\
\hline $\mathrm{COAV}_{\mathrm{STA}}$ & {$\left[\mathrm{kgDQO} \cdot \mathrm{m}^{-3} \cdot \mathrm{d}^{-1}\right]$} & 28,7 & & - & & & & - & & - & & & \\
\hline $\mathrm{CORV}_{\mathrm{SFE}}$ & {$\left[\mathrm{kgDQO} \cdot \mathrm{m}^{-3} \cdot \mathrm{d}^{-1}\right]$} & - & & - & & & & 5,0 & & - & & & \\
\hline COAV $_{\text {CTA }}$ & {$\left[\mathrm{kgSAC} \cdot \mathrm{m}^{-3} \cdot \mathrm{d}^{-1}\right]$} & 26,6 & & - & & & & - & & - & & & \\
\hline $\mathrm{CORV}_{\mathrm{CTFE}}$ & {$\left[\mathrm{kgSAC} \cdot \mathrm{m}^{-3} \cdot \mathrm{d}^{-1}\right]$} & - & & - & & & & 24,8 & & - & & & \\
\hline $\mathrm{M}_{\mathrm{SVT}}$ & {$[\mathrm{g}]$} & - & & - & & & & 23,2 & \pm & 0,5 & ( & 3 & ) \\
\hline $\mathrm{n}_{\mathrm{H} 2}$ & {$\left[\mathrm{molH}_{2} \cdot \mathrm{d}^{-1}\right]$} & - & & - & & & & 0,20 & & - & & & \\
\hline PrM & {$\left[\mathrm{molH}_{2} \cdot \mathrm{m}^{-3} \cdot \mathrm{d}^{-1}\right]$} & 27,9 & & - & & & & - & & - & & & \\
\hline PrME & {$\left[\mathrm{molH}_{2} \cdot \mathrm{kgSVT}^{-1} \cdot \mathrm{d}^{-1}\right]$} & 8,79 & & - & & & & - & & - & & & \\
\hline $\mathrm{RMCA}_{\mathrm{C}, \mathrm{m}}$ & {$\left[\mathrm{molH}_{2} \cdot \mathrm{kgSAC}{ }^{-1}\right]$} & 1,71 & & - & & & & - & & - & & & \\
\hline $\mathrm{RMCA}_{\mathrm{S}, \mathrm{m}}$ & {$\left[\mathrm{molH}_{2} \cdot \mathrm{kgDQO}^{-1}\right]$} & 1,58 & & - & & & & - & & - & & & \\
\hline $\mathrm{RMCR}_{\mathrm{C}, \mathrm{m}}$ & {$\left[\mathrm{molH}_{2} \cdot \mathrm{kgSAC}^{-1}\right]$} & - & & - & & & & 1,83 & & - & & & \\
\hline $\mathrm{RMCR}_{\mathrm{S}, \mathrm{m}}$ & {$\left[\mathrm{molH}_{2} \cdot \mathrm{kgDQO}^{-1}\right]$} & - & & - & & & & 8,98 & & - & & & \\
\hline $\mathrm{V}_{\mathrm{T}}$ & {$[\mathrm{L}]$} & 4,5 & \pm & 0,1 & c & 25 & ) & - & & - & & & \\
\hline $\mathrm{V}_{\mathrm{F}}$ & [L] & 1,9 & \pm & 0,1 & c & 25 & ) & - & & - & & & \\
\hline
\end{tabular}

*Número de amostras consideradas. 


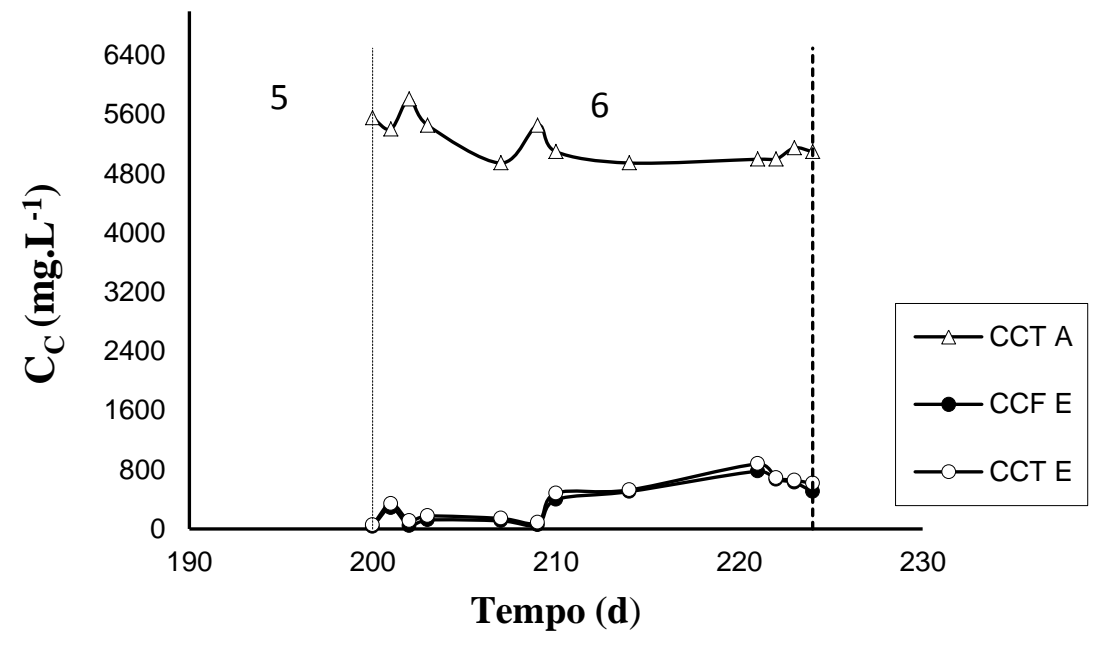

Figura 5.85: Concentração de carboidratos afluente e efluente para amostras filtradas e não filtradas na condição 6.

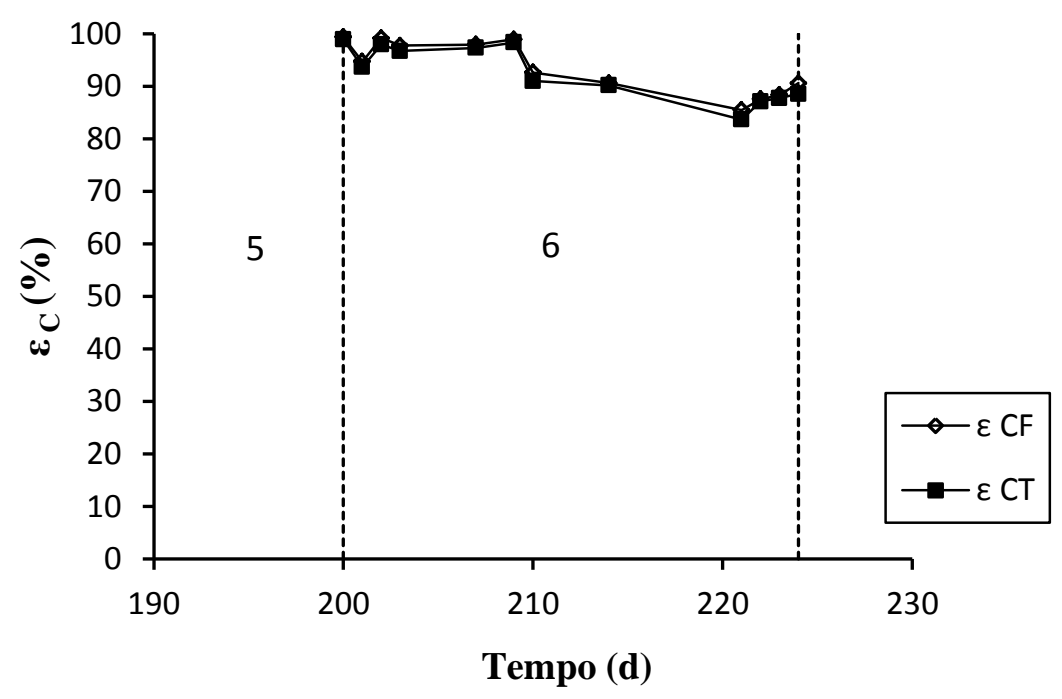

Figura 5.86: Eficiência de remoção de carboidratos para amostras filtradas na condição 6. 


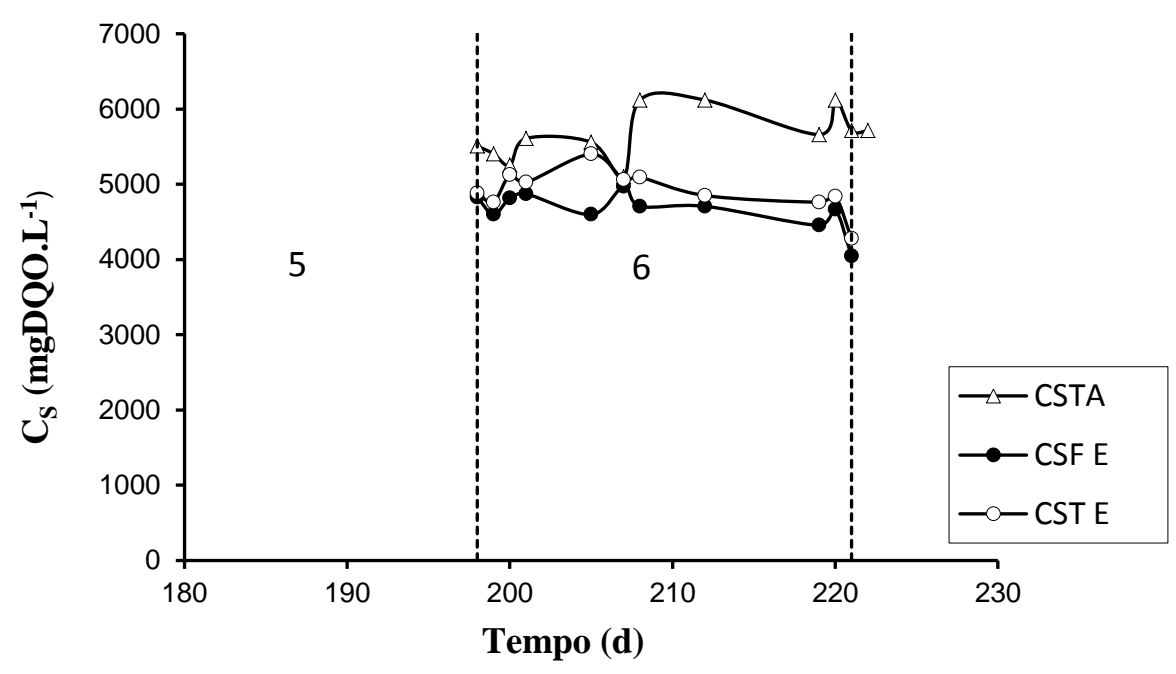

Figura 5.87: Concentração de matéria orgânica (DQO) afluente e efluente para amostras filtradas e não filtradas na condição 6 .

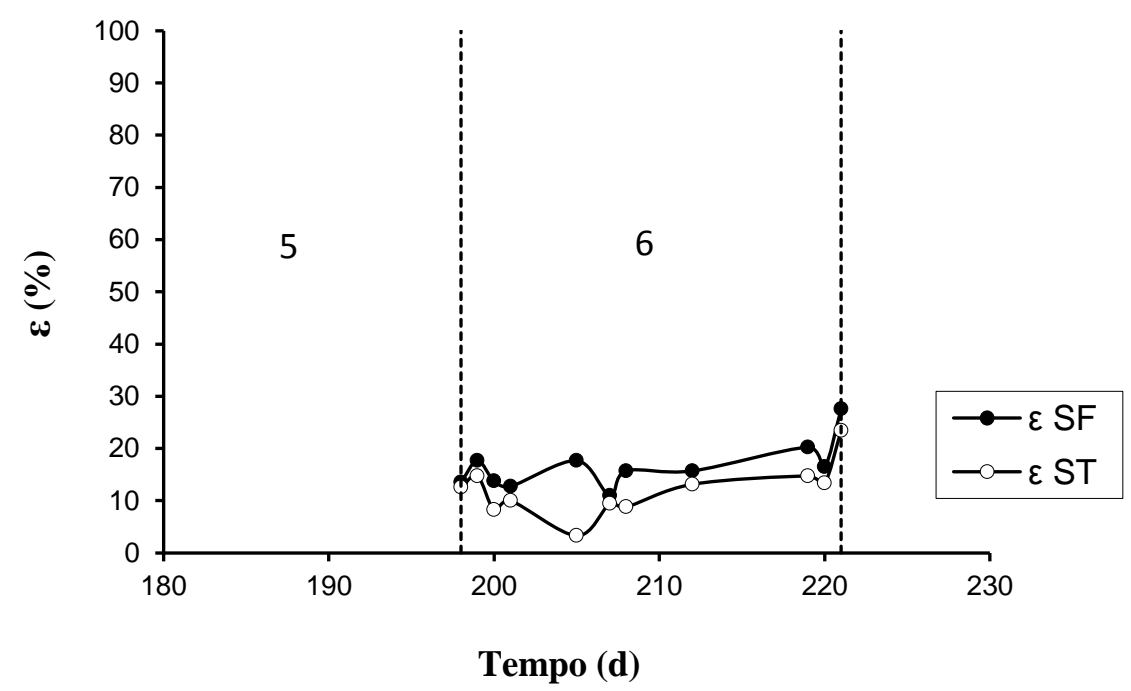

Figura 5.88: Eficiência de remoção de matéria orgânica (DQO) para amostras filtradas e não filtradas na condição 6 . 
A Tabela 5.22 apresenta os valores da concentração média dos compostos intermediários, obtidos em triplicata, contidos no efluente do sistema. O método cromatográfico aplicado não detectou acetona e metanol. A Figura 5.89 mostra a concentração dos ácidos no efluente e afluente. A concentração média de ácidos no efluente foi de $678 \mathrm{mgHAc} . \mathrm{L}^{-1}$ enquanto que no afluente foi de $31 \mathrm{mgHAc} . \mathrm{L}^{-1}$.

Tabela 5.23: Concentração dos compostos intermediários na condição 6.

\begin{tabular}{|c|c|c|c|c|c|c|c|}
\hline \multirow{3}{*}{$\begin{array}{c}\begin{array}{c}\text { Produtos } \\
\text { intermediários }\end{array} \\
\text { Acetona }\end{array}$} & \multicolumn{6}{|c|}{ Concentração média } & \multirow{3}{*}{$\begin{array}{c}\text { Porcentagem } \\
(\%)\end{array}$} \\
\hline & \multicolumn{3}{|c|}{$\mathrm{mg} \cdot \mathrm{L}^{-1}$} & \multicolumn{3}{|c|}{ mmol.L $\mathrm{L}^{-1}$} & \\
\hline & - & \pm & - & - & \pm & - & \\
\hline Metanol & - & \pm & - & - & \pm & - & 0,0 \\
\hline Etanol & 382,5 & \pm & 136,6 & 8,2 & \pm & 2,9 & 98,4 \\
\hline n-Butanol & 6,1 & \pm & 2,0 & 0,1 & \pm & 0,0 & 1,6 \\
\hline Acético & 752,3 & \pm & 255,5 & 12,5 & \pm & 4,3 & 48,2 \\
\hline Porpiônico & 96,5 & \pm & 40,1 & 1,3 & \pm & 0,5 & 6,2 \\
\hline Isobutírico & 114,9 & \pm & 85,6 & 1,3 & \pm & 1,0 & 7,4 \\
\hline Butírico & 315,4 & \pm & 77,9 & 3,6 & \pm & 0,9 & 20,2 \\
\hline Isovalérico & 9,9 & \pm & 1,1 & 0,1 & \pm & 0,0 & 0,6 \\
\hline Valérico & 49,9 & \pm & 11,0 & 0,5 & \pm & 0,1 & 3,2 \\
\hline Capróico & 222,2 & \pm & 68,4 & 1,9 & \pm & 0,6 & 14,2 \\
\hline
\end{tabular}

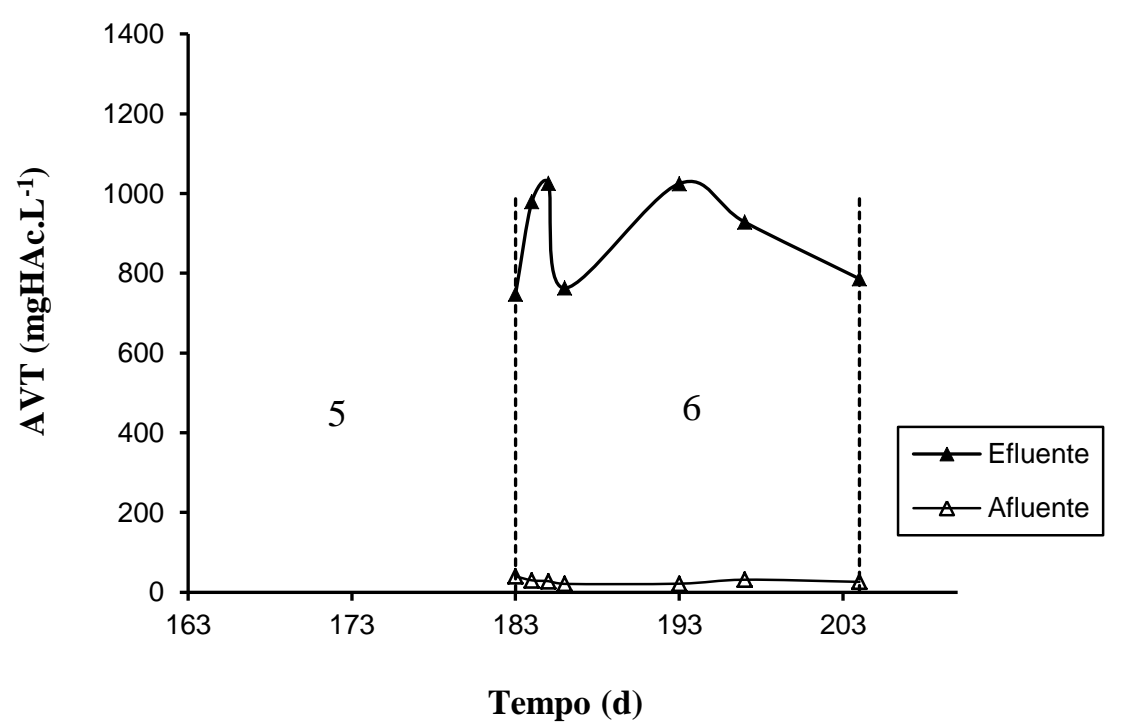

Figura 5.89: Concentração de ácidos voláteis totais afluente e efluente na condição 6. 
O acúmulo de ácidos orgânicos no interior do reator provocaram a redução instantânea do $\mathrm{pH}$ assim que o afluente entrava em contato com o meio residual no interior do reator. A Figura 5.90, apresenta os valores de $\mathrm{pH}$, afluente e efluente, ao longo do período experimental. O valor médio do $\mathrm{pH}$ afluente foi de 7,3 e de 4,8 para o efluente.

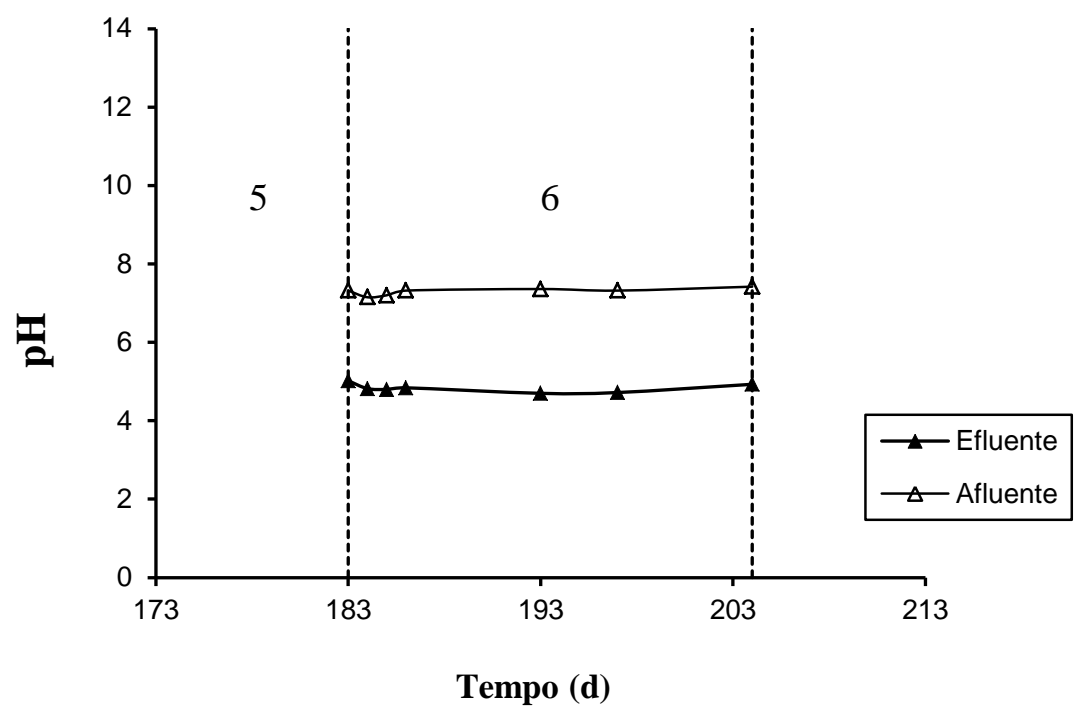

Figura 5.90: Valores de pH afluente e efluente na condição 6.

A Figura 5.91 apresenta as concentrações, afluente e efluente, da alcalinidade ao longo da operação. Os valores médios de alcalinidade foram de 777 e $328 \mathrm{mgCaCO}_{3} \cdot \mathrm{L}^{-1}$ para o afluente e efluente, respectivamente.

O monitoramento da série de sólidos é mostrado na Tabela 5.24, cujos valores indicam um baixo teor de SSV no efluente e afluente.

A produção do biogás, em aspecto quantitativo, 6 pode ser observada na Figura 5.92. A média de produção foi de 1620 mL (CNTP). 


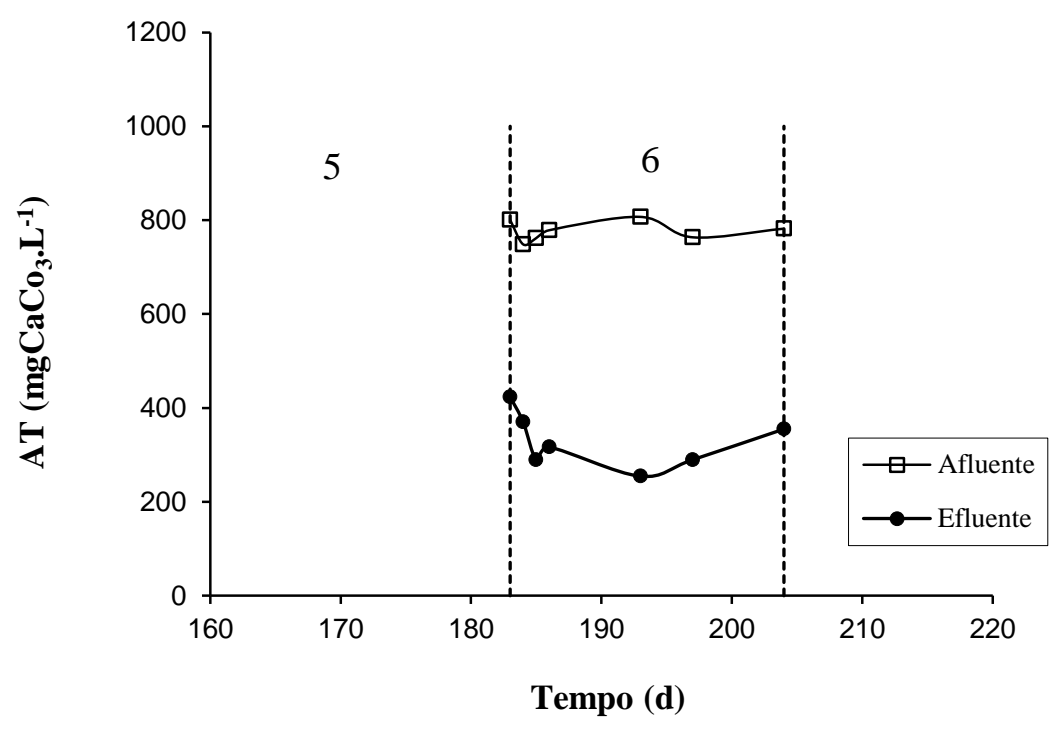

Figura 5.91: Concentração de alcalinidade total afluente e efluente na condição 6.

Tabela 5.24: Série de sólidos afluente e efluente na condição 6.

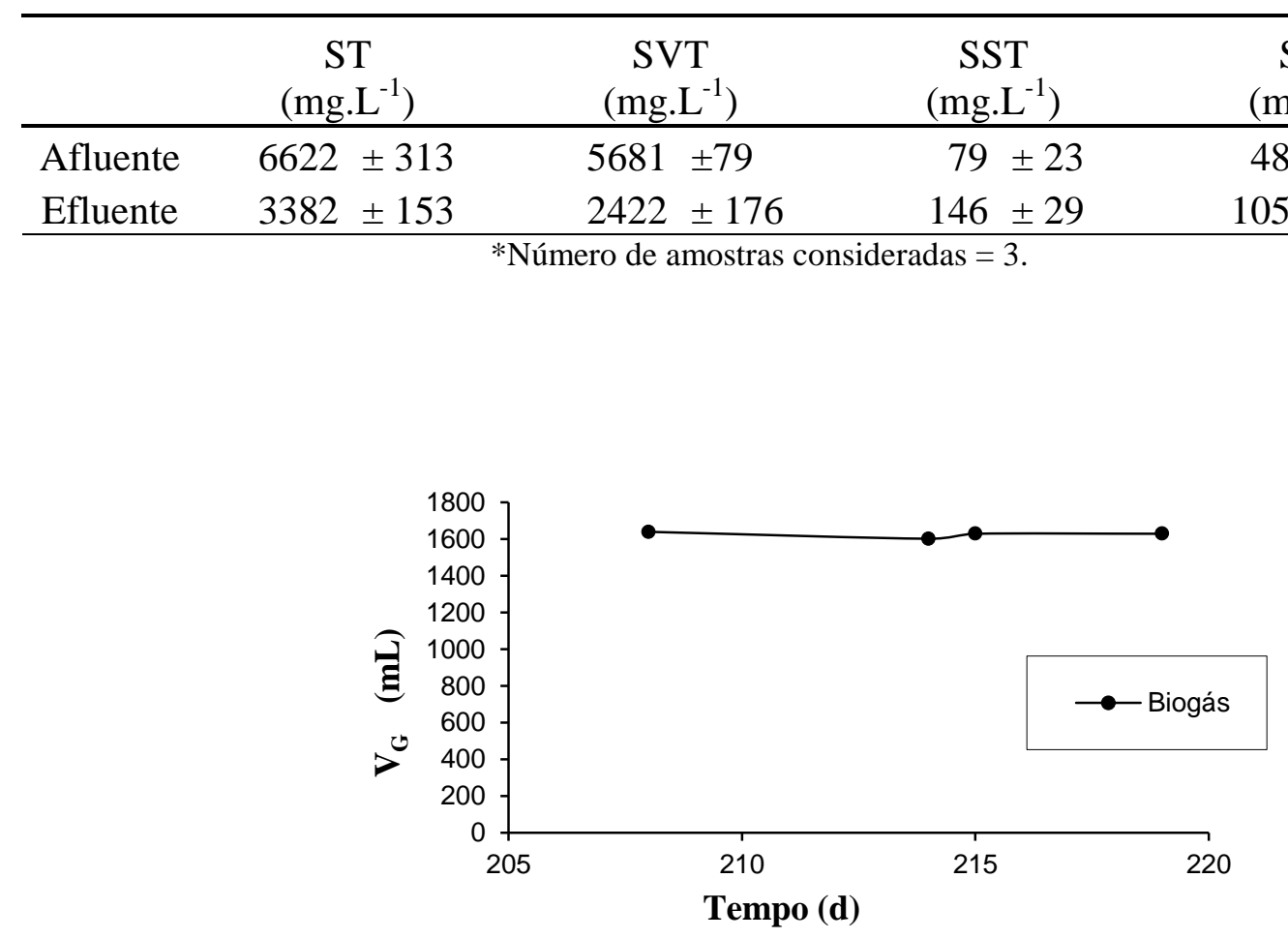

Figura 5.92: Volume total de biogás produzido na condição 6. 


\subsubsection{Monitoramento ao longo do ciclo}

A Figura 5.93 apresenta os valores da concentração de carboidratos ao longo do perfil de operação. No tempo inical o valor da concentração é de $4820 \mathrm{mgSAC} \cdot \mathrm{L}^{-1}$. A redução imediata da concentração inicial deve-se ao volume residual de meio existente no interior do recipiente de recirculação. Como pode ser observado na Figura 5.93(a) e 5.93(b), após 1,3 horas de ciclo praticamente todo substrato é removido, atingindo uma eficiência de $99 \%$ com um residual de $55 \mathrm{mgSAC} . \mathrm{L}^{-1}$ ao final das 2 horas de ciclo.

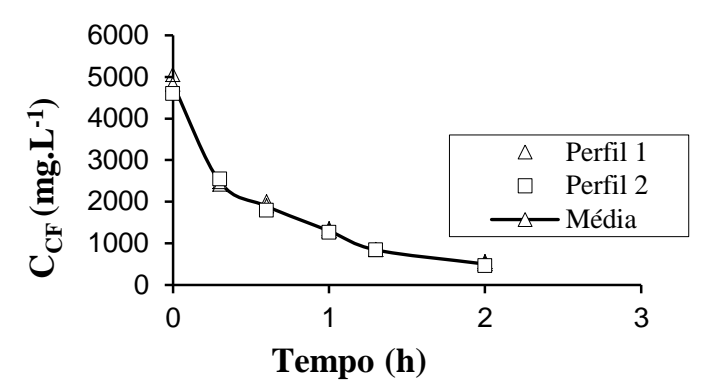

(a)

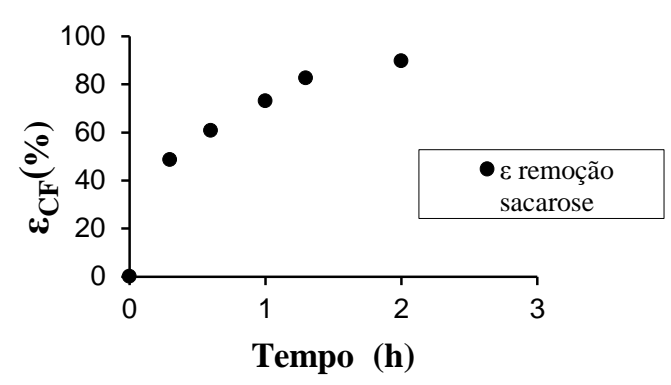

(b)

Figura 5.93: (a) Concentração de carboidratos e (b) eficiência de remoção para amostras filtradas ao longo do ciclo na condição 6.

A Figura 5.94 representa o comportamento da matéria orgânica ao longo do ciclo. No inicio do ciclo a concentração é de $5992 \mathrm{mgDQO} . \mathrm{L}^{-1}$, reduzindo a $4911 \mathrm{mgDQO} . \mathrm{L}^{-1}$ em 1 hora de ciclo e chegando a $4702 \mathrm{mgDQO} . \mathrm{L}^{-1} \mathrm{em} 2$ horas de ciclo. 


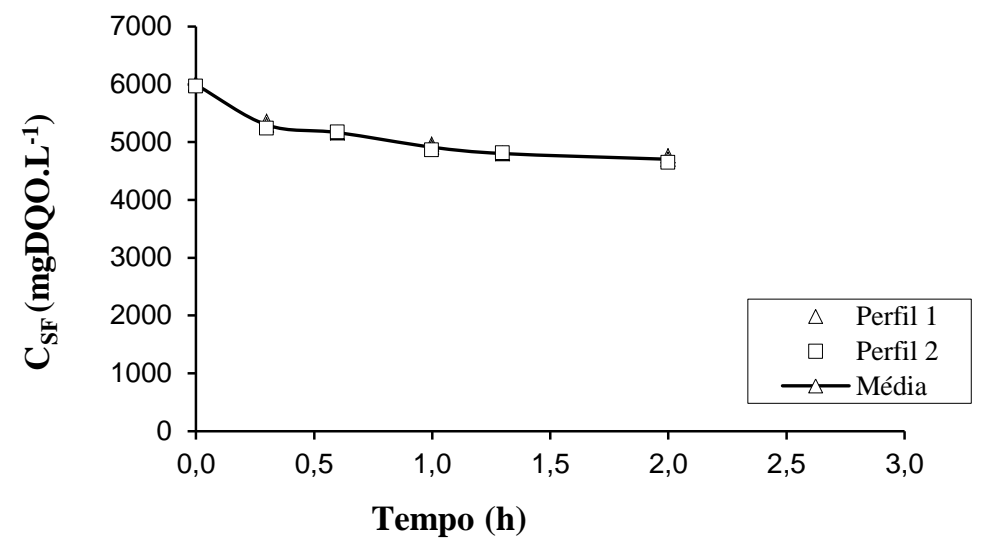

Figura 5.94: Concentração de matéria orgânica (DQO) para amostras filtradas ao longo do ciclo na condição 6.

A produção de ácidos voláteis é representada na Figura 5.95. No tempo inicial a concentração de ácidos é de 115 mgHAc. $\mathrm{L}^{-1}$, tendo um crescimento acentuado em 0,6 hora e atingindo o valor de $685 \mathrm{mgHAc} . \mathrm{L}^{-1}$, seguido de um aumento menos acentuado, chegando ao valor de 942 mgHAc.L $L^{-1}$ com 2 horas de ciclo. A média da concentração de ácidos voláteis ao longo do ciclo foi de $659 \mathrm{mgHAc} . \mathrm{L}^{-1}$.

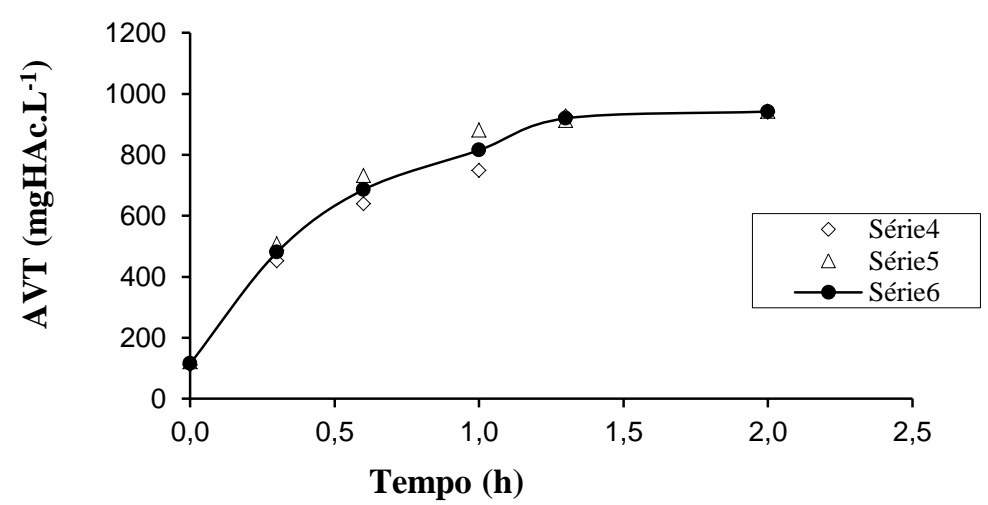

Figura 5.95: Concentração de ácidos voláteis totais ao longo do ciclo na condição 6. 


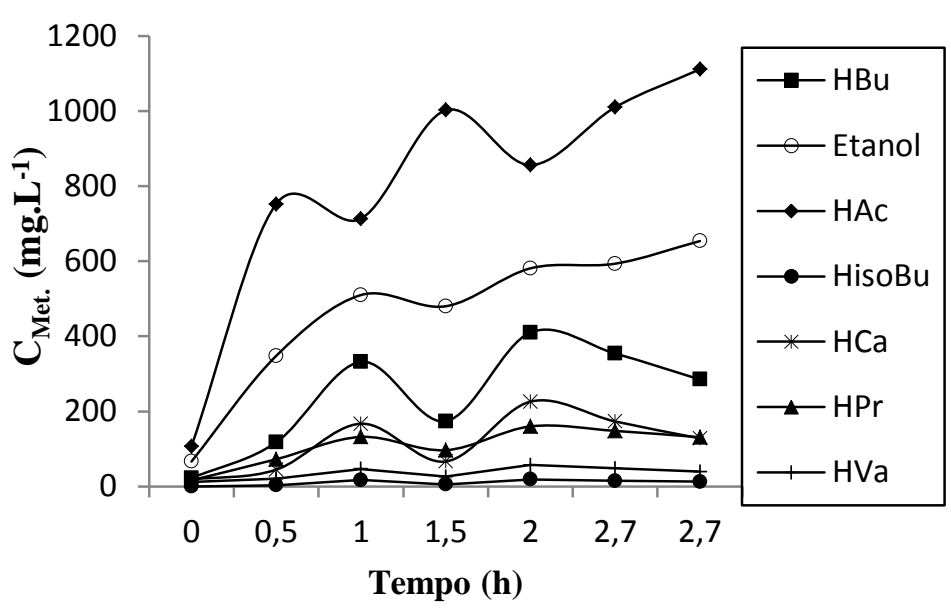

Figura 5.96: Concentração dos compostos intermediários ao longo do ciclo na condição 1.

A Figura 5.96 permite observar a predominância do ácido acético, mostrando um crescimento acentuado nos primeiros 40 minutos de ciclo, chegando a $713 \mathrm{mg} . \mathrm{L}^{-1}$ e mantendo um crescimento menor a partir desse ponto, atingindo o valor de $1060 \mathrm{mg} . \mathrm{L}^{-1}$ ao final do ciclo de 2 horas. A Figura 5.97 apresenta o comportamento da alcalinidade total ao longo do ciclo. No inicio do ciclo a alcalinidade é de $737 \mathrm{mgCaCO}_{3}$, ocorrendo uma redução nos primeiros 20 minutos e atingindo o valor de $302 \mathrm{mgCaCO}_{3}$ ao final do ciclo de 2 horas.

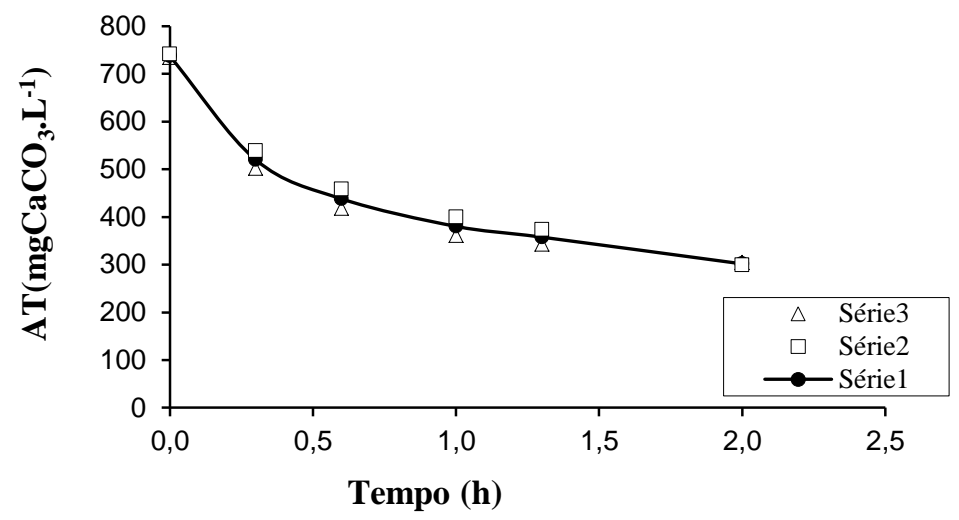

Figura 5.97: Concentração de alcalinidade total ao longo do ciclo na condição 6. 
O perfil dos valores de $\mathrm{pH}$ mostrados na Figura 5.98 indicam que o valor inicial de 7,0 é reduzido ao valor de 5,7 devido aos ácidos voláteis no interior do reator, mantendo-se constante durante todo o ciclo, demonstrando a estabilidade do mesmo.

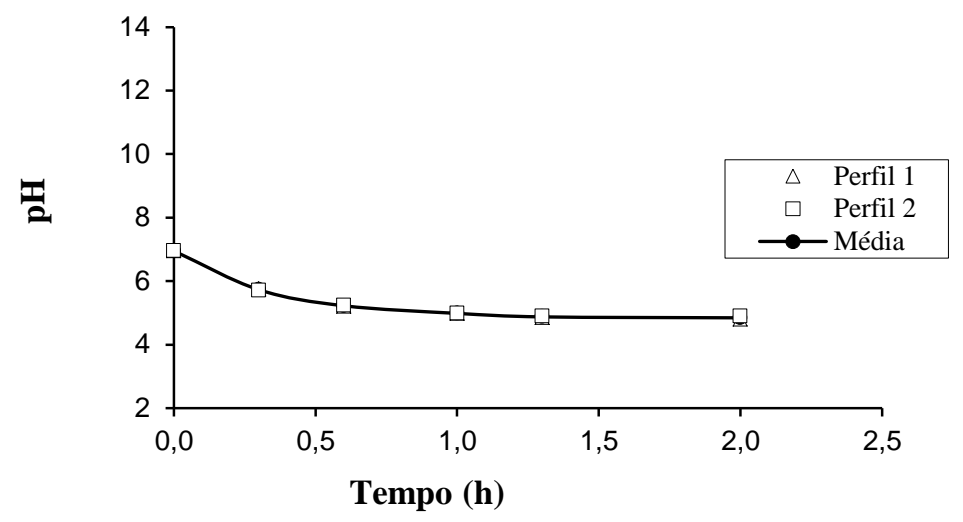

Figura 5.98: Valores de pH ao longo do ciclo na condição 6.

A Figura 5.99 permite observar que a produção do biogás é crescente durante quase todo o ciclo, atingindo o valor máximo de $939 \mathrm{~mL}$ (CNTP) ao final do ciclo. A Tabela 5.25 resume os valores da produção, concentração, fração molar e os volumes individuais da mistura gasosa. A Figura 5.100 apresenta os volumes específicos $\mathrm{H}_{2}, \mathrm{CO}_{2}$ e $\mathrm{CH}_{4}$ produzidos durante o ciclo. Nos primeiros 40 minutos são produzidos $280 \mathrm{~mL} \mathrm{de} \mathrm{H}_{2}$, atingindo o valor máximo de $457 \mathrm{~mL}$ ao final das 2 horas de ciclo. Não foi detectado metano.

Tabela 5.25: Produção e composição do biogás produzido ao longo do ciclo na condição 6.

\begin{tabular}{ccccccccccc}
\hline \multirow{2}{*}{ Tempo (h) } & \multirow{2}{*}{$\mathrm{V}_{\mathrm{G}}(\mathrm{mL})$} & \multicolumn{3}{c}{$\mathrm{C}_{\mathrm{G}}\left(\mathrm{mmol.L^{-1 } )}\right.$} & \multicolumn{3}{c}{ Fração Molar (\%) } & \multicolumn{3}{c}{ Volume (mL) } \\
& & $\mathrm{H}_{2}$ & $\mathrm{CO}_{2}$ & $\mathrm{CH}_{4}$ & $\mathrm{H}_{2}$ & $\mathrm{CO}_{2}$ & $\mathrm{CH}_{4}$ & $\mathrm{H}_{2}$ & $\mathrm{CO}_{2}$ & $\mathrm{CH}_{4}$ \\
\hline 0,0 & 0 & 0,0 & 0 & 0,0 & 0 & 0 & 0 & 0,0 & 0,0 & 0 \\
0,3 & 0,0 & 2,6 & 10 & 0,0 & 21 & 79 & 0 & 137 & 503 & 0 \\
0,6 & 640 & 5,5 & 14 & 0,0 & 29 & 71 & 0 & 280 & 854 & 0 \\
1,0 & 1134 & 7,2 & 15 & 0,0 & 32 & 68 & 0 & 471 & 999 & 0 \\
1,3 & 1470 & 8,2 & 16 & 0,0 & 33 & 67 & 0 & 468 & 1168 & 0 \\
1,7 & 1636 & 10,1 & 18 & 0,0 & 37 & 63 & 0 & 457 & 1162 & 0 \\
\hline
\end{tabular}




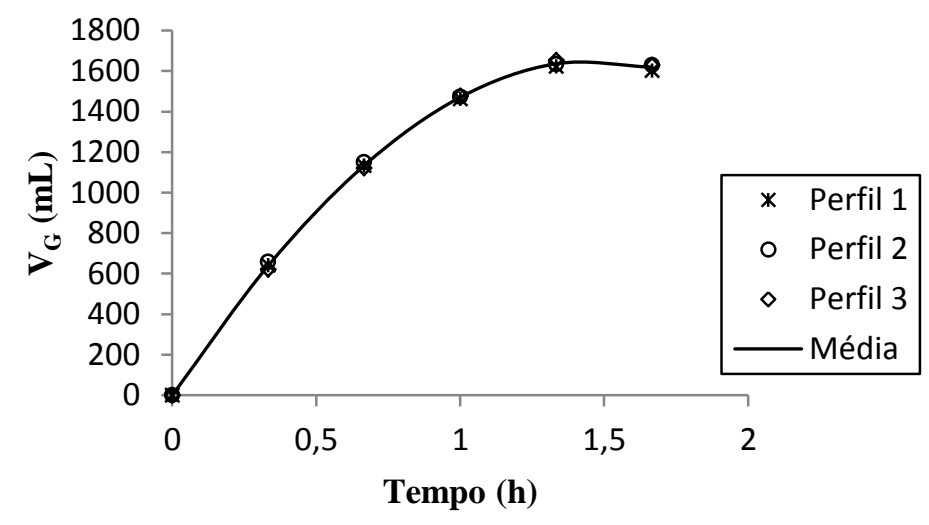

Figura 5.99: Volume total de biogás produzido ao longo do ciclo na condição 6.

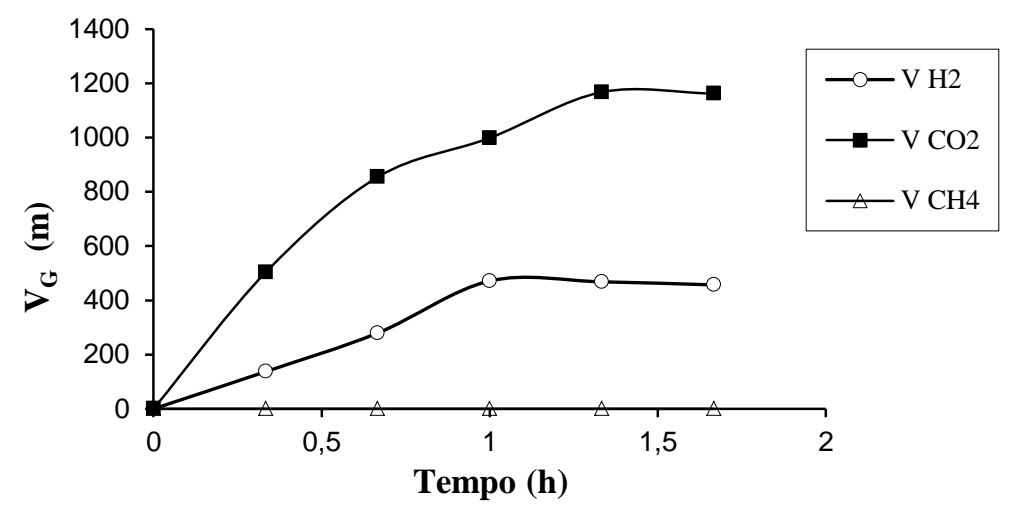

Figura 5.100: Volumes de $\mathrm{H}_{2}, \mathrm{CO}_{2}$ e $\mathrm{CH}_{4}$ produzidos ao longo do ciclo na condição 6. 


\subsection{Análise geral das condições experimentais estudadas}

Nesta parte será feita uma discussão global dos parâmetros analisados anteriormente visando uma análise geral do comportamento do sistema.

A Figura 5.101 mostra as seis diferentes condições experimentais de DQO utilizadas no projeto e na Figura 5.102 a eficiência de remoção de DQO, sendo que a média para amostras filtradas foi de $18 \%$, mantendo esta estabilidade durante toda a fase experimental. Dessa forma, pode-se observar que as diferentes cargas orgânicas volumétricas aplicadas a partir de diferentes tempos de enchimento e concentração afluente, não influenciaram a remoção de DQO, pois a matéria orgânica foi transformada resultando em remoções reduzidas em todas as condições.

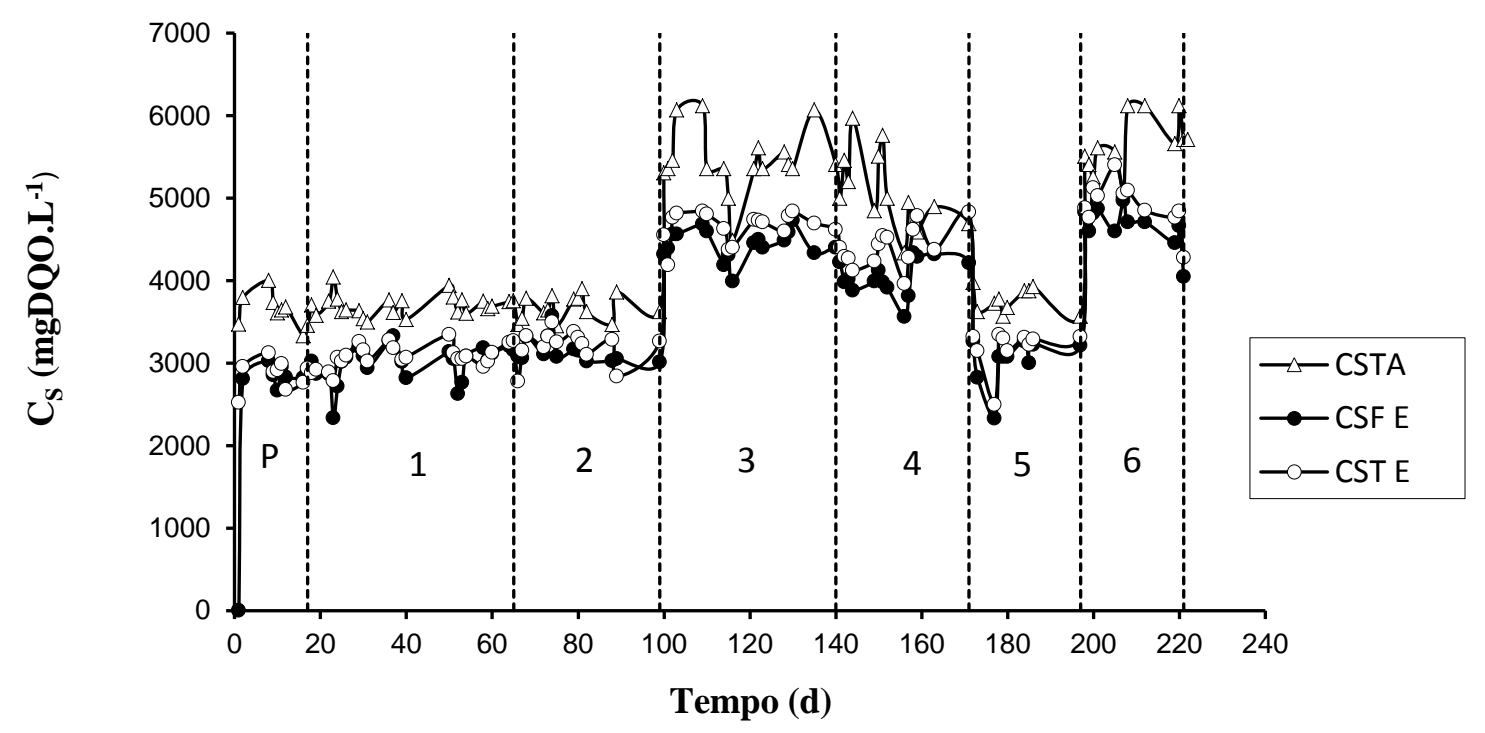

Figura 5.101: Concentração de matéria orgânica (DQO) para amostras filtradas e não filtradas em todas as condições. 


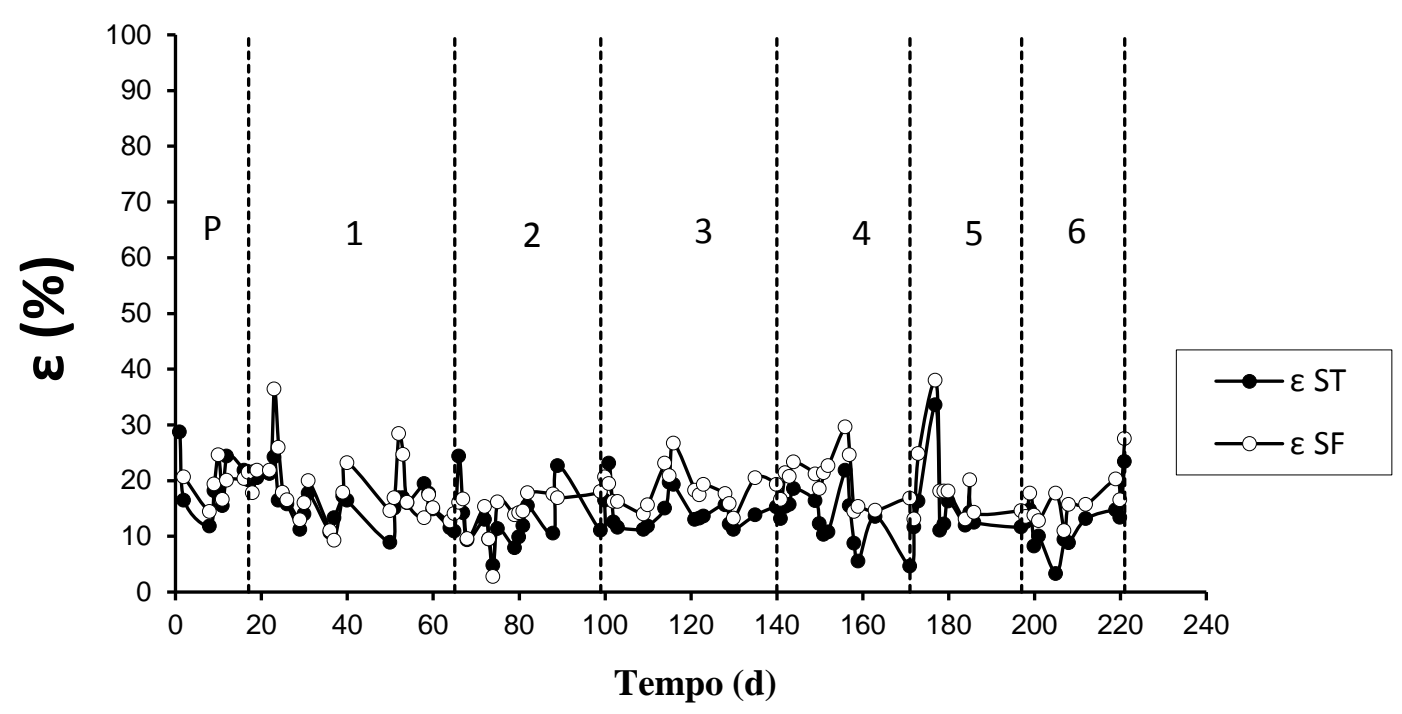

Figura 5.102: Eficiência de remoção de matéria orgânica (DQO) para amostras filtradas e não filtradas em todas as condições.

A Figura 5.103 exibe o comportamento da concentração de carboidratos afluente e efluente em todas as condições, podendo-se observar que praticamente toda a sacarose introduzida no reator foi consumida, dando origem aos ácidos e alcoóis intermediários resultantes da acidogênese do processo. A Figura 5.104 exibe a eficiência de conversão de carboidratos durante a fase experimental, obtendo-se a média de remoção de $98 \%$, o que demonstra uma acidogênese eficiente e estável durante toda a fase experimental. As elevadas cargas orgânicas referente às condições 5 e 6 causaram uma pequena redução na eficiência de conversão de carboidratos de $99 \%$ para $95 \%$ e $94 \%$ respectivamente.

Dessa forma, pode-se observar que em todas condições experimentais as quais o sistema foi exposto a eficiência de conversão de carboidratos se manteve elevada e aproximadamente constante, não sendo significativamente influenciada pela carga orgânica aplicada que foi diferente em função do tempo de ciclo e da concentração afluente.

De um modo mais detalhado a condição experimental 1 o reator foi operado com concentração de $3230 \mathrm{mg} \cdot \mathrm{L}^{-1}$ e tempo de ciclo de 4 horas resultando em 9,3 kgDQO.m ${ }^{-3} \cdot \mathrm{d}^{-1}$ 
de COAV atingindo uma eficiência de conversão de sacarose de $99 \%$ para as amostras filtradas. Na condição experimental 2 o reator foi operado com concentração de 3182 mgSAC.L $L^{-1}$ e tempo de ciclo de 3 horas resultando em $12,4 \mathrm{kgDQO} . \mathrm{m}^{-3} \cdot \mathrm{d}^{-1}$ de COAV atingindo uma eficiência de conversão de sacarose de $99 \%$ para as amostras filtradas. Na condição experimental 3 o reator foi operado com concentração de $5043 \mathrm{mgSAC} . \mathrm{L}^{-1}$ e tempo de ciclo de 4 horas resultando em 13,8 kgDQO. $\mathrm{m}^{-3} \cdot \mathrm{d}^{-1}$ de COAV atingindo uma eficiência de conversão de sacarose de $99 \%$ para as amostras filtradas. Na condição experimental 4 o reator foi operado com concentração de $4277 \mathrm{mgSAC} . \mathrm{L}^{-1}$ e tempo de ciclo de 3 horas resultando em 17,1 kgDQO.m ${ }^{-3} \cdot \mathrm{d}^{-1}$ de COAV atingindo uma eficiência de conversão de sacarose de $99 \%$ para as amostras filtradas. Na condição experimental 5 o reator foi operado com concentração de $3647 \mathrm{mgSAC} . \mathrm{L}^{-1}$ e tempo de ciclo de 2 horas resultando em 19,0 kgDQO. $\mathrm{m}^{-3} \cdot \mathrm{d}^{-1}$ de COAV reduzindo a eficiência de conversão de sacarose para $95 \%$ em termos de amostras filtradas. Na condição experimental 6 o reator foi operado com concentração de $5245 \mathrm{mgSAC} . \mathrm{L}^{-1}$ e tempo de ciclo de 2 horas resultando em 28,7 kgDQO. $\mathrm{m}^{-3} \cdot \mathrm{d}^{-1}$ de COAV reduzindo a eficiência de conversão de sacarose para $94 \%$ em termos de amostras filtradas.

Os principais metabólitos produzidos durante a operação foram o acido acético, etanol e ácido butírico, produzidos de forma similar durante toda a fase de operação. De acordo com a Tabela 5.26 e a Figura 5.105, pode-se observar que o principal metabólito gerado a partir da conversão da sacarose visando a produção de biohidrogênio foi o ácido acético com exceção da condição experimental 1 na qual houve uma mudança com a ocorrência de maior concentração do ácido butírico. A concentração de ácido acético manteve uma média de $752,3 \mathrm{mg} . \mathrm{L}^{-1}$, chegando a atingir 1060,5 mg. $\mathrm{L}^{-1}$ na condição experimental $6 . \mathrm{O}$ ácido butírico manteve uma média de $315,0 \mathrm{mg} . \mathrm{L}^{-1}$ chegando a atingir $438,9 \mathrm{mg} . \mathrm{L}^{-1}$ na condição experimental 1. 


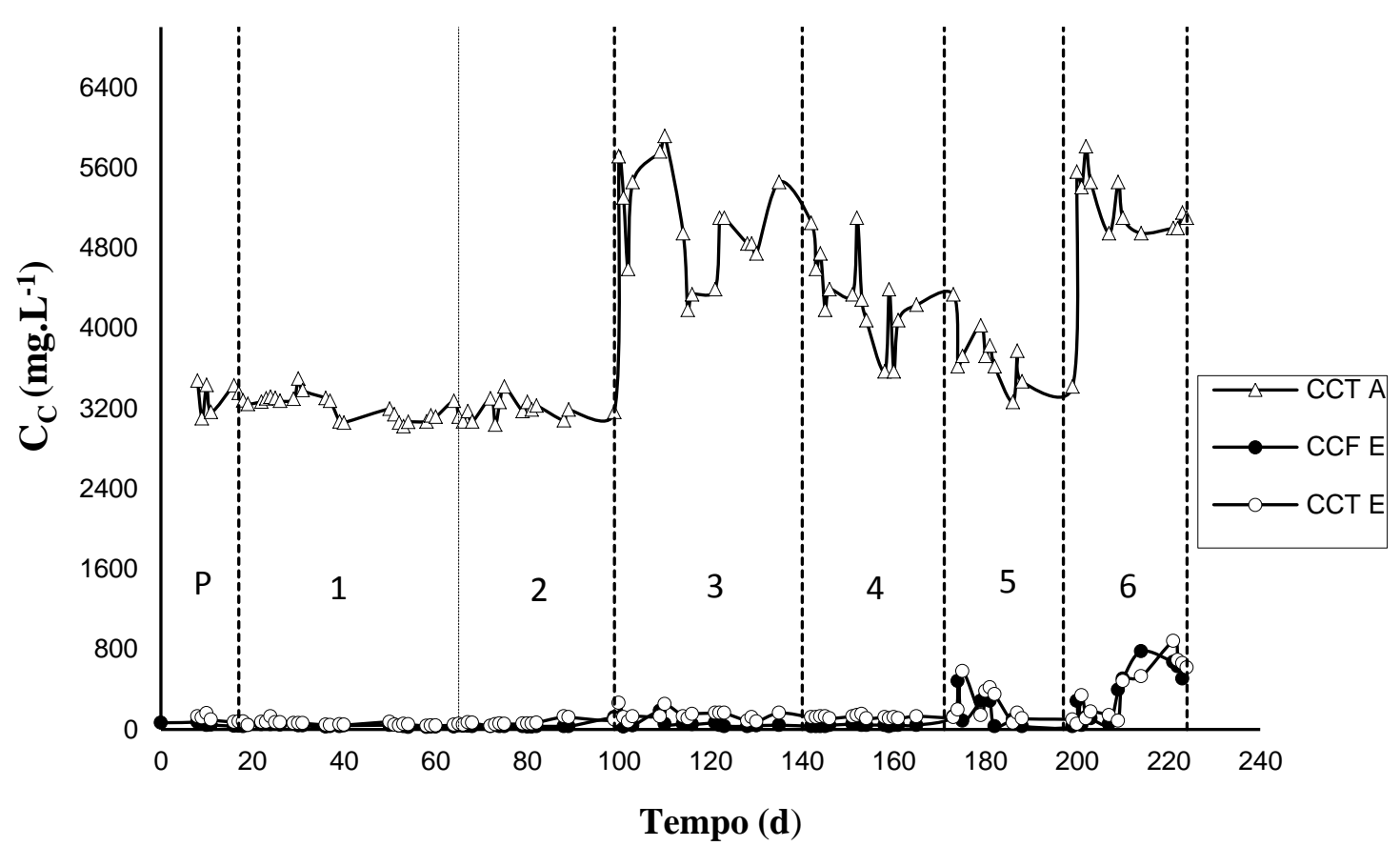

Figura 5.103: Concentração de carboidratos afluente e efluente para amostras filtradas e não filtradas em todas as condições.

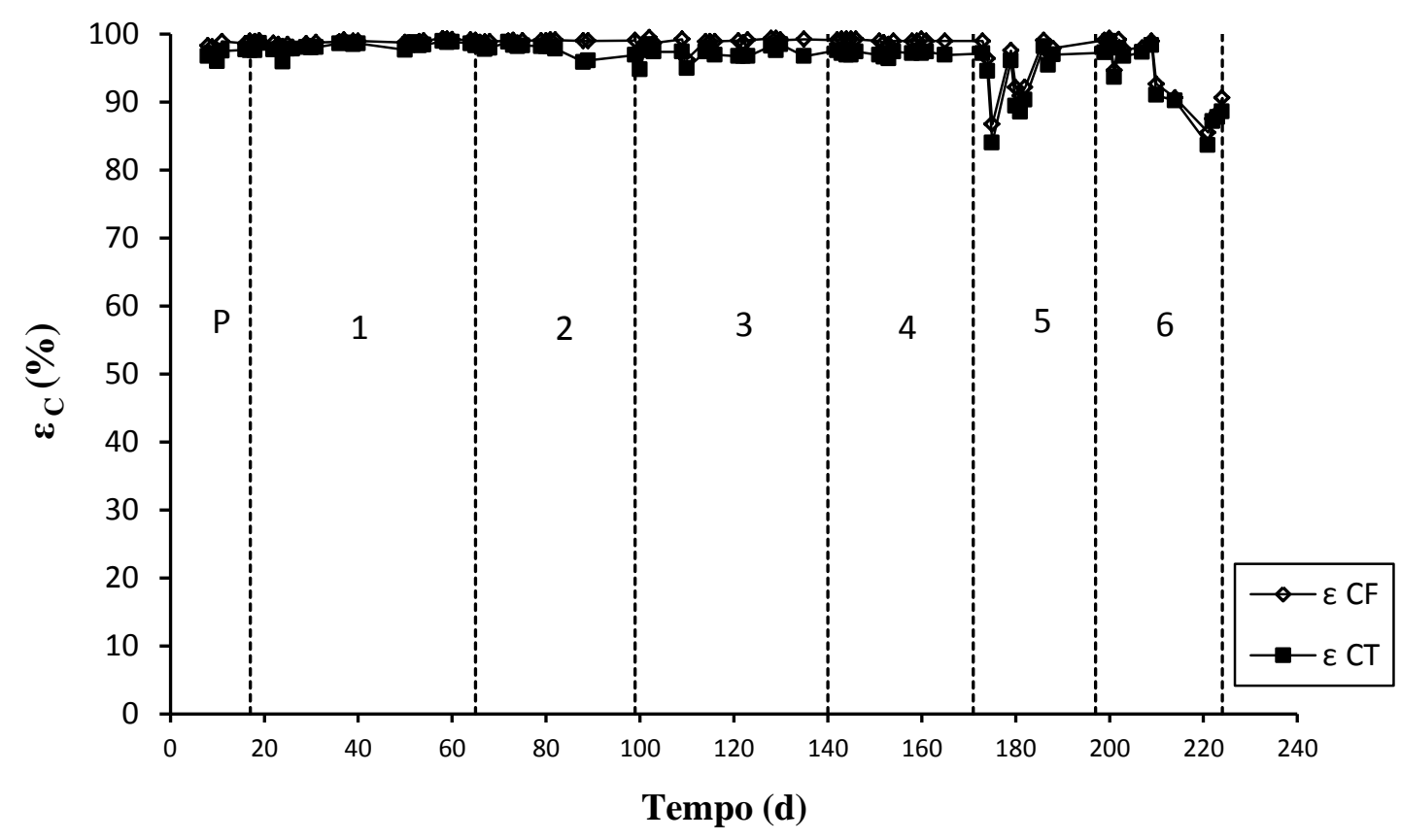

Figura 5.104: Eficiência de conversão de carboidratos para amostras filtradas e não filtradas em todas as condições. 
A concentração de etanol teve uma média de $382,5 \mathrm{mg} . \mathrm{L}^{-1}$ chegando atingir $623,5 \mathrm{mg} . \mathrm{L}^{-}$ ${ }^{1}$ durante a condição experimental 6 , porém nas outras cinco condições a concentração de etanol manteve-se próxima de $300 \mathrm{mg} \cdot \mathrm{L}^{-1}$. A concentração média de etanol superior aos valores obtidos por Fernandes (2008) que foi de aproximadamente $105 \mathrm{mg} . \mathrm{L}^{-1}$ e de Lima (2011) que foi de aproximadamente $150 \mathrm{mg} \cdot \mathrm{L}^{-1}$.

Vale mencionar os valores obtidos para o ácido capróico, cuja geração pode ser atribuída à fermentação secundária do etanol durante a produção fermentativa do hidrogênio.

Tabela 5.26: Concentração dos compostos intermediários em todas condições.

\begin{tabular}{cccccccc}
\hline \multirow{2}{*}{$\begin{array}{c}\text { Espécie } \\
\left(\mathrm{mg} . \mathrm{L}^{-1}\right)\end{array}$} & 1 & 2 & 3 & 4 & 5 & 6 & Média \\
\cline { 2 - 8 } Acetona & - & - & - & - & - & - & - \\
Metanol & - & - & - & - & - & - & - \\
Etanol & 376,1 & 202,2 & 367,0 & 392,5 & 333,8 & 623,5 & 382,5 \\
n-Butanol & 10,1 & 6,0 & 5,1 & 5,3 & 4,5 & 5,6 & 6,1 \\
Ácido acétido & 326,1 & 623,0 & 800,0 & 925,9 & 778,6 & 1060,5 & 752,3 \\
Ácido propiônico & 78,0 & 55,2 & 54,7 & 107,5 & 144,1 & 139,6 & 96,5 \\
Ácido isobutírico & 254,6 & 131,5 & 87,0 & 153,7 & 48,9 & 14,0 & 114,9 \\
Ácido butírico & 438,9 & 267,2 & 211,0 & 355,7 & 300,0 & 319,5 & 315,4 \\
Ácido isovalérico & 11,1 & 10,2 & 8,8 & 11,0 & 9,7 & 8,7 & 9,9 \\
Ácido valérico & 46,0 & 47,4 & 36,4 & 66,3 & 59,6 & 44,0 & 49,9 \\
Ácido capróico & 242,0 & 282,1 & 181,4 & 316,3 & 161,0 & 150,6 & 222,2 \\
\hline
\end{tabular}




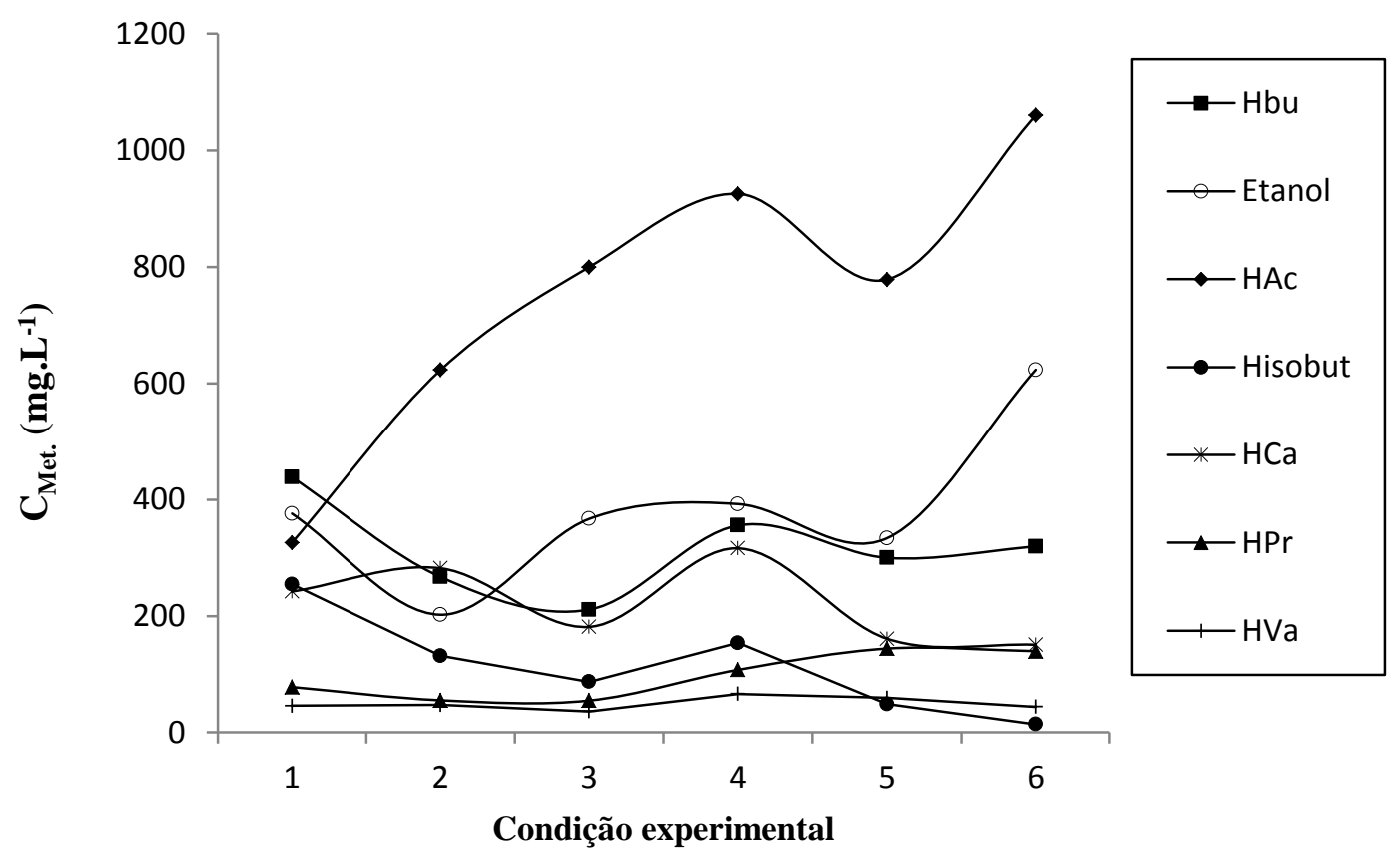

Figura 5.105: Concentração dos compostos intermediários em todas condições.

O balanço de matéria orgânica (DQO) efluente foi realizado de acordo com as equações listadas na Tabela 5.27 na qual são exibidos os equivalentes-grama de oxigênio consumido para os principais metabólitos, sacarose e biomassa presente no efluente. A Tabela 5.28 apresenta os valores do balanço da DQO efluente de cada condição e sua respectiva concordância, podendo-se observar que tais resultados ficaram próximos de $100 \%$, ou seja, de uma maneira geral, os metabólitos monitorados no efluente condizem com os valores de DQO monitorados. 
Tabela 5.27: Equações bioquímicas e equivalente-grama dos compostos em DQO.

\begin{tabular}{ccc}
\hline Espécie química & Equações bioquímicas & $\begin{array}{c}\text { Equivalente-grama } \\
\left(\mathrm{gO}_{2} / \mathrm{g}\right)\end{array}$ \\
\hline Sacarose & $\mathrm{C}_{12} \mathrm{H}_{22} \mathrm{O}_{11}+12 \mathrm{O}_{2} \rightarrow 12 \mathrm{CO}_{2}+11 \mathrm{H}_{2} \mathrm{O}$ & 1,123 \\
Etanol & $\mathrm{C}_{2} \mathrm{H}_{6} \mathrm{O}+2 \mathrm{O}_{2} \rightarrow 2 \mathrm{CO}_{2}+3 \mathrm{H}_{2} \mathrm{O}$ & 1,391 \\
Ácido acético & $\mathrm{CH}_{3} \mathrm{COOH}+2 \mathrm{O}_{2} \rightarrow 2 \mathrm{CO}_{2}+2 \mathrm{H}_{2} \mathrm{O}$ & 1,006 \\
Ácido propiônico & $\mathrm{CH}_{3} \mathrm{CH}_{2} \mathrm{COOH}+7 / 2 \mathrm{O}_{2} \rightarrow 3 \mathrm{CO}_{2}+3 \mathrm{H}_{2} \mathrm{O}$ & 1,514 \\
Ácido isobutírico & $\mathrm{CH}_{3} \mathrm{CH}_{2} \mathrm{CH}_{2} \mathrm{COOH}+5 \mathrm{O}_{2} \rightarrow 4 \mathrm{CO}_{2}+4 \mathrm{H}_{2} \mathrm{O}$ & 1,818 \\
Ácido butírico & $\mathrm{CH}_{3} \mathrm{CH}_{2} \mathrm{CH}_{2} \mathrm{COOH}+5 \mathrm{O}_{2} \rightarrow 4 \mathrm{CO}_{2}+4 \mathrm{H}_{2} \mathrm{O}$ & 1,818 \\
Ácido valérico & $\mathrm{CH}_{3} \mathrm{CH}_{2} \mathrm{CH}_{2} \mathrm{CH}_{2} \mathrm{COOH}+13 / 2 \mathrm{O}_{2} \rightarrow 5 \mathrm{CO}_{2}+5 \mathrm{H}_{2} \mathrm{O}$ & 2,036 \\
Ácido isovalérico & $\mathrm{CH}_{3} \mathrm{CH}_{2} \mathrm{CH}_{2} \mathrm{CH}_{2} \mathrm{COOH}+13 / 2 \mathrm{O}_{2} \rightarrow 5 \mathrm{CO}_{2}+5 \mathrm{H}_{2} \mathrm{O}$ & 2,036 \\
Ácido capróico & $\mathrm{CH}_{3} \mathrm{CH}_{2} \mathrm{CH}_{2} \mathrm{CH}_{2} \mathrm{CH} \mathrm{COOH}_{2}+8 \mathrm{O}_{2} \rightarrow 6 \mathrm{CO}_{2}+6 \mathrm{H}_{2} \mathrm{O}$ & 2,196 \\
Biomassa & $\mathrm{C}_{5} \mathrm{H}_{9} \mathrm{O}_{3} \mathrm{~N}+11 / 2 \mathrm{O}_{2} \rightarrow 5 \mathrm{CO}_{2}+9 / 2 \mathrm{H}_{2} \mathrm{O}$ & 1,343 \\
\hline
\end{tabular}

Tabela 5.28: Valores do balanço de DQO efluente.

\begin{tabular}{|c|c|c|c|}
\hline $\begin{array}{c}\text { Condição } \\
\text { experimental }\end{array}$ & $\begin{array}{l}\text { DQO Efluente (I) } \\
\quad\left(\mathrm{mg} \cdot \mathrm{L}^{-1}\right)\end{array}$ & $\begin{array}{c}\text { DQO Metabólitos + } \\
\text { DQO C } \text { CFE }_{\text {II })} \\
\left({\left.\mathrm{mg} . \mathrm{L}^{-1}\right)}\right.\end{array}$ & $\begin{array}{l}\text { Concordância entre } \\
\text { (I) e (II) } \\
(\%)\end{array}$ \\
\hline 1 & 3067,0 & 3064,5 & 99,9 \\
\hline 2 & 3152,0 & 2793,1 & 88,6 \\
\hline 3 & 4442,0 & 2821,5 & 63,5 \\
\hline 4 & 3995,0 & 3715,4 & 93,0 \\
\hline 5 & 3037,0 & 2988,6 & 98,4 \\
\hline 6 & 4661,0 & 3733,1 & 80,1 \\
\hline
\end{tabular}




\subsubsection{Biogás}

No meio líquido a eficiência de conversão da sacarose foi estável em todas as condições, assim como a geração de metabólitos intermediários sem a remoção de matéria orgânica (DQO), como discutido anteriormente.

A produção de biogás em termos volumétricos é apresentada na Figura 5.106, pela qual se pode observar que o aumento da carga orgânica volumétrica aplicada em função da redução do tempo de ciclo e mesma concentração afluente (condições 1/2/5 e 3/4/6 - redução de $50 \%$ no tempo de ciclo) resultou em um aumento da produção do biogás. Quando o aumento de carga orgânica volumétrica aplicada foi ocasionado pelo aumento da concentração afluente e mesmo tempo de ciclo (condições 1/3, 2/4 e 5/6 - aumento de 50\% na concentração afluente) resultou também em um aumento da produção do biogás, porém de maior intensidade, ou seja, a produção de biogás é mais sensível à variável concentração afluente em relação ao tempo de ciclo.

Comparando as condições 4/5 nas quais se tem a mesma carga orgânica volumétrica aplicada, sendo que a condição 5 foi realizada com menores concentração afluente e tempo de ciclo em relação à condição 4, observa-se uma maior produção de biogás para a condição 4, ou seja, a redução no tempo de ciclo com uma proporcional redução na concentração afluente (de modo a manter a mesma carga orgânica volumétrica) não favorece a produção de biogás.

Através da análise qualitativa do biogás foi possível identificar as frações de cada constituinte, podendo a partir de então correlacionar estas frações com os volumes obtidos. A Tabela 5.29 apresenta composição do biogás em cada condição experimental, obtendo-se um valor médio de $37 \%$ para o hidrogênio (desvio padrão de $3 \%$ ), ou seja, a carga volumétrica 
aplicada não influenciou a composição de hidrogênio no biogás formado. Como consequência, quando o aumento da carga orgânica volumétrica aplicada foi em função da redução do tempo de ciclo e mesma concentração afluente (condições 1/2/4 e 3/4/6 - redução de $50 \%$ no tempo de ciclo) a composição de biohidrogênio permaneceu aproximadamente igual (média de 36\% e desvio padrão de 2,5\%). Quando o aumento de carga orgânica volumétrica aplicada foi em função do aumento da concentração afluente e mesmo tempo de ciclo (condições $1 / 3,2 / 4$ e 5/6 - aumento de 50\% na concentração afluente) a composição de biohidrogênio também permaneceu aproximadamente igual.

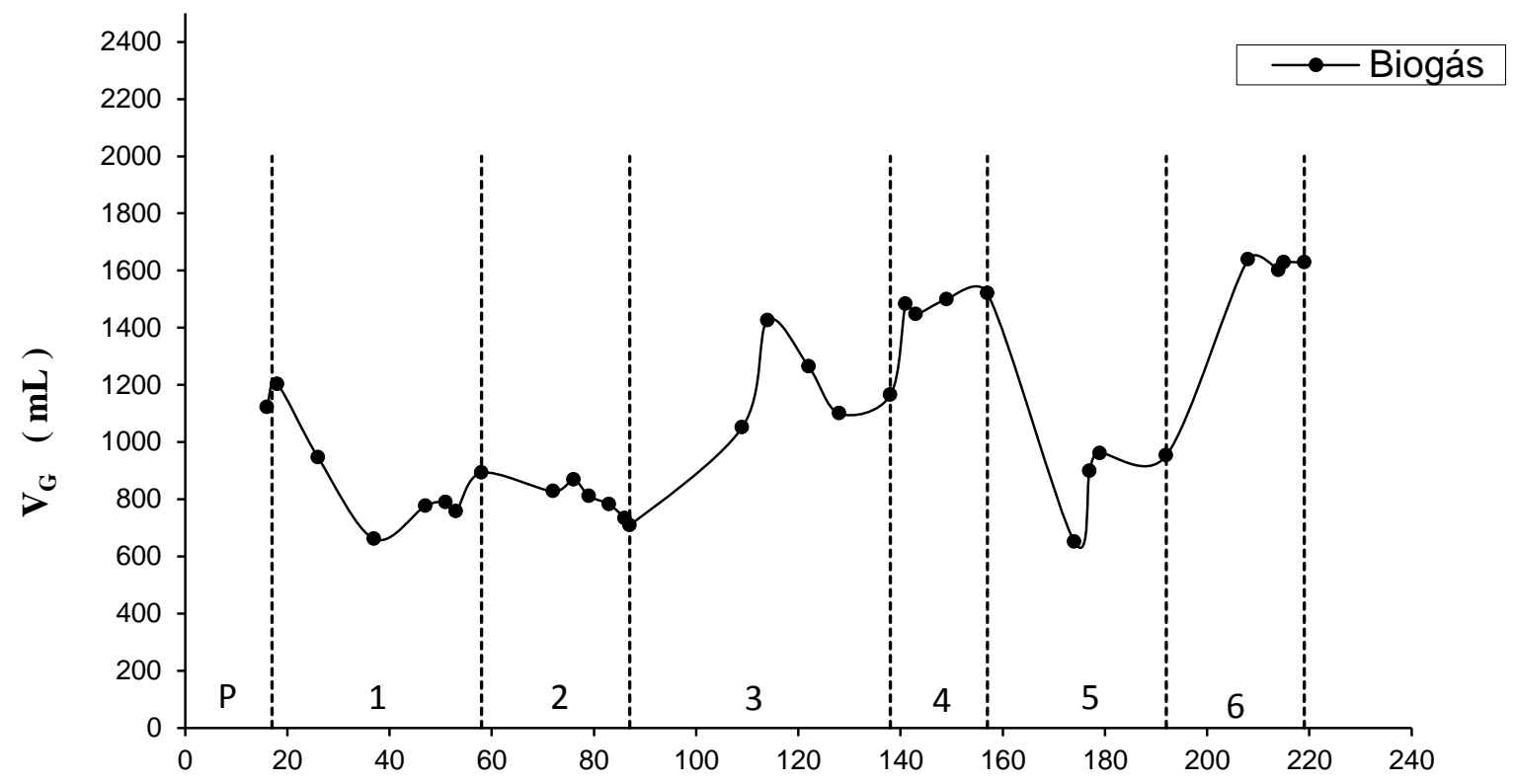

Tempo (d)

Figura 5.106: Volume total de biogás produzido ao longo do ciclo em todas condições.

Tabela 5.29: Composição do biogás produzido em todas condições.

\begin{tabular}{ccccccc}
\hline $\begin{array}{c}\text { Composição } \\
{[\%]}\end{array}$ & 1 & 2 & 3 & 4 & 5 & 6 \\
\hline $\mathrm{CH}_{4}$ & 0,0 & 0,0 & 0,0 & 0,0 & 0,0 & 0,0 \\
$\mathrm{H}_{2}$ & 36,2 & 34,0 & 36,8 & 32,2 & 38,9 & 36,6 \\
$\mathrm{CO}_{2}$ & 63,8 & 66,0 & 63,2 & 67,8 & 61,1 & 63,4 \\
\hline
\end{tabular}


Os volumes dos constituintes do biogás obtidos em todas condições são apresentados na Figura 5.107. Os valores médios de produção foram de $366 \mathrm{~mL}$ para o $\mathrm{H}_{2}$ (desvio padrão de $71 \mathrm{~mL}$ ) e de $820 \mathrm{~mL}$ para o $\mathrm{CO}_{2}$, não ocorrendo $\mathrm{CH}_{4}$ durante toda a fase de operação. De uma maneira geral, quando o aumento da carga orgânica volumétrica aplicada foi em função da redução do tempo de ciclo e mesma concentração afluente (condições 1/2/5 e 3/4/6 - redução de 50\% no tempo de ciclo) o volume de biohidrogênio produzido aumentou ligeiramente na sequência das condições 3/4/6 e permaneceu aproximadamente igual na sequência das condições 1/2/5. Quando o aumento de carga orgânica volumétrica aplicada foi em função do aumento da concentração afluente e mesmo tempo de ciclo (condições 1/3, 2/4 e 5/6 - aumento de 50\% na concentração afluente) o volume de biohidrogênio produzido apresentou uma tendência de aumentar. Assim, a concentração afluente parece influenciar de forma mais pronunciada a produção de biohidrogênio do que o tempo de ciclo. Tal comportamento é semelhante ao do volume total de biogás produzido, pois as condições apresentaram aproximadamente a mesma composição, independente da carga orgânica volumétrica aplicada.

Assim, comparando as condições 4/5, ou seja, mesma carga orgânica volumétrica aplicada com menores concentração afluente e tempo de ciclo na condição 5 em relação à condição 4, observa-se uma maior produção de biohidrogênio na condição 4, mantendo-se a característica de que a redução no tempo de ciclo com uma proporcional redução na concentração afluente (e mesma carga orgânica volumétrica) parece não favorecer a produção de biogás.

A Tabela 5.30 exibe os indicadores de produção de biohidrogênio do sistema em todas condições experimentais.

$\mathrm{O}$ indicador produção de biohidrogênio $\left(\mathrm{n}_{\mathrm{H} 2}\right)$ não deve ser utilizado na análise do sistema, pois os resultados indicam que a carga aplicada, seja pela modificação do tempo de 
ciclo ou da concentração afluente, não altera a produção de biohidrogênio de modo sistemático. Tal comportamento pode ser atribuído pela não inclusão nesse parâmetro dos fatores de engenharia envolvidos nas diferentes condições.

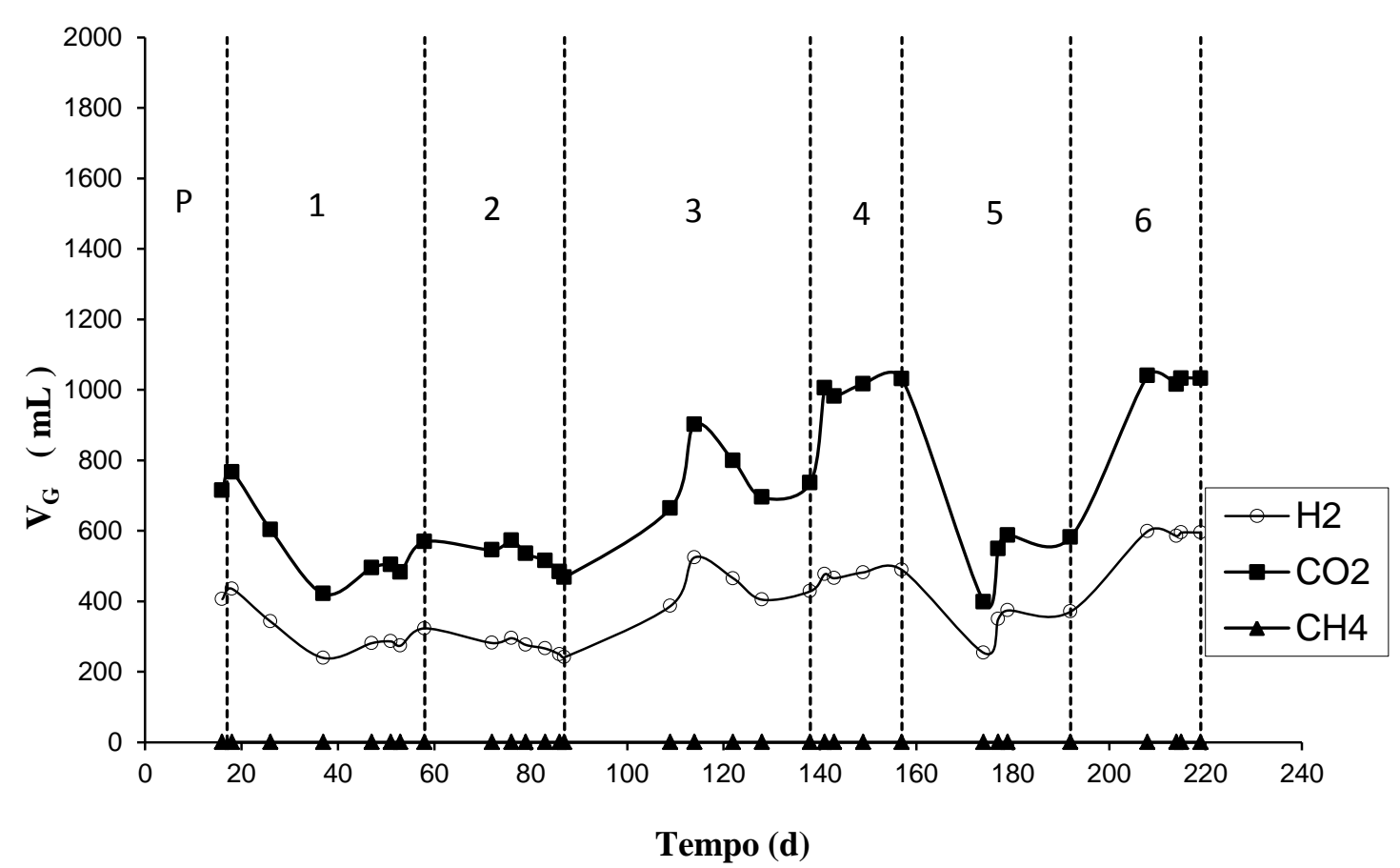

Figura 5.107: Volumes de $\mathrm{H}_{2}, \mathrm{CO}_{2}$ e $\mathrm{CH}_{4}$ produzidos em todas condições.

Nesse contexto, os indicadores produtividade de biohidrogênio em termos volumétricos (PrM) e específicos (PrME) incluem, respectivamente, os fatores volume do biorreator (PrM) e quantidade de biomassa no biorreator (PrME) no valor da produção de biohidrogênio. Analisando a produtividade volumétrica tem-se uma relação direta com a carga orgânica volumétrica aplicada (condições 1/2/4/3/5/6) com uma maior sensibilidade da concentração afluente (condições 1/3, 2/4 e 5/6 - aumento de 50\% na concentração afluente) do que o tempo de ciclo (condições 1/2/5 e 3/4/6 - redução de 50\% no tempo de ciclo).

Os indicadores baseados em carga aplicada, tanto carga orgânica volumétrica aplicada (DQO - RMCA $\mathrm{S}_{\mathrm{s}, \mathrm{n}}$ ) quanto carga de carboidratos aplicada $\left(\mathrm{RMCA}_{\mathrm{C}, \mathrm{n}}\right)$, mostram 
comportamentos semelhantes, pois o valor de matéria orgânica medida como DQO é resultante dos carboidratos (sacarose) adicionados ao afluente. Assim, quando o aumento da carga orgânica volumétrica aplicada foi em função da redução do tempo de ciclo e mesma concentração afluente (condições 1/2/5 e 3/4/6 - redução de 50\% no tempo de ciclo) a produção de biohidrogênio foi maior para o maior tempo de ciclo. Quando o aumento de carga orgânica volumétrica aplicada foi em função do aumento da concentração afluente e mesmo tempo de ciclo (condições 1/3, 2/4 e 5/6 - aumento de 50\% na concentração afluente) a produção de biohidrogênio foi maior para a menor concentração afluente quando o ciclo foi de 4 horas, ou seja, o maior valor de tempo de ciclo. Entretanto, esse comportamento se inverteu para os tempos de ciclo de 3 e 2 horas, ou seja, nesses valores de tempo de ciclo a maior produção de biohidrogênio ocorreu para a maior concentração afluente. Vale destacar que essa inversão de comportamento ocorreu com valores de produção de hidrogênio próximos.

Comparando as condições 4/5, ou seja, mesma carga aplicada com menores concentração afluente e tempo de ciclo na condição 5 em relação à condição 4, observa-se uma maior produção de biohidrogênio na condição 4, ou seja, a redução no tempo de ciclo com uma proporcional redução na concentração afluente (e mesma carga orgânica volumétrica) parece não favorecer a produção de biogás.

$\mathrm{O}$ indicador baseado em carga orgânica volumétrica removida $\left(\mathrm{DQO}-\mathrm{RMCR}_{\mathrm{S}, \mathrm{n}}\right)$ não deve ser considerado devido ao comportamento aproximadamente constante e de valor reduzido da remoção de matéria orgânica (DQO) em todas condições, independente da carga aplicada. Nesse ponto é importante citar o resultado obtido por Bhaskar (2008), o qual estudou a produção de biohidrogênio a partir de efluente sintético em condições anaeróbias acidogênicas, variando a carga orgânica aplicada ao sistema de 6,3 a 7,9 kgDQO.m ${ }^{-3} \cdot \mathrm{d}^{-1} \mathrm{e}$ obtendo uma redução do $\mathrm{RMCR}_{\mathrm{S}, \mathrm{n}}$ de 13,4 para $6,1 \mathrm{molH}_{2} \cdot \mathrm{kgDQO}^{-1}$. 
$\mathrm{O}$ indicador baseado em carga de carboidratos removida (sacarose $-\mathrm{RMCR}_{\mathrm{C}, \mathrm{n}}$ ) possivelmente seja o indicador mais adequado para a análise do desempenho do sistema, pois quantifica a produção de biohidrogênio em termos do substrato efetivamente consumido, mostrando uma relação entre a produção do produto de interesse (biohidrogênio) e o consumo do reagente disponibilizado (sacarose). Entretanto, a análise dos resultados obtidos é análoga àquela efetuada para o indicador baseado em carga de carboidratos aplicada. Tal fato ocorreu nesse estudo, pois em todas condições a remoção de carboidratos foi semelhante e elevada, não tendo sido medidos valores significativamente distintos em função das diferentes cargas aplicadas. Dessa forma, quando o aumento da carga aplicada foi em função da redução do tempo de ciclo e mesma concentração afluente (condições 1/2/5 e 3/4/6 redução de $50 \%$ no tempo de ciclo) a produção de biohidrogênio foi maior para o maior tempo de ciclo. Quando o aumento de carga aplicada foi em função do aumento da concentração afluente e mesmo tempo de ciclo (condições 1/3, 2/4 e 5/6 - aumento de 50\% na concentração afluente) o comportamento foi análogo ao anterior, ou seja, a produção de biohidrogênio foi maior para a menor concentração afluente quando o ciclo foi de 4 horas, ou seja, o maior valor de tempo de ciclo, entretanto, esse comportamento se inverteu para os tempos de ciclo de 3 e 2 horas, ou seja, nesses valores de tempo de ciclo a maior produção de biohidrogênio ocorreu para a maior concentração afluente, destacando-se que essa inversão de comportamento ocorreu com valores de produção de hidrogênio próximos.

Comparando as condições 4/5, ou seja, mesma carga aplicada com menores concentração afluente e tempo de ciclo na condição 5 em relação à condição 4, observa-se uma maior produção de biohidrogênio na condição 4 , ou seja, a redução no tempo de ciclo com uma proporcional redução na concentração afluente (e mesma carga orgânica volumétrica) parece não favorecer a produção de biogás. 
Tabela 5.30: Indicadores de produção de biohidrogênio do sistema em todas condições.

\begin{tabular}{cccccccc}
\hline \multirow{2}{*}{ Indicador } & Unidade & \multicolumn{7}{c}{ Condição experimental } \\
\cline { 3 - 8 } & & 1 & 2 & 3 & 4 & 5 & 6 \\
\hline $\mathrm{n}_{\mathrm{H} 2}$ & {$\left[\mathrm{~mol}_{\mathrm{y}} \mathrm{d}^{-1}\right]$} & 0,15 & 0,12 & 0,18 & 0,19 & 0,13 & 0,20 \\
$\mathrm{PrM}$ & {$\left[\mathrm{molH}_{2} \cdot \mathrm{m}^{-3} \cdot \mathrm{d}^{-1}\right]$} & 21,0 & 16,9 & 24,7 & 25,7 & 18,2 & 27,9 \\
$\mathrm{PrME}$ & {$\left[\mathrm{molH}_{2} \cdot \mathrm{kgSVT}^{-1} \cdot \mathrm{d}^{-1}\right]$} & 6,87 & 5,54 & 8,15 & 8,47 & 5,73 & 8,79 \\
$\mathrm{RMCA}_{\mathrm{C}, \mathrm{m}}$ & {$\left[\mathrm{molH}_{2} \cdot \mathrm{kgSAC}^{-1}\right]$} & 4,16 & 2,55 & 3,14 & 2,88 & 1,60 & 1,71 \\
$\mathrm{RMCA}_{\mathrm{S}, \mathrm{m}}$ & {$\left[\mathrm{molH}_{2} \cdot \mathrm{kgDQO}^{-1}\right]$} & 3,66 & 2,21 & 2,90 & 2,43 & 1,55 & 1,58 \\
$\mathrm{RMCR}_{\mathrm{C}, \mathrm{m}}$ & {$\left[\mathrm{molH}_{2} \cdot \mathrm{kgSAC}^{-1}\right]$} & 4,21 & 2,58 & 3,17 & 2,91 & 1,69 & 1,83 \\
$\mathrm{RMCR}_{\mathrm{S}, \mathrm{m}}$ & {$\left[\mathrm{molH}_{2} \cdot \mathrm{kgDQO}^{-1}\right]$} & 19,6 & 15,6 & 15,7 & 11,5 & 8,09 & 8,98 \\
\hline
\end{tabular}

\subsubsection{Análises microbiológicas}

A biomassa presente no interior do reator foi amostrada ao final de cada duas condições experimentais consecutivas para exames por microscopia óptica, ou seja, por luz comum por contraste e por fluorescência. Assim, não foram detectadas nenhuma forma fluorescente. A Figura 5.108a-b-c correspondem, respectivamente, às condições 1/2, 3/4 e 5/6, cuja interpretação indicam o predomínio de bacilos e filamentos com a presença de endósporos em todas as condições analisadas, não ocorrendo diferenças significativas entre as condições com relação a biomassa. A presença de endósporos e a presença na composição do efluente de metabólitos como etanol, ácido butírico e acido acético, acompanhados da produção de gás hidrogênio indicam provavelmente uma fermentação por bactérias do gênero Clostridium (Lin et al, 2007). 

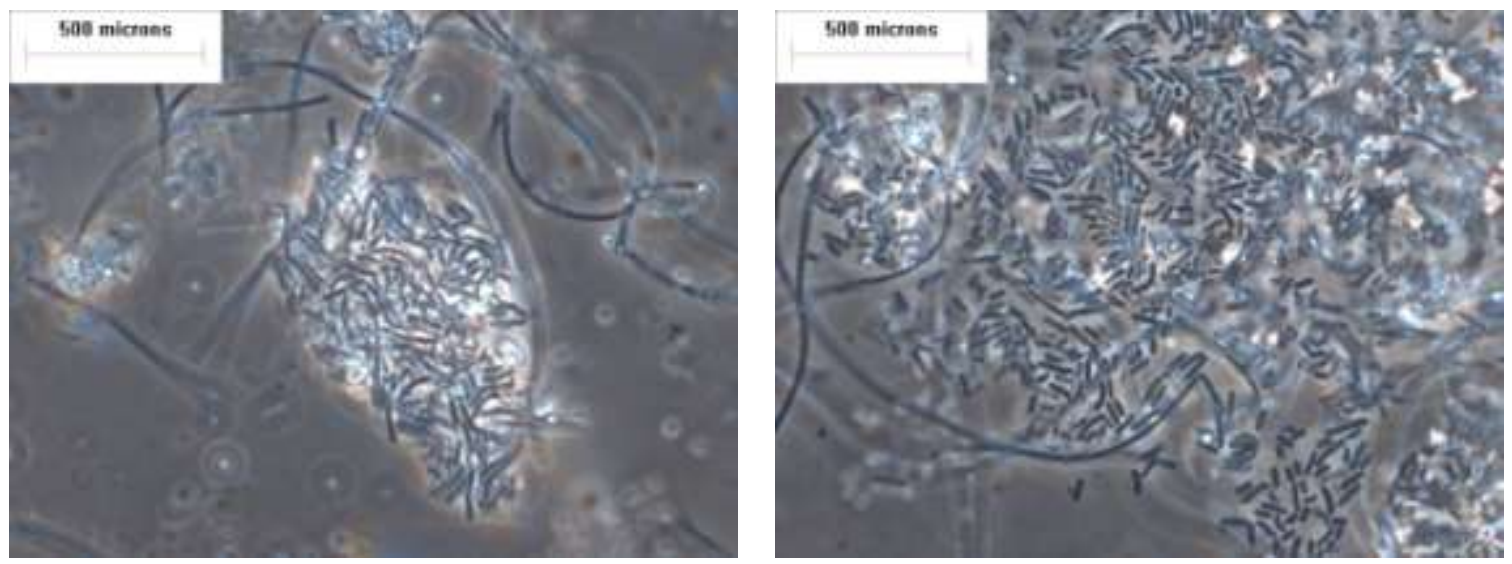

(a) Condições 1 e 2
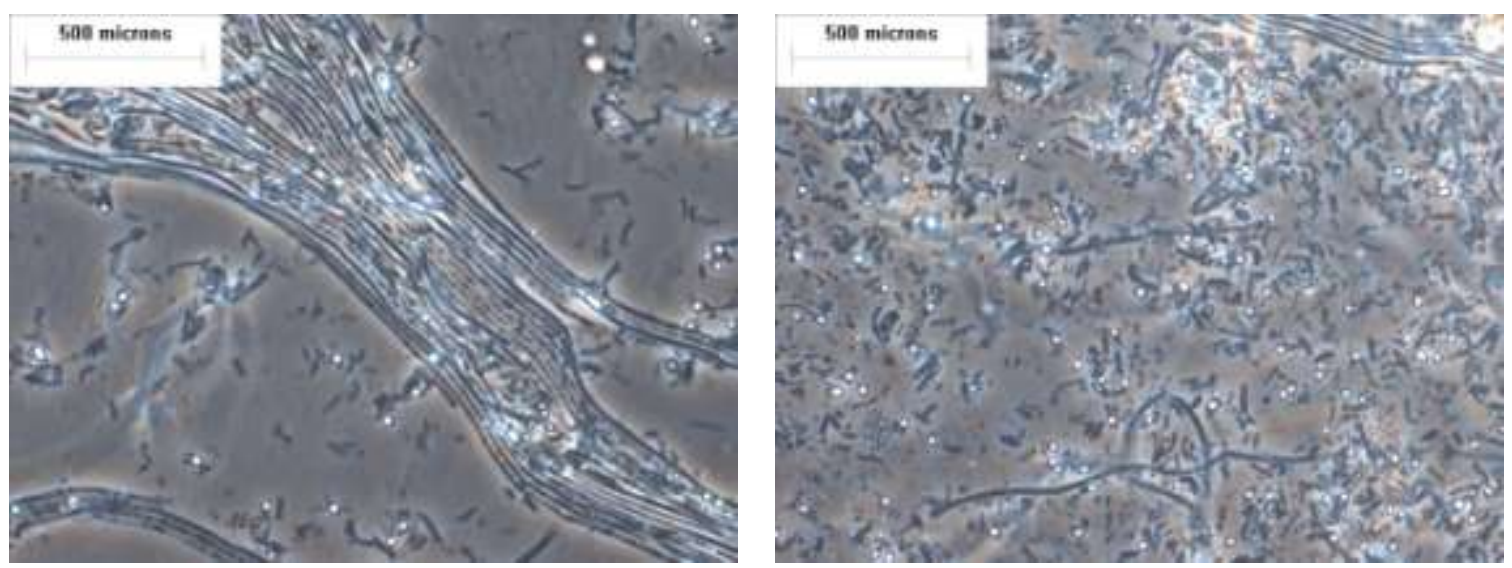

(b) Condições 3 e 4
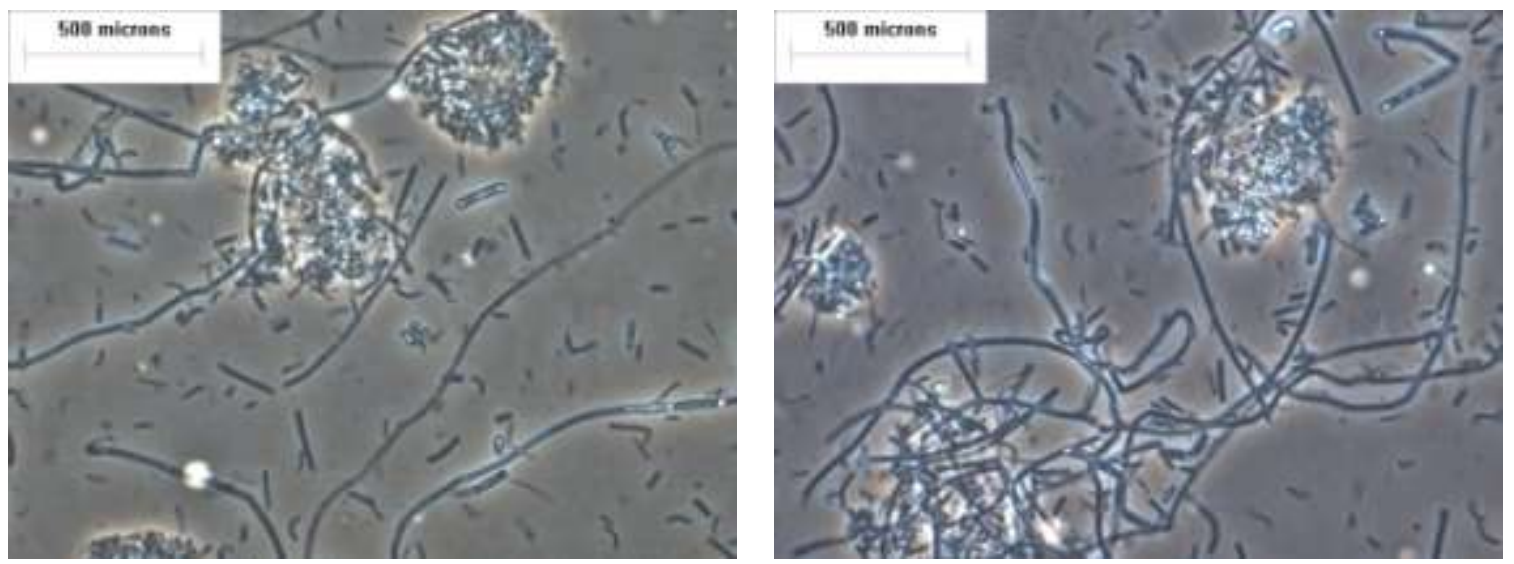

(c) Condições 5 e 6

Figura 5.108: Exames microbiológicos da biomassa em todas condições. 


\section{CONCLUSÕES}

Os resultados obtidos permitiram concluir de um modo geral que é possível produzir biohidrogênio com AnSBBR com recirculação da fase líquida tratando água residuária sintética a base de sacarose.

De acordo com os resultados apresentados pode-se concluir de modo específico que:

- O sistema manteve uma eficiência de conversão de carboidratos (sacarose) na faixa de $90 \%$ durante toda a fase experimental, produzindo uma elevada concentração dos principais ácidos voláteis como o ácido acético e ácido butírico, assim como foram obtidas elevadas concentrações de etanol;

- O sistema manteve uma eficiência de conversão de matéria orgânica (DQO) na faixa de $20 \%$ durante toda a fase experimental;

- O aumento das cargas orgânicas aplicada e removida influenciou de maneira negativa quanto ao indicador rendimento molar de hidrogênio (RMCA e RMCR), tanto em termos de matéria orgânica (DQO) quanto em termos de carboidratos (sacarose), sendo que a condição experimental 1 (menor concentração afluente e maior tempo de ciclo) apresentou os melhores resultados em termos de RMCA e RMCR;

- A produção do biogás total variou principalmente em função do aumento da carga orgânica causado pelo aumento da concentração de substrato afluente em detrimento ao aumento causado pelo tempo de ciclo;

- A composição do biogás nas condições experimentais variou de 32 a $40 \%$ de $\mathrm{H}_{2}$ e de 60 a $68 \%$ de $\mathrm{CO}_{2}$, não ocorrendo o aparecimento de $\mathrm{CH}_{4}$ em nenhuma das condições impostas ao sistema; 
— Os exames de microbiologia microscopia óptica comum, ou seja, por luz comum por contraste e por fluorescência, mostraram que de uma maneira geral durante todas as condições não foram detectadas nenhuma forma fluorescente e obteve-se a indicação de predomínio de bacilos e filamentos com a presença de endósporos em todas as condições analisadas, não ocorrendo diferenças significativas entre as condições com relação a biomassa, sendo que a presença de endósporos e a presença na composição do efluente de metabólitos como etanol, ácido butírico e acido acético, acompanhados da produção de gás hidrogênio indicam provavelmente uma fermentação por bactérias do gênero Clostridium. 


\section{REFERÊNCIAS BIBLIOGRÁFICAS}

ALBANEZ, R.; CANTO, C.S.A.; RATUSZNEI, S.M.; RODRIGUES, J.A.D.; ZAIAT, M.; FORESTI, E. Feasibility of a sequencing reactor operated in batch and fed-batch mode applied to nitrification and denitrification processes. Revista de Química Teórica Y Aplicada - Afinidad, 66, 44-55, 2009.

Alvers, M.M.; Abreu, A.A. (2006) Produção de hidrogênio a partir de resíduos. Revista $\begin{array}{llllll}\text { Eletrônica da } & \text { Universidade do } & \text { Minho. } & \text { Disponível } & \text { em }\end{array}$ http://repositorium.sdum.uminho.pt/bitstream/1822/5858/1/Valor-Residuos\%5B1\%5D.pdf. Acessado em 10/11/2010.

ALZATE-GAVIRIA, L.M.; SEBASTIAN, P.J.; PÉREZ, A.; EAPEN, D. Comparison of two anaerobic systems for hydrogen production from the organic fraction of municipal solid waste and synthetic wastewater. International Journal of Hydrogen Energy, 32, 31413146, 2007.

ANGENENT, L.T.; SUNG, S.; RASKIN, L. Methanogenic population dynamics during startup of a full-scale anaerobic sequencing batch reactor treating swine waste. Water Research, 36, 4648-4654, 2002.

ARGUN, H.; KARGI, F.; KAPDAN, I.; OZTEKIN, R. Biohydrogen production by dark fermentation of wheat powder solution: Effects of $\mathrm{C} / \mathrm{N}$ an $\mathrm{C} / \mathrm{P}$ ratio hydrogen yield and formation rate. International Journal of Hydrogen Energy, 33, 1813-1819, 2008. 
AROOJ, M. F.; HAN, S.; KIM, S.; KIM, D.; SHIN, H. Effect of HRT on ASBR converting starch into biological hydrogen. International Journal of Hydrogen Energy, 33, 6509-6514, 2008.

BAGLEY, D. M. E BRODKORB, T.S. Modeling microbial kinetics in an anaerobic sequencing batch reactor - model development and experimental validation. Water Environmental Research, 71, 1320-1332, 1999.

BERGAMO, C.M.; MONACO, R.; RATUSZNEI, S.M.; RODRIGUES, J.A.D.; ZAIAT, M.; FORESTI, E. Effects of temperature at different organic loading levels on the performance of a fluidized-bed anaerobic sequencing batch bioreactor. Chemical Engineering and Processing, 48, 789-796, 2009.

BEZERRA, R.A.; RODRIGUES, J.A.D.; RATUSZNEI, S.M.; ZAIAT, M.; FORESTI, E. Effects of feed time, organic loading and shock loads in the anaerobic whey treatment by an AnSBBR with circulation. Applied Biochemistry and Biotechnology, 157, 140-158, 2009.

BORGES, A.C.; SIMAN, R.R.; RODRIGUES, J.A.D.; RATUSZNEI, S.M.; ZAIAT, M.; FORESTI, E.; BORZANI, W. Stirred anaerobic sequencing batch reactor containing immobilized biomass: a behavior study when submitted to different fill times. Water Science and Technology, 49, 311-318, 2004.

BRITO, A.G.; RODRIGUES, A.C.; MELO, F.L. Feasibility of a pulsed sequencing batch reactor with an anaerobic aggregated biomass for the treatment of low strength wastewaters. Water Science and Technology, 35, 193-198, 1997. 
CAMARGO, E.F.M.; RATUSZNEI, S.M.; RODRIGUES, J.A.D.; ZAIAT, M.; BORZANI, W. Treatment of low-strength wastewater using immobilized biomass in a sequencing batch external loop reactor: influence of the medium superficial velocity on the stability and performance. Brazilian Journal of Chemical Engineering, 19, 267-275, 2002.

CHEBEL, F.X.; RATUSZNEI, S.M.; RODRIGUES, J.A.D.; ZAIAT, M.; FORESTI, E. Analysis of performance of an anaerobic sequential batch reactor submitted to increasing organic load with different influent concentrations and cycle lengths. Applied Biochemistry and Biotechnology, 133, 171-187, 2006.

CHEN, W. SUNG, S. CHEN, S. Biological hydrogen production in an anaerobic sequencing batch reactor: $\mathrm{pH}$ and cyclic duration effects. International journal of hydrogen energy, 34, 227-234, 2009.

CHERNICHARO, C.A.L. Principios do Tratamento Anaeróbio de Águas Residuárias: Reatores Anaeróbios. Belo Horizonte: Desa/ UFMG, 1997.

DAGUE，R.R.; HABBEN， C.E.; PIDAPARTI, S.R. Initial studies on the anaerobic sequencing batch reactor. Water Science and Technology, 26, 2429-2432, 1992.

DAMASCENO, L.H.S.; RODRIGUES, J.A.D.; RATUSZNEI, S.M.; ZAIAT, M.; FORESTI, E. Effects of feeding time and organic loading in an anaerobic sequencing batch biofilm reactor (ASBBR) treating diluted whey. Journal of Environmental Management, 85, 927 935, 2007. 
DAMASCENO, L.H.S.; RODRIGUES, J.A.D.; RATUSZNEI, S.M.; ZAIAT, M.; FORESTI, E. Effect of mixing mode on the behavior of an ASBBR with immobilized biomass in the treatment of cheese whey. Brazilian Journal of Chemical Engineering, 25, 291-298, 2008.

DAS, D.; VEZIROGLU, T. N. Advances in biological hydrogen production processes. International Journal of Hydrogen Energy, 33, 6046-6057, 2008.

DEL NERY, V. Utilização de lodo anaeróbio imobilizado em gel no estudo de partida de reatores de fluxo ascendente com manta de lodo. Dissertação (mestrado), Escola de Engenharia de São Carlos, USP, 1987.

DILALLO, R. E ALBERTSON, O.E. Volatile acids by direct titration. Journal of Water Pollution Control Federation, 3, 356-365, 1961.

DING, J.; LIU, B.; REN, N.; XING, D.; GUO, W.; XU, J.; XIE, G. Hydrogen production from glucose by co-culture of Clostridium Butyricum and immobilized Rhodopseudomonas feacalis RLD-53. International Journal of Hydrogen Energy, 34, 3647-3652, 2009.

DUBOIS, S.M.; GILLES, K.A.; HAMILTON, J.L.; REBERS, P.A.; SMITH, F. (1956) Colorimetric Methods for determination of sugar and related substance. Analytical Chemistry, $228,13-21$

FERCHICHI, M.; CRABBE, E.; GIL, G.; HINTZ, W.; Almadidy, A. Influence of initial pH on Hydrogen production from cheese whey. Journal of Biotechnology, 120, 402-409, 2005. 
FERNANDES, L.; KENNEDY, K.J.; NING, Z. Dynamic moleling of substrate degradation in sequencing batch anaerobic reactors (SBAR). Water Research, 27, 1619-1628, 1993.

FERNANDES, B.S. Produção de hidrogênio em reator anaeróbio de leito fixo. Tese (Doutorado) Departamento de Hidraulica e Saneamento, Escola de Engenharia de São Carlos, Universidade de São Paulo, São Carlos, 2008.

FORESTI, E. Anais do III taller y seminario latino Americano. Tratamento anaeróbio águas residuales. Montevideo, 1994.

FRIEDL, G.F.; MOCKAITIS, G.; RODRIGUES, J.A.D.; RATUSZNEI, S.M.; ZAIAT, M.; FORESTI, E. AnSBBR applied to organic matter and sulfate removal: interaction effect between feed strategy and COD/Sulfate ratio. Applied Biochemistry and Biotechnology, 159, 95-109, 2009.

HORIUCHI, J.; SHIMIZU, T. TADA, K.; KANNO, T.; KOBAYASHI, M. Selective production of organic acids in anaerobic acid reactor by $\mathrm{pH}$ control. Bioresource Technology, 82, 209-213, 2002.

ITO, T.; NAKASHIMADA, Y.; SENBA, K.; MATSUI, T.; NISHIO, N. Hydrogen and ethanol production from glycerol containing wastes discharges after biodiesel manufacturing process. Journal of Bioscience and Bioengineering, 100, 260-265, 2005. 
JEONG, T.; CHA, G.; YOO, I.; KIM, D. Hydrogen production from waste activated sludge by using separation membrane acid fermentation reactor and photosynthetic reactor. International Journal of Hydrogen Energy, 32, 525-530, 2007.

KHANAL, S. K.; CHEN, W.; LI, L.; SUNG, S.; Biological hydrogen production: effects of $\mathrm{pH}$ and intermediate products. International Journal of Hydrogen Energy, 29, 1123-1131, 2004.

LEITE, J.A.C.; FERNANDES, B.S.; POZZI, E.; BARBOZA, M.; ZAIAT, M. Application of an anaerobic packed-bed bioreactor for the production of hydrogen and organic acids. International Journal of Hydrogen Energy, 33, 579- 586, 2008.

LIN, C.; LAY, C. Carbon/nitrogen ratio effect on fermentative hydrogen production by mixed microflora. International Journal of Hydrogen Energy, 29, 41-45, 2004.

LIN, C.; LAY, C. Effects of carbonate and phosphate concentrations on hydrogen production using anaerobic sewage sludge microflora. International Journal of Hydrogen Energy, 29, 275-281, 2004.

LIN, C.; CHANG, R. C. Fermentative hydrogen production at ambient temperature. International Journal of Hydrogen Energy, 29, 715-720, 2004.

LIN, C.; LAY, C. A nutrient formulation for fermentative hydrogen production using anaerobic sewage sludge microflora. International Journal of Hydrogen Energy, 30, 285$292,2005$. 
LIN C.; WU, S.; CHANG, J.; Fermentative hydrogen production with a draft tube fluidized bed reactor containing silicone-gel-imobilized anaerobic sludge. International Journal of Hydrogen Energy, 31, 2200-2210, 2006.

LIN, P. Y.; WHANG, L. M.; WU, Y. R.; REN, W. J.; HSIAO, C. J.; LI, S, L.; CHANG, J. S.; Biological hydrogen production of the genus Clostridium: Metabolic study and mathematical model simulation. International Journal of Hydrogen Energy, 32, 1728-1735, 2007.

LIMA, D.M.F. Influencia da razão de recirculação na produção de hidrogênio em reator anaeróbio de leito fixo. Dissertação (mestrado) - Escola de Engenharia de São Carlos Departamento de Hidráulica e Saneamento, Universidade de São Paulo, 2011.

LIU, X.; ZHU, Y.; YANG, S. Butyric acid and hydrogen production by Clostridium Tyrobutyricum ATCC 25755 and mutants. Enzyme and Microbial Technology, 38, 521$528,2006$.

MASSÉ, D.I.; MASSE, L. Treatment of slaghterhouse wastewater in anaerobic sequencing batch reactors. Canadian Agricultural Engineering, 42, 131-137, 2000.

MCCARTY,P.L One Hundred Years of Anaerobic Treatment. Proceedings of the Anaerobic Digestion Symposium, 1981. 
MICHELAN, R.; ZIMMER, T.R.; RODRIGUES, J.A.D.; RATUSZNEI, S.M.; MORAES, D.; ZAIAT, M.; FORESTI E. Effect of impeller type and mechanical agitation on the mass transfer and power consumption aspects of ASBR operation treating synthetic wastewater. Journal of Environmental Management, 90, 1357-1364, 2009.

MOHAN, S. V.; BABU, V. L.; BHASKAR, Y. V.; SARMA, P. N. Influence of recirculation on the performance of anaerobic sequencing bath biofilm reactor (AnSBBR) treating hypersaline composite chemical wastewater. Bioresource Technology, 98, 1373-1379, 2006.

NG, W.J. (1989) A sequencing batch anaerobic reactor for treating piggery wastewater. Biological Wastes. 28, 39-51, 2007.

MOHAN, S. V.; MOHANAKRISHNA, G.; RAGHAVULU, S.V.; SARMA, P.N. Enhancing biohydrogen production from chemical wastewater treatment in anaerobic sequencing batch biofilm reactor (AnSBBR) by bioaugmenting with selectively enriched kanamycin resistant anaerobic mixed consortia. International journal hydrogen energy, 32, 3284-3292, 2007.

NISHIO, N.; NAKASHIMADA, Y. Recent development of digestion process for energy recovery from wastes. Journal of Bioscience and Bioengineering, 103, 105-112, 2007.

NOVAES, L.F.; BORGES, L.O.; RODRIGUES, J.A.D.; RATUSZNEI, S.M.; ZAIAT, M.; FORESTI, E. Effect of fill time on the performance of pilot-scale ASBR and AnSBBR applied to sanitary wastewater treatment. Applied Biochemistry and Biotechnology, 162, 885-899, 2010. 
OLIVEIRA, D.S.; PRINHOLATO, A.C.; RATUSZNEI, S.M.; RODRIGUES, J.A.D.; ZAIAT, M.; FORESTI, E. AnSBBR applied to the treatment of wastewater from a personal care industry: effect of organic load and fill time. Journal of Environmental Management, 90, 3070-3081, 2009.

OLIVEIRA, R.P.; GHILARDI, J.A.; RATUSZNEI, S.M.; RODRIGUES, J.A.D.; ZAIAT, M.; FORESTI, E. Anaerobic sequencing batch biofilm reactor applied to automobile industry wastewater treatment: volumetric loading rate and feed strategy effects. Chemical Engineering and Processing, 47, 1380-1389, 2008.

ORRA, A.A.; RATUSZNEI, S.M.; RODRIGUES, J.A.D.; FORESTI, E.; ZAIAT, M. Effects of feeding strategies on the performance of an anaerobic discontinuous reactor containing immobilized biomass with circulation system for liquid-phase mixing. Water Science and Technology, 49, 303-310, 2004.

O-THONG, S.; PRASERTSAN, P.; INTRASUNGKHA, N.; DHAMWICHUKORN, S.; BIRKELAND, N. Optimization of simultaneous thermophilic fermentative hydrogen production and COD reduction from palm oil mil effluent by Thermoanaerobaterium-rich sludge. International Journal of Hydrogen Energy, 33, 1221-1231, 2008.

OZTEKIN, R.; KAPDAN, I.; KARGUI, F.; ARGUN, H. Optimization of media composition for hydrogen gas production from hydrolyzed wheat starch by dark fermentation. International Journal of Hydrogen Energy, 33, 4083-4090, 2008. 
PEIXOTO, G. Produção de hidrogênio em reator anaeróbio de leito fixo e fluxo ascendente a partir de água residuária de industria de refrigerante. Dissertação (Mestrado) - Escola de Engenharia de São Carlos, Departamento de Hidraulica e Saneamento, Universidade de São Paulo, São Carlos, 2008.

RIPLEY, L.E.; BOYLE, W.C.; CONVERSE, J.C.. Improved alkalimetric monitoring for anaerobic digestor of high-strength wastes. Journal of Water Pollution Control Federation, 58, 406-411, 1986.

RODRIGUES, J.A.D.; PINTO, A.G.; RATUSZNEI, S.M.; ZAIAT, M.; GEDRAITE, R. Enhancement of the performance of an anaerobic sequencing batch reactor treating low strength wastewater through implementation of a variable stirring rate program. Brazilian Journal of Chemical Engineering, 21, 423-434, 2004.

RODRIGUES, J.A.D.; RATUSZNEI, S.M.; CAMARGO, E.F.M.; ZAIAT, M. Influence of agitation rate on the performance of an anaerobic sequencing batch reactor containing granulated biomass treating low-strength wastewater. Advances in Environmental Research, 7, 405-410, 2003.

SABOURIN-PROVOST, G.; HALLENBECK, P.C. High yield conversion of a crude glycerol fraction from biodiesel production to hydrogen by photofermentation. Bioresource Technology, 100, 3513-3517, 2009.

SHIZAS, I.; BAGLEY, D.M. Improving anaerobic sequencing batch reactor performance by modifying operational parameters. Water Research, 36, 363-367, 2002. 
SILVA, G. P.; MACK, M.; CONTIERO, J.; Glycerol: A promising and abundant carbon source for industrial microbiology. Biotechnology Advances, 29, 30-39, 2009.

STANDARD Methods for the Examination of Water and Wastewater APHA, AWWA, WPCF. $19^{\text {th }}$ edition, American Public Health Association, Washington, 1995.

TANISHO, S; ISHIWATA, Y. Continuous hydrogen production from molasses by fermentation using urethane foam as a support of flocks. International Journal of Hydrogen Energy, 20, 541-545, 1995.

TANISHO, S; ISHIWATA, Y. Continuous hydrogen production from molasses by the bacterium Enterobacter aerogenes. International Journal of Hydrogen Energy, 19, 807812, 1994.

TANISHO, S. A scheme for developing the yield of hydrogen by fermentation. An Approach to Environmentally Acceptable Technology, 131-140, 2001.

TURCOT, J.; BISAILlON, A.; HALLENBECK, P. Hydrogen production by continuous cultures of Escherichia coli under different nutrient regimes. International Journal of Hydrogen Energy, 33, 1465-1470, 2008.

VAZQUEZ, G.D; ARRIGA, S.; MONDRAGÓN, F.A.; RODRÍGUEZ, A.L.; COLUNGA, L.M.R.; FLORES, E.R. Fermentative biohydrogen production: trends and perspectives. Reviews in Environmental Science Biotechnology, 7, 27-45, 2008. 
WANG, J.; WAN, W. (2008) Comparison of different pretreatment methods for enriching hydrogen-producting bacteria from digested sludge. International Journal of Hydrogen Energy, 33, 2934-2941.

WU, S.Y; LIN, C.N.; CHANG, J.S.; LEE, K.S.; LIN, P.J. Hydrogen production with immobilized sewage sludge in three-phase fluidized-bed bioreactor. Biotechnology Progress, 19, 828-832, 2003.

WU, K.; SARATALE, G. D.; LO, Y.; CHEN, W.; TSENG, Z.; CHANG, M.; TSAI, B.; SU, A.; CHANG, J. Simultaneous production of 2,3-butanediol, ethanol and hydrogen with a klebsiella sp. Strain isolated from sewage sludge. Bioresource Technology, 99, 7966-7970, 2008.

YANG, Y.; TSUKAHARA, K.; SAWAYAMA, S. Biodegradation and methane production from glycerol-containing synthetic wastes with fixed-bed bioreactor under mesophilic and thermophilic anaerobic conditions. Process Biochemistry, 43, 362-367, 2008.

ZHANG, Z. P.; SHOW, K. Y.; TAY, J. H.; LIANG, D. T.; L, D. J.; JIANG, W. J. Effect of hydraulic retention time on biohydrogen production and anaerobic microbial community. Process Biochemistry, 41, 2118-2123, 2006.

ZAIAT, M.; CABRAL, A.K.A.; FORESTI, E. Horizontal-flow anaerobic immobilized sludge reactor for wastewater treatment: conception and performance evaluation. Brazilian Journal of Chemical Engineering, 11, 33-42, 1994. 
ZAIAT, M.; RODRIGUES, J.A.D.; RATUSZNEI, S.M.; CAMARGO, E.F.M.; BORZANI, W. Anaerobic sequencing batch reactors for wastewater treatment: a developing technology. Applied Microbiology and Biotechnology, 55, 29-35, 2001.

ZIMMER, T.R.; MICHELAN, R.; CANTO, C.S.A.; RODRIGUES, J.A.D.; RATUSZNEI, S.M. Feed strategy study of a mechanically stirred anaerobic sequencing batch reactor equipped with a draft tube applied to whey treatment. Brazilian Journal of Food Technology, 11, 288-298, 2008. 


\section{ANEXO I}

Tabela AI-1: Concentração de matéria orgânica (DQO) afluente e efluente em todas condições.

\begin{tabular}{|c|c|c|c|c|c|c|}
\hline $\begin{array}{c}\text { Condição } \\
\text { Experimental }\end{array}$ & $\begin{array}{l}\text { Tempo } \\
\text { (dia) }\end{array}$ & $\begin{array}{c}\mathrm{C}_{\mathrm{ST}-\mathrm{A}} \\
\left(\mathrm{mg} \cdot \mathrm{L}^{-1}\right)\end{array}$ & $\begin{array}{c}\text { CSF-E } \\
\text { (mg.L-1) }\end{array}$ & $\begin{array}{c}\varepsilon_{\mathrm{SF}} \\
(\%)\end{array}$ & $\underset{\left(\mathrm{mg} \cdot \mathrm{L}^{-1}\right)}{\mathrm{C}_{\mathrm{ST}}}$ & $\begin{array}{l}\varepsilon S T \\
(\%)\end{array}$ \\
\hline $\mathrm{p}$ & 1 & 3472 & - & - & 2523 & 28,7 \\
\hline $\mathrm{p}$ & 2 & 3798 & 2808 & 20,6 & 2957 & 16,4 \\
\hline $\mathrm{p}$ & 8 & 4004 & 3028 & 14,4 & 3122 & 11,8 \\
\hline $\mathrm{p}$ & 9 & 3733 & 2854 & 19,3 & 2896 & 18,1 \\
\hline $\mathrm{p}$ & 10 & 3606 & 2668 & 24,6 & 2917 & 17,5 \\
\hline $\mathrm{p}$ & 11 & 3641 & 2953 & 16,5 & 2993 & 15,4 \\
\hline p & 12 & 3677 & 2831 & 20,0 & 2677 & 24,3 \\
\hline 1 & 16 & 3330 & 2819 & 20,3 & 2767 & 21,8 \\
\hline 1 & 17 & 3458 & 2883 & 21,4 & 2934 & 20,0 \\
\hline 1 & 18 & 3703 & 3019 & 17,7 & 2881 & 21,5 \\
\hline 1 & 19 & 3580 & 2869 & 21,8 & 2921 & 20,4 \\
\hline 1 & 22 & 3749 & 2871 & 21,8 & 2892 & 21,2 \\
\hline 1 & 23 & 4044 & 2334 & 36,4 & 2783 & 24,2 \\
\hline 1 & 24 & 3774 & 2718 & 25,9 & 3069 & 16,4 \\
\hline 1 & 25 & 3621 & 3015 & 17,8 & 3023 & 17,6 \\
\hline 1 & 26 & 3641 & 3065 & 16,5 & 3092 & 15,78 \\
\hline 1 & 29 & 3631 & 3196 & 12,9 & 3259 & 11,22 \\
\hline 1 & 30 & 3539 & 3085 & 15,9 & 3158 & 13,98 \\
\hline 1 & 31 & 3499 & 2940 & 19,9 & 3021 & 17,73 \\
\hline 1 & 36 & 3764 & 3268 & 10,9 & 3279 & 10,69 \\
\hline 1 & 37 & 3611 & 3330 & 9,2 & 3182 & 13,32 \\
\hline 1 & 39 & 3754 & 3015 & 17,8 & 3042 & 17,16 \\
\hline 1 & 40 & 3529 & 2820 & 23,1 & 3069 & 16,41 \\
\hline 1 & 50 & 3942 & 3136 & 14,5 & 3345 & 8,89 \\
\hline 1 & 51 & 3800 & 3052 & 16,8 & 3121 & 15,00 \\
\hline 1 & 52 & 3616 & 2627 & 28,4 & 3050 & 16,92 \\
\hline 1 & 53 & 3764 & 2765 & 24,6 & 3053 & 16,86 \\
\hline 1 & 54 & 3601 & 3081 & 16,0 & 3084 & 15,99 \\
\hline 1 & 58 & 3749 & 3184 & 13,2 & 2958 & 19,43 \\
\hline 1 & 59 & 3657 & 3032 & 17,4 & 3022 & 17,70 \\
\hline 1 & 60 & 3687 & 3116 & 15,1 & 3126 & 14,85 \\
\hline 1 & 64 & 3743 & 3206 & 12,6 & 3248 & 11,52 \\
\hline 2 & 65 & 3754 & 3158 & 14,0 & 3271 & 10,93 \\
\hline 2 & 66 & 3468 & 3083 & 16,0 & 2778 & 24,38 \\
\hline 2 & 67 & 3545 & 3061 & 16,6 & 3153 & 14,17 \\
\hline 2 & 68 & 3784 & 3323 & 9,5 & 3331 & 9,32 \\
\hline 2 & 72 & 3606 & 3109 & 15,3 & 3196 & 13,00 \\
\hline 2 & 73 & 3641 & 3324 & 9,5 & 3325 & 9,47 \\
\hline 2 & 74 & 3815 & 3571 & 2,7 & 3497 & 4,79 \\
\hline 2 & 75 & 3453 & 3080 & 16,1 & 3256 & 11,35 \\
\hline 2 & 79 & 3774 & 3166 & 13,7 & 3383 & 7,91 \\
\hline 2 & 80 & 3784 & 3152 & 14,1 & 3311 & 9,86 \\
\hline 2 & 81 & 3902 & 3141 & 14,4 & 3236 & 11,89 \\
\hline
\end{tabular}




\begin{tabular}{|c|c|c|c|c|c|c|}
\hline $\begin{array}{c}\text { Condição } \\
\text { Experimental }\end{array}$ & $\begin{array}{c}\text { Tempo } \\
\text { (dia) }\end{array}$ & $\begin{array}{c}\text { CST-A } \\
\text { (mg.L-1) }\end{array}$ & $\begin{array}{c}\mathrm{C}_{\mathrm{SF}-\mathrm{E}} \\
\left(\mathbf{m g} \cdot \mathbf{L}^{-1}\right)\end{array}$ & $\begin{array}{l}\varepsilon_{\mathbf{S F}} \\
(\%)\end{array}$ & $\begin{array}{c}\text { C }_{\text {ST-E }} \\
\left(\mathbf{m g . L ^ { - 1 }}\right)\end{array}$ & $\begin{array}{l}\varepsilon_{\mathrm{ST}} \\
(\%)\end{array}$ \\
\hline 2 & 82 & 3621 & 3020 & 17,8 & 3105 & 15,5 \\
\hline 2 & 88 & 3468 & 3027 & 17,6 & 3287 & 10,5 \\
\hline 2 & 89 & 3861 & 3053 & 16,9 & 2840 & 22,7 \\
\hline 2 & 99 & 3621 & 3012 & 18,0 & 3267 & 11,1 \\
\hline 3 & 100 & 5304 & 4323 & 20,6 & 4554 & 16,4 \\
\hline 3 & 101 & 5355 & 4389 & 19,4 & 4191 & 23,1 \\
\hline 3 & 102 & 5457 & 4565 & 16,2 & 4763 & 12,6 \\
\hline 3 & 103 & 6069 & 4565 & 16,2 & 4818 & 11,6 \\
\hline 3 & 109 & 6120 & 4686 & 14,0 & 4840 & 11,2 \\
\hline 3 & 110 & 5355 & 4598 & 15,6 & 4807 & 11,8 \\
\hline 3 & 114 & 5355 & 4191 & 23,1 & 4631 & 15,0 \\
\hline 3 & 115 & 4998 & 4312 & 20,9 & 4378 & 19,6 \\
\hline 3 & 116 & 4488 & 3993 & 26,7 & 4400 & 19,2 \\
\hline 3 & 121 & 5355 & 4455 & 18,2 & 4741 & 13,0 \\
\hline 3 & 122 & 5610 & 4499 & 17,4 & 4730 & 13,2 \\
\hline 3 & 123 & 5355 & 4400 & 19,2 & 4708 & 13,6 \\
\hline 3 & 128 & 5559 & 4488 & 17,6 & 4598 & 15,6 \\
\hline 3 & 129 & 5406 & 4587 & 15,8 & 4785 & 12,2 \\
\hline 3 & 130 & 5355 & 4730 & 13,2 & 4840 & 11,2 \\
\hline 3 & 135 & 6069 & 4334 & 20,4 & 4697 & 13,8 \\
\hline 3 & 140 & 5406 & 4400 & 19,2 & 4620 & 15,2 \\
\hline 4 & 141 & 4998 & 4224 & 16,6 & 4400 & 13,1 \\
\hline 4 & 142 & 5457 & 3982 & 21,4 & 4290 & 15,3 \\
\hline 4 & 143 & 5202 & 4015 & 20,7 & 4268 & 15,7 \\
\hline 4 & 144 & 5967 & 3883 & 23,3 & 4125 & 18,5 \\
\hline 4 & 149 & 4845 & 3993 & 21,1 & 4235 & 16,4 \\
\hline 4 & 150 & 5508 & 4125 & 18,5 & 4444 & 12,2 \\
\hline 4 & 151 & 5763 & 3982 & 21,4 & 4543 & 10,3 \\
\hline 4 & 152 & 4998 & 3916 & 22,7 & 4521 & 10,7 \\
\hline 4 & 156 & 4335 & 3564 & 29,6 & 3960 & 21,8 \\
\hline 4 & 157 & 4947 & 3817 & 24,6 & 4279 & 15,5 \\
\hline 4 & 158 & 4692 & 4334 & 14,4 & 4620 & 8,8 \\
\hline 4 & 159 & 4590 & 4290 & 15,3 & 4785 & 5,5 \\
\hline 4 & 163 & 4896 & 4323 & 14,6 & 4378 & 13,5 \\
\hline 4 & 171 & 4692 & 4213 & 16,8 & 4829 & 4,6 \\
\hline 5 & 172 & 3978 & 3267 & 13,1 & 3322 & 11,6 \\
\hline 5 & 173 & 3621 & 2827 & 24,8 & 3146 & 16,3 \\
\hline 5 & 177 & 3723 & 2332 & 38,0 & 2497 & 33,6 \\
\hline 5 & 178 & 3774 & 3080 & 18,1 & 3344 & 11,0 \\
\hline 5 & 179 & 3570 & 3080 & 18,1 & 3300 & 12,2 \\
\hline 5 & 180 & 3672 & 3080 & 18,1 & 3146 & 16,3 \\
\hline 5 & 184 & 3876 & 3267 & 13,1 & 3311 & 11,9 \\
\hline 5 & 185 & 3876 & 3003 & 20,1 & 3223 & 14,3 \\
\hline 5 & 186 & 3927 & 3223 & 14,3 & 3289 & 12,5 \\
\hline
\end{tabular}




\begin{tabular}{ccccccc}
\hline $\begin{array}{c}\text { Condição } \\
\text { Experimental }\end{array}$ & $\begin{array}{c}\text { Tempo } \\
(\mathbf{d i a})\end{array}$ & $\begin{array}{c}\mathbf{C}_{\text {ST-A }} \\
\left(\mathbf{m g . L} \mathbf{- 1}^{-\mathbf{1}}\right)\end{array}$ & $\begin{array}{c}\mathbf{C}_{\text {SF-E }} \\
\left(\mathbf{m g . L}^{-\mathbf{1}}\right)\end{array}$ & $\begin{array}{c}\mathbf{\varepsilon}_{\mathbf{S F}} \\
(\boldsymbol{\%})\end{array}$ & $\begin{array}{c}\mathbf{C}_{\text {ST-E }} \\
(\mathbf{m g . \mathbf { 1 }})\end{array}$ & $\begin{array}{c}\mathbf{\varepsilon}_{\mathbf{S T}} \\
(\boldsymbol{\%})\end{array}$ \\
\hline 5 & 197 & 3570 & 3212 & 14,5 & 3322 & 11,6 \\
6 & 199 & 5508 & 4829 & 13,5 & 4884 & 12,5 \\
6 & 200 & 5406 & 4598 & 17,7 & 4763 & 14,7 \\
6 & 201 & 5253 & 4818 & 13,7 & 5126 & 8,2 \\
6 & 205 & 5610 & 4873 & 12,7 & 5027 & 10,0 \\
6 & 207 & 5559 & 4598 & 17,7 & 5401 & 3,3 \\
6 & 208 & 5100 & 4972 & 11,0 & 5060 & 9,4 \\
6 & 212 & 6120 & 4708 & 15,7 & 5093 & 8,8 \\
6 & 219 & 6120 & 4708 & 15,7 & 4851 & 13,1 \\
6 & 220 & 5661 & 4455 & 20,2 & 4763 & 14,7 \\
5 & 221 & 6120 & 4664 & 16,5 & 4840 & 13,3 \\
\hline
\end{tabular}




\section{ANEXO II}

Tabela AII-1: Concentração de carboidratos (sacarose) afluente e efluente em todas condições.

\begin{tabular}{|c|c|c|c|c|c|c|}
\hline $\begin{array}{c}\text { Condição } \\
\text { Experimental } \\
\end{array}$ & $\begin{array}{c}\text { Tempo } \\
\text { (dia) }\end{array}$ & $\begin{array}{c}\mathrm{C}_{\mathrm{CT}-\mathrm{A}} \\
\left(\mathrm{mg} \cdot \mathrm{L}^{-1}\right)\end{array}$ & $\begin{array}{c}\mathrm{C}_{\mathrm{CF}-\mathrm{E}} \\
\left(\mathrm{mg.L^{-1 }}\right)\end{array}$ & $\begin{array}{l}\varepsilon_{\mathrm{CF}} \\
(\%)\end{array}$ & $\begin{array}{c}\text { C }_{\text {CT-E }} \\
\left(\mathbf{m g . L} \cdot L^{-1}\right)\end{array}$ & $\begin{array}{l}\varepsilon_{\mathrm{CT}} \\
(\%)\end{array}$ \\
\hline $\mathrm{P}$ & 8 & 3476 & 68 & 98,3 & 129 & 96,8 \\
\hline $\mathrm{P}$ & 9 & 3101 & 75 & 98,1 & 119 & 97,0 \\
\hline $\mathrm{P}$ & 10 & 3433 & 102 & 97,5 & 162 & 96,0 \\
\hline $\mathrm{P}$ & 11 & 3167 & 44 & 98,9 & 100 & 97,5 \\
\hline 1 & 16 & 3432 & 45 & 98,6 & 75 & 97,7 \\
\hline 1 & 17 & 3356 & 34 & 98,9 & 77 & 97,6 \\
\hline 1 & 18 & 3279 & 36 & 98,9 & 78 & 97,6 \\
\hline 1 & 19 & 3244 & 32 & 99,0 & 44 & 98,6 \\
\hline 1 & 22 & 3269 & 44 & 98,6 & 75 & 97,7 \\
\hline 1 & 23 & 3300 & 50 & 98,5 & 74 & 97,7 \\
\hline 1 & 24 & 3315 & 58 & 98,2 & 131 & 95,9 \\
\hline 1 & 25 & 3305 & 50 & 98,5 & 69 & 97,9 \\
\hline 1 & 26 & 3274 & 62 & 98,1 & 70 & 97,8 \\
\hline 1 & 29 & 3295 & 45 & 98,6 & 62 & 98,1 \\
\hline 1 & 30 & 3499 & 61 & 98,1 & 64 & 98,0 \\
\hline 1 & 31 & 3381 & 40 & 98,8 & 63 & 98,1 \\
\hline 1 & 36 & 3305 & 37 & 98,8 & 45 & 98,6 \\
\hline 1 & 37 & 3274 & 28 & 99,1 & 42 & 98,7 \\
\hline 1 & 39 & 3070 & 33 & 99,0 & 50 & 98,5 \\
\hline 1 & 40 & 3060 & 33 & 99,0 & 45 & 98,6 \\
\hline 1 & 50 & 3198 & 40 & 98,8 & 76 & 97,6 \\
\hline 1 & 51 & 3142 & 44 & 98,6 & 46 & 98,6 \\
\hline 1 & 52 & 3060 & 48 & 98,5 & 40 & 98,8 \\
\hline 1 & 53 & 3024 & 35 & 98,9 & 54 & 98,3 \\
\hline 1 & 54 & 3065 & 31 & 99,0 & 52 & 98,4 \\
\hline 1 & 58 & 3070 & 22 & 99,3 & 34 & 98,9 \\
\hline 1 & 59 & 3131 & 24 & 99,3 & 40 & 98,8 \\
\hline 1 & 60 & 3116 & 25 & 99,2 & 37 & 98,8 \\
\hline 1 & 64 & 3274 & 29 & 99,1 & 45 & 98,6 \\
\hline 2 & 65 & 3116 & 29 & 99,1 & 54 & 98,3 \\
\hline 2 & 66 & 3070 & 39 & 98,8 & 45 & 98,6 \\
\hline 2 & 67 & 3172 & 36 & 98,9 & 72 & 97,8 \\
\hline 2 & 68 & 3070 & 34 & 98,9 & 66 & 97,9 \\
\hline 2 & 72 & 3300 & 33 & 99,0 & 36 & 98,9 \\
\hline 2 & 73 & 3040 & 30 & 99,1 & 53 & 98,3 \\
\hline 2 & 74 & 3264 & 43 & 98,7 & 57 & 98,2 \\
\hline 2 & 75 & 3417 & 31 & 99,0 & 54 & 98,3 \\
\hline 2 & 79 & 3172 & 31 & 99,0 & 57 & 98,2 \\
\hline 2 & 80 & 3264 & 32 & 99,0 & 58 & 98,2 \\
\hline 2 & 81 & 3188 & 28 & 99,1 & 58 & 98,2 \\
\hline 2 & 82 & 3228 & 28 & 99,1 & 68 & 97,9 \\
\hline 2 & 88 & 3080 & 32 & 99,0 & 131 & 95,9 \\
\hline 2 & 89 & 3188 & 32 & 99,0 & 123 & 96,1 \\
\hline
\end{tabular}




\begin{tabular}{|c|c|c|c|c|c|c|}
\hline $\begin{array}{c}\text { Condição } \\
\text { Experimental }\end{array}$ & $\begin{array}{l}\text { Tempo } \\
\text { (dia) }\end{array}$ & $\begin{array}{c}\mathbf{C}_{\mathrm{CT}-\mathrm{A}} \\
\left(\mathrm{mg} \cdot \mathrm{L}^{-1}\right)\end{array}$ & $\begin{array}{c}\mathbf{C}_{\mathrm{CF}-\mathrm{E}} \\
\left(\mathrm{mg}^{-1} \mathbf{L}^{-1}\right)\end{array}$ & $\begin{array}{l}\varepsilon_{\mathrm{CF}} \\
(\%)\end{array}$ & $\begin{array}{c}\mathrm{C}_{\mathrm{CT} \cdot \mathrm{E}} \\
\left(\mathrm{mg} \cdot \mathrm{L}^{-1}\right)\end{array}$ & $\begin{array}{l}\varepsilon_{\mathrm{CT}} \\
(\%)\end{array}$ \\
\hline 2 & 99 & 3167 & 30 & 99,1 & 98 & 96,9 \\
\hline 3 & 100 & 5712 & 121 & 97,6 & 264 & 94,8 \\
\hline 3 & 101 & 5304 & 68 & 98,6 & 121 & 97,6 \\
\hline 3 & 102 & 4590 & 26 & 99,5 & 77 & 98,5 \\
\hline 3 & 103 & 5457 & 66 & 98,7 & 132 & 97,4 \\
\hline 3 & 109 & 5763 & 39 & 99,2 & 132 & 97,4 \\
\hline 3 & 110 & 5916 & 187 & 96,3 & 253 & 95,0 \\
\hline 3 & 114 & 4947 & 55 & 98,9 & 132 & 97,4 \\
\hline 3 & 115 & 4182 & 55 & 98,9 & 110 & 97,8 \\
\hline 3 & 116 & 4335 & 55 & 98,9 & 154 & 96,9 \\
\hline 3 & 121 & 4386 & 50 & 99,0 & 165 & 96,7 \\
\hline 3 & 122 & 5100 & 66 & 98,7 & 165 & 96,7 \\
\hline 3 & 123 & 5100 & 44 & 99,1 & 165 & 96,7 \\
\hline 3 & 128 & 4845 & 33 & 99,3 & 88 & 98,3 \\
\hline 3 & 129 & 4845 & 33 & 99,3 & 121 & 97,6 \\
\hline 3 & 130 & 4743 & 44 & 99,1 & 77 & 98,5 \\
\hline 3 & 135 & 5457 & 39 & 99,2 & 165 & 96,7 \\
\hline 3 & 142 & 5049 & 44 & 99,1 & 121 & 97,6 \\
\hline 4 & 143 & 4590 & 33 & 99,2 & 121 & 97,2 \\
\hline 4 & 144 & 4743 & 33 & 99,2 & 132 & 96,9 \\
\hline 4 & 145 & 4182 & 33 & 99,2 & 132 & 96,9 \\
\hline 4 & 146 & 4386 & 33 & 99,2 & 110 & 97,4 \\
\hline 4 & 151 & 4335 & 44 & 99,0 & 132 & 96,9 \\
\hline 4 & 152 & 5100 & 55 & 98,7 & 143 & 96,7 \\
\hline 4 & 153 & 4284 & 66 & 98,5 & 154 & 96,4 \\
\hline 4 & 154 & 4080 & 44 & 99,0 & 110 & 97,4 \\
\hline 4 & 158 & 3570 & 44 & 99,0 & 121 & 97,2 \\
\hline 4 & 159 & 4386 & 44 & 99,0 & 110 & 97,4 \\
\hline 4 & 160 & 3570 & 33 & 99,2 & 121 & 97,2 \\
\hline 4 & 161 & 4080 & 44 & 99,0 & 110 & 97,4 \\
\hline 4 & 165 & 4233 & 44 & 99,0 & 132 & 96,9 \\
\hline 4 & 173 & 4335 & 44 & 99,0 & 121 & 97,2 \\
\hline 5 & 174 & 3621 & 132 & 96,4 & 198 & 94,6 \\
\hline 5 & 175 & 3723 & 484 & 86,7 & 583 & 84,0 \\
\hline 5 & 179 & 4029 & 88 & 97,6 & 143 & 96,1 \\
\hline 5 & 180 & 3723 & 286 & 92,2 & 385 & 89,4 \\
\hline 5 & 181 & 3825 & 330 & 91,0 & 418 & 88,5 \\
\hline 5 & 182 & 3621 & 286 & 92,2 & 352 & 90,3 \\
\hline 5 & 186 & 3264 & 33 & 99,1 & 66 & 98,2 \\
\hline 5 & 187 & 3774 & 99 & 97,3 & 165 & 95,5 \\
\hline 5 & 188 & 3468 & 77 & 97,9 & 110 & 97,0 \\
\hline 5 & 199 & 3417 & 33 & 99,1 & 99 & 97,3 \\
\hline 6 & 200 & 5559 & 33 & 99,4 & 55 & 99,0 \\
\hline 6 & 201 & 5406 & 286 & 94,7 & 341 & 93,7 \\
\hline 6 & 202 & 5814 & 44 & 99,2 & 110 & 98,0 \\
\hline
\end{tabular}




\begin{tabular}{ccccccc}
\hline $\begin{array}{c}\text { Condição } \\
\text { Experimental }\end{array}$ & $\begin{array}{c}\text { Tempo } \\
(\mathbf{d i a})\end{array}$ & $\begin{array}{c}\mathbf{C}_{\text {CT-A }} \\
(\mathbf{m g . L})\end{array}$ & $\begin{array}{c}\mathbf{C}_{\mathbf{C F}-\mathbf{E}} \\
\left(\mathbf{m g . L ^ { - 1 }}\right)\end{array}$ & $\begin{array}{c}\boldsymbol{\varepsilon}_{\mathbf{C F}} \\
(\boldsymbol{\%})\end{array}$ & $\begin{array}{c}\mathbf{C}_{\mathbf{C T}-\mathbf{E}} \\
\left(\mathbf{m g . .}_{\mathbf{1}}\right)\end{array}$ & $\begin{array}{c}\boldsymbol{\varepsilon}_{\mathbf{C T}} \\
(\boldsymbol{\%})\end{array}$ \\
\hline 6 & 203 & 5457 & 121 & 97,7 & 176 & 96 \\
6 & 207 & 5457 & 121 & 97,8 & 176 & 96,7 \\
6 & 209 & 4947 & 110 & 98,0 & 143 & 97,3 \\
6 & 210 & 5457 & 55 & 99,0 & 88 & 98,4 \\
6 & 214 & 5100 & 396 & 92,7 & 484 & 91,0 \\
6 & 221 & 4947 & 506 & 90,6 & 528 & 90,2 \\
6 & 222 & 4998 & 781 & 85,5 & 880 & 83,7 \\
6 & 223 & 4998 & 671 & 87,6 & 693 & 87,1 \\
6 & 224 & 5151 & 627 & 88,4 & 660 & 87,8 \\
\hline
\end{tabular}




\section{ANEXO III}

Tabela AIII-1: Volume total e específicos do biogás em todas condições.

\begin{tabular}{|c|c|c|c|c|c|c|c|}
\hline $\begin{array}{c}\text { Condição } \\
\text { Experimental }\end{array}$ & $\begin{array}{l}\text { Tempo } \\
\text { (dia) }\end{array}$ & Pulsos & $\begin{array}{l}\text { Volume } \\
\text { (mL) }\end{array}$ & $\begin{array}{c}\text { Volume } \\
\text { corrigido } \\
\text { (mL-CNTP) }\end{array}$ & $\begin{array}{c}\mathrm{CH}_{4} \\
(\mathrm{~mL}-\mathrm{CNTP})\end{array}$ & $\underset{(\mathrm{mL}-\mathrm{CNTP})}{\mathbf{H}_{2}}$ & $\begin{array}{c}\mathrm{CO}_{2} \\
(\mathrm{~mL}-\mathrm{CNTP})\end{array}$ \\
\hline 1 & 16 & 416 & 1360,3 & 1121,4 & 0,0 & 406,2 & 715,2 \\
\hline 1 & 18 & 446 & 1458,4 & 1202,2 & 0,0 & 435,4 & 766,8 \\
\hline 1 & 26 & 351 & 1147,8 & 946,2 & 0,0 & 342,7 & 603,5 \\
\hline 1 & 37 & 245 & 801,2 & 660,4 & 0,0 & 239,2 & 421,2 \\
\hline 1 & 47 & 288 & 941,8 & 776,3 & 0,0 & 281,2 & 495,1 \\
\hline 1 & 51 & 293 & 958,1 & 789,8 & 0,0 & 286,1 & 503,7 \\
\hline 1 & 53 & 281 & 918,9 & 757,5 & 0,0 & 274,3 & 483,1 \\
\hline 1 & 58 & 331 & 1082,4 & 892,2 & 0,0 & 323,2 & 569,1 \\
\hline 2 & 72 & 307 & 1003,9 & 827,5 & 0,0 & 281,6 & 545,9 \\
\hline 2 & 76 & 322 & 1052,9 & 868,0 & 0,0 & 295,4 & 572,6 \\
\hline 2 & 79 & 301 & 984,3 & 811,4 & 0,0 & 276,1 & 535,3 \\
\hline 2 & 83 & 290 & 948,3 & 781,7 & 0,0 & 266,0 & 515,7 \\
\hline 2 & 86 & 272 & 889,4 & 733,2 & 0,0 & 249,5 & 483,7 \\
\hline 2 & 87 & 263 & 860,0 & 708,9 & 0,0 & 241,3 & 467,7 \\
\hline 3 & 109 & 390 & 1275,3 & 1051,3 & 0,0 & 386,8 & 664,5 \\
\hline 3 & 114 & 529 & 1729,8 & 1426,0 & 0,0 & 524,7 & 901,3 \\
\hline 3 & 122 & 469 & 1533,6 & 1264,2 & 0,0 & 465,1 & 799,1 \\
\hline 3 & 128 & 408 & 1334,2 & 1099,8 & 0,0 & 404,6 & 695,2 \\
\hline 3 & 138 & 432 & 1412,6 & 1164,5 & 0,0 & 428,4 & 736,0 \\
\hline 4 & 141 & 550 & 1798,5 & 1482,6 & 0,0 & 476,9 & 1005,7 \\
\hline 4 & 143 & 537 & 1756,0 & 1447,5 & 0,0 & 465,6 & 981,9 \\
\hline 4 & 149 & 556 & 1818,1 & 1498,8 & 0,0 & 482,1 & 1016,7 \\
\hline 4 & 157 & 564 & 1844,3 & 1520,3 & 0,0 & 489,0 & 1031,3 \\
\hline 5 & 174 & 242 & 791,3 & 651,4 & 0,0 & 253,5 & 397,9 \\
\hline 5 & 177 & 334 & 1092,2 & 899,1 & 0,0 & 349,9 & 549,2 \\
\hline 5 & 179 & 357 & 1167,4 & 961,0 & 0,0 & 374,0 & 587,0 \\
\hline 5 & 192 & 354 & 1157,6 & 952,9 & 0,0 & 370,8 & 582,1 \\
\hline 6 & 208 & 608 & 1988,2 & 1638,9 & 0,0 & 599,0 & 1039,9 \\
\hline 6 & 214 & 594 & 1942,4 & 1601,2 & 0,0 & 585,2 & 1015,9 \\
\hline 6 & 215 & 604 & 1975,1 & 1628,1 & 0,0 & 595,1 & 1033,0 \\
\hline 6 & 219 & 604 & 1975,1 & 1628,1 & 0,0 & 595,1 & 1033,0 \\
\hline
\end{tabular}




\section{ANEXO IV}

Tabela AIV-1: Valores de $\mathrm{pH}$, alcalinidade total, alcalinidade a bicarbonato e ácidos voláteis totais do afluente em todas condições.

\begin{tabular}{|c|c|c|c|c|c|}
\hline $\begin{array}{c}\text { Condição } \\
\text { Experimental }\end{array}$ & $\begin{array}{l}\text { Tempo } \\
\text { (dia) }\end{array}$ & pH & $\begin{array}{c}\mathrm{AT} \\
\left(\mathrm{mgCaCO}_{3} \mathrm{~L}^{-1}\right)\end{array}$ & $\begin{array}{c}\mathrm{AB} \\
\left(\mathrm{mgCaCO}_{3} \mathrm{~L}^{-1}\right)\end{array}$ & $\begin{array}{c}\text { AVT } \\
\left(\text { mgHAc. }^{-1}\right)\end{array}$ \\
\hline 1 & 1 & 6,3 & 452,7 & 421,7 & 43,6 \\
\hline 1 & 2 & 6,4 & 507,2 & 489,3 & 25,3 \\
\hline 1 & 3 & 6,2 & 424,6 & 411,6 & 18,4 \\
\hline 1 & 4 & 6,3 & 458,9 & 445,4 & 19,0 \\
\hline 1 & 7 & 6,5 & 419,8 & 402,8 & 24,0 \\
\hline 1 & 8 & 6,3 & 421,9 & 406,6 & 21,6 \\
\hline 1 & 9 & 6,4 & 463,1 & 446,6 & 23,3 \\
\hline 1 & 10 & 6,4 & 475,2 & 456,5 & 26,3 \\
\hline 1 & 11 & 6,5 & 439,7 & 422,5 & 24,2 \\
\hline 1 & 14 & 6,7 & 279,1 & 262,4 & 23,5 \\
\hline 1 & 15 & 6,4 & 250,0 & 229,9 & 28,4 \\
\hline 1 & 21 & 6,6 & 334,8 & 311,0 & 33,5 \\
\hline 1 & 22 & 6,6 & 340,4 & 325,4 & 21,2 \\
\hline 1 & 24 & 6,3 & 270,1 & 255,4 & 20,7 \\
\hline 1 & 25 & 6,4 & 281,9 & 263,5 & 25,9 \\
\hline 1 & 35 & 6,5 & 280,9 & 263,8 & 24,1 \\
\hline 1 & 36 & 6,4 & 275,9 & 253,7 & 31,3 \\
\hline 1 & 37 & 6,5 & 272,6 & 253,0 & 27,6 \\
\hline 1 & 38 & 6,5 & 317,7 & 305,8 & 16,8 \\
\hline 1 & 39 & 6,5 & 311,0 & 295,3 & 22,2 \\
\hline 1 & 43 & 6,6 & 302,5 & 286,0 & 23,2 \\
\hline 1 & 44 & 6,6 & 264,1 & 253,0 & 15,6 \\
\hline 2 & 58 & 7,3 & 499,7 & 473,7 & 36,6 \\
\hline 2 & 59 & 7,3 & 528,1 & 511,3 & 23,7 \\
\hline 2 & 60 & 7,2 & 541,5 & 524,7 & 23,7 \\
\hline 2 & 64 & 7,1 & 473,0 & 455,0 & 25,4 \\
\hline 2 & 65 & 7,3 & 648,4 & 630,0 & 25,9 \\
\hline 2 & 66 & 7,2 & 508,1 & 489,3 & 26,5 \\
\hline 2 & 67 & 7,3 & 543,2 & 516,0 & 38,3 \\
\hline 2 & 73 & 7,4 & 539,8 & 527,0 & 18,0 \\
\hline 2 & 74 & 7,6 & 607,3 & 592,8 & 20,5 \\
\hline 2 & 78 & 7,3 & 605,5 & 588,7 & 23,6 \\
\hline 3 & 79 & 7,3 & 855,9 & 841,0 & 21,0 \\
\hline 3 & 85 & 7,2 & 850,6 & 816,6 & 47,8 \\
\hline 3 & 86 & 7,4 & 786,7 & 753,8 & 46,2 \\
\hline 3 & 94 & 7,4 & 902,1 & 881,2 & 29,4 \\
\hline 3 & 95 & 7,4 & 884,3 & 862,7 & 30,5 \\
\hline 3 & 99 & 7,4 & 777,9 & 754,7 & 32,8 \\
\hline 3 & 100 & 7,4 & 712,0 & 692,2 & 27,9 \\
\hline
\end{tabular}




\begin{tabular}{|c|c|c|c|c|c|}
\hline $\begin{array}{c}\text { Condição } \\
\text { Experimental }\end{array}$ & $\begin{array}{c}\text { Tempo } \\
\text { (dia) }\end{array}$ & $\mathbf{p H}$ & $\begin{array}{c}\mathrm{AT} \\
\left(\mathrm{mgCaCO}_{3} \mathrm{~L}^{-1}\right)\end{array}$ & $\begin{array}{c}\mathrm{AB} \\
\left(\mathrm{mgCaCO}_{3} \mathrm{~L}^{-1}\right)\end{array}$ & $\begin{array}{c}\text { AVT } \\
\left.\left(\text { mgHAc. }^{-1}\right)^{-1}\right)\end{array}$ \\
\hline 3 & 101 & 7,4 & 726,8 & 701,2 & 36,1 \\
\hline 3 & 106 & 7,3 & 717,0 & 701,1 & 22,4 \\
\hline 3 & 107 & 7,4 & 705,4 & 686,8 & 26,2 \\
\hline 3 & 108 & 7,4 & 746,6 & 730,7 & 22,4 \\
\hline 3 & 113 & 7,4 & 721,6 & 706,7 & 21,0 \\
\hline 3 & 114 & 7,3 & 778,2 & 762,1 & 22,7 \\
\hline 3 & 116 & 7,3 & 773,0 & 752,4 & 29,1 \\
\hline 3 & 120 & 7,4 & 812,5 & 793,4 & 26,8 \\
\hline 3 & 121 & 7,4 & 786,7 & 769,4 & 24,4 \\
\hline 4 & 123 & 7,5 & 865,4 & 850,1 & 21,6 \\
\hline 4 & 128 & 7,4 & 961,4 & 941,7 & 27,7 \\
\hline 4 & 129 & 7,3 & 888,1 & 858,6 & 41,5 \\
\hline 4 & 130 & 7,2 & 837,5 & 808,8 & 40,4 \\
\hline 4 & 134 & 7,3 & 823,5 & 801,9 & 30,5 \\
\hline 4 & 135 & 7,3 & 825,3 & 797,7 & 38,8 \\
\hline 4 & 136 & 7,3 & 823,5 & 803,9 & 27,7 \\
\hline 4 & 137 & 7,6 & 827,0 & 805,4 & 30,5 \\
\hline 4 & 141 & 7,3 & 765,9 & 727,0 & 54,8 \\
\hline 4 & 142 & 7,4 & 889,8 & 848,5 & 58,2 \\
\hline 4 & 143 & 7,4 & 818,3 & 772,3 & 64,8 \\
\hline 4 & 144 & 7,3 & 827,0 & 755,8 & 100,2 \\
\hline 4 & 148 & 7,4 & 814,8 & 783,3 & 44,3 \\
\hline 4 & 149 & 7,4 & 814,8 & 784,1 & 43,2 \\
\hline 5 & 157 & 7,1 & 557,7 & 537,4 & 28,5 \\
\hline 5 & 158 & 7,2 & 556,0 & 524,4 & 44,5 \\
\hline 5 & 162 & 7,2 & 609,2 & 576,0 & 46,7 \\
\hline 5 & 163 & 7,3 & 550,8 & 524,7 & 36,8 \\
\hline 5 & 164 & 7,3 & 604,0 & 570,1 & 47,8 \\
\hline 5 & 169 & 7,3 & 564,6 & 552,9 & 16,5 \\
\hline 5 & 170 & 7,2 & 557,7 & 543,7 & 19,8 \\
\hline 5 & 171 & 7,2 & 545,7 & 530,1 & 22,0 \\
\hline 5 & 172 & 7,7 & 561,5 & 546,3 & 21,4 \\
\hline 5 & 176 & 7,2 & 593,4 & 574,4 & 26,7 \\
\hline 6 & 183 & 7,3 & 800,4 & 772,2 & 39,8 \\
\hline 6 & 184 & 7,2 & 748,5 & 727,3 & 29,8 \\
\hline 6 & 185 & 7,2 & 761,9 & 742,2 & 27,7 \\
\hline 6 & 186 & 7,3 & 778,6 & 763,8 & 20,9 \\
\hline 6 & 193 & 7,4 & 807,1 & 791,9 & 21,5 \\
\hline 6 & 197 & 7,3 & 763,6 & 741,3 & 31,4 \\
\hline 6 & 204 & 7,4 & 782,0 & 763,6 & 25,9 \\
\hline
\end{tabular}


Tabela AIV-2: Valores de $\mathrm{pH}$, alcalinidade total, alcalinidade a bicarbonato e ácidos voláteis totais do efluente em todas condições.

\begin{tabular}{|c|c|c|c|c|c|}
\hline $\begin{array}{c}\text { Condição } \\
\text { Experimental }\end{array}$ & $\begin{array}{c}\text { Tempo } \\
\text { (dia) }\end{array}$ & pH & $\begin{array}{c}\mathrm{AT} \\
\left(\mathrm{mgCaCO}_{3} \mathrm{~L}^{-1}\right)\end{array}$ & $\begin{array}{c}\mathrm{AB} \\
\left(\mathrm{mgCaCO}_{3} \mathrm{~L}^{-1}\right)\end{array}$ & $\begin{array}{c}\text { AVT } \\
\left(\text { mgHAc. }^{-1}\right)\end{array}$ \\
\hline 1 & 1 & 4,8 & 229,5 & 0,0 & 719,4 \\
\hline 1 & 2 & 4,9 & 275,8 & 0,0 & 673,2 \\
\hline 1 & 3 & 4,9 & 270,0 & 0,0 & 819,0 \\
\hline 1 & 4 & 4,8 & 227,6 & 0,0 & 723,9 \\
\hline 1 & 7 & 5,2 & 345,2 & 0,0 & 723,0 \\
\hline 1 & 8 & 4,8 & 246,5 & 0,0 & 681,2 \\
\hline 1 & 9 & 4,8 & 228,7 & 0,0 & 699,7 \\
\hline 1 & 10 & 4,8 & 243,6 & 0,0 & 750,3 \\
\hline 1 & 11 & 4,8 & 227,3 & 0,0 & 728,5 \\
\hline 1 & 14 & 4,7 & 146,3 & 0,0 & 697,6 \\
\hline 1 & 15 & 4,7 & 156,3 & 0,0 & 828,1 \\
\hline 1 & 21 & 4,8 & 162,9 & 0,0 & 560,4 \\
\hline 1 & 22 & 4,8 & 222,7 & 0,0 & 605,9 \\
\hline 1 & 24 & 4,4 & 49,4 & 0,0 & 624,9 \\
\hline 1 & 25 & 4,5 & 141,0 & 0,0 & 487,1 \\
\hline 1 & 35 & 4,5 & 100,3 & 0,0 & 613,6 \\
\hline 1 & 36 & 4,5 & 85,3 & 0,0 & 655,3 \\
\hline 1 & 37 & 4,5 & 78,6 & 0,0 & 551,6 \\
\hline 1 & 38 & 4,5 & 102,0 & 0,0 & 665,3 \\
\hline 1 & 39 & 4,5 & 98,7 & 0,0 & 581,4 \\
\hline 1 & 43 & 4,4 & 33,4 & 0,0 & 577,8 \\
\hline 1 & 44 & 4,6 & 130,4 & 0,0 & 542,2 \\
\hline 1 & 58 & 5,2 & 412,8 & 0,0 & 770,7 \\
\hline 2 & 59 & 5,0 & 280,8 & 0,0 & 681,7 \\
\hline 2 & 60 & 4,9 & 304,2 & 0,0 & 924,0 \\
\hline 2 & 64 & 4,9 & 294,1 & 0,0 & 676,1 \\
\hline 2 & 65 & 4,9 & 329,2 & 0,0 & 647,9 \\
\hline 2 & 66 & 5,0 & 351,0 & 0,0 & 600,6 \\
\hline 2 & 67 & 4,9 & 315,9 & 0,0 & 768,5 \\
\hline 2 & 73 & 4,9 & 232,3 & 0,0 & 716,1 \\
\hline 2 & 74 & 5,0 & 355,2 & 0,0 & 720,2 \\
\hline 2 & 78 & 5,0 & 282,3 & 0,0 & 561,5 \\
\hline 2 & 85 & 4,9 & 436,8 & 0,0 & 1024,9 \\
\hline 3 & 86 & 5,0 & 463,5 & 0,0 & 1129,4 \\
\hline 3 & 94 & 5,0 & 520,3 & 0,0 & 1103,1 \\
\hline 3 & 95 & 5,1 & 610,9 & 0,0 & 1198,7 \\
\hline 3 & 99 & 5,0 & 561,1 & 0,0 & 1053,2 \\
\hline 3 & 100 & 4,8 & 431,8 & 0,0 & 1173,6 \\
\hline 3 & 101 & 4,8 & 362,6 & 0,0 & 1109,1 \\
\hline 3 & 106 & 5,0 & 512,6 & 0,0 & 1110,7 \\
\hline 3 & 107 & 4,9 & 395,6 & 0,0 & 1125,5 \\
\hline
\end{tabular}




\begin{tabular}{|c|c|c|c|c|c|}
\hline $\begin{array}{c}\text { Condição } \\
\text { Experimental }\end{array}$ & $\begin{array}{l}\text { Tempo } \\
\text { (dia) }\end{array}$ & pH & $\begin{array}{c}\mathrm{AT} \\
\left(\mathrm{mgCaCO}_{3} \mathrm{~L}^{-1}\right)\end{array}$ & $\begin{array}{c}\mathrm{AB} \\
\left(\mathrm{mgCaCO}_{3} \mathrm{~L}^{-1}\right)\end{array}$ & $\begin{array}{c}\text { AVT } \\
\left(\text { mgHAc. }^{-1}\right)\end{array}$ \\
\hline 3 & 108 & 4,9 & 380,7 & 0,0 & 986,2 \\
\hline 3 & 113 & 5,0 & 352,7 & 0,0 & 776,4 \\
\hline 3 & 114 & 4,9 & 401,1 & 0,0 & 893,5 \\
\hline 3 & 116 & 4,9 & 409,7 & 0,0 & 974,4 \\
\hline 3 & 120 & 4,9 & 479,9 & 0,0 & 687,4 \\
\hline 3 & 121 & 5,0 & 464,5 & 0,0 & 1157,8 \\
\hline 3 & 123 & 5,0 & 486,8 & 0,0 & 842,4 \\
\hline 4 & 128 & 5,0 & 518,2 & 0,0 & 1228,4 \\
\hline 4 & 129 & 5,0 & 483,3 & 0,0 & 1201,3 \\
\hline 4 & 130 & 5,0 & 490,3 & 0,0 & 1073,3 \\
\hline 4 & 134 & 5,0 & 486,8 & 0,0 & 900,0 \\
\hline 4 & 135 & 5,0 & 464,1 & 0,0 & 918,3 \\
\hline 4 & 136 & 5,0 & 490,3 & 0,0 & 949,3 \\
\hline 4 & 137 & 5,0 & 493,8 & 0,0 & 794,5 \\
\hline 4 & 141 & 4,9 & 431,0 & 0,0 & 1068,3 \\
\hline 4 & 142 & 4,9 & 406,5 & 0,0 & 1044,5 \\
\hline 4 & 143 & 4,9 & 434,4 & 0,0 & 1168,6 \\
\hline 4 & 144 & 4,9 & 441,4 & 0,0 & 1266,1 \\
\hline 4 & 148 & 4,9 & 455,4 & 0,0 & 1093,3 \\
\hline 4 & 149 & 4,9 & 431,0 & 0,0 & 1283,2 \\
\hline 4 & 157 & 5,2 & 343,2 & 0,0 & 634,6 \\
\hline 5 & 158 & 5,2 & 343,2 & 0,0 & 603,9 \\
\hline 5 & 162 & 5,2 & 350,1 & 0,0 & 665,4 \\
\hline 5 & 163 & 4,9 & 290,0 & 0,0 & 689,0 \\
\hline 5 & 164 & 4,9 & 278,0 & 0,0 & 785,1 \\
\hline 5 & 169 & 5,1 & 346,6 & 0,0 & 498,5 \\
\hline 5 & 170 & 4,8 & 214,5 & 0,0 & 762,0 \\
\hline 5 & 171 & 4,8 & 243,7 & 0,0 & 672,5 \\
\hline 5 & 172 & 4,8 & 248,8 & 0,0 & 685,4 \\
\hline 5 & 176 & 5,0 & 302,6 & 0,0 & 786,4 \\
\hline 5 & 183 & 5,0 & 423,6 & 0,0 & 747,6 \\
\hline 6 & 184 & 4,8 & 370,1 & 0,0 & 980,0 \\
\hline 6 & 185 & 4,8 & 289,7 & 0,0 & 1026,1 \\
\hline 6 & 186 & 4,8 & 316,5 & 0,0 & 762,7 \\
\hline 6 & 193 & 4,7 & 254,5 & 0,0 & 1025,0 \\
\hline 6 & 197 & 4,7 & 289,7 & 0,0 & 928,2 \\
\hline 6 & 204 & 4,9 & 355,0 & 0,0 & 786,1 \\
\hline
\end{tabular}




\section{ANEXO V}

Tabela AV-1: Valores de Perfis da condição 1.

\begin{tabular}{cccccccc}
\hline Tempo & $\begin{array}{c}\mathrm{C}_{\mathrm{SF}} \\
{\left[\mathrm{mgDQO}^{-1} \mathrm{~L}^{-1}\right]}\end{array}$ & $\begin{array}{c}\mathrm{C} \mathrm{CF} \\
{\left[\mathrm{mgSAC} \cdot \mathrm{L}^{-1}\right]}\end{array}$ & $\begin{array}{c}\mathrm{AP} \\
{\left[\mathrm{mgCaCO}_{3} \cdot \mathrm{L}^{-1}\right]}\end{array}$ & $\begin{array}{c}\mathrm{AI} \\
{\left[\mathrm{mgCaCO}_{3} \cdot \mathrm{L}^{-1}\right]}\end{array}$ & $\begin{array}{c}\mathrm{AT} \\
{\left[\mathrm{mgCaCO}_{3} \cdot \mathrm{L}^{-1}\right]}\end{array}$ & $\begin{array}{c}\mathrm{AVT} \\
{\left[\mathrm{mgCaCO}_{3} \cdot \mathrm{L}^{-1}\right]}\end{array}$ & $\begin{array}{c}\mathrm{V}_{\text {biogás }} \\
{[\mathrm{mL}]}\end{array}$ \\
\hline 0,00 & 3366,0 & 2018,5 & 0,0 & 156,6 & 156,6 & 191,5 & 0,0 \\
0,50 & 3076,7 & 766,70 & 0,0 & 175,7 & 175,7 & 546,1 & 476,2 \\
1,00 & 2865,5 & 292,0 & 0,0 & 174,0 & 174,0 & 653,5 & 766,4 \\
1,50 & 2752,7 & 72,0 & 0,0 & 187,9 & 187,9 & 660,5 & 887,7 \\
2,00 & 2830,3 & 29,1 & 0,0 & 177,5 & 177,5 & 648,7 & 937,1 \\
2,50 & 2933,1 & 36,3 & 0,0 & 163,5 & 163,5 & 530,5 & 952,4 \\
3,00 & 2970,0 & 33,0 & 0,0 & 175,7 & 175,7 & 718,8 & 952,4 \\
3,70 & 2995,8 & 32,4 & 0,0 & 177,5 & 177,5 & 722,1 & 952,4 \\
\hline
\end{tabular}

Tabela AV-2: Valores de Perfis da condição 2.

\begin{tabular}{cccccccc}
\hline Tempo & $\begin{array}{c}\mathrm{C}_{\mathrm{SF}} \\
{\left[\mathrm{mgDQO} \cdot \mathrm{L}^{-1}\right]}\end{array}$ & $\begin{array}{c}\mathrm{C}_{\mathrm{CF}} \\
{\left[\mathrm{mgSAC} \cdot \mathrm{L}^{-1}\right]}\end{array}$ & $\begin{array}{c}\mathrm{AP} \\
{\left[\mathrm{mgCaCO}_{3} \cdot \mathrm{L}^{-1}\right]}\end{array}$ & $\begin{array}{c}\mathrm{AI} \\
{\left[\mathrm{mgCaCO}_{3} \cdot \mathrm{L}^{-1}\right]}\end{array}$ & $\begin{array}{c}\mathrm{AT} \\
{\left[\mathrm{mgCaCO}_{3} \cdot \mathrm{L}^{-1}\right]}\end{array}$ & $\begin{array}{c}\mathrm{AVT} \\
{\left[\mathrm{mgCaCO}_{3} \cdot \mathrm{L}^{-1}\right]}\end{array}$ & $\begin{array}{c}\mathrm{V}_{\text {biogás }} \\
{[\mathrm{mL}]}\end{array}$ \\
\hline 0,0 & 3664,4 & 2618,9 & 359,3 & 158,8 & 518,1 & 96,7 & 0,0 \\
0,5 & 3061,3 & 773,9 & 0,0 & 361,0 & 361,0 & 456,9 & 571,5 \\
1,0 & 2882,6 & 259,1 & 0,0 & 330,9 & 330,9 & 663,8 & 790,7 \\
1,5 & 2904,0 & 61,1 & 0,0 & 314,2 & 314,2 & 736,5 & 835,6 \\
2,0 & 2945,8 & 67,7 & 0,0 & 309,2 & 309,2 & 592,0 & 835,6 \\
2,7 & 2988,7 & 33,0 & 0,0 & 284,1 & 284,1 & 655,5 & 835,6 \\
\hline
\end{tabular}

Tabela AV-3: Valores de Perfis da condição 3.

\begin{tabular}{cccccccc}
\hline Tempo & $\begin{array}{c}\mathrm{C}_{\mathrm{SF}} \\
{\left[\mathrm{mgDQO} \cdot \mathrm{L}^{-1}\right]}\end{array}$ & $\begin{array}{c}\mathrm{C}_{\mathrm{CF}} \\
{\left[\mathrm{mgSAC} \cdot \mathrm{L}^{-1}\right]}\end{array}$ & $\begin{array}{c}\mathrm{AP} \\
{\left[\mathrm{mgCaCO}_{3} \cdot \mathrm{L}^{-1}\right]}\end{array}$ & $\begin{array}{c}\mathrm{AI} \\
{\left[\mathrm{mgCaCO}_{3} \cdot \mathrm{L}^{-1}\right]}\end{array}$ & $\begin{array}{c}\mathrm{AT} \\
{\left[\mathrm{mgCaCO}_{3} \cdot \mathrm{L}^{-1}\right]}\end{array}$ & $\begin{array}{c}\mathrm{AVT} \\
{\left[\mathrm{mgCaCO}_{3} \cdot \mathrm{L}^{-1}\right]}\end{array}$ & $\begin{array}{c}\mathrm{V}_{\text {biogás }} \\
{[\mathrm{mL}]}\end{array}$ \\
\hline 0,0 & 5431,5 & 3371,1 & 268,7 & 415,3 & 684,0 & 321,8 & 0,0 \\
0,5 & 4746,5 & 1721,5 & 0,0 & 645,6 & 645,6 & 542,7 & 510,4 \\
1,0 & 4493,5 & 1056,0 & 0,0 & 560,1 & 560,1 & 594,2 & 873,4 \\
1,5 & 4301,0 & 621,5 & 0,0 & 509,5 & 509,5 & 639,1 & 1101,6 \\
2,0 & 4158,0 & 330,0 & 0,0 & 516,5 & 516,5 & 808,5 & 1227,4 \\
2,5 & 4152,5 & 130,9 & 0,0 & 499,1 & 499,1 & 796,4 & 1275,9 \\
3,0 & 4169,0 & 55,0 & 0,0 & 497,3 & 497,3 & 821,3 & 1284,9 \\
3,7 & 4268,0 & 16,0 & 0,0 & 465,9 & 465,9 & 575,4 & 1284,9 \\
\hline
\end{tabular}


Tabela AV-4: Valores de Perfis da condição 4

\begin{tabular}{cccccccc}
\hline Tempo & $\begin{array}{c}\mathrm{C}_{\mathrm{SF}} \\
{\left[\mathrm{mgDQO} \cdot \mathrm{L}^{-1}\right]}\end{array}$ & $\begin{array}{c}\mathrm{C}_{\mathrm{CF}} \\
{\left[\mathrm{mgSAC} \cdot \mathrm{L}^{-1}\right]}\end{array}$ & $\begin{array}{c}\mathrm{AP} \\
{\left[\mathrm{mgCaCO}_{3} \cdot \mathrm{L}^{-1}\right]}\end{array}$ & $\begin{array}{c}\mathrm{AI} \\
{\left[\mathrm{mgCaCO}_{3} \cdot \mathrm{L}^{-1}\right]}\end{array}$ & $\begin{array}{c}\mathrm{AT} \\
{\left[\mathrm{mgCaCO}_{3} \cdot \mathrm{L}^{-1}\right]}\end{array}$ & $\begin{array}{c}\mathrm{AVT} \\
{\left[\mathrm{mgCaCO}_{3} \cdot \mathrm{L}^{-1}\right]}\end{array}$ & $\begin{array}{c}\mathrm{V}_{\text {biogás }} \\
{[\mathrm{mL}]}\end{array}$ \\
\hline 0,0 & 4671,6 & 4156,5 & 359,3 & 239,0 & 598,3 & 152,3 & 0,0 \\
0,5 & 4119,5 & 1320,0 & 0,0 & 536,5 & 536,5 & 634,7 & 590,3 \\
1,0 & 3877,5 & 814,0 & 0,0 & 516,4 & 516,4 & 831,7 & 1002,8 \\
1,5 & 3916,0 & 441,7 & 0,0 & 496,4 & 496,4 & 977,2 & 1266,0 \\
2,0 & 3718,0 & 200,2 & 0,0 & 432,9 & 432,9 & 1091,6 & 1421,5 \\
2,7 & 3239,5 & 62,7 & 0,0 & 402,8 & 402,8 & 1143,5 & 1488,9 \\
\hline
\end{tabular}

Tabela AV-5: Valores de Perfis da condição 5

\begin{tabular}{cccccccc}
\hline Tempo & $\begin{array}{c}\mathrm{C}_{\mathrm{SF}} \\
{\left[\mathrm{mgDQO} \cdot \mathrm{L}^{-1}\right]}\end{array}$ & $\begin{array}{c}\mathrm{C}_{\mathrm{CF}} \\
{\left[\mathrm{mgSAC} \cdot \mathrm{L}^{-1}\right]}\end{array}$ & $\begin{array}{c}\mathrm{AP} \\
{\left[\mathrm{mgCaCO}_{3} \cdot \mathrm{L}^{-1}\right]}\end{array}$ & $\begin{array}{c}\mathrm{AI} \\
{\left[\mathrm{mgCaCO}_{3} \cdot \mathrm{L}^{-1}\right]}\end{array}$ & $\begin{array}{c}\mathrm{AT} \\
{\left[\mathrm{mgCaCO}_{3} \cdot \mathrm{L}^{-1}\right]}\end{array}$ & $\begin{array}{c}\mathrm{AVT} \\
{\left[\mathrm{mgCaCO}_{3} \cdot \mathrm{L}^{-1}\right]}\end{array}$ & $\begin{array}{c}\mathrm{V}_{\text {biogás }} \\
{[\mathrm{mL}]}\end{array}$ \\
\hline 0,0 & 3468,0 & 3468,0 & 117,0 & 277,4 & 394,4 & 292,1 & 0,0 \\
0,3 & 3388,0 & 1430,0 & 0,0 & 267,4 & 267,4 & 727,7 & 312,4 \\
0,6 & 3377,0 & 737,0 & 0,0 & 217,3 & 217,3 & 753,7 & 551,2 \\
1,0 & 3080,0 & 473,0 & 0,0 & 205,6 & 205,6 & 758,9 & 727,8 \\
1,3 & 2992,0 & 187,0 & 0,0 & 203,9 & 203,9 & 790,1 & 853,3 \\
2,0 & 2915,0 & 55,0 & 0,0 & 208,9 & 208,9 & 837,9 & 938,9 \\
\hline
\end{tabular}

Tabela AV-6: Valores de Perfis da condição 6

\begin{tabular}{cccccccc}
\hline Tempo & $\begin{array}{c}\mathrm{C}_{\mathrm{SF}} \\
{\left[\mathrm{mgDQO} . \mathrm{L}^{-1}\right]}\end{array}$ & $\begin{array}{c}\mathrm{C}_{\mathrm{CF}} \\
{\left[\mathrm{mgSAC} \cdot \mathrm{L}^{-1}\right]}\end{array}$ & $\begin{array}{c}\mathrm{AP} \\
{\left[\mathrm{mgCaCO}_{3} \cdot \mathrm{L}^{-1}\right]}\end{array}$ & $\begin{array}{c}\mathrm{AI} \\
{\left[\mathrm{mgCaCO}_{3} \cdot \mathrm{L}^{-1}\right]}\end{array}$ & $\begin{array}{c}\mathrm{AT} \\
{\left[\mathrm{mgCaCO}_{3} \cdot \mathrm{L}^{-1}\right]}\end{array}$ & $\begin{array}{c}\mathrm{AVT} \\
{\left[\mathrm{mgCaCO}_{3} \cdot \mathrm{L}^{-1}\right]}\end{array}$ & $\begin{array}{c}\mathrm{V}_{\text {biogás }} \\
{[\mathrm{mL}]}\end{array}$ \\
\hline 0,0 & 5992,5 & 4819,5 & 526,4 & 213,9 & 740,4 & 121,1 & 0,0 \\
0,3 & 5296,5 & 2480,5 & 0,0 & 538,1 & 538,1 & 508,9 & 639,8 \\
0,6 & 5164,5 & 1892,0 & 0,0 & 457,9 & 457,9 & 732,4 & 1133,9 \\
1,0 & 4911,5 & 1298,0 & 0,0 & 399,4 & 399,4 & 882,1 & 1470,2 \\
1,3 & 4801,5 & 841,5 & 0,0 & 372,7 & 372,7 & 912,7 & 1636,0 \\
2,0 & 4702,5 & 500,5 & 0,0 & 299,2 & 299,2 & 943,4 & 1619,2 \\
\hline
\end{tabular}

